


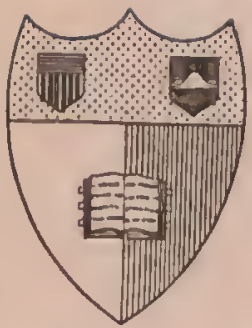

\section{Carnell Aluiuersity Tihrary}

3thara. Neu Vork

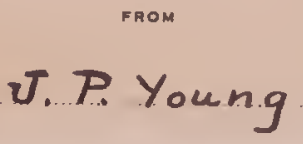

ALBERT R, MANN LIBRARY

New York State Colleges

OF

Agriculture and Human Ecology

AT

CORNELI. UNIVERSITY 


\section{DATE DUE}

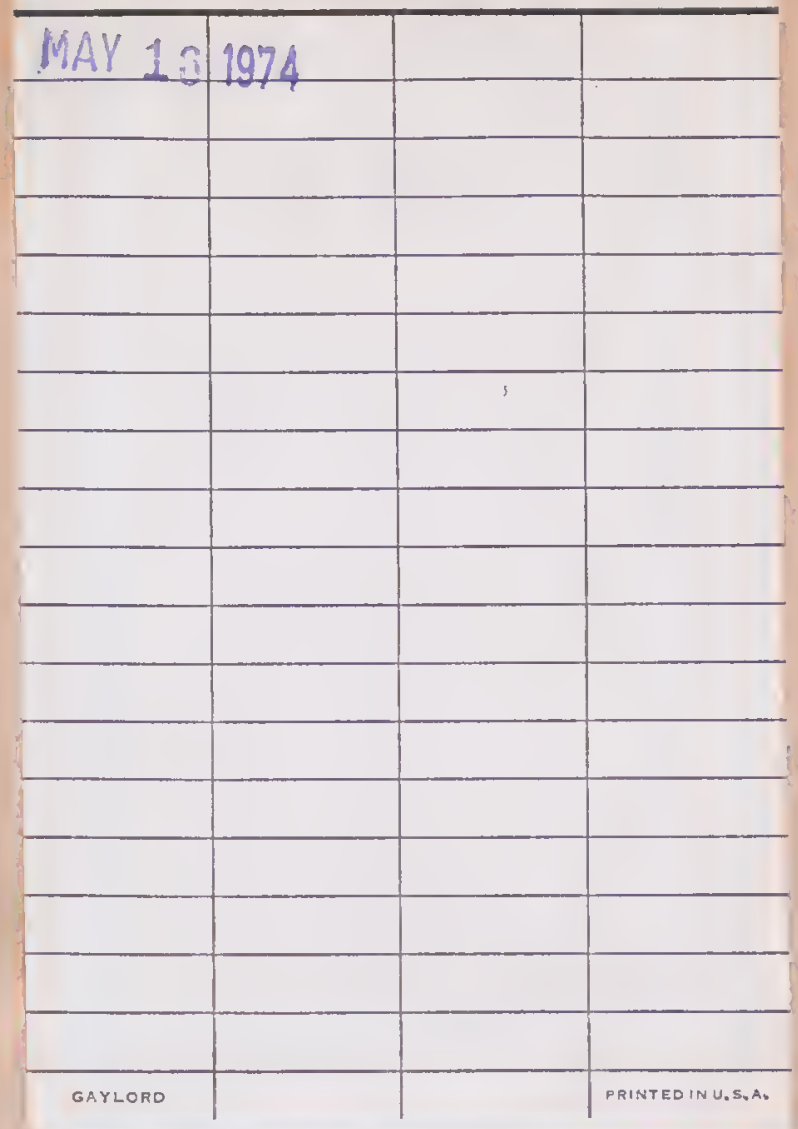






\section{MÉLANGES}

\section{DE.BOTANIQUE}

E $T$

DE VOYAGES. 
Ouvrage du même A uteur, qui se trouve chez le mëme Libraire.

Essats sUr la Végétation considérée dans le: Dévelorpement des Botrgeons; 1 vol. in-8., fig. . . . . . $5 \mathrm{fr}$. Le même, sur grand raisin. . . . . . . . . . 6 Le même, sur grand raisin vélin. . . . . . . . 8

\section{Sous Presse :}

Historrs: générale de la Familue deg Orenidées.

Historre particultike des Orcmótes des Isles australes D'Afriour; 1 vol. in-8., avec 100 planches, dessinées et gravées par l'Auteur.

Ouvrage eommencé en 1804, qui se continucra quand les circonstances le permettront.

Histoire des Véch́taux mecutiridis dans les Isles australes D'Afriqur. Première Partie, contenant les deseriptions et les figures des $\mathrm{PJ}_{a n t e s}$ qui forment des genres nouvenux ou qui perfectionnent les anciens, in- $4^{\circ}$.

120 planches doivent la compléter : 3o sont faites depuis long-temps, 


\section{MÉLANGES}

\section{DE BOTANIQUE}

sT.

\section{DE VOYAGES;}

Par Aubert DU PETIT-ThounR,

Directcur de la Pépinïre impériale du Roule, Membre des Socićtés d'Agriculture et Philomatique de Paris, ct de l'Académic Phytologique de Gorenki.

(Avec unc cartc et 18 planches.)

PREMIER RECUEIL.

A PARIS,

Chez Artius BERTRAND, Libraire, rue Haute-

- feuille, $\mathrm{n}^{\circ} .25$.

I 8 I $\mathrm{r}$. 
nicns! si vous saviez ce qu'il m'en coû́te pour être louḱ de vous!

J'ai royagé pendant dix ans; je m’étois réuni a vec mon illustre frère, et $j$ 'a vois concouru comme lui, par le sacrifice entier de ma fortune, au noble but de la recherche de M. de la Peyronse; mais j'arouerai, ponr moi, que je n'étois entrainé dans celte glorieuse entreprise que par l'espoir qu'elle me fourniroit l'occasion de visiter des contrées qui n'eussent pas encore attiré l'attention des Botanistes, afin d'y recueillir quelque Plante nouvelle, ou pour y saisir des faits qui pussent un jour aider à completter la chainc de la Végétation. Une suite de malheurs fit échouer notre armement, et mon frère vit tous ses projets s'évanouir; les miens surmontant la perte de ma fortune, se trouvèrent exécutés en partie, quoique j'eusse été entraîné dans une autre direction que celle que j'avois projettée.

De retour en Europe, jétois donc disposé, comme tous les autres voyageurs, à faire connoître toutes les découvertes qui pouvoient le rendre remarquable.

Cependant, depuis huit ans que je suis de retour, je n’ai encore publié qu'une très-petite partie de ce que j’ai rapporté. On doit penser que des obstacles majeurs m'ont empêché de satisfaire plutôt la curiosité publique. 
Pour qu'on puisse juger des contrariélés que j’ai éprouvées, je vais exposer les efforts que j’ai faits jusqu'à présent pour publier les matériaux que j’ai rapportés.

Dans l'élat actuel de la science, l'établissement des genres nouveaux étant la partie la plus importante, j'ai cherché à faire connoître d'abord ceux que j'avois déterminés; j’ai voula les raltacher aux deux ouvrages les plus importans qui aient paru jusqu'à présent sur celte natière; les Ordines naturales de M. de Jussieu, et les Tllustrationes de M. de Lamarck. Dès I 796 j'avois enroyé à M. de Jussieu la suite des genres que javois établis à Madagascar, rangés suivant sa méthode; mais de retour ici, voyant que ce savant s'occupoit à préparer unc nouvelle édition de son ouvrage, $j$ aurois attendu çe moment si désiré par tous les amateurs de la Botanique, afin de les roir se fondre dans son travail et occuper la place qui lui auroit paru la plus convenable; mais il falloit les lu faire connoître jusque dans leurs plus petits détails, afin qu'il pût mieux saisir leurs rapports; c'éloil en publiant leur figure avec les détails les plus exacts, et tels que je les avois dessinés sur le vivant. Rien ne me parut plus convenable pour ce projet que d'adopter le format quavoit pris M. de Lamarck, et sur lequel il a réduit tout ce 
qu'on a voit acquis jusqu'à présent sur l'Iconographie des genres.

En sorte que je me faisois gloire de faire de mon travail un supplément au sien; mais je n'ad’optai pas sa nuarche, ni dans la distribution de ces genres, ni dans leur description. D'abord, pour la première, comme ils devoient être intercalés tôt ou tard a vec les anciens, peu importoit l'orlre dans lequel je les présentois; en second lieu, M. de Lamarck avoit suivi le Systême de Linné, et il étoit aisé de voir, par la manière dont il s'est exprimé dans tous ses ouvrages, que ce n'étoit pas de son propre gré, mais qu'il avoit été obligé de se conformer au plan tracé par les Editeurs-libraires.

Quant aux descriptions, j'avois choisi une formule employée par M. Correa, dans les Transactions de la Société Linéenne de Londres, parce qu'elle réunissoil tous les avantages qu'avoient procurés les progrès de la science.

Ayant entrepris à mes frais la publication de cet ouvrage, j'étois plus indépendant; mais je n'ai pas joui long-temps de cet avantage.

J'avois fait graver les dix planches qui composoient ma première livraison; mais voyant qu'entre mes dessins et les épreuves il y en avoit trois par les calques et les décalques, et qui tenroient toujours de plus en plus à s'éloigner de 
mes traits, j'entrepris de les mettre moi-même à l'eau-forte, afin sur-tout de conserver l'exactitude des détails de la fructification; ensuite je les faisois achever par un artiste. J'avois déjà complété les planches qui devoient composer la seconde livraison; mais malgré le peu de frais que demandoit l'impression du texte, je ne me trouvai pas it même d'y subvenir; alors je pris le parti de me remettre entre les mains d'un libraire, j'espérois par là obtenir plus de célérité dans la publication de cet ouvrage. 11 en arriva tout le contraire; car les circonstances où il se trouva ne lui ayant pas permis de le publier, il fut obligé de le céder à un second libraire; et celui-ci ne s'accommodant pas de la simplicité de trait que javois adoptée, fit retravailler les planches de manière à pouvoir être tirées en couleur.

Du moins, dans les vingt premières planches qui devoient former, suivant mon plan, les deux premières livraisons, on avoit conservé les contours et les détails de la fructification, en sorte qu'il n'y avoit qu'un surcroît de travail et de dépenses, par conséquent; mais les six premiëres de la troisième livraison furent effacées totalement.

La science a donc perdn nécessairemeut quant. à l'exactitude. Quant à l'élégance, on n'a rien gagné, car on a calqué exactement les contours que 
j’avois donnés, mais je n'ai jamais pu faire rétablir les délails de la fructification. En sorte que le seul résultat de cette opération a élé d'augmenter de plus du double le prix de l'ourrage, sans aucun avantage réel. Il paroît que le libraire n'a pas trouvé sou compte à ce changement, car cet onvrage seste enfoui dans ses magasins; cependant les témoignages flatteurs qui me sont parvenus des différens points de l'Europe, me prouvent que la continuation paroît être désirée; je ne donte pas même quion ne me fasse des reproches à ce sujet et qu'on ne m'accuse de ce.retard.

Mlais cette augmentation de prix a un côté sous lequel elic me touche sensiblement, le voici: T'avouerai qu’à mon retour en Europe ayanı été effra yć, pour la science, de voir le luxe a vec lequel on publioit les ouvrages de Botanique, je ne pus m'empêcher d'en témoigner naïvement mon opinion à ce sujet, et je le fis de la manière la plus simple.

D'abord, dans le Discours Préliminaire de cet ouvrage, après a voir indiquéle nombrede planches de chaque numéro, j’avois annoncé la modicité du prix auquel je réduisois leur valeur; ensuite, dans l'Introduction, voici ce que j’ai dit, pag. 6: “ 11 ne " me reste plus quà dire mn mot sur les figures, " il devroit être d'cx́cuse pour oser présenter des 
) esquisses aussi imparfaites, dans un moment " où une foule de superbes ouvrages semblent " se disputer la prééminence pour la beauté et ) l'exactitude.

"Mais le vœu des vrais Botanistes m'encourage; ils verront sans doute avec plaisir une w tentative pour ramener la simplicité, qui doit "diminuer les frais de cette partie importante de "La science. "

Cette dernière phrase m'avoit attiré, sans que je m'en doutasse, l'animadversion d'un de nos Botanistes, qui crut y voir la critique de ses travaux.

Par là je me trouve en contradiction avec moimême; et le Libraire, qui vraisemblablement ne s'est pas donné la peine de lire lni-mème cet ouvrage, devenu sa propriété, l'a laissé subsister.

J'avois fait le projet, d'abord, de joindre à chaque cahier une dissertation détachée; c'est pour cela que dans le premier numéro j'en avois mis en tête une sur la germination du Cycas ( 1 ); mais je trouvai plus convenable de consacrer uniquement cet ouvrage aux genres nouveaux, en sorte que je sacrifai tous les exemplaires déjà impri-

(I) J'ai vu avec satisfaction que M. Robert Brown a confirmé mes observations sur ce singulier végétal ( $V_{o y}$. le Prodrome de la Flore de la Nouvelle Hollande, $\mathrm{I}^{\mathrm{Te}}$. part. , pag. 34 ). 
més, etj'annonçai dans la Préface que je ferois, de ces merceaux détachés, un ouvrage sous le titre de Mélanges.

Il y a bientôt quatre ans que j'ai voulu commencer à mettre à csécution ce projet, en faisant imprimer quelques morceaux.

Dans le principe, les différens Mémoires que j’arois lus àl'Institnt, sur l'Organisation Végétale, devoient en laire partie; mais se succédant plus rapidement que je ne l'espérois, j’ai préféré de les réunir dans un seul volume. Entin en voilà cinq que je lais paroìtre : ils sont détachés les uns des autres, et commencent chacun une pagination, parce qu'il y en a qui doivent être continués; cependant j'e piere que, tels quils sont, ils auront assez dintérêt pour mériter l'attention.

Si je parviens à pullier la continuation de ceux qui doivent en avoir, ils seront précédés chacun d'un Discours Préliminaire ou Avant-Propos, où je renclrai compte du bnt où j’ai voulu tendre; mais ' $n$ attendant je vais l'expliquer sommairemont pour tous. J'ai suivi pour leur arrangement lorilie de dite de leur composition, et je les imprime textuel!ement tels que je les ai esquissés; par là on aura la suite des efforts que j’ai faits pour exposer les connoissances que j'ai acquises.

$1^{\circ}$. Enchainement des.Ëtres, de I $788 ; 2^{\circ}$. Ge- 
nera Nova Madagascarica, $179^{6} ; 3^{\circ}$. Observationssur les Plantes des Tsles australes de l'Afrique, $1800 ; 4^{\circ}$. Cours de Botanique, 180 r $; 5^{\circ}$. Description des Isles de Tristan d'Acugna, 1802.

\section{Dissertation surl'Enchaînement des Êtres.}

C'est avec raison que je mets ce morceau en tête, car c'est le premier ouvrage que j'ai composé. J'élois en garnison à Lille en ${ }_{17} 87$, livré déjà depris huit ans à l'étude de la Botanique; mais ien fitisois un simple amusement, me contentant de recomoître les Plantes que je rencontrois, el de les ranger tant bien que mal en herbier. Jétois loin de penser à écrire jamais sur ce sujet: un hasard me détermina. Me trouvant de garde, je relevai' un capitaine du régiment d'Auvergne, M. le Gonidec de Traissan, que je connoissois de nom et rle figure sans lui avoir jamais parlé, je sa vois seulement quil étoit Membre et Secrétaire d'une Sociétésavante qui venoit de se former sous le titre de Collège des Philalèthes. Tandis qu'on relevoit les sentinelles, je canse avec lui de cette société; il finit par me demander pourcquoi je ne me proposerois pas pour en faire partie. Lui ayant demandé quelle démarche il falloit faire pour cela, il me répondit qu'il falloit présenter des mí- 
moires; je lui répliquai que jusqu'à ce moment je n'avois jamais écrit, sur aucun sujet, une plrase de suite; il m'engagea à essayer', et nous nous quittâmes. Resté seul, cette idée s'empare de moi ; ce qui me paroissoit le plus difficile, étoit de trouver un sujet. J'en passe plusieurs en revue; la nuit s'écoula sans que je pusse fermer l'ceil; enfin au matin je me trouve fixé sur l'Enchaínement des Êtres; il avoit été souvent le sujet de mes méditations, mais sans aucune suite, seuleunent en spéculation.

J'esquisse rapidement un plan; mais n'ayant point l'habitude de manier la plume, la plus grande partie de mes idées s'échappent. Cependant je parviens à faire un brouillon que je montre à mon introducteur : il m'encourage; au hout de quelques jours, ayant présenté un esquisse, je fus reçu de cette Société. On m'engagea à continuer mon travail; mais je ne tardai pas à m'apercevoir que j'avois pris un sujet beancoup trop vaste pour un début, et que les difficultés sans nombre m'arrêtoient à chaque pas. Cependant les encouragemens que je reçus me déterminèrent.

Une séance publique devoit avoir lieu, on me pressa vivement à terminer mon ouvrage pour cet instant: suirunt mon usage, j'attendis jusqu'au dernier moment. Entin je me déterminai : c'étoit 
encore un jour de garde, et dans les vingt-quatre heures j'achevai l'ouvrage tel qu'il est. Le célèbre Buffon venoit de mourir, lidée me vint de le terminer par son éloge. Quoique cette dissertation fût d'un genre trop sévère pour une pareille occasion, on daigna m'encourager par des applaudissemens. On me sollicita ensuite pour la faire imprimer; j'y résistai long-temps, parce que je regardois plutôt ce morceau comme un plan que comme un ouvrage complet; enfin, je me déterminai à le livrer à l'impression, mais je n'en fis tirer qu'une centaine d'exemplaires qui furent distribués à mes connoissances; $j$ 'en ofliris aussi à MM. Jussieu, Lamarck et Lacépède.

C'est donc une réimpression de cette Dissertation que je publie,maintenant, et dans le fond je la regarde comme un Discours préliminaire. En sorle que je me suis trouvé avoir fait la Préface de mes ouvrages ringt ans avant d'en publier aucuin.

Je fis quelques autres Disscrtations; mais entraîné par l'élan que j’avois reçu, je regrettois de ne pas me livrer à des travaux plus importans; je l'eusse peut-ĉtre entrepris, si la révolution qui survint, ne m'eût arraché à la vie qué j'avois menée jusqu'alors: je me trouvai jeté dans une autre carrière, m'étant réuni à mon frère. 
A près plusieurs événemens qui changèrent ma destination, je partis d'Europele 7 septembre $179^{2}$. Au bout de quatre mois de traversée j'arrivai à Tristan d'Actugna, où je recueillis les matériaux que j’ai cmployés dans le cinquième Mémoire.

Au mois de janvier suivant j'arrivai au Cap de Bonne-Espérance, j’y suis restéquinze jours. Ce fut le 2 mai que je débarquai à l'Ile-de-France; pendant deux ans je la parcourus, et j'y fis une abondante récolte. Je l'avois déjà réunic, en un corps d'ouvrage, lorsque je partis pour Madagascar.

\section{Genera nova Madagascarica.}

Je suis arrivé à Madagascar en juillet $\mathrm{r} 79^{5}$, et j'en suis reparti en janvier I 796, en sorteque j'y ai passé six mois; mais payant le tribut à ce climat meurtrier, jc fus plus d'un mois malade sans pouvoir sortir. Je me trouvai environné de tant d'objets nouveaux, que je ne pus moccuper que de Bolanique; mon temps se passoit à faire des courses, ordinairement l'après-midi, et j'cmployois la matinéc à examiner mes récoltes, décrire tous les objets qui me paroissoient nouvcaux, dessiner les plus remarquables, et dessécher le tout on lierbier. Je n'avois pour guide que le Systema $V_{e-}$ getabilium de Murrai, et le Genera Plantarum 
de Jussieu. Ce dernier ouvrage me ful d'une bien plus grande ressource que le premier.

J'étois imbu des principes de cet excellent ouvrage, ainsi que du'Traité des I'ruils de Gartner, en sorle que je ne négligeai aucune des particularités de l'intéricur du Fruit et des Graines; je m'occupai sur-tout à décrire les Genres qui me paroissoient nouveaux, avec tout le soin dont j'étois capable.

Voulant résumer leur caraclère, je suivis le plan de M. de Jussieu; je me flattois d'ajouter quelques pages à son excellent livre.

Il en résulta l'écrit que je présente ici. De retour à l'Ile-de-France, l'influence du climat que je venois de quitter m'y poursuivit, $i l$ en résulta une fière-quarte qui me tourmenta pendant neuf mois: Je m'en débarrassai insensiblement; mais je restai tellement affoibli, que je crus ne ponvoir me rétablir qu'en repassant en Europe. J'élois prêt à partir en profitant d'un passage que le Gouvernement m'accorda sur la frégate la Cibèle; mais m anıi, M. du Morier, distingué par la variété de ses connoissances et l'aménité de son caractère, qui avoit élé envoyé, en r 79r, par le roi, comme commissaire, me rencontra peu de jours avant celui qui étoit fixé pour mon départ; il me reproclia de ce que je men retournois en Europe sans 
avoir vu Bourhon, la scur aînée de ces Colonies. Il me fait les offres les plus obligeantes, en me disant qu'une famille à laquelle il étoit sur le point de s'allier, alloit devenir aussi la mienne; je n'eus pas de peine à me rendre à son invitation, car jéprouvois un vif' regret de m'en retourner en Europe sans avoir vu ce pays intéressant; je ne fus pas trompé dans mon attente, car jouissant pendant trois ans et demi d'une hospitalité fraternelle, j'eus le loisir de visiter les parties les plus reculées de cette île curieuse, et j'envoyai à M. de Jussieu celte esquisse de mes Genres de Madagascar.

De retour en Europe je le retrouvai dans son cabinet. Comme je l'ai déjà dit, j’aurois attendu que ce savant, en publiant la seconde Edition de ses Genres, y fit eutrer les miens en lui facilitant les moyens de les mieux comoître par la publication des figures dans mes Genres nouveaux.

Mais cet ouvrage ayant cité suspendu, ainsi que je l'ai rapporté, je me déterminai à retirer ma Notice des mains de M. de Jussieu, et à la publier comme un Prodrome; une circonstance particuliere me pressant alors, je lıâtai son impression sans me domer le temps de la corriger et de la soumettre à l'examen des personnes plus ver'sées dans la langue latine. En sorte qu'ayant pris la même forme que M. de Jussicu, cette conformité 
n'a servi qu’à faire sentir la différence entre l'élégance de son style et la rudesse du mien.

Chacun des Genres quej'ai décrits devroit reparoitre dans la même forme que les précédens, a vec les Figures que j'ai rapportées de mon voyage. Je ne les regarderai donc comme complets, que lorsqu'ils auront ainsi reparu, et là toutes les fautes qui me sont échappées seront corrigées.

Il y a des fautes de langage; la plupart, un écolier de sixième les eût évitées, et un bon prote suffisoit pour les faire disparoître.

Il y a d'autres fautes plus graves qui se sont glissées par inadvertance; ainsi dans le Leucosia $n^{\circ} \cdot 79$, $j$ ai mis ovarium inferum au lieu de superum.

La nomenclature est fort imparfaite, n'étant: que provisoire.

J'ai laissé beaucoup de noms des habitans de Madagascar.

Lorsque jai trouvé que les genres pouvoient se rapporter à quelques-uns des anciens, mais qu'ils présentoient des caractères particuliers qui laissoient du doute, $j$ 'ai laissé subsister le nom avec la terminaison oüdes, Olyroüdes, Pseudaleioüles, à l'imitation de Linné, dans son Flora Zeylanica.

D'autres fois j'ai retourné les noms; Maburnia, Burmania; Cavinium, Vaccinium; Starbia, Bart- 
sia; Nortenia, Torenia; d'autres fois avec un changement; Aspilia, Spilanthus; Hidrotia, Hidrolax; Maralia, Aralia; Lenidia, Dillenia; Altheria pour Waltheria; Thelira, Hirtella ; Metrocynia, Cynometra; Ptelidinum, Pteloea.

Dans quelques occasions jai rétabli les noms précédens, quand j’ai reconuu depuis l'identité évidente des geures; tels sont les Olyra, Lysianthus, Ethulia, Gchna.

J'ai emprunté, le plus quejai pu, les noms d'un savant Botaniste espagnol, Noronha, qui m'a précédé rlans ce pays.

Je l'aurois fail plus souvent si j'avois pu reconnoître ses noms; mais je n'ai eu en ma possession qu'un catalogue des Plantes qu'il avoit observées dans les mêmes lieux que j'avois parcourus, et il n'y avoit que les noms de genres et les trivianx de Linné rapportés anx Familles d'Adanson et au systême sexuel de Linné; mais ce qui rend ce travail très - précicux, ce sont les noms Madecasses ou du pays. C'est par leur moyen que j'en ai découvert beaucoup, et j'en ai deviné un assez grand nombre.

J'ai donné le commencement de ce catalogue; si, comme je le désire, je peux le continuer, alors je ferai connoître plus amplement les travaux de ce savant. 
J'aurois conservé avec d'antant plus de plaisir les Noms de ce Botaniste, qu'ils sont généralement hien composés; mais, autant que j'ai pu en juger, Noronha, avant de partir pour son royage, a voit plus d'érudition puisée dans les livres, que de science fondée sur l'observation de la nature.

J'ai formé les autres Noms du mienx qu'il m'a été possihle. J'en ai consacré un petit nombre d'autres à la mémoire de Botanistes, sur-tout à des Français trop oublics, tels sont ceux-ci:

Barbeuia, Barben du Bourg; Lestibudesia, Lestibondois; Bonamia, Bonami; Mauneia, Mauni, enfin Noronia, à Noronla. Celui-ci a été consacré par mon ami Stadman à ce savant voyageur dont nous venous de parler.

Je le répète, celte Nomenclature est absolument provisoire; elle ne sera fixée que lorsque chacun de ces Genres aura passé dans mes Plantes nouvellesets'y trouvera figuré, en sorte que, jusquelà, je me croirai en droit de changer son Nom on un meilleur.

On peut donc prendre, par cette Notice, une idée de ceque seroit cet ouvrage s'il étoit continué. J'y donne le Caractère de quatre-vingt-neuf Genres : il y en a environ vingt qui sont évidemment des anciens; mais, d'un autre cóté, jen ai au moins un pareil nombre que jai ćtabli à l'lsle- 
de-France, sans compter ceux qu'un examen plus approfondi m’a fait reconnoître depuis, et dont je n'ai pas fait mention ici.

En outre, j'ai plusieurs Familles naturelles sur lesquelles j’ai fait des travaux particuliers, et dont je n’ai pas détaché les Genres nouveaux que j'y ai observés; telles sont les Fougères, les Orchidées, etc. : d'où l'on peut conclure facilement que mon voyage aura valu à la Science l'élablissemenı de cent Genres nouveaux au moins.

De temps en temps il s'en trouve quelques-uns que d'autres voyageurs publient : ainsi mon Genre Potameia paroît être le même que le Cenarhenes de $\mathrm{M}$. de la Billardière. Cet auteur pense, comme moi, que ce Genre appartient à la Famille des Lauriers; mais M. de Jussieu, d'après la position de son emlsyon, le rapporte aux Protées, et IV. Robert Brown vient de confirmer ce rapprochement. Le genre Alsodeia paroît être le même que le Ceranthera que M. de Beauvois a établi dans sa Flore d'Owore "' du Benin. 11 le rapporte à la famille des Méliacées: je persiste toujours à le regarder comme très - voisin du genre Viola,' et par conséquent de la mème Famille que lui. C'est principalement le Fruit qui m'a indiqué ce rapprochement. Comme il paroît que M. Beauvois n'a pas été à même d'observer à maturité celui 
d'aucune de ses deux Espèces, il n'a pu indiquer sa Classification qu'a vec doute.

Il paroìt aussi, suivant la remarque de $\mathbf{M}$. de Jussieu, que le Genre Richaca est le même que le Cassipourea d'Aublet, ou le Legnotis de Swarts. Comme M. de la Billardière a depuis long-lemps rendu à son malheureux compagnon de voyage, Riche, les honneurs botaniques, en lui consacrant un Genre, j'aurois toujours été obligé de changer: ce nom.

Si je me trouve à mème de continuer ces Mélanges, je publicrai à la suite de cette Notice plusieurs morceaux, qui formeront les foudemens de la Flore de Madagascar; ils seront renfermés dans un seul volume; d'abord je termineraile catalogue de Noronha, en y joignant la liste alphabétique des noms Madecasses, ensuite les descriptions de Plantes données par Flaccour, avec l'indication des Synonymes que j'aurai pu découvrir. J'extrairai pareillement des antres voyageurs ce qu'ils ont écrit sur les Végétaux de cette grande île. Enfin, je terminerai par l'exposition des Espèces que jai trouvées moi-mème dans ce pays.

M. Römer m’ayant demandé mon agrément pour réimprimer cette Notice dans l'ouvrage dont il vient de commencer la publication sous le titre de Collectanea Botanica, je me suis empressé 
d'acquiescer à cette demande qui fait honnetir à cet opuscule.

\section{II. Observations sur les Plantes des Isles aus- trales d'Afriquc.}

Si dans le précédent morceau j’ai voulu donner l'esquissc de mes Genres, dans celui-ci c'est an aperç des Espèces. Voici ce qui lui a donné naissancc. Dans une course que je fis dans les montagnes de Bourbon, il m'étoit cntré une épine de Palmisic dans la plante du pied; il en résulta un dépùt qui mempêcha, pendant six semaines, de mettre le pied à terre. Un habitant du voisinage se irouvant a voir les quatre premiers volumes de la prartic Botanique de l'Encyclopédie, il me les jucta; ce qui me donna occasion d'y relever les Plantes de ces îles que j'n vois eu occasion le con-noître; je pris'le parti d'adresser mes remarques à M. Lamarck lui-mème, sans savoir quand je les lui enverrois; ce ne fnt qu'un an aprés, lorsque je fus de retour à l'Isle-de-France, que je jus le laire. Mais comme jen'avois pas eu de nouvelles directes de ce Savant, ainsi que de tons cenx à qui j'avois écrit, et ne sachant pas qui avoit survécu à l'lorrible tourmente politiqne, j'avois pris le parti d'ajouter à son adresse: on son absence, au Prési- 
'dent de la Société Pliilomatique : on m'a voit dit que cette Société étoit la mềme que celle d'Histoire Naturelie, qui mavoit admis au nombre de ses membres. M. de Lamarck voyant cette addition, renvoya le paquet, sans le décacheter, à cette Société, et on en a publié quelrques articles daus son Bulletin. Comme j’avois jeté dans cette notice quelques-unes de mes idées sur les rapports des Plantes, j’aicherché à le ravoir; mais re n'est qu'au bout de six ans que l'on a pu le retrouver. Je le publie tel que je l'ai composé. J'ai seulement eu l'attention de marquer par une astérisque quelques additions que j'ai laites.

I a continuation nécessaire de cet ouvrage sera le catalogue de toutes les Plantes citées dans l'Encyclopédie, qui se trouvent sur les trois îles que j’ai parcourues.

Henreusement cet ouvrage vient l'êtro conduit à sa fin; mais il demande un supplément presqu'aussi considérable que l'onvrage lui-même; et comme M. Poiret, qui en est maintenant l'auteur, y travaille arec le zèle el l'assiduité qui lui sont naturels, il faut espérer qu'il le conduira bientót à sa perfection. J'y joindrai quelques autres morceaux sur la filore compráé de ces deux iles, en sorte qu'il en résultera un volume analogue à celıi qui traitera de Madagascar. 


\section{Cours de Botanique.}

J'ai annoncé cet ouvrage dans la Préface de mes Plantes nonvelles: on ne pourra le juger que lorsqu'il scra complet. Je l'avois entrepris à l'Isle-deFrance, ou j'espérois pouvoir le publicr: j'en avois dëjà exćculé six Promenades ou lecons; mais c'est eu vain que je fis quelques tentalives pour y parvenir.

Cet ouvrage, par la forme que je lui ai donnée, ne paroîtra pas convenir à nu grand nombre de personnes; d'abord c'est à l'enfance qu'il paroît destiné, sccondement il est adapté au Climat de l'isle-de-France.

Ellectivement, par le plan que jai suivi, c’est un pere qui donne des lecons de Botanique à son fils. J'ai voulu faire voir comment on pouvoit s'élever graduellement, depuis l'ignorance la plus complète d'une Science, jusqu'à son ensemble. Ici ce n'est pas aux enlans que j'ai destiné cet ouvrage, mais c'est anx pères et mères que je l'adresse. C'est l'exemple d'un mode particulier d'instruclion que je présentc; et dans quelquesunes des Promenades suivantes je ferai voir comment il peut avoir son application à d'autres sciences; en second lieu, les notes formeront un 
second Cours pour des personnes plus âgées, parce que, par la manière dont elles sont disposées, c'est l'application des principes de la Botanique aux Plantes les plus généralement connues.

Quant à l'inconvénient qui résulte du Climat que j’ai choisi pour lieu de la scène, roici comment j'ai cru pouvoir y remédier : d'abord j'ai eu l'attention de ne choisir, comme exemple, que des Plantes cultivées, ou celles qui se trouvent répandues sous tous les Climats; en sorte que le plus grand nombre de ces cxemples se trouvent par-tout.

J'aurai soin, par la suite, d'ajouter à la fin de chaque Promenade la citalion des Plantes de notre pays analogues à celles qui seroient trop étrangères, en sorte que les mêmes développemens pourrout leur convenir.

Mais, de plus, chaque note deviendra un tableau qui peindra quelque chose de particulier, et l'ensemble pourra donner une idée de la Végétation de ces pays éloignés; et les comparaisons que je ferai avec les productions de notre sol, le rendront, j'espère, d'un intérĉt général.

Pour donner une idée plus complète de ce que sera cet ouvrage lorsqu'il sera fini, je vais en présenter le Plan général. 
$I^{r}$. Promenade. Des différentes parties qui composent ordinairement une Fleur.

II. Promenade. Du rapport que ces différentes parties ont entr'elles.-De leur Absence et de leur Présence.

III. Promenade. Des varia lions de Forme que peuvent subir ces diffërentes parties. - De leur Usage.

IVe. Promenade. De l'utilité de ces variations pour trouver le nom d'une Plante qu'on voit pour la première fois.- Des Systèmes ct des Méthodes.

$V$. Promenade. Des rapports que les Plantes ont entr'elles. - Des Familles naturelles.

VT: Promenade, manquée à crusse de la pluie. De la manière d'allumer du Feu. - De son application et de son action sur les différens corps. - Commencement d'un coms de Chimic.

VII. Promenade. Culture des Plantes annuelles. - De leur Germination.

VIIT. Promenade. Culture des Arbres utiles: - Le Verger. - Distinction des Herbes et des Arbres.

IX: Promenarle. Des Plantes commerciales cultivées en grand. - La Sucreric. - LiIndigoterie. - La Cafeterie.

$X$. Promenade. Courses dans les pays incultes 
et les bois. - Des différens usages des Plante; sauvages.

XI. Promenade. Course au bord de la Mer. - Des différences des Plantes suivant la nature du sol.

$X I I$. Promenarle. Incursion sur une montagne. - Commencement d'un cours de Géographie.

$X I I I^{2}$. Promenade. Résumé général. - Toutes ces parties forment une Science qu'on nomme la Botanique. - De ses rapports avec l'Histoire naturelle en général. - De la Nature et de son Auteur.

Chaque Promenade sera accompagnée d'une Planche au moins; clle sera destinée à développer les principes de la Science. Je n'en ai pas mis à celle-ci, mais celle qui lui appartient paroîtra avec la seconde Promenade, si je me trouve à même de la publier.

\section{Description de lîle de Tristan d'Acugna, et Esquisse de sa Flore.}

Lorsque je me trouvai de retour en Europe, en septembre 1802 , je sentis plus vivement que jamais la privation de toute espece de fortune. Pendant mon voyage j'étois scul; mais je venois me réunir à ce qui restoit de ma famille, et le 
plaisir que j'ćprouvois étoit cruellement altéré par l'idée que je venois pour augmenter la difficulté qu'ils ćprouvoient déjà pour pouvoir subsister. Je me flattois que les Mntérianx que je rapportois étoient de nature à exciter assez puissamment l'attention pour que leur publication pût au moins me procurer l'existence. Mais il falloit les faire connoître, je crus que le moyen le plus simple, pour y parvenir, étoit de les présenter à la première classe de l'Institut.

Il me parut suffisant de lui offrir des morceaux de différens geures, afin qu'on pût juger l'ensemble de mes travaux. La description d'une lle peu fréqueutée me parut la plus propre à remplir mon but. C'est donc dans cette intention que jai composé la dernière pièce dè ce recueil.

Depuis que ce morceau est imprimé, j’ai eu occasion de reconnoître que le genre que j’ai nomné Ponceletia paroì être le même que le Trachinotia de la Flore de l'Amérique septentrionale de Michaux, on le Limnetis de M. Persoon, Synopsis Plantarum; il comprend le Dactylis Cynosuoïles avec qui ma Plante paroît avoir beaucoup de rapports, et depuis ce temps M. Robert Brown vient de donner le nom de Ponceletia a un des nombreux genres qu'il a formés dans sa Flore de la Nouvelle-Hollande. 
En outre, d'après une lettre que j'ai reçue de IM. Swarts, l'Asplenium filipendulafolium, n०.72, est le Grammitis cheilanthoides, lécrit et mentionné dans son Synopsis Filicum, pag. 23, 2.19, 4r9. Ce qui me surprend, c'est que cet Auteur l'annonce comme originaire de l'Hle Maurice ou de France, je ne l'ai trouvée qu'à Tristan d'Acugna, et il n'est point dans l'Herbier de Commerson : jignore comment elle est parvenue dans les mains de M. Swarts, à moins qu'elle ne lui ait été communiquée par un de ses compatriotes, chirurgien à bord d'un vaisseau de la Compagnnie des Indes, qui relàcha à l'I!c-de-France, et à qui je donnai heaucoup de Plantes sèches.

Depuis ce moment j'ai lu plus de trente Mémoires à la première Classe de l'Institut, dont quinze sont imprimés textuellement, tels que je les ai lus, en sorte qu'on peut juger par là, quant au fond et à la forme, des efforts que j'ai faits pour faire connoître les matériaux que j’a vois recueillis.

Tels sont donc les cinq Morceaux qui composent ce Recueil : trois peuvent être regardés comme le commencement d'aulant d'ouvrages. Je pourrois facilement les continuer et les completter dans un espace de temps assez coirt, en publiant de nouveaux volumes de Mélanges rui en comprendroient des portions. Je commea- 
cerois clracun d'eux par une partie de la Relation de mon Voyage el de la description des pays que j'ai parcourus, en y joignant une suite de vues et de dessins d'un genre absolument neuf, que j'ai annoncés depuis plusieurs années sous le titre de Péripanorama. C'est effectivement une collection de vues horizontales, ou véritables Panorama (voyez le Moniteur, janvier 1805 ).

Je donnerois aussi des figures de Plantes, à la suite des autres morccaux, telles que celles qui sont dans ce volume. J'en publicrois encore quelques-unes de T'ristan d'Acugna, en sorte que chaque volume contiendroit environ vingt Feuilles d'impression et vingt Planches..

Mais je me tron ve furcé d'en rester à celui-ci, tant que je n'aurai pas recouvré les dépenses que j’ai été obligé de faire, à moins que je ne trouve un Libraire qui veuille s'en charger. On doit donc, jusque-là, le regarder commo s'il étoit conplet.

C'est une semblable cause qui mempêche de prod'uire l'Histoive des Plantes de la Familledes Orchidées des Isles australes d'Afrique. J'cu ai présenté le manuscrit écrit depuis dix ans, et quarante Planches déja gravées à l'eau-forte, par moi, à la première classe de l'Institut, en 1806 .

Deux ans après, en r 808 , jai présenté à la même Classe soixante-six Planches terminées; et 
sur ce que les commissaires me représentèreni qu'ils ne pouvoient lire le terte qui les accompagnoit, j'en fis imprimer denx Fenilles, mais j'en suis resté là.It me reste encore vingt-cinq Planches à faire pour completter l'Ouvrage, mais je ne peux me déterminer à y mettre la main que lorsque je serai sûr que je pourrai faire rentrer les fonds que cet ouvrage me coùte déjà, et que je ne serai pas obligé d'en faire d'autres pour le conduire à sa perlection.

Cet ouvrage est donc dans le mêne cas que mes Plantes nouvelles, qui, si j'eusse été secondé, seroient achevées depuis deux ans.Il m'eût été aussi facile rie publier un recueil semblable sur la Famille des Fongères. J'en ai mis le manuscrit sous les yeux des Commissaires chargés de faire un rapport sur mes travaux à l'Institut; mais ils n'ont pas jugé à propos d'en parler. J'aurois pu leur soumettre parcillement plus de cent Graminées dessinées avec beancoup de détails et d'une manière que je crois neuve. Il n'est grière de Famille un peu considérable sur laquelle je n'aie des travaux de mène genre.

J'ai saisi tontes les antres occasions qui se sont présentées depuis mon retour, pour faire connoître les malériaux que jai recueillis, notamment dans le noureau Dictionnaire d'His- 
toire Naturelle. M. de Jussien, à mon relour, m'avoit engagé à me réunir à ses nombreux collaborateurs; mais comme ils s'étoient déjà partagé les différentes Familles du Règne végétal, il me fallut choisir parmi les Plantes exotiques celles qui éloient les moins connues et sur lesquelles je pouvois avoir quelque nouveau renseignement. Enfin, M. de Jussieu me donna l'lonorable commission de faire, à sa place, l'article Botanique.

J'ai du moius fait voir par ce tableau rapide de la science, présenté d'une manière neuve, que je n'étois étranger à aucune de ses parties, et qu'arec plus de temps j'étois capable de traiter chacune d'elles arec plus de développement. L'article CA Lac, qui termine mes Observations sur les Plantes des Isles australes d'Afrique, est extrait de ce Dictionnaire.

Ce n'est pas par l'abondance de mes matériaux ni par la quantité de Plantes que j’ai recueillies, que je crois mon Voyage remarquable, c'est l'effet des circonstances qui m'ont jeté dans des contrées plus on moins aboudantes. Aiusi, dans trois jours j'ai recueilli cent Plantes sur l'ile de Tristan d'Acugna; dans quinze jours, six cents au Cap de Bonne-Espérance. J'ai été deux ans à l'Isle-deFrance arant d'aroir completté ce nombre, tandis que dans six mois Madagascar m'en a procuré 
huit cents; et dans trois ans et demi que j’ai passé à Bourbon, je n'ai pas augmenté ma collection de plus de deux cents Plantes nouvelles.

Et si le malheur eût voulu que j'eusse fait naufrage en arrivant au port, et que j'eusse perdu toute ma récolte, je serois descendu Botaniste, et jaurois encore été en état de faire jouir ma patrie du fruit de dix ans de Voyages.

Je l'ai prouvé d'une manière incontestable, en. fondant sur l'examen seul du Marronier d'Inde et du Tilleul une nouvelle Théorie de la Végétation, que j’ai développée dans douze Essais.

Ces Essais sont encore un ouvrage commencé et qui se trouve arrèté à la première partie; mais malgré l'abondance des matériaux que j’ai déjà rassemblés, je suis encore obligé d'en ajourner la suite jusqu'au moment où je pourrai subvenir à ses frais.

En terminant ce premier Volume j’ai donné le plan d'un second, dans lequel, continuant la série de ces Essais, je les portois au nombre de vingt; ils devoient completter un Cours de Botanique générale; mais, depuis, réfléchissant sur ce sujet, et sur-tout éclairci par le Cours que je viens de donner sur cette matière à l'établissement que je dirige, je crois plus convenable de reprendre les deux derniers Essais et de les fondre dans 
imposant de tant d'objets qui partagent avec lui l'existence, tout lui offre un sujet d'admiration. Mais il ne s'en tient pas là, il étudie leurs caractèes, combine leurs rapporls, el., profitant des conmoissances qu'il acquier, il sait s'entourer de ceux qui peurent lui être de quelqu'ulilité, tandis qu'il en écarte d'antres do .I il auroit à craindre quelque dommage. Ciest beaucoup, il se montre déjà bien supéricur à ces animaux qu'il a domptés ou qu'il a forcés de fuir a son aspect : un sentiment plus noble est venu metlre le comble à sa grandeur; il s'élève, par la contemplation, à l'auteur de tant le merveilles; et, pénétré de reconuaissance, illui offre le tribut de ses hommages. Voila deux motifs qui nous rendent l'étude de la naturc hien recommandable. Aussi ses charmes et sou utilié n'échappent à personne. Le sauvage, dans seș cliansons grossières, en fait une peinture si énergique, qu'il prouve que malgré son apathic il a fait des observations qui ont échappé à la science même.

Mais si nous enorgucillissant de nos succès, nous voulions saisir d'un seul comp d'œil tout cet ensemble, le sentiment de notre foilblesse succéderoit, et notre espril se trouveroit accablé sous le fardcau qu'il auroit voulu soulever. Il a fallu le partager : la philosophie est venue prêter le flambeau de l'analyse, ct circonscrivant le domaine de clıaque science, ne les a isolées que pour qu'elles puissent se porter des secours plus efficaces. Ainsi, tandis que te Pliysicien cherche à découvrir les propriétés de la naličre, le Chimiste s'applique à déterminer sa composition, l'A̧natomiste (1) suit les organes 
qui l'animent, le Naturaliste ne s'occupe que de l'extérieur. Ceux-ei veulent pénétrer les causes, celui-là se borne a.observer. les résultats. Il sembleroit, d'après cela, que le Naturaliste, simple observateur, dût rarement s'éearter de l'objet de ses recherehes; tandis que le Physieien, entouré de ses instrumens, le Chimiste cmployant ses dissolvans, l'Analomiste son seapel, doivent quelquefois s'égarer, uc eommoissant pas la réaction des intermèdes qu'ils emploient, et en attribuer les effels aux corps qu'ils examinent. Mais bientôt la nême foiblesse qui a fait divisei les scienees, forcera le Naturaliste à recourir au même moyen, qui entrâ̂nera peut-être autant d'inconvéniens que les instrumens de ceux-ei. Si, après s'être oceupé des objets en particulicr, il veut jugrer de leurs rapports et voir leur enelıânement, il se perd bientôt, cet inımense tableau ne pent être saisi que par la sagesse infinie qui l'a ordonné. Il est obligé, pour le mettre à sa portéc, de le subdiviser; la nature elle-même semble le favoriser, et condescendre, pour ainsi dire, à notre petitesse. Tandis qu'elle lie des êtres par les rapports les plus frappans, elle en isole d'autres; il cherehe a profiter de ees intervalles, et part de là pour former des classes et des ordies. Oubliant bientôt qu'il dait suivre la nature et mon l'assujettir, il s'astreint à un seul principe qu’il a découvert, ne faisant pas attention qu'elle varie aulant ses causes que ses effets; ses conpes moins heureuses sćparent des objets' qui àvoient beaueoup d'affinités, tandis qu'il en joint de disparates. De là sont venues tant de méthodes qui se sont détruites l'une 
après l'autre, étant plutôt le travail de l'imagination que le résultat de l'observation. Cependant, malgré lcurs points différens de départ, ils n'ont pu parvenir à bouleverser 111 graud nombre de séries, qui ont résisté ì leurs différentes analyses. Cet accord prouve ccrtainement qu'elles ont des rapports naturels qui n'ont pu échapper à persolme; ccpendant, des savans distingués en ont jugé différenment, et ont assuré qu'on ne pouvoil tracer de divisions sans rompre quelques affiuités; ne voyant que les défauts de leurs rystêmes, ils les ont tous proscrits, se fondant sur le: célebre axiome: La nature ne fait point de saut. Mais le prenant dans le scus le plus strict, n'ont-ils pas euxmêmes vouln domner des luis à celle qu'ils prétcndoient. affranchir ? Ne pouvant méconnoître la plupart des lacunes, ils les ont attribuces au défant de mos con-noissances. C'est en partie vrai, mais je doute qu'il nous: füt possible de combler les vides apparens qui les. sćparent; d'aillcurs, jouissons, en atrendant, des fácilités qu'ils nous doment.

Comme l'Histoire Naturelle est une science de faits, c'est clle-mêne qu'il faut cousulter. Je vais présenter un tableau snccinct de ses principales divisions. Je In'arrîtcrai sur-tont à examiner les tîtres qu'on regarde communément comme destinés à en lier les différentes parties, el qui, dans' la spéculation, paroissent d'uı genre douteux. C'est parmi les animaux qu'ils sont le. plus remarquables; e'est aussi parmi eux que je les. considérerai. L.es végélaux fouruiront quelques olsservations sur les différcos ordres naturels qu'on a voulu 
UES E E T R E S.

tracer. Je finirai par hasarder quelques idées sur le plan qu'il seroit le plus eonvenable d'adopter pour pouvoir suivre l'enchaînement des Ėtres; enchaînement que je suis loin de eontester, mais qui existe bien différemment de ce qu'on-l'a conçu généralement, et dont, par le défaut de nos moyens, nous ne pourrons jamais suivre la continuité; le fil nous en ćchappera tonjours. Cette esquisse, que je vais présenter, sera bien foible; mais des lignes traeées presqu'au liasard suffisent aus Géomètre pour démontrer la proposition la plus compliquée.

La première division qui se présente est celle des Trois Règnes. Elle est généralement adoptéc. Rien ne paroît, au premier coup d'œil, nieux prononcé. Uue matière brute compose le Règne minéral; dénuée d'organes, elle ne eroît que par la juxtà-position des substances qui eoncourentà sa fornation: les Végétanx en sont pourvus. Par leur moyen, ils s'assimilent, et font scrvir à leurs développemens les corps qui les environnent; mais fixés au même licu, ils n'ont d'autres monvemens que eeux de leur organisation propre, ou eeux qui leur sont commuuiqués par les corps environuans, taudis que les $A$ nimanx ayant, les mêmes développemens, joujssent du sentiment qui leur fait distingner les alimens qui leur sont propres, et du mouvement, qui leur donue la faeulté de s'en approeher.

Voilà donc déjà trois parties quon peut eonsidérer séparément; on peut mêrué ne s'altacher qu'à une seule. Le Minćralogiste deseendra dans les eutrailles de la terre, suivra les différentes veines qui la partagent; lo 
Botaniste, moissonnant à la surface, décrira les végétaux qui la couvrent, tandis que le Zoologiste observera les mours des animaux qui viennent animer la scène.

Quoiqu'ils semblent avoir des districts bien séparés, ne se rencontreront-ils pas dans quelques parties? ne trouveront-ils point des Etres mitoyens qu'ils pourroient également revendiquer? C'est ce qu'il faut examiner avec atteution. De ces trois Règnes, deux paroissent se rapprocher beancoup, le Végetal et l'A nimal; ils ont l'un et l'autre la faculté de se reproduire : aussi plusicurs Physiciens les ont-ils confondus sous le nom d'Litres organiques. Celui d'inorganiques a été donné aux Minéraux. Ces derniers semblent être la source et le résiclu des autres. C'est daus leur sein que ceux-ci puisent leur subslance; c'est là que se confondent leurs déponilles. Les Végélaux sont cependant les seuls qui paroissent directement tirer de ce vaste dépôt; il faut, pour ainsi dire, qu'ils donnent une première vie à la matière avant qu'elle puisse convenir aux Animaux. C'est une nouvolle ligne de démarcation entre les deux Regnes. Mais les extrêmes se tomchent souvent, voyons les limites; c'est là que nous nous assurerons si elles sont bien tranchantes, si aucun Etre ué leur a échappé.

La spéculation en imaginoit déjà, lorsque le Polype vint s'offrir aux yeux de Trembley, il sembloit venir joindre ces deux Règnes : son étonnante reproduction, sas ( mbranchemens le rapprochoient des plantes; mais hientôt ses mouvemerıs spontanés et sa façon de vivre le fixcrcnt parmi les A nimaux. Une autre classe de pro- 
ductions a occásionné de plus grands embarras; c'est celle des Zoophytes, que leur forme a fait connoître sous le nom de Plantes marines, tels que les Coraux, les Madrepores, et les Sertulaires, etc. Aussi ont-elles éprouvé de grandes variations: les Anciens les regardoient comme des espèces de pierres qui végétoient. Marsigli crut appercevoir des fleurs qui s'épanouissoient, d'après cela il les rangea parmi les plantes. Mais Peyssonel, et bien long-temps avant lui, un Italien nommé Impcrato, reconnurent leur aninalité. Les Polypes vinrent mettre le sceau à celte découverte. Les fleurs apperçues par Marsigli, sous la loupe des Jussieu et des Réaumur se changèrent en animalcules, el ces plantes devinrent des Polypiers. Depuis, presque tous les savans ont adopté leur animalité, en la modifiant pourtant, et leurs différentes opiuions prouvent que la nature de ces substances singulières n'est pas encore bien connue. L'élément qu'ils habitent, et leur petitesse sont des obstacles presque insurmontables : la Nature a jetć un voile surle noud qui joint ces deux sérics : le Métaphysicieu pourra bien essayer de le soulever; mais le Naturaliste, craiguant de s'égarer, cherchera des objets qui n'échappent point à sa vue : conccvant bien la possibilité de cette jonction, il attendra, pour l'admettre, qu'clle soit prononcée plus distinctement.

De ces trois Tableaux, Te plus remarquable est celui du Règne animal, tous les ćlémens sont animés par sa présence; la forme des Etres qui le composent, variée à l'iufini, semble être modifiće pour ne laisses 
aucun espace vide; leur taille ct leurs couleurs n'offrent pas moins de diversités. A leur lête se trouve l'Homno. J'ai déjà fait apperecvoir la supériorité que lui dommoit son intelligence; un scul trait suffira pour la confirmer. Que les Sauvages les plus brutes se trouvent exposés an froid, à l'aile dn frottement de deux morccaux de bois ils en tirent du feu, dont ils forment un brasiec qu'ils entl'elienuent aussi long-temps que leurs liesoins l'exigncut; lorsqu'ils l'abandonnent, des singes, et sur-tout l'Orang-oulang, s'en approchent, ils se délocteut. près de cette chalcur factice, mais sans l'cutretenir, sans s'aviser d'y mettre celte branche qu'ils tiennent à la main, et sur laquelle on s'est tant récrié, saus nîme rapprocher les lisons qui, s'ćcarlant du foyer, finissent par s'éteindrc. Il seroit aisé de rapprocher des faits aussi frappans; mais je ne m'y arrêterai pas davantage : cherchons les moyens que la Nature peut nous avoir ménagés pour nous reconnoître dans cette foule. 'Táchons de nous assurer si les six classes que l'on compte ordinairement parmi eux, sont naturelles. Ces six classes sont: les Quadrupedes, les Oiseaux, les Puissous, les Reptiles, Ics Insectes et les Vers (a).

I.es Quadrupedes sont à la tête, leur exlérieur les rapproche de nous; examinons quels scront les caractères qui nous les feront connoìtre, et qui nous empếcheront de les confondre avec les especes voisincs. Si nous nous en tenons simplement à celui de quadru-

(a) Un changement importaut a été fait depuis dans cette classification ( 2 ). 
D F $S$ है T R E S .

pède, les Lézards, les Grenouilles et les Tortues sembleroint en faire partie: les autres reptibles, se traînant sur leurs pas, franchiront les barrières qui sembloient les écarter. Les poils qui couvrent les uns, les ćcailles, le têt qui défendent les autres, ne seront pas des distinctions plus trancliantes; nous verrons les Tatous et le Diable de Jasa, l'un couvert de véritables écailles, les autres, armés de cuirasse, la détruire. Laqualité d'Ovipares et de Vivipares ne suffira pas encore; quelques Lézards étant vivipares, il faudra y joindre celle d'allaiter lcurs petits, les Quadrupèdes seuls étant munis de cette source précicuse où leurs rejctons puisent unc nourriture proportionnée à leur foilblesse. Les mêmes caractères nous serviront ì écarter les Oiscaux : en vain le poil, se ramifiant, s'est changé en plume légèrc; en vain leur bouche s'est aiguiséc et a formé un bec; en vain ceux-lì semblent atiachés à la terre, tandis que les autres franchissent le vague des airs; on pourroil trouver quelque point de réunion. La légèretć de l'Écureuil supplée aux ailes, les arbres les plus élevés deviennent son séjour : des $\mathrm{mcm}-$ branes qui joignent les quatrc jamıbes d'unc cspèce voisine, la rapprochent encore plus des habitans de l'air, et méritent au Polatouche le nom d'Écureuil volant; par leur moyen il prolonge son saut et franchit de $r$ ands espaces; mais il nc peut retarder sa chîte quc de quelques instans, il lni faut toujours un premier élan, qu'il ne peut renouveler qu'en touchant le solide. Ces membranes s'amincissent ct s'étendent davantage dans la Chauve-sonris; les articulations de ses doigts se sont 
alongées, et soatiennent de véritables âlles, à l'aide desquelles elle cherche dans les airs sa proie; elle semble même avoir perdu toute autre façon de se mouvoir; w'ayant des ongles que pour s'accrocher, elle ne se trainc qu'avec beaucoup de difficultés sur la terre.

Mais sans nous arrêter à sa forme el à l'espèce même de ses aîles, qui la différencient des autres volatiles, nous ne la verrons point conver, et des manelles, ses dents et ses poils la joindront aux quadrupèdes, malgré sa singularité. C'est là certainement la saillic la plus remarquable vers les oiscaux : le muscau affilé des Fourmilliers et des Tamanduas ne nous offrira point d'équivoque, quoique sa forme et son usage le fassent ressembler au bec des Pies ( 3 ).

Peut-être ont-ils des rapports plus marqués avec les Poissons? Effectivement, les chainous semblent se rapprocher : le Rat d'eau, la Loutre et lc Castor nagent et plongent dans l'eau avec antant de facilité qu'ils marclıent et courẹnt sur terre. Mais hientôt nous verrons disparoître le terrestre. Déja les Phoques et les Lions marins se trainent arec peinc sur la vase et le sable qui bordent l'élément qu'ils labilent de préférence, leurs mernbres s'allongent, et se réunissant, ne sont plus propres à les soutenir sur la terre; ceux de devant, an contraire, se raccourcissant, ne leur fournissent plus que des nageoires commodes. Malgré́ cela on né peut néconnoître tous les autres caractères des quadrupedes, leurs membres n'ont fait que changer de destination. Mais ces mains et ces pieds sé sont évanouis tout-ifiait, et ne sont remplacés que par de véritables 
nageoires dans la Baleine, les Marsouins et les autres Cétacées ; leur extérieur est celui des Poissons : cependant ces énormes colosses ont des poumons et allaitent leurs petits: ne pouvant parcourir que le sein des eaux, ils sont obligés de venir à sa surface jour de celui qu'ils ne scmblent quitter qu'à regret, tandis qu'on voit nager autour d'elle leur Baleincau. Celui-ci ne trouve de nourriture que dans le sein qui l'a porté; toute leur confor mation intérieure ne peut les faire méconnoître, et indique leurs rapports avec les Quadrupedes. Mais il faut laisser ces détails à l'anatomie comparée : l'extérieur même, qui paroît tant se rapprocher des Poissons, suffira pour en les séparer. Lesnageoires, dans ceux-ci, sont des rayons cartilagineux qui soutiennent des membranes minces et transparcites pour la plupart; dans les autres, an contraire, c'est une masse solide qui n'a d'autre mouvcment que celui de l'articulation. La situation de la queue vient meltre le dernier trait à leur différcnce : les Poissons l'ont perpendiculaire, et elle est horizontale dans les Cétacèes, d'où leur vient le nom de Plagiures. C'est une trace informe des pieds que la position fail encore reconnoître; ainsi, malgré l'apparence, voilà encore les limites des Quadrupèdes fixées de ce côté-là, ce qui achève de les isoler entièrement.

Les Oiseaux vont actuellement fixer notre attention. L'élćgance des formes, la richicsse des couleurs, se réunissent pour en former la classe la plus brillante. Parcourant, comme les Quadrupèdes, la surface de la terre, ils ont de plus la faculté de s'élever dans l'air, et de le fendre avec la plus grande vélocité. Nous avons 
vu dans la Chauve-souris à quel point ceux-ci tendoient à s'en rapprocher, royons de ce côté s'ils ne viendront pas seconder cette transition; mais en vain nous épuiserons lcurs nombreuses tribus, nous ne tronverons aucuu individu qui puisse se lier avec celle espèce étrangère; et si l'observation nous fait découvrir des saillies ver's cette classe, elles nous écarteront beaucoup de ce point. Si nous suivons le sentiment de tous les naturalistes, l'A utruche sera regardéc comme la plus'voisine des Quadrupedes : effeclivement, des traits assez saillans l'en rapprochent, sa taille, son intérieur ne sont plus ceux d'ur Oiseau, ses ailes ne lui servent plus a s'élever dans les airs; ne pouvant faire quitter la tcre à une telle masse, elle sait sculement les tendre au vent en manière de voile, et par ce moyen accélérer sa course; si elle pond, elle ue communique point à ses oufs celte clialeur douce qui est Décessaire pour développer ceux des autres; une espèce de corne arme ses pieds au lieu d'ergois; ses plumes sont plus effilées; ce sera, si l'on peul se servir de celle expression, loisean le moins oisean. Mais combien ne faudroitil pas de chainons intermédiaires pour combler l'espace qui reste encore a franchir? el comme nous l'avons dejà fait remarquer, ce ne sera certainement pas la Chauve-souris d'où partira la cliaine, ils scmblent, au contraire, être les deux plus ćloignés, puisque la qualifé scule de volatile a pu rapprocher celle-ci des Oiseaus, landis que l'autre ne s'en écarte qu'en perdant celtc mine qualité. La hauteur du cou, l'élévation du dos en forme de bosse, ont pu faire trouver quelque 
ressemblance entre l'Autruche et le Chameau; mais cè n'est qu'un apperçu qui ne peut soutenir un examen séricux. Saus nous y arrêter davantage, suivons les Oiseaux dans les autres rapprochemens qu'ils pourront nous fournir avec les autres classes, nous verrons plusieurs de leurs tribus s'approcher des eaux, el faire la guerre à ses habilans; tandis que quelques-uns d'eux volent à la surface, fondent sur leur proic, l'emportent et vont la dévorer sur la plage, d'autres y font un séjour continuel : lcur pieds ne pouvant plus leur servir qu'à fendre l'élément humide, ils peuvent encore, à l'aide de leurs ailes, l'abandonner; nais cette faculté est entièrenıcnt refusćc au Pingouin, qui ne quitte la mer que pour venir léposer ses ocufs sur le sable, ou il 'est obligé de les couver, ce qui vient ôter toute espèce d'équivoque. La même distance que nous avons remarquée entre l'Autruche et le Chauve-souris, existera entre lui et le Poisson volant. Celui-ci, ð l’aide de ses longues nageoires, évite la poursuite de ses concitoyens, qui lui font la guerre, en s'élevant hors de l'eau, et faisant dans l'air un assez long trajet; mais il reste toujour's tribulaire de l'élément qu'il est forcé de quitter, car il retombe dès que l'bumidité quil a puiséc dans son scin s'est évaporée. Si celle espèce ne nous prouve point une connexion entre les Oiseaux, elle sert à nous convaincre qu'ils n'ont pas le domaine exclusif de l'air. Nous retrouverous même celte propriété parmi les Reptiles; car en écartaut les fables des dragons et autres serpens âlés, il existe des Lézards qui, comme le Polatouche, savent se soutenir eu l'air à l'aide de mem- 
branes qu'ils étendent comme lui. L'on en cite même un de l'ile d'Amboine, qui a de véritables aîles; mais ce sont des Etres isolés. Il est une autre classe beaucoup plus nombrense, qui prouve que le vol n'est pas leur attrihut distinctif; ce sont les Insectes: effẹctivement, leurs innombrables familles fourmillent dans les airs. Le Roilelet, le Colibri et l'Oisenu-mouche se confondent avec plusieurs d'entr'eux par la petitesse de leur taille. Ces derniers, sur-tout, ont des rapprochemens marqués avec les Papillons : comme eux, c'est des fleurs qu'ils tirent leur nourriture, avec lesquelles les uns et les autres viement disputer d'éclat et de frâicheur'; c'est is l'aide d'une trompe qu'ils y puisent le. suc micllé qu'elles renferment; et plus particulièrement comme une espèce d'entr'eux (les Sphinx bourdons), ils épuisent leurs provisions de neclar sans se poser, ne se fixant près d'elles que par les vibrations multipliées de lcurs aîles. Le microscope fait connoître que celte poussière brillante qui couvre les â̂les des Papillons, et qui fait leur beauté, est uße quantité prodigieuse d'écailles artistement rangćes, qui a quelque ressemblance avec les plumes. Dans celte espèce, cette ressemblance est encore plus marquée et peut même s'observer à l'ocil un; le duvet dont ils sont couverts est extrêmement épais et plus particulic̀rement encore sur leur corps. 'Tels sont les traits qui tendent à les rapprocher; mais combien n'en manque-t-il pas pony les réunir entièrement? La plus légère altention fera disparoître toute idée de çonnexion; il suffira encore d'interroger' leur'configuraion estérieure. La nais- 
DE S $\hat{\mathbf{E}}$ T R E S.

sance des uns et des autres sera encore plus tranchante et ne laissera aucun doute; ce qui achevera pareillement d'isoler les Oiseaux.

Nous avons déja eu lieu d'examiner la tendance que les Poissuus avoient vers les Oiseaux et les Quadrupèdes, il ne nous reste done plus qu'ì les observer du côté des Reptiles, des Insectes et des Vers. Du côké des Insectes, on ne connoît pas de saillies bien remarquables : c'est l'Hippocambé ou Cheval-marin qui paroît tenir les derniers rangs; mais il n'y a point d'Insectes auxquels on puisse le comparer. Ici, peut-être, avons-nous beaucoup d'espèces à connoître. L'élément qu'habitent ces animaux en a sûrement dérobé beaucoup aux naturalistes. Peut-être lieroient-ils à cette classe un animal que la singularité a fait ranger parmi les Vers; c'est la Séche: si la multiplicité de ses bras lui avoit fait donner par les anciens le nom de Polype, il ne doit pas être confondu pour cela avec les animalcules auxquels les modernes l'ont transporté. Son organisation est bien au-dessus de la leur, et certaincment, quoiqu'il ait la vie fort dure, ses tronçons ne donneroient pas de nouveaux individus. Cet animal a deux yeux qui paroissent conformés comme ceux des autres Poissons. $1 \mathrm{l}$ a une partie solide intérieure, connue par l'usage qu'en font les orfévres et les oiseleur's sous le non d'Os de Séche, dont il se débarrasse tous les ans. Je suis persuadé que ce singulier animal, observé avec soin, fourniroit des rapprochemens plus marqués, qui finiroient par le joinde entièrement; mais ce ne seroit qu'en l'ćloignant de la classe où on ne l'a placé qu'en 
attendant; il u'est point destiné, par conséquent, a former une jonction entr'elles deux(4). Celle deReptiles est plus apparente: la plupart des uns et des autres sont couverls d'écailles. Un grand nombre de ceux-ci sont amphibies, quelques-uns même habitent continuellement les eaux; mais les Poissons n'extraient de cet élément le peu d'air qui leut est nécéssaire, que par leurs ouies; c'est une parlie arec leurs naggcoires, qui les caractérise principalemént. Dans quelques espèces elles sont pen sensibles et avoient éclappé aux yeux des olsservateurs. On avoit même cru découvrir de véritables poumons daus les Chiens-de-mer, ce qui avoit déterminé le célèbre Linné à les ranger avec les Iraies, et quelques aulres genres, parmi les Reptiles, sous le nom de Ninntes. C'étoit par une suite des principes qu'il avoit adoptés pour hase de son systène, 'pu'il se voyoit forcé, pour ainsi dire, d'admettre cette disparate; elle avoit été sentic par tout le monde, et on s'ćtoit élevé contre; de nouvelles observalions sont venues à l'appui, ct ont confirmé les soupçon qu'clle avoit fail nâtre. On a recomu des onïes aux Chiens-de-mer, et leur pounon s'est trouvé analogue à la vessie, qui, dans les autres cspères, leur sert nonter el à descendre par la pression.

Si les Reptiles different des Puissons, ainsi que nous venons de le voir, il n'est pas moins difficile de les rassembleı sons un. caractère commun: les uns ont quatre pieds; les autres, dépourvus de ce secours; ne peuvent que se trainer sur le ventre. Oı a donné le nom d'Amplibie aux uns, el celui de Serpent aux 
autres: ce nom d'Amphibie a été 17 par la plupart des d'cntr'eux d'cntr'eux le soient, il en est beaucoup d'autres qui n'approchent jamais de l'eau, qui même l'ont en lıorreur. Les Grenouilles, les Lézards et les Tortues sont au nombre des premiers. Ici se trouve un des exemples les plus frappans des nuances que la Nature peut employer pour réunir différentes parties, c'est celle qui joint les Lézards aux Serpens; si ceux-ci ont des paltes, clles n'empêchent pas lcur ventrc de toucher la terie; la configuration de la tête et des écailles est la mênuc, lcurs mocur's sont semblables; le corps du Seps, cspèce de lézard, est plus effilé, ses patles sont plus écartées et très-courtes; souvent on ne les apperçoit pas, alors on ne peut les distinguer des Serpens. Le célebre pieds, ce sont ceux de deriere; et jen ai vu un au cabinet du Roi, qui a voit été envoyé depuis peu, auquel M. de Lacépède donne le nom de Cannelé, qui n'en a pareillement que deux, qui sont très-petits; ce sont ceux de devant, ils sont fixés immédiatcment au-dessous de la tête. Voilà un des passages les nicux marqués que l'on connoisse, quiscmble favoriser l'opinion reçue, que re u'est que par le défaut de nos connoissances en histoire naturclle, que nous appercevons des vides daus la chainc; mais avant cette découverte on avoit de forles présomptions pour admettre cette connexion: ainsi elle n'est venue que les confirmer; mais pour en former une cntr'eux, les Insectes et les Vers, il fundroit bien des Etres intermédiaires : la Sur l'Enchainement des fires. 
Grenouille, par ses métamorphoses, pourra tendre vers les Insectes; ct la figurc allongéc, saus articulation, des Serpens, pourra les faire comparer aux V crs. Mais lc plus léger examen suffira cncorc pour faire évanonir toute apparence de jonction : quoique les mus et les autres soient condamnés à ramper, on trouvera même dans cette démarelıe qui les rapproche, les moyens de les distinguer : le Serpent ne s'avance đqu'en traçant sur le terrain des sinnosités, prenant un point d'appui sur ses écailles qu'il redresse; ct c'est en ligne directe que les Ver's se menvent, ćtant composés d'un grand nombre d'anneaux flexibles; ils allongent en avant la parlie antérienre, et reportent, en se ramassint dessus, le reste du corps (5).

Il ne nous reste plus qu'i: distinguer les denx dernières classes. Les Insectes se divisent assez naturellement en deux paries; d'un côté seront ceux qui naissent dans leur état de perfection, et n'éprouvent d'autres changemens que ccux que lcur fait épronver l'accroissement; les autres scmblent avoir deux vies bien différentes, dans la prenière ils paroissent plus ou moins informes, prennent leur accroissenent, et subissent différentes mues, après lesquelles ils éprouvent une espèce d'engourdissencut, d'ou ils sortent en se trouvant revếlns d'une nouvelle existcnce bien plus brillante que la premic̀e ; la plupart sont pourvus d'ailcs ou la Nature déploic sa parure la plus recherchéc; ce sont, pour ainsi dire, des habits de noces dignes de sa magnificence, car ce u’est que dans cet élat qu’ils travaillent à lcur reproduction. Beaucrup même n'ont plus que les or- 


$$
\text { U E S } \hat{E} \text { T R E S. }
$$

ganes propres à satisfaire ce vocu de la nature, et périssent dés qu'ils l'ont rempli. Cette division ma paroît plus naturelle que celle acioptéc en Inscetesailés et aptères $(G)$; dans les premiers on est ohligé d'en rans er" gui n'ont jamais d'ailes, tels que les femclles de certains Papillons, le Ver-luisant et les Fourmis travilleuses. Ce n'est pas que celle que je propose ne fit sujettc is quelques exceptions; mais, oulre qu'clles serojent moins nombreuses, on trouveroit facilerncut de nouveaux caractères qui viendroient la cousolider, tels que le nombre de leurs pattes; cenx qui se mélamorphosent n'en ont jamais que six, au licu que les aulyes en ont prespue toujonrs au moins louit; les arliculations du corps sont noins marquécs; plusicurs n'ont point d'yenx à rćsran. Quoique ceux-ci soient moins nonbrcux, ils semblent, par leur taille, oceupor les extrênes. Les Crabes présentent dles espèces grimantesques, relativement aux autres, et les Cirous finissent jar ćchapper à lí vue; ils diminucnt encorc dans les Monocles, qui foumillent dans les caux pendant l'été. Ces derniers sont revêtus d'unc espéce de coquille bivalve qui peut les rapprocher les 'Testacécs; mais leurs pattes, leurs aritemes ct leur. aecouplencut enspecherunt de les confurdre. Dans som chat parfait, la scconde division ne peut vifirir ancua point de rémnion: comme c'est de ce point quil faut lartir, ils son! par conséqucnt Jicn sćparés; mais cependant, a leur naissance, on peut les confondre. I áa plupart méme des Iusectes, daus leur état de larve, portent le non de Ver's, cl n'en paroissent pas distingués au preniner coup d'cuil. La méprise est cependant aisée à ćvitcr: les 
véritables Vers rampent entièrement, n'ayant point de pattes; au lieu que les larves en ont au moins six. Quelques espèees de Vers ont des bras qui leur servent à saisir leur proie, mais jamais pour ehanger de place; ainsi le earactère des Vers est d'être apodes ou sans pieds.

Telles sont les six parties qui peuvent être détachées du grand tableau des Animanx, sans rompre aueune affinité connuc, et auxquels peuvent être rapportées toutes les espèces qu'on a eu jusqu'a présent occasion de remarquer: elles ont paru assez distinetes, pour que des savans aient cherché a nous en faire connoître telle et telle partie, indépendamment des autres.

Mais on est cncore loin des espèces; pour y parvenir, il a fallu des subdivisions; de-là sont nés les Familles, les Ordres et les Genres. Ces coupes ont été plus ou moins heureuses : quelques-unes ont été avoućes par la Nature, les autres n'ont paru dépendre que des prineipes fondamentaux des méthodes, et onl autant varié qu'eux; leur examen demanderoit des délails qui formeroient des volumes. On sent qu'elles doivent itre aussi multipliées en raison des besoins; car si l'on comple les espèces renfermées dans chaque elasse, on les trouvera fort inégales; si l'on considere la taille et l'importance du rôle qu'elles jouent, l'équilibre renaîtra. Par exemple, les Quadrupèdes et Célaeées ne vont pas au-dela de quatre ecnts, tandis que l'on eonnoît près de dix mille Insectes; les Oiseaux montent à deux mille, les Poissons à douze cents, les Reptiles à six cents, et les Vers à deux mille. 'Tel est le tableau numé- 
rique yu'un autcur $(a)$ vient de présenter récemment, de sos connoissances en histoirc naturelle. Il ne l'a donné, et je ne le répète que comme un apperçu fort incomplet, qui doit être augmenté ct peut-être doublé par les voyages savans qui se succèdent rapidement depuis quelques années. On ne peut pas même croire que cette proportion se conserve, car il doit nous rester très-peu de Quadrupèdes à connoître, tandis que les autres classes, sur-tout les Insectes et les Vers, doivent cncore offrir d'amples moissons aux naturalistes; les derniers smr-tout, s'il y faut joindre, comme il y a tout lieu de le penser, ces myriades d'animalcules qui semblent éclore sous le foyer du microscope de Spalanzani, deviendront innombrables.

En cherchant, pour ainsi dire, les jointurcs du régne animal, je nen ai présenté que le squelette; je vais actucllement le considerer sous un point de vue plus intécessant: c'est dans ses rapporls généraux avec. l'homme el la dégradation de ses organes; mais mes moyens et les hornes que je me suis prescrites, ne me permetlent que de l'effleurer. Engagés par leux ressemblance avec l'homme, nous avons placé les Quadrupèdes aux premiers rangs, ce sont eux qui nous offriront aussi les traits les plus marqués d'intelligence el de sagacité. C'est parmi cux que l'Homme trouvera des csclaves

(a) M. De La Metrerie, dans un savant Discours sur nos connoissances en Hisloire naturelle, inséré dans le Journal d'Hisloire Naturelle qu'il rédige actuellement ( 7 ). 
soumis et des donestiques fideles, il y rencontrera aussi ses enncmis les plus andacienx.

La légèreté est l'altribut des Oiscaux, de-là dependent leurs moeurs générales; leur domnant de grands moyens de chercher leurs alimens, el des facilités pour fuir le danger, ils ont rarement besoin d'cuployer la rusc: c'est par la vélocité que le Faucon clierclic à surprendre la Colombe, c'est par elle que celle-ci cherrhé a l'éviter. Elle augnicnte aussi cn cux cet amour de la liberté qui est l'apanage de tout litre animé : si nous arous pəuplé nos basses-cours dies espéces les plus lonrles, elles n'y sont retenues que par le bien-être qu'elleş y éprouvent, jusquiau moment que nous avons assigné pour les sacrifier à notre voracilé : ce sont des parasites qui uẹ tendent en rien, par cux-mêmes, à nous dédonmager des soins que nous en prenons.

Nous ne connoissons les Poissons que par le guerre contimulle que nous leur livrons, gucrrc ou le puissant cmploic la vusc. Leurs habitalions les dérobent à nos poursuites; c'est par les filcts, les appâts, que nous les rendous tributaires de nos tables. Ici l'intelligence conmence à décliner, beancoup.

Au seul nom de Reptiles et de Serpens, l'on voit souvent frémir les personnes les plus courageuses. Les poisons dont quelques-uns sont armés, la figure hideuse de quelques autres, laisscut une impression qui se répand sur tout le reste; à cela se joint l'iuulilité ap-. parente de la plupart, qui a fait prononcer contr'eux unc espèce de proscriplion qui tendroit à leur destruction, si a lapproche du moindre danger ils ne se ca- 
choicnt dans leur retraile souterraine : celte timidité leur a fait accorder la prudence; ecprndant, quand ils ue sont pas aninús par la colèrc, la stupidité paroît ćtre leư parlage. Jes liabitans des pays cliauds, où ils sont plus multipliés, connoissent les services qu'ils nous rendent par la guerre continuelle qu'ils livrent aux insectes et autres petits animaux qui rendroient ces elimats inhabitables; aussi le Négre a-t-il dressć des autels à quelques espèces.

L’intelligenee paroît renaitre dans les Insectes, ils offrent aux olservaleurs des traits étommans de sagaeite; mais avec un peu d'atlention on verra que la plupart sont le fruit d'un instinct aveugle, et non de la réflexion. L'Abcille, par exemple, qui nous enrichit de ses travaux, dont l'industrie paroît merveilleuse, quion la suive dès sa naissance, on la verira renfermée dans une cellule, sous la forme de larve; devenue Abcille parfaite, elle percera l'enveloppe gui la relenoit; sans aucune lecon, elle sortira de la ruche sans se troniper, elle ira se charger, sur les fleurs, de miel et de cire; rapportant son butin, elle le façonnera en liexagone avee autant de rógularié que celles qui ont déjà l’expérience de plusieurs mois. Cette cire et ce micl sont un vol que nous eommetlons sonvent aux dépens de l'animal. 11 en est de mêne de la soie que fle la Clıcnille du múricr. Ce sont la les services les plus importans que nous en tirons. Nous en compterons nu lien plus grand nombre parmi nos ennemis, peu en ćtat de nous nuire individuellement; leurs aftaques multi- 
pliées nous les rendent insupportables, ct leur petitesse les met à l'abri de notre vengeance.

Les Vers se trouvent aux derniers rangs; c'est parmi eux que viennent se ranger les Polypes et autres Zoophytes, dont nous avons déja parlć. Plusieurs sens se sont évanonis, la vuc sur-tont paroît lcur être refusée.

On prétend cependant que le Limaçon voit : car des quatre cornes qui terminent sa tête, les deux plus longues portent, dit-on, de véritables yeux qui sont au bout de ce tube, en forme de lunettes (a). Mais quoique les Naturalistes y aient distingué les différentes parties qui constituent cet organe, il cst trèsdouteux qu'elies aient celtc destination; on doit les regarder plutôt comme des espèces de bàtons qu'il porte en avant, pour l'avertir, par le tact sculement, des obstacles qui se présentent; quel que soit le danger, ce n'est qu’après l'avoir touché qu'il se délermine à se cacher dans la retraite porlative que la Nature lui a donnćc ; ainsi, quoiqu'elle paroisse l'avoir négligé, elle n'a pas moins assuré son existence; et la vuc, ce sens dont la privation nous paroît à juste titre le comble du malhicur, en feroit peut-ître un continucl pour ces animaux, la faculté loco-motive disparoissant insensiblement parmi cux: les moyens de fuir le danger leur sont ôtés; ils auroicnt été dans des angoisses perpétuelles: pour les dédommager, clle a augmenté l'insensibilité qui

(a) De nouvelles observations m'ont donné lieu de croire que cétoit véritablement des yeux; car la Porcelaine qui n'a que deux tentacules aigus au sommet, à leur base dleux yeux apparens. 
règne déjả parmi les Insectes, et heur a donné de plus de grandes facilićs pour réparer les pertes que la mutilation pourroit leur occasionner : si elle a pourvu à la conservation des individus, elle n'a pas négligé celle des cspices. Jusqu'ici lc concours des deux sexes a paru une loi nécessairc pour la propagation; là ils commencent à se réunir en un seul iudividu, et ì présenter de véritables liermaphrodites; ils disparoissent ensuite, et ce n'cst plus que par boutures que se reproduisent une partié des Polypes et autres espèces voisines.

Nous sommes done arrivés à-peu-près aux derniers termes de l'Animalité, nous devons par conséquent nous trouver sur les confins du Règne végétal. Là se présente un problême important à résoudre, il s'agit de déterminer quelle est la Plante qui aura le plus de rapport avec le Règne Animal. Je crois que de longtemps on ne sera en élat de le résoudre que par approximation. Si nous voulous prendre pour guides ceux qui de leur cahinet ont voulu régler la nature, et suivre l'échelle des Etres qu'ils ont esquissés, aux derniers termes de l'animal doit correspondre la plante la plus parfaite; et en suivant ses dégradations, son dernier terme répondra pareillement au premier des Minéraux. Mais l'cmbarras sera de trouver celte plante parfaite; si nous les écoutons encore, nous choisirons la Sensitive; le mouvement particulier dont elle est douée, semble la faire participer aux qualités des animaux; à ce premier rang se tronvera aussi la Dionée attrapemouche, dont les feuilles, en se serrant, renferment 
les Insectes qui ont l'imprudence de se poser dessus. Nais si nous les rapprochons pour les comparer, toute ressemblance s'évanouira; lorganisation de la plante nous paroitra aussi compliquée que celle du Polype sera simple; et sans entrer dans des détails qui deviendroient fastidieux, on verroit qu'ancune des plantes réputées parfaites ne pourroil venir se joindre ici : ce ne sera qu'en redescendant, que nous rencontrerons quelqu'analogie; et si nous nous arrêtons aux Conferves et Bissus, qui occupent les derpiers rangs, ils nous fourniront quelques traits de ressemblance. Leur fructificalion est absolument inconnue, ils ne se multiplient que par les rameaux et les parties qui s'en détachent; la simplicilé de leur construction cadre parfaitement avec celle des Polypes. Mais ils sont encore loin de se toncher; ce sont denx sćrics convergentes dont il nous nanque bien des termes, el dout le dernicr, de part et d'autre, est la maticre brute ct inorganisée; ainsi elles nous mènent l'une et l'autre daus le Règne Minéral. Cesceroit peut-être eu s'éloignant également de ce point, et par conséquent, de ces deux règnes, que nous placerions aux dernicrs rangs les Ninéraux les plus parfaits, telles que ces belles mines d'argent arhoriscées, qu'on regarde communément. comme destinces à former le passage de ceux-ci aux végéliux.

Celte idce demanderoit à êlre ạpprofondie; mais pour la suivre avec détail, combien ne faudroil-il pas d'observations délicates? Hil comme les oljets finiroient par échapper aux sens, elle ne pourroit être disculée 
que par la Métaphysique la plus abstraitc. L'unc et l'autre sont hors de ma portéc; ausi je laisserai le soin de chercher le triple noeud qui joint ces trois parties, à des mains plus labiles. Je me contenterai d'eu avoir fait sentir la possibilité. Je ne m’arếlerai pas uon plus au liègne minéral, il tient très-peu à l'Histoire natnturelle proprement dite. I'observalion scule ne suffit pas pour saisir les caractères qui peuvent diffúrencier les espèces; il faut absolument y joindre l'Analyscehimique, elle scule a tracé ses coupes et l'a divisé en Terres, Scls et Minéraux. C'est elle seule aussi qui peut faire connoîles la nature et la proportion des subsiances qui composent différens individus, scul moyen de les dislinguer sûrement.

C'est donc sur le Règne Végétal que nous allons arrêter nos regards; c'est ici, sur-tout, qure sc sont développés les systèmes ct les métlodes; c'est là qu'on les a vus se succéder rapidement, et se former des débris des unes el des autres. La raison en est simple et naturelle. Parmi les Auimaux les coupes ont paru se présenter sans efforts. Ici il a fallu tâtonmer et les chelcher; ct quoique les Végćtaux soient plus nombreux, unc plus grande, uniformité paroìt régner parmi cux: la coulcur même, cette modification des corps qui scmble si changeante, se fixc, et le vert domine dans la plus grande partic. C'est sur les différentes façons de se mouvoir que sont fondées les principales divisious des A ninıaux; les subdivisions même roulent particulièrement sur leurs picels, leurs naggeoires et lcurs â̂les. Ici, le repos est,absolu: la houche, cet organe 
qui leur sert à prendre leurs alimens, fournit encore des facilités que nous ne retrouvons plus parmi les Plantcs. Ce n'est qu’à l'extrémitć des tulues capillaires de leurs racines, que la Nature a placé les pores inperceptibles par ou elles puisent dans le sein de la terre les sucs nourriciers, tandis qu'elle en a mis d'autres sur leurs feuilles pour aspirer de l'air les principes qui y voligent. Ces parties sont trop difficiles à observer, ct ne peuvent servir par conséquent à les caractériser.

Après quelques essais infructuenx pour les classer sous différens aspects, tous les efforts se sont réunis sur unc seule partie, partie ou la nature scmble se dédommager de l'espèce de monolonie répandue sur le reste de la plante; c'est la Fleur : les coulcurs brillantes dont elle est peinte, l'élégance de sa forme, les doux parfums que souvent ellc exhale, tout altire vers elle les regards et l'admiration. L'attention du vulgaire, ainsi quc celle du savant, se fixeront également sur celte éclatante parure, qui, à son apparition, semble donner une nouvelle existence aux individus qu'elle décore; mais avec cettc différence, que l'un s'en amuscra quelques inslans, au lieu que l'autre y cherchera de l'instruction. A pres avoir adniré son cnsemble, il la décomposera, et 'âchera de décourrir l'usage d'un organe oi la $\mathrm{Na}$ ture déploie ses riclicsses avec tant de complaisance; il observera une première enveloppe qui lui sert de hase, à laquelle il donnera le nom de Calice. Ensuite s'en irouvera une seconde; c'est en clle que résident ces coulcurs frappantes:il l'appdlera Corollc. Plusicurs 
fllamens terminés par un bouton se trouveront disposés circulairement dans l'intérieur : ce sont les Étamines. Ils entourent les cmbryons du fruit, qui sont surmontés d'un filet plus ou moins loug: cette partie recevra le nom de Pistil. Avec un peu d'attention il verra les boutons qui terminent les étanines, s'ouvrir et répandre une poussière jaunâtre; alors la scène changera, les Étamines se flétriront, les Pétales qui composent la Corolle se faneront pareillement; le Pistil seul semblera prendre une nouvelle vie, et finira par devenir un fruit qui renfermera dans sou sein les gages d'une fécondité inćpuisable. Quelques autres observations aclieveront de le mettre sur la voie, et la destination de tout cet appareil sera contuc. Il veria que ces voiles de pourpre et d'azur cachoient un lit nuptial, ¿̀ l'ombre duquel s'accomplissoit le mystère de la Génération. Voila donc les sexes qui reparoissent; nous les avons vus se confondre et s'évanouir dans les derniers Animaux; les premiers Végétaux que nous avons rencontrés ne nous cn out offert non plus aucune trace. Dans les Vers, le défaut de mouvenent sembloit prescrire la réunion des deux dans le même individu; ici, le repos est encore plus absolu; aussi les voyonsnous le plus souvent dans la même Fleur. Mais comme les ressources de la Nature sont sans bornes, elle les a séparées dans d'autres, tantôt sur la même plante,tantôt sur d'autres; alors ce sont les vents qui sont chargés de répandre la poussière fécondante, et d'en imprégner le Pistil.

Ce n'est donc que dans celte partic intéressante qu'on 
a pu trouver une physionomic qui présentât des caractères assez nomlurenx pour différencier les espèces. Aussi, toutes les méthodes el les systémes qui ont été imaginés pour faciliter l'étude de la Botanique, roulentils sur les différentes parties dont nous avons vu qu'ćtoit composée la fleur. Iournefort, le premicr, a onvert cette roule: il promène votre vue sur la Corolle, vous fait renarquer les différentes modifications dont elle est susceptible: vous en admirez la régularité dans ces belles coupes, ces bassins découpés si élégamment. L’irrégularité cles antres ne vous paroît pas moins piquante. Si vous prenez pour guide Livvé, son illustre rival, il vous invilcra à leurs noces, ce sera sur les fítamines et les Pistils qu'il dirigera votre attentiou, il vous développera leur code malrimonialy tous les aspects sous lesquels il vous les fera envisager vous feront découvrir de nouveaux pliénomènes. Sans vouloir les comparer, ce qui est très-difficile, vu les différentes époques où ils ont paru, l'un et l'autre sont utiles pour résondre le prollềme sur lequel est fondéc l'étude de la Bolanique, déterminer le nom qui a été donné à telle Plante que vous avez devant les yeux. Il n'en est pas de même si vous voulez juger des rapports qu'elles ont eutr'elles : l'un et l'autre vous égarcroicut. Tournefont, après avoir tuacé son plan, a souvent été effrayé des disparates qu’il entrainoit; il a cherché à faire disparoître les plus apparentes; mais en évilant très-peu cet inconvénient, il est tombé dans un plus grand, en gênaut sa marche; LIN ví au contraire, inébranlable, ne clıcrchant que la sûrcté, a tranclić lıa- 
diment, sans s'embarrasser si ses coupes étoient naturelles ou non. Les méthodes des autres auteurs qui ont parcouru la même carrière, participent plus ou moins à leurs avantages et à leurs défauts. Parmi elles, il faut distingruer l'ingénieuse analyse de M.DELAMArck, qui vous conduit comme par la main. Quelle que soit celle qu'on adopte, on ne doit la regarder que comme un moyen purement mécanique qu'il faut bien distinguer des connoissances qu’i] nous fait acquérir. Lorsque par son secours on est parvenu à distinguer un grand nombre de plantes, il futudroit pouvoir imiter le célèbre Conquérant du Mexique, qui, abordé à la terre où le conduisoit son ambition, lorûla les vaisseaux qui l'y avoient apporté: de même, il faudroit abandonner et tâcher d'oublier les routes qui vous ont conduits, et ne plus admettre de classes qu'autant qu'elles paroîtroient autoriséés par la Nature. Mais c'est une tâche difficile : les auteurs lés plus célèbres ont cherché à la, remplir; ils ont plus ou moins approché du but qu'ils s'étoient proposé ( $(i)$, sur-tout $M$. DE

(a) Ies principales divisions de ce savant système sont fondées sur les Lobes ou Cotylédons des semences, et partagent les végélaux eu Acotyledones, Monocotyledones et Dicotyledones. Cette coupe paroît d'une pratique dilficile; car, outro qu'il est bien des plantes qu'on ue peut observer à leur naissance, on est rarement à portéc d'examiner les autres; mais comme elle est très-naturelle, bien d'autres caractères la confirment. Le plus souvent le port suffit pour les classer, même pour l'wil le moins exercé : il est très-peu de cas oí 
Jussiev, dans l'ordre qu'il a si heureusement établi au Jardin du Roi ; mais ils eu sont encorc restés bien loin. Pour s'en convaincre, il suffit de suivre les ordres naturels qu'ils ont présentés, et de les comparer cnsemble. La Nature est simple, sa marche doit l'être par conséquent, et n'être qu'une: cependant vous verrez autant de suites différentes que d'ouvrages, se rapprochant assez pour les détails; ce n'est que lorsqu'il s'agit d'en former un toul, qu'on les voit varier.

Un léger examen du Règne Végétal suffira pour découvrir la cause de ces variations. Plus des trois quarts des plantes comnues viennent se ranger en séries plus ou moins étendues, anxquelles on a donné le nom de Familles; ce sont elles qui, échappant à toutes les coupes que l'imagination a pu suggérer, étant liées par des rapports si multipliés, se retrouvent dans toutes les méthodes; la plupart même reparoissent dans le système de Lrnaé, quoiqu'il semble avoir affecté de les négliger.

Telles sont les Mousses vivaces, qui, malgréles frimas, parent encore la terre de la plus riante verdurc; les Fougères, qui végètent dans les cndroits les plus sombres; les Palmiers, ces arbres si précieux aux habitans des Tropiques, auxquels ils fournissent abondamnent le vivre et le couvert; les Graminées essenticlles, dont les semences, dans tous les climats, sont

l'on soit obligé de recourir à la germination d'une plante, pour déterminer sa place (8). 
la base de la nourriture de l'homme, et les fenilles celle des animaux qu'il rassemble autonr de lui, qui donnent le plus de Sucre, présent inestimable; les brillantes Liliacées, qui sont les délices des fleuristes; les Labiées odorantes, dout la singularité des flenrs contraste avec la régularité de leurs tiges carrées et de leurs feuilles opposées; les Borraginées aqueuses, d'oit souvent l'on voit les fleurs les plus délicates sortir de tiges et de feuilles désagréahles par la rudesse des poils dont elles sont hérissées; les Composées, si nonbreuses, dont les fleurs brillautes, modelées sur l'astres du jour, affectent de tourner vers lui leur disque doré ou pourpré; les Rubiacées, à feuilles étoilées, qui possèdent des vertus tinctoriales, et, dans les pays chauds, domnent le Cafó et le Quinquina; les rustiques Ombellifêres, dont une partie, eultivée daus nos jardins, présente des légumes salutaires et des semences odorantes, tandis que d'autres, habitant les endroits humides, font craindre des poisons; les fertiles Crucifères, qui remplissent nos cliamps et nus jardins de denrées p̧récieuses, fomrnissent à la médecine de puissans antiscorbutiques, et offrent aux fleuristes les plus belles décorations de leurs parterres, satisfaisant à-la-foís la vue et l'odorat; les Renoncules, plus éclatantes encore, mais qui sont loin de participer à leurs qualités bienfaisautes, car beaneoup recèlent des sucs très-àcres, qui, dans plusieurs, deviemuent des poisons actifs; les Caryophyllées, encore aussi brillantes que ces deux dernières, qui, sans êlre anssi ntiles que les unes, ne renferment du moins aucure espèce nuisible; les Alal-

Dissertation. 
vacées, dont les qualités émollientes sont annoncées par la mollesse de lenr port; les Légumineuses, qui renversent si efficacement la distinction établie entre les Arbres el les Herbes, aussi remarquable par la structure de leurs fleurs, que recommandable par leurs senences farmeuses; les Rosacées enfin, qui depuis la linise parfumée qui se cache sous le gazon, la Pêche succulente qui garnit nos espaliers, jusqu'à la Poire fondante qui peud dans nos vergers, fournit nos tables des fruits les plus délicieux, et, pour couronner ses faveurs, nous offre la Rose, celte reine des fleurs!

Voila les principales familles qui partagent le règne végélal; il en est cneore d'autres dont les caractères, gruoique bien prononcés, sont plus difficiles à saisir, ou qui sont peu étendus; mais plusieurs espèces sont isolées et refusent de se ranger parni elles; ou si, séduit par quelqu'apparence, on vent les en approcher, elles viennent rompre l'uniformité qui régnoit dans les autres; clles ont reçu le nom d'Anomale: tandis yu'elles font le désespoir des spéculatenrs qui les regardent comme des sujets rebelles, elles procurent souvent d'agréables jouissances an Botaniste-pratique, par la facilité que donnent leurs traits marqués, de les reconuoilye au prenice coup-d'ail ; ils sont quelquefuis si saillans, que lorsqu'au milieu de ses courses it en rencontre une pour la jremiere fois, son nom est la premicre exclamalion qui sort de sa bouclic; au lien que si le hasard le dirige sul un individn appartenant à une famille nombretise, la joic d'une découverle est 
DES ÊT T E S.

troublée par l'idée du travail qui l'attend, pour déterminer précisément le nom qui lui convient; il craint de s'égarer. Légers soucis qui sont loin d'altérer la douce sérénité dont jouit le paisible amatenr de la nature $1 \mathrm{Ce}$ sont donc ces Anomales qu'on a regardées comme un des principaux écucils qui ont fait échoucr la plupart des ordres naturels qu'on a teutés. C'est aux crochets qu'on a été obligé de faire ponr les enchainner avec les autres, qu'on a attribué le défaut d'ensemble qui s'y remarque : clles en sont, en effet, en partie cause; mais je crois que la route qu'on a suivic jusqu'à présent, a encore plus égarć; tous ont paru partir d'un même principc faux : on a cru qu'il falloit et que l'on pouvoit ranger tous les Etres sur nne seule ligne droite, et qu'en partant du premier tous les autres-devoient suivre immédialcment. La Nature est loin de suivre cette marche : on a reproché aux auteurs méthodistes de lui prêter leur foiblesse; mais il me scmble qu'il y en a encore plus dans celle-ci, parce que nous ne pouvons par'venir à faire une chose qu'aprics l'avoir essayće, passer à une idée sans y être conduit par une autre. Nous croirons qu'clle est obligéc de s'y assujétir. Oh non! Elle agit bien plus librement, ses productions sont jetées avec bien plus de variété, et si clle nous laisse entrevoir quelque clıose de ses plans, elle nous en dérobe hien davanlage ! Si nons jugeons d'après ce peu que nous appercevons, les Litres forment un lissu plus ou moins làche, formé d'embranchemens qui se subdivisent à l'infini; effectivemenl, en résumant ce que nous avons dit des Quadrupèdes, nous les 
avons vus également s'approcher, quoique sans toucher d'un côlé des Oiscaux, de l'autrc des Poissons; enfin. des Quadrupedes vivipares. Jes aulres classes nous ont présenté de pareils enbranchemens. Les trois regues même fenderit vers le même point. On a sculi la même chose dans les Végétaux; c'est là ce qui a occasionné ces variations singulicres que nous avons remarquées: les Familles se sont éloignées ou rapproclıées, suivant qu'on les a considérées sous tel ou lel rapport.

Ce n'est que dans la Naturc qu'on peul trouver unc comparaison qui donnc unc idéc d'elle. Lorsque les ténebres sont venues inscnsiblement enlever la vue du magnifique spectacle que présente la surface de la lerre, l'ail de lobservalcur se lourne ress le Ciel, la splendeur de ccluiqu'il découvre le dédommage de la varićlé de celui qu'il a perdu. D’abord toul le Firmament lui paroil égalenent parsemé d'ćloiles : leur multilude lc jelle dans un élonnement muet; mais bientût il rassied son jugement: ces astres se groupant, its lui présentent des figures circonscrites; son imagination vientason secours; il finit par reconnoitre les animanx ou autres sigues, dont les coustellations ont pris le nom que les modernes leur ont conscrvé. Superbes Allégories dansle principe, par lesquelles les premiers Astronomes graverent en traits de feu des Calcndriers à la portée de tous les humains! Sous ce point de vuc, elles scmbleroicnt êtle des signes de convention; nais comme on clierchoit en même temps la facilité de l'obscrvation, on suivoil exactement les contours que le hasard présentoit; ainsi, les sept étoiles brillantes qui foirt partic de la grande 


$$
\text { D E S E T R E } \mathrm{E} \text {. }
$$

Ourse, qui ont donné leur nom au septentrion, qu'elles servent í faire reconnoitle, distingućes anssi bien par les habitans de la campagne que par les Astrumomes, ont reça d'eux le nom de Chariut de Darid; les Pléiades. cclui de la Ponssiniere : le brillant Grion ne leur échappe pas; sa ccinlure est pour cux les trois Rois. Sans aucun maithe, ils distinuent assez nẹtement lẹs antres constellations, qu'ils isolent i-pentprès comme les savans, sans avoir cependant communication de leurs idées; ce qui prouve que les uns et les autres ont snivi dans leurs séparations des traces indiquées nalurellement. Ii cn est de même de l'enchainement des líres; ils sont jecés par groupes plus nu moins serrés; l'art ne consiste quä les détacher sans rompre de suiles marquécs. 11 y a encore' $m$ autre trait de conformité, c'est que, si nons changions de place, et que nous nous trouvions jetés dans le tourbillon d'une autrc ctoile fixe, nous verrions les autres sous un aspect hien différent. Il en seroit de mêne si nous nous trourions enrichis d'nn sixieme sens : tous nos ordres établis súvanouiroient. en découvrant de nouveanx rajpports ; mais comme l'uu et l'autre sont impossibles, nous devons nous borner à suivre ce que nous apercevons, sans nous jeter dans de vaines spéculations.

Il suivroit. de-là, que le moyen de rangor les Lìtres d'une façon ápprochanle de la na! ure, seroit d'en former une espèce de tablean comparable en quelque sorte à unc carte de géograplice $(9)$; les trois rènes semient fignrés par trois continens, les familles hien prounncées seroient réunies en pclotonseré, imitant nu royaume; 
les' genres, des provinces. Il faudroit découvrir deux lois différentes susceptibles de calcul (a), qui répondroient aux longitudes el latiludes, qui serviroient à déterminer, indépendamment des autres espices, la place que telle ou telle doit occuper. I aes Anomales alors n'embarrasseroient plus, elles se trouveroient jetcées dans unc espèce de solitude : si de nouvelles découverles tendoient à les joindre à d'aulres espèces, elles se trouveroient naturellement placées, sans occasionner de déraugament. On pourroit encore, par ce moyell, exprimer certains rapports apparens, mais qui sont contrarićs par des dissonances plas nombreuses, qui existent souvent entre deux L̈tres; ils ressembleroient a la position de certaines villes qui, quoique situées près l'une de l'autre, sont obligićes de faire de longs circuits pour se communiquer. Cette jdéc pourra paroître ridicule et chimérique à lien des égards, si l'on ne fait pas attenlion que c'est une comparaison qui me semble plus propre ì expliquer ma pensée que les plus longs liscours. Je crois cependant qu'on en pourroit tirer parti. Tin l'adoptant, on auroit fait un pas de plus. Une simple ligne sembloit pouroir embrasser ce vaste plau, et là il se trouve dessinć sur une surface : il y a apparence qu'il approcheroit encore plus de son modele, si on pouvoit y joindre

(a) M. le chevalier Dr Lamarck, dans le Discours préliminaire de la Flore Française, propose un calcul fort ingénieux pour juger des rapporls waturels des Plaules, qui pourroit être employé en partie. 
la troisième dimension, et quill se trouvât exprimé par un solide; car si, par exemple, on consideroit cet enchainement, comme formant un arbre dont les branches s'étendent de toutes parts, combien n'en déroheroit-on pas à la vue, si on se contentoit de le peindere sur une surface? ct il n'cn est aucunc à rejetcr, il faut que jusquä̀ ses dernieres fenilles tout soit présenté dins un jour facile à saisir.

Telle est la principale difficulté qui s'oppose à la perfection de l'Histuire nalurelle; tel est le moyen qui me paroit le plus propre à la sur:nonter; mais elle ne cioit point décourager cenx qui soccupent de celte science interessante : ct quand il scroit démontré qu'ors ne ponra jamais la vaiucre, il resteroil toujours lo champ le plus vaste, avant de parvenir ì celle borne, qui laissera toujours anx observalen's des trésors qu'ils ye pouront jamais épuiser.

En vous entretenant si long-temps sur l'Histoire raturelle, la foiblesse de mes talens ria certainement servi qu'à vous rappeler le sentiment de la perte irréparable que celte science vient de faire: Burfon (10) n'est plus, sa brillante et laborieuse carrière vient de se terminer; et quoiqu une vicillesse avancéc $y$ ait mis fin, on n’a songé à son élentue que lorsqu'elle a été fimmic. Cet âge eulevant les forces, étcignant la chaleur, a souvent terni le's lauriers des plus grands grénies; mais c'est en vain qu'il avoit accumulé les infirmités sur lc corps du Natmıliste Français, son espurt. restoit libre au milicu des sonfrances. L'Histoire de l'Aimaut, complétant celle des Minéraux, sortoil de sa 
plume, lorsquu'il a été enlevé aux sciences ct à ses amis; c'est encore une partie arhevée du vaste plan qu'il avoit concu; et depris pres de quarante ans qu'il on avoit commencé l'exécution, on peut juger, d'après ce qu'il nons en laisse, que sa vie doubléc eût à peine suffi pour conduire cette superise entreprise à sa fin. Mais il laisse des modèles à ses surcesseurs; et le soin qu'il avoit pris de les choisir lni-même nous étoit déjà garant que son génie revivroit parmi cux. L'Histoire des Quadrupèdes Oviparcs, par M. De Lacépède, acliève de nous cn convaincre.

En paraissant, l'ouvrage de M. Bufros reçut le sceau de l'immortalité; passant rapidement entre toutes les mains, il fit naître un goût nniversel pour l'Histoire naturelle, qui lui fit faire de rapides progrès. Obligé souvent de rapporter des faits qu'il n'avoit pu voir, il s'ćtoit quelquefois égaré, en suivant des gnides trompeurs; mais ces crreu's, loin de nuire à sa gloire, n'ont fait que l'augmenter par la noblesse avec laquelle il s'est rétraclé de celles dont il a pu avoir commoissance: profitant des critiques, quand il en reconnoissoit la justesse, le silcnce étoit la réponse qu'il opposoit aux antres. 'Travaillant pour l'immortalité, c'étoit à clle scule q̧u'il s'en rapportoit, et il ne s'ahaissoit point à descendre dans l'arêne. Ceitc condnite, dictée par une noble confrance, avoit forcé l'envic a respecter sa personne; et si l'on a attaquié ses systênıes, on a été forcé d'admirer le génie qui les avoit imaginés. Mais c'est à la postérité, a qui il cn a appelé, à juger de la place qu’ils doivent occuper, à les adonter comme des vérités, ou les reléguer 
parmi ces brillantes liypollieses que n'a cessé d'cnfanter l'esprit humain. Qucl que soit leur sort, il restera toujours fixć, conme Écrivain, parni ces grands nuîtres qui, paroissaut en foulc au siecle de Louis XIV, se sont succédés jusqu'a lui, et ont donné à notrc languc cetle prémineure qu'aucune nation ne peut nous disputer: eonme Naturaliste, il se trouvera anx preniers rangs, ct eomne plysicien, son nom suivra ceux des Descalites et des Newton.

Quoique l'Histoire Naturelle soit la partie ois il ait le plus déployé ses talens, il avoit cultivé avècsucès tontes les autres branches de physique; il cn est peu qui ne lui doivent quelques découvertes: la plus connue est cclle de son miroir ardent. Les aneiens historiens sc réunissoient pour assurer qu'Arcumsne, au siége de Syracuse, avoit cmbiasé, par leur moyen, une parkic de la flotle de Marcellus. Descartes, ne connaissant que l'effet des miroirs concares, avoit reléguć .ce fait au rang des fables, et l'oni n'aroit osé réclanıcr contre une telle autorité; nais Beffos, rémissant par un mćcanisme des plus adroits, le foyer d'un grand nombre de miroirs dirigés sur un seul point, porla au loin l'incendie, et donna la preuve la plus eonvaineante (l'expérience) de la possibilité de ec fail: ee ne fut qu'alors que d'anciens manuscrits, qui avoicnt été inconnus, furent mis au jour; par les détails qu'ils donnècul sur la machine aneienne, ils aehevècul de prouver que Buffon avoit deviné la penséc d'A cunvene. Mais eontent d'avoir rengé ce grand homme, et les Iistoriens qui déposoient de ses talens, 
entraincé par d'autres oecupations, il abandonna des expériences qui auroient suffi pour immortaliser tout autre plyysicien.

Appelé souvent à la capitale par la place que ses talens lui avoient donnće, il s'occupoit à ranger, dans le Cabinet du Tioi, les productions de la nature, arrivant de tons les climals : elles lui étoient envoyées comme un tribut payé à son géuic; dans ses mains, ce vaste dépôt devenoit un temple digne de la nature. Par ses soins le jardin s'anrandissant, doubloit presque le nombre des Végétanx auxquels il éloit destiné, et devenoit en míne temps la promenade la plus agréable de Paris. bientót on alloit y voir placer la Ménagerie. $\mathbf{\Lambda}$ Versailies elle ne semble destinée qu’à faire parlie du faste qui environne le trône: transportée dans cette enceinte, sous ses yeux, elle alloit achever de la consacrer à la Nature, et devenoit en même temps nu monument de la confance qu'avoit en lui noire auguste Monarque, et du zèle avec lequel il protege les sciences el les arts. C'éloit au milieu de ces oecupations qu'il assembloit ses malérianx. Mais c'étoit principalement à sa terre de Montlars qu'il composoit ses immortels onvrages; an milieu de ses jardins, cutouré de la Nature, c'étoit là qu'il en parloit en la consultant; ce n'étoit qu'après en avoir fouillé les Archives dans les montagies qui environnent, qu'il traçoit ses Epoques; et ce n'étoit qu'après en avoir fait exploiter les mines et établi de superbes forges, qu'il traitoit de la Minéralogie.

C'est aussi dans cette retraite que, se délassant de ses. 


\section{DES H: T R E .}

travaux, il sc livroit aux douceurs de la vic privée, et que, porlant au milicu de sa famille ct de ses amis celte bonhomic précicuse qui souvent est l'attribut du génie, mettant tout le monde à l'aise, il faisoit oublier le grand homme admiré de toule l'Europe, pour ne laisser voir qu'un simple particulier, doué de toutes les vertus qui font le bonheur de la socićté.

Entrainé par un zèle pcut-être indiscret, j’ai voulu, devant les amis de la verité, payer un léger tribut à la cendre de ce grand hommc. La connoissance que vous avez tous de ses ouvrages, vous en donnera une plus grande idéc que tout ce que je pourrois ajouter; d'ailleurs, les socićtés savantes qui se sont fait honneul de le comptcr parmi leurs mcmbres, ront sc hâter d'atlacher à sa tombe les lauriers que l'Europe savante lui décerne.

\section{NOTES.}

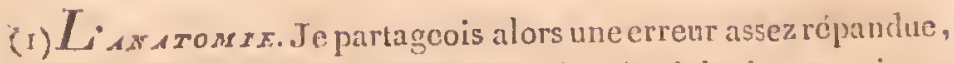
relle qui faisoit de l'Anatomie et de la Physiologie une science distincle de l'Histoire naturelle; mais elle consistoit plutôt dans le mot que dans le fait, car dès l'instant que l'on aroit admis la distiuction des corps naturels en Organiques et Inorganiques, il étoit tout simple de chercher le genre on les caractères des premiers dans leurs Organcs. Aussi, depuis les travaux de Perrault, et des autres savans qui ont illustré le berceau de l'Académiè des sciences, l'Aualomic comparée 
a presque toujours aecompagné la Zoologie. Elle avoit déjả pris u! plus grand essor par les Iravaux de Daubenton; mais c'étoit à M. Cuvier qu'il ćloit réservé de la fixer à sa vérituble place, en la rendant, par ses nombreuses observations, la base de l'Thistoire uaturelle des animaux. La méme inarclıe a été suivie à-peu-près daus la Bolanique: depuis Grew et Malpighi, la Physiologic et l'Organisation végélale étoient devenues, dans le fond, les guides de la Bolanique; mais ce n'est que depuis qu'on s'est lirré plus partieulièrement à l'étude des rapporls maturels, qu'on a senti davantage le besoin de pérétrer plus intimenent dans la strueture des Végétaux.

(2) Classification. Des cliangemens importans ont élé opérés dans la elassification des animaux, mais ils ne tombent que sur les deux dernières classes, celles des Insectes et des V crs, chacune d'elle ayaut ćlé partagée en plusieurs autres, et ensuito mélées entr'elles. D'abord M. Cuvier, par l'cxamen approfondi qu'il a fait des organes de la respiration, de la circulation et de la digestion, plaça les Mollusques immédiatement audessons des Poissons; les Vers proprement dits, dont ils étoicut délachés, vinrent cnsulte; puis les Crustacées et les Insectes, dont eeux-ci faisoicul parlie; enfin les Polypes, qui terminemt la série. M. Lamarck, que les circonstances ont forcé de sus: pendre ses travaux botaniques, pour se livrer entiòement it l'enseignement de ces deux dernicres classes, les sépura des quatre premières, par la considération de l'absence des Vertèbres; de-lit deux graudes divisions, auinanx verlébrés el animaux invertébrés. De plus, il a détaché une nouvelle classe. des Insectes, eelle des Arachnides : il al rapporté les Vers it la suite des Insectes, el ensuile il a formé la elasse des Radiaires, d'une partie des Polypes, ce qui porte à onze lo nombre des classes qu'il admet.

1, Manmifères. 2, Oiscaux, 3, Repliles. 4, Poissons. 5, Mollusques. 6, Cruslacées. 7, Arachnides. 8, Insectes. э, Vers. Io, Radiaircs. I , Polypes. 
(3) Bec des Pics. Ta découverte de la Nouselle-Hollande, celle cinquièrue partie du Globe, a ouvert un vaste champ anx Naturalistes : ils n'ont fait enco re que l'elleurer; cependant ils en ont déjà rapporté une foule de productions végétales et animales qui présentent de graudes différences avec tout ce que l'on counoissoit jusqu'alors. Il s'y est trouvé sur-tout des Quadrupèdes très-singuliers.

L'Ornithorhingue, entr'autres, a le bec d'un Canard : solı intérieur ne seroit pas moins extraordinaire, s'il étoit ovipare comme on a cru pouvoir le soupçomner, quoigu'il ressemble extérieurement aux autres Mammifères. Mais quand même on viendroit à vérifier cette anomalie, il resteroit toujours la grande difficulté de déterminer l'Oiseau auprès duquel on pourroit le placer.

(4) La Sèche. La nouvelle classification des animaux vient d'exéculer ce rapprochement, que j'indiquois alors vaguement; car la Sèche, se trouvant à la têle de la classe des Mollusques, suit immélliatement les Poissons: plusieurs autres animaux aussi singuliers viennent se grouper autour de hui; ils ontentrainé avec enx les Limaces, et ensuite tous les animaux à coquilles ou Testacścs. J'avoue que, malgré lcs preures anatumiques sur lesquelles reposent ces changemens, j'ai peine à croire que les T'eslacées doivesst précéder les Insectes, dans une clussification fondée sur la perfection des organes.

(5) Les Grenouilles et les Salamandres présentent de grandes singularités et sembleut destinées à joindre les Poissons aux Reptiles, car daus leur premier état de Tétard, leur respiration ne s'opère que par le inoyeu de brouchies analogues aux ouies des Poissons; mais parrenues à leur point de perfection, leurs poumons se développent, et ce n'est plus que par leur moyen qu'ils respirent. Il s'est trouvé deux animaux dont la conformation étoit si siugulière, đquon aroit révoqué 
en doute leur existcnce, l'un est la Siréne Lacertine, ot l'autre le Protée Anguin. On a prétendu qu'ils avoicut, dans tout le cours de leur vic, des bronchies. M. Cuvier vient de démêler avec beaucoup de sagacité tont ce que leur organisation prćsente dc singulier, et il a démoutré que malgré leurs vérilables anomalics on ne pouvoit les écarter de cette sćrie d'animaux : on la distingue maintenant des autres Reptiles, conme famille, par le nown de Batracicus.

(6) Insectes Aptíres. Ce projet a cnçore ćté cxéculé par les nouveanx mélhodistes, en élablissant les doux classes des Crustacćcs et des Arachnides; cllessont en clfet très-distinctes. On les trouvera peu nombreuses en espèces, si l'on ne consilc̀re que les travaux des Naturalistes précédens; la première même ne comprend qu'un seul geure de Linnéc, celui des Cancers; mais un a ćtabli plusieurs aulres avec beaucoup de fondement : ils se chargent tous les jours de nouvelles espèces, soit par des observations plus précises, soit par les soins des voyageurs. La seconde est à-peu-près dans le même cas : les Araignées, sur-toul. qui lui donment son nom, devicnnent inmombrables.

(7) Nombre des animanx. On sail qu'ils oul angmenté beaucoup depuis quc cel ouvrage cst écrit. M. De la Melherie a continué à présenter, au commencement de cliaque année, le tableau des progrès de chaque partic de l'Histoire naturelle.

Comme il étoil facilc de le prévoir, ce sont les dcrnières classes qui se sont curichies le plus; aiusi les Insectes deviennent innombrables, ils ne tarderont pas à dépasser à cux seuls, cn nombre, tout le règne végétal. Kiopinion assez génćralcment adopléc, que chawyre espèce de plantes nourrit des espèces d'Insectes particulières, faisoit depuis long-temps présumer ce résultal. Celle buse n'est pas tout-à-fait cxacte, car il y a beaucoup de plantes sur lesquclles on n'a pas encorc trouvé d'Inscctes : d'uu autre côté, les mĉmes espèces se retrouvent sur des végétaux 
différens; mais aussi il y a tel arbre qui nourrit un grand nombre d'Insectes différens, le Chểne sur-tout.

(8) Ce savant système. J'entrevoyuis dejjà la possibilité de pouvoir distinguer, par le port seulement, les Monocotylédones des Dicotylédones; mais ce ne fut qu'd l'aspect des Palmiers et autres arbres Monoeotylédones, que je pus me faire une vér table idée de la différence d'organisation de ces deux grandes séries. Daubenton avoit dejà fait sentir cette vérité; mais il étoit réservé à M. Desfontaines de la meltre dans son plus grand jour. Le nombre des parties de la fructification est jusqu’à présent le moyen le plus facile de les distiuguer; leurs étamines ef lcurs fruits présentent toujours le nombre trois, simple ou double, dans les Monoeotylédones: il se retrouve bien dans quelques Dieotylédones, mais elles dépendent plus souvent du nombre einq.

(9) Une carte de Géographie. Linné a dit clans la Philosoplica Botanica (page 279): Plante omnes utringue affinitulem monstrant uti territorium in mappá geographicâ. Mais c'est Haller, qui a le premier exprimé cette idée dans son énuméralion des plantes de la Suisse, en sorte que tout ce que je dis à ce sujet, n'est, au fond, qu'un eormmentaire de ees deux auteurs. Cette opinion m'étoit venue avant d'avoir été à même de connoître l'un ou l'autre. Il en est de même de la plupart de celles que j'expose ici : elles m’avoieut été suggórées prineipalement par la lecture de la Contemplation de la Nature et autres ouvrages de Bonnet, et celle de l'Historre nalurelle de Buffon.

Beaucoup d'autres auteurs oilt adopté cette idée, et ont chelché à l'exécuter; Herman, célèbre professeur de Strasbourğ, l'a appliquée uu règne animal, sous le titre de Tabula $A / f i$ rilatum. Giseke dans les Ordines Naturales de Linné, a exéculé une carle daus laquelle ces ordres soul distribués. Par la sulfince de chaque cas, il cherche à donner mue idée de létendue proportionnelle de chaque ordre. 
Plus récemment, Batsch a publié, sous le titre de Trabula Affinitatum reğni végetabilis, une nouvelle édition d'un ouvrage dans lequel il cherche aussi à exprimer graphiquement les rapports des différents groupes ou familles des végétaux. Cet ouvrage renferme des idées qui m'ont paru heureuses; mais l'ensemble est loin de présenter un résultat salisfaisant.

J'ai encore été précédé par Linné, dans l'opinion que les trois règnes tendent à se réunir dans un seul point. Voici ce que dit ce célèbre Naturaliste à ce sujer, Philosophicu Botunica ( page 97 6. I53).

Nuturz ipsat sociat et conjungit lapides et plantas, plantas et animalia; hoc faciendo non connectit perfectissimas plantas cum animalibus maximé imperfectis dictis, sed imperfecta animalia et imperfectas plantas combinat.

(ro) Bufron. Ce morceau n'a que le méritc d’être le premier hounmage public qu'on ait rendu à ce grand écrivain. Excité pur la circonstincce, je rassemblai à la lâte quelques matériaux. Le titre de Pline Français qu’on lui avoit donué, et celui de Pline Suédois qu’avoit inćrité pareillement Liuné, m’avoit suggéré l'idée de comparer d'abord ces deux Naturalistes modernes entr'eux, et ensuite de les rapprocher de l'auteur latin; mais il cût fallu plus de temps, et sur-tout plus d'instruction que je n'ell avois pour l'exécuter; en sorte que je fus forcé de supprimer l'esquisse que $j$ 'en avois faite : comme cette idée découloil facilemınt de l'espèce de rivalité qui a existé entre ces deux grands hommes, elle fut préserstée a M. Condorcel, qui enl a fait un des principaux ornemens de son éloge de Buffon. 


\section{OB S E R VAT I ONS}

S U R I E

\section{GENERA NOVA MADAGASCARIENSTA.}

$J_{F}$ rends compte, dans le Discours Préliminaire, de la manière dont cet Ouvrage a été eomposé, et des motifs qui m’ont engagé à le publier. Je ne le regarde que comme une espèce de Prodromzls, destinć ì supplćer et annonccr l'ouvrage plus imposant que j’ai commencé à publicr, et qui se trouve arrêté depris plusieurs années. Si celui-ci cût été aussi promptement terminé que j’aurois dû l'cspérer, l'autrc n'eûl pas paru.

Je sais que dans plus d'une oceasion le carnetère des Genres que je publie cst incomplet; ct quelquefois il s'y est glissé des erreurs graves; les unes ne sont que des fautes typographiques; d'autres sont de vrais solécismes que mon peur d'usage de la Langue latine m'ont fait commettre, et qu'un peu plus d'attention $\mathrm{m}$ 'eût fait éviter faeilement. Il en est quelques autres qui tiennent plus dircctement à la Scicuce : ce sont des méprises dans lescquelles trop de précipitation a pu mentrniner; mais jusqu'à présent j’ai étć le seul à les reconnoître, et je nc crois pas qu'elles soient en grand nombre. Personne donc n'a pu ditectement me trouver cn faute commc Bolaniste; et je crois avoir donné plus de détails sur les parties des Fruitset Graines qu'ancun royageur n’en a publić jusqu'à présent.

Cependant je vois continuellement cxprimer du doute, soit sur les faits que jexpose, quand ils contrarient trop fort les principes adoptés, soit sur los affinités des Genres que j'indique. Je erois que l'élau quc donnent les objets vus cn grand dans la mature, avec tous leurs aeeessoires, formc quelçuefois une espèce d’instinct plus sûr que la froide contemplation des Herbicrs. 
J'ai annoncé, dès mon arrivée, que la graine de l'Ambor $a$ avoit un Périsperme et d'autres caractères qui l'éloignoient des Figuiers et autres arbres de la Famille des Urticées, où on l'avoit placée. J'ai publié sette opiuiou daus l'arlicle $A m b o r a$ du Dictionnaire des Sciences maturelles, et daus l'exanen du genre Monimia ( Plantes Nouvelles, pag. 35). On u'y a pas fait altention; mais heureusement que M. de Jussieu se trouvoit avoir des Graines encore en bon état : il les a données à examiner à un Naturaliste dont la sagacilé et le vaste savoir sont égalemẹnt counus, et il a trouvé l'intérieur de ces Graines conforme à ce que j’avois anuoncé; alors $\mathbf{M}$. de Jussieu a été obligé de former la nonvelle Fannille des Monimices. J'ai dil de même depuis long-temps que le Fissilia avoit un très-petit embryon logé an sommet d'un Périsperme considárable. On en a douté encore, jusqu'à ce que le mêıne observaleur l'eût retrouvé sur des Graiues sc̀ches, ce qui a encore engagé $M$. de Jussieu is changer la place qu'il avoit assignée à ce Genre : c'est daus le deruier cuhier des Anuales du Musce (lom. XV, nº 6), qu'il vient de l'iudiquer : cela fail partie d'un Mimoire dans lequel ce Savant passe en revue tous les Genres nouveaux élablis depuis la publication de son Onvrage, et qui appartienneut à une portion de la série des Plantes à fleurs inonopétales.

A raison de ce Périsperme du Fissilia, M. de Jussieu pense qu’il doir être écarté de mon Psendaleira, qui en est privé; mais la stucture intérienre de la Graine de ce genre est si siugulière, comme le fera voir sa figure, que je n'ai pas osé prononcer sur son vrai caractère. Tontes les autres parties semblent s'accorder pour réunir daus un senl groupe avec le Fissilia, rolax. T., le Psendaleia et le Psendaleioides. C'est, sur-tout, daus la Famille des Apociuées, que M. de Jussieu s'écarte le plus de nou avis. Aiusi il réunit comme congenère le TanGluiniu avec lOchrosia, cepentant le premier se distinguo de tous les autres Genres de colle Famille, par son Fruit constamment monosperme, et par 'l'Embryon de sa Graine privée de Périsperme, étaut composé de deux Colylédous épais, 
laissant un vide considérable dans leur milieu, faits qui out été aperçus par Gærtner. Voy. Cerbera, tom. II, pag. Ig2, tabl. 123.

Il réunit pareillement le Plectaneia nu Plumeria : cependant le prenier se distingue par un Ovaire simple qui devient une Capsulc très-longue, en forme de Silique, et qui resseuble it celle de quelques Bignones; tandis que dans l'autre ce sont deux vrais Follicules très-distiucts.

Suivant M. de Jussieu, le caractère que j'ai donné de l'Alafia demande à être confirmé; je le pense aussi : car il est si singulier, qu’il semble ne poứoir s'accorder avec les lois de la Végétation. Il consiste en cinq filamens qui partent de lit base des Autlères, et qui vont s'attacher au style au-dessous du Stigmate. Quoique j'eusse déconvert celte struclure par la dissection de Fleurs fraîclıes, et que je l'eusse dessiné sur-lechamp, jai tonjours craint de m'être fait illusion; et peu de temps après mon retour en Europe, j'ai été confirmé dans ce doute, en examinaut des fleurs du Nerium oleandor, ou Láurier-Rose ; car j'aperçus que les Authères étoient, comme dans mon Genre, attachées par un Filament au Style ; Inais examinant avec attentiou. j’aperçus que ce filament n'étoit qu'une production glutineuse qui n'existoit qu'apròs l'épauouissement de la Fleur; et même l'humeur qui la forme est si tenace, que je me suis aperç, cet automne, que, comme dans beaucoup d'autres A pocinées, les Mouches qui insinuoient entre les Anthères leur trompe pour s'en nourrir, y restoient prises.

En'voyaul ce lait, je me rappelai le Genre Alafia, et jen disséquai quelques fleurs sèches; la facilité arec Iaquelle l'attache des Etamines a cédé, laissant à peine une trace, me fait présumcr qu'elles sont de même nature que celles du $\mathrm{Ne}$ rium. On pourroit croire, d'après cela, que ces deux arbustes sont du même Genre; mais l'Alafía n'a pas d'appendice à la gorge de la Corolle ni aux Authères.

M. de Jussieu rapporte le $Y$ ahea de $\mathbf{M}$. de Lamarck à l'Eclities: si, comme son nom lindique, c'est le "rahé ou Liane gomme élastique de Madagascar, ce sont deux Genres trèg. distincts; car dans le premier l'Ovaire est simple et devient 


\section{(4)}

me Traie souvent du volume de la plus grosse poire de BonClurétien, dont elle a la forme, et qui contieut un grand nombre de Graincs logées dans une pulpe aqueuse d'un goût trèsagréable ; l'ayaut regardé comme congéuèrc du Pacouria d'Aublet, je n'en ai pas fait mention daus mon Genera Nova.

M. de Jussieu persistc à regarder le Bonamia comme faisant partic des Borraginées, quoique j'aie indiqqué dans mes Plantes Nouvellcs les raisons qui m’ont engagé à le transporter a la Famille des Liserons. M. Robert Brown pense comme moi à cet égard, dans son Prodromtis de da Flore de la NouvclleHollande : il regarde ce Geure comme très-voisin de celui qu'il nomme Breweria et du Forana.

J'ai vu avee satisfaction que dans d'autres occasions ce savant Naturaliste confirmoit plusieurs faits quc $j$ 'avois annoncés, et sur lesquels on avoit laissé entrevoir quelques doutes, la Germination du Cycas entrautres: il parle aussi des pores que j'ai observés au sommct du Périspcrme de la Graine, et que j’ai regardés comme des Matrices destinées à rccevoir lcs Embryons.

Je suis bien aise d'aroir cette occasion de témoigncr publiquement à M. Robert Brown, mon triple camarade, comme Officicr d'infanterie, comme Voyageur, et comme Botaniste naturaliste, la reconnoissance que j'ai de ce qu'il a bicn voulu m'adresser son excellent Ouvrage, ct de l'assurer que personue n'a cherché plus que moi à profiter des cormoissanccs inmenses qui y sont répandues.

Le Gentrc Calvaria de Gxertner le fils, pag. $117 \mathrm{ct} \mathrm{pl.} 200$ et 201, ne nic paroît pas différer du Sideroxylum Linné, et du Bumelia de Swartz, par la Tleur ; car, dans les trois Genres, l'Ovairc rontient cinq Ovulcs on Embryons de Graines; mais dans la Maturation il sc fait des changemens singuliers, $1^{\circ}$. par l'avortement du plus grand nombre de ces Ovules; $2^{n}$. par leur déplacennent; étant verticaux dans lc principc, ils tendent à devenir plus ou moins horizontaux. Les différentes Espiceses que ¡’ai cu occasion d'examiner, présentent des nuances graduées en ces altérations. I’ai un J'ruil du Calvaria major de Gertuer, qui contieut deux Graines. 


\title{
GENERA NOVA
}

\section{MADAGASCARIENSIA,}

\author{
SE C UND U M
}

\section{METHODUM JUSSIÆANAM}

\author{
DIS POS I T A.
}

e

\section{A C O T Y LE D O N ES.}

F I L I C E S.

Plurima genera nova condidi in reformatione exaratâ hujus ordinis, ratione prasentia vel absentia annuli et involacri, iconibus illustratá.

1. VALLIFILIX, A P. Lygodiun, Swartz; Ugran, Cavanille; Odontopteris, Bernhardi; Ramonda, Mirbel; HYDroglossum, Wildenow. Capsula solitaria, alsque ammlo sub laciniis foliorum replicatis. - Filix scandens, folia sublipinnaza oris laciniatis. Valli-pana. Rlieed. Malab. 12, 'T. I. Ophiuglossum scandens, Limn. Sed proprio genere, sic visum postea recentioribus botanicis, ut patet ex novis nominib. s.

2. SCYPHOFILIX, A P. Involucrum calicinum cupulilorme, continens plurimas capsulas amnulatas, disco folii inferiore, adnatum. Frons decompositus. An Davallia, Smith? Giveriz Nors. 


\section{MONOCOTYLEDONES.}

\section{N A I A D E S.}

3. OUVIRANDRA, A P. Calix : foliola 3, colorata, lanceolata. Stanina; filancnta 6 , basi dilatata; anthcre apice insertac. Pistil. ovar. 3; styli o. Folliculi 3 , intcrnè dehisccntes. Semina 2, basi affixa; embrio absquc perispermo; foliun primarium plicatum in lobo. Herba aquaica, radix nuberosa, oblonga; folia radicalia, petiolana, demcrsa, pentiariter pertusa, parallelugrammice fonestrata. Scapus radicalis, medio inflatus ; spicnlis aliqnot terminatus; flores rosei odorati. Ouvirandrou it Madagascariensibns, ex quo nomen diductmn Radic edulis. Menuruta est it D. Adanson, Famille des plantes, p. 462. Hydrogeton, Persoon Synopsis.

4. DiCR AEA , A P. Podostemon, Michaux. Calix; urceolus radica!:s, polyphyllus; stylus clongatus, sústiucns genilatia; squamme 2 , an verus calis? Filamentum unicum, basi ovarii insertum, bifurcatum now $Y$; anthere biloculares, dorso affixa. Ovariun ovatum; styli 2 divaricari. Cupsula miuima nutans, 2-valvis unilocularis; recepaculum ccutrale carnosum. Semina plura, minima, basi allixa. Herbula aquatica, radix sel caulis laminosa, more Hepaticarun, mpilns repens; folia demersa, tenerrima, fiagilia, more Filicum consolnta, et habitu simillima, precipné Trichomanibus; radices fingifera, aplyylla, in sicco repentes.

5. HYDROST $A$ CHYS, $\Lambda$. P. Diöca; fores densc spicati. Flos mascul.; calix; squamma axi perpendicularis, apice recurvo. Stanen unicum; anthera sessilis; loculi 2 distincti. Flos femineus; calix id.; ovar. sub squammâ lateus; styli 2. Capsula ovata, hinc compressa, unilocularis, bivalvis, polvsperma; semina parictibus affixa. Herlia aquaticu, demerisa" ; finlin diversa in speciehns diversis; scapi centrales. lilores in amentis spica-formibus disposiu. Ydo६ aqua, s? $\alpha$ เs spica.

6. HALOPHILA, A P. Dioïca. Flos masculus, solitarius. Calix. Vagina spathacea, conici. Stanen unicum, filamentum elongatun; anthera clongata; pollen viscidum, agglutinatum. Flos femineus in distincto individuo; calix id. Ovar. simplex; stylus tenuis, clongatus; apice 3-lidus, lnciuiis expansis. Capsula r-loculars, 3-ralvis, polysperma. Seunina minuta, 
parietibus affixa. Merbula maritima, in asuosis proveniens, radices reptantes. Folin radicalia, petiolata, pellucida, stipula rotundura', regni pellucida. Flores soliurii, axillares.

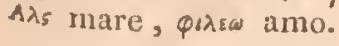

7: DTPLANTHERA, A P. Diöica. Fros masculus. Calix o. Stamina; filamentum unicum, elongatum, axillare; authera duplex, dorso agglutinata, allera minor inferior, utraque biloba; pollen; massa, glomerata, viscida. Flus femineus... Ilerbulu maritima, in astuosis proveniens; radices reptantes; folia basi vaginantia, graminea Zoslera; sed longe minora; flamentum nudum, axillare. Flos femineus, mihi ignotus. $\Delta$ irdoos duplex, et anthera.

8. TRISTICHA. Calix 3-phyllus, inferus. Stamen unicum, colollâ longior inter 2 foliola insertum; anthera internè adnata. Ovariuu simplex; siyli 3 breves, reflexi. Capsula 3-valvis, I-locularis; semina minuta, pariclina. Herbula multiformes, nomen; flores solicarii, pedicellati. Tģıs tres, strxos ordo.

\section{$G R A M I N E A E$.}

9. MICROTHUARFIA, A P. Flores polygami. Rachis membranacea, unilateralis, basi concava; gluma hermaphrodita unica ad basim, cetera mascule. Flos hermaphroditus, gluma exterior, biflora; ex his unus hermaphroditus, alter masculus. Flos hermaphr. gluma iuterior, tenuis; slamina 3. Styl. 2. Sligmata penticilliformia. Flores masculi conformos. Semen rachide replicato, obsoletè iuvoluto, culmo resupiuato. Culmi repentes, radicantes, folia breviu comentosa. Spica terminales. Mox̧os parvus, Evapos Lolium. Thuareia, Pcrs. Syn.

Io. OLYRA, L. Flores dicliues, monoïci, masculi et feminci in cádenı paniculâ. Flos nasc. Iongè minor; glumi simplex, bivalvis; valva altera major aristala; filamenta 3. valva 2 , sub inecjuales, ventricose gluna interior, valva firmtricosa, sulcala; arista terminalis; stipantia ovarium. Stylus fina, inacualcs. Stamina 3 abortiva Fructus : Siylus unicus; stigmati 2 penicilliformia. involvens sema interior, connivens, indurata, nitida, aretè sccedens I

Iฐ. BAMBOS, A P. Bambusa, Sclireb? Spicula conica, 
compressa, sub billora. Gluma imbricata, lanceolato-acula, conuiveutes, exteriores breviores, extima interue sulcala. squatumula 3 roluudate; stamina 6 , quadaun abortientia, iutrà squammulas insurta. Ovar. pedicellatum; st ylus simplex, longitudine staminum, apice 3-fidus; stiguala hirta. Semeu triquetrum, squammulis stipatum; corculum centrale, examinaudum. Ific referendum Arundinem Bambos L. sub quo nomine multas confunduntur species. Proximum si non idem Nastus, Comnn., Juss.

\section{J U N C I.}

12. XYROIDES. Calix petaloideus, tubulosus, profundè 3-fidus, apice fimbriatus; fasciculi villosi ad faucen calicis, pili articulati. Stamina 3, laciniis calicinis inserla. Ovar. ovalum; stylus longiludine calicis, apire 3-ficl. ; stigmata 3, crassi, hirsuta Cipsula tenuis, unilocularis, 3-valvis. Semina numerosa, valvis afixia, minuta, ovala, fulcata. Herbre palustres, exspitosa; folia raelicalia, ensiformia, wginumia. Scapus. Flares capitati imbricati, squammis latis. Multum refert ad Xyridem, sid capsula nnilocularis. Curté Xyridis species.

13. MABURNIA, A ]'. Calix superus? trigonus, trialatus, iu tubo superiits producto continuo ovario; appendices 6; corollic forme quorum 3 exteriores majores; stamiua 6 per paria lineâ coujuncla, sub latioribus foliolis recondita. Ovariuu inferum, calici coalitup. Styl. longiludiue tubi; stigma capitatun 3-lobun. Capsula 3-locularis, polyspernat. Plancula palustris, aplayllar; scapus brevis apree 3-2 florns ; squammule sparsie. An Burmatia is $N$. Limatrok, inemoratu int. Encyclopédie par ordre de nuaticies.

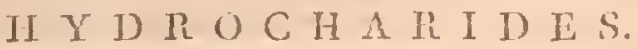

I in descriptione invertende sunt. Jistil. Ovarium oblongun, apice produclum, calici et stamiuferum. Stylus simplex; stigma unicum. Stanina; filamenta 3 ; anthera iulerne adnata, 2-Pocularis; filamenta 3, allerma sterilia, lungiom. Calix, foliola 3, linearia. Capsula tenuis, oblunga, unilocularis, trivalvis. Semina trino urline parietilus alfixa, winua, sul-

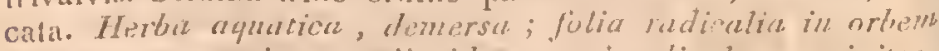
disposita, orraminea, pullucida; scupi radicalss, ancipitess,

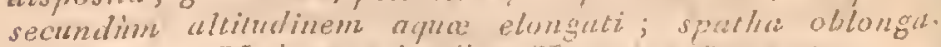
Ahé-lhorac, Madaguscaricusibus. Nomen mazss, scaleo. 


\section{O R C H I D E N.}

Plurima genera nova coudidi in reformatione hujus ordinis exaratâ, iconibus illnstratâ, mox prodiurá.

\section{I C O T Y L E D O N E S.}

\section{A P E T A L AE.}

\section{A U R I.}

15. AgATOPHYlium, Comm. Juss. Evoda, Gierin. Calix campanulatus, apice 6 -fidus; laciniae 3 extcriores, majores. Corolla o; squamnula 6, ut in Lauris. Filamenta 12 bino ordine disposita; anthera adıate, internè biloculares, bivalves. Filamenta 3 interiora, stcrilia (Nectarium, L. in Lamis). Ovarium superum fuudo calicis insertum; stylus unicus. Fructus. Calix fance coarctatus, laciniis caducis rel persistentibus, bacce formam el consistentiam inducns, basi semi 6-locularis. Scmen unicun, nudum; integumentum propriun eranescens. Embrio absque perispermo, radicula superior, basi 6-lobans. lobis rolundat is cotyledonibus crassis eflormatis. A rhores habiun Lauri; mica species aromatica. Ex hoc novo carncter" ad virum reformesto, pratet maximam. alfinitatem cum Lauro, erujus Lentim differt structuris staminum ot fructiss.

I6. POTAMEIA, A P. Calix urceolatus 4-lobus. Sianina 4; filamenta brevia, lita, lobis calicinis affixa ; antherx, loculis distinctis. Glandulx f basi ovarii, subrotunde. Ovariun simplex; stylus subnullus. Drupa ovala, versus basin allenuata monosperma; nucleus; testa, fragilis. Enbrio absque perispermo; lobi crassi ; radicula lateralis, infera. Fintex expansus, rami erecti, folia alterna, linearidanceolata; fores paniculati, axillares, parvi, globnlosi. Nomen is voce groci $\cdot$ Mo 7 pes $_{3}$, Fluvius, quia secundim amnes crescit.

\section{A M A R A N T H I.}

17. LESTIBUDESIA, A P. Nova menera. Tab. XVI. Calix, foliola 5-concava. Corolla o. Filamenta 5 in disco coalita; anthera subrotunda; ovar. subrotundum, 4-lobum. Styı.o; stignata i-elongata, pubescentia. Capsula unilocularis, 
polysperma. Semina funiculo centro affixa, minuta, compressa, nitida, subrostrata ; embryo cylindricus, incurvus, typo farinaceo circumposilus. Arbuscula, tami virgati; folia alterna; flores spicati, terminales, tenues. A venerabili D. Lestiboudois, Botanographia Belgica autore.

\section{A P E T A L AE, INCERTAE SEDIS.}

I8. BARBEUIA. Calix monophyllus, profundè 5-fidus; lacinia concava, membranacea. Corolla o. Stamina numerosa; filamenta complanata, brevia, fundo calicis inserta ; authere oblonga, sagillatx. Ovarium superum; styli 2 breves, crassi, hirsuti. Capsula biloba, bilocularis, loculis monospermis. Semina affixa, semi-arillata. Frmex debilis, surmentosus, vicinis plantis adharens; rammli flexiles, debiles; folin alterna, petiolata, ovata, oblonga, glaberrima, lurida; flores fasciculati; pedunculus communis, brevis, elongatus, compressus. Tota planta sul dessicatione nigrescit. An qnadam affinitas cum Prockiis? A D. Barbeu Du Bourg, Flore P'arisiensis, momine Bolaniste François, autore.

I9. MAUNEIA. Calix monophyllus, 5-lobus, planus. Coroll. o. Stamina numerosa, calici inserta; anthere trunci apice inserla. Ovar. nnicum; stylus staminibus longior; stigmal. 3. Bacci ovala, acuminala stylo persistente, 3 vel 2-sperma aborku. Semina ovata, Irasi umbilicata, apice acumimala. Perisperınum carnosum; enbrio inversus, planus, latitudine seninis, viridis; radicula brevis, crassa. Frutex erecius ; folia alterna, ovata, dentata; spina axillares; flares solitarii, axillares. An quadam affinitas cum Flaccurtiâ? A D. Mauny, Flore Cienomanensis autore.

20. PHYSENA, Nor. Calix 5-6-fidus, minimus. Coroll. o. Stanina 10-12 el ultri, calice multo longiora; filamenta temuissina, dcbilia; anthere oblonge, acuminatre. Ovarium supcrum ninimum f-spernum. Styli 2 lineares. Testa fragilis, inflata, membranacea, acuminata, unilocularis; semen minicum, superstes, crnssum, fundo aftivm, undiqne liherum; iutegumcntum coriaceum, tomentoso-carnosim; zona longitudiutis, glabra ; radicula lateralis protuberans ; cotyledones carnosie, in massam solidam coadunalx. Fritex vel arbuscula. Folia altema, breviter pretiulatu, ovcuto-acuta, marginibus undulatis. Nömen à frucru inflaso фuosw. Varonthe, in collectione seminum D. De Sussien. 
21. DILOBEIA, A P. Calix; foliola 4. Coroll. o. Stamina 4. Pistillum, ovarium unicum. Fruclus....

Arbor excelsa, folia alterna, upice biloba; glandula ex newo primario producto; lobi angulosi, flores parsi, paniculati.

\section{O N O P E T A L AE. \\ L Y S I M A C H I AE.} PE D I C I A R E S.

22. CAMPULEIA. A P. Calix tubulosus, subventricosus, Io-strialus, 5-partilus, laciniis acutis. Corolla irregularis; tubus elongatus, linearis, versus apicem, incurvus; limbus planus, obliquus, bipartitus; labiun superius, semibifidum, inferum, 3-lobatum, lobis a equalibus subrotundacis. Stamiua 4 didynama, curvura lubi inscrta, superiora, filamenta hrevia ; altera subsessilia; anthera ovate, apice insertze biloba, intus dehiscentes. Stylus, ante anthesin, stamina vix altingens, deindé elongatus ad longitudinem corollæe, el ejus curvaluram obsequens; stigma inflatum. Capsula orata, cornpressa, bivalvis, bilocularis; dissepinientun valvis oppositumi, ibique insertum. Senina plurima, minuta, ovalo-acuminata, striata. Merbu perennis, labihus lBartsix; radix squnmunosa; canlis simplex, folin basi oppositu, deindè alterna; flores solitarii, axillares, bractea limeares 2. Rhinatho et Barlsia affinis, sed ab utroqne discinctum genus. Kupwudos,

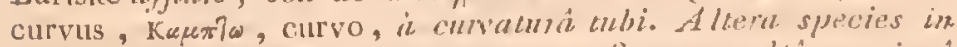
cultis insula Francia irrepsit ann. I 800 , corolía coccinent. spectabilis, sed more Orobaluches radicum. parasition, indis plantis vicinis noxin, precipue Maici. Genus proximnm Budleïæ et Piripec. Aubl. ex Juss.

23. STARBTA, A P. Calix inequalis, 5-fidus, laciniis aculis. Corolla globulosa, inaqualis, ventricosa, bilobata; labium superum brevius fissum, inferum, 3-lobun. Stamilla didynama , inclusa; filamenla hirsula; anthere loculi 2 inaquates, apice aristati, divaricati. Stylus incurvatus; stigma oblongum, compressum. Capsula 2-locularis, calice irrclusa; maluritate f-raly is. Stmina numerosa, minula, placentso centrali alfixi, vagi nâ cyliudricâ inclusa. Herba hubitu Darbsixe; camlis eecragnnns ; Folia busi opposiu, olcinde alcerna; flores axillares, soli- 
carii, subsessiles. Bractere 2 lineares; corolla globulosa. An eadem lecru ad caput Bona Spei, scd minor, pra Rhinantho Capensi lialuira? Muluis caracteribns, is Rhinantho vel Barlsiầ diversa. Calix ct semina, Schwalbex, ex icone Gertuer, 55, f. 2.

\section{J A S M I N E AE.}

24. NORONHTA, Stad.; Brinia, Nor. Calix minimus, 4-lidus. Corolla globulosa, crassa, profuudè 4-fida. Stamina; anthera 2 in fundo corollx el subsiantiâ ipsâ recondile. Ovariuu miümum, conicum, 2-loculare, 4-spermum. Sıyl.o. Drupa oblonga; nucleus bilocularis, tesla solida. Semenunicum, crassuns; raclicula supera; cotyledones crassa, absque perispermo, lypogea. A rbuscula. Folin oppositu, chartucea; fhores racemosi, axillares. Ilice referendum Oleam enarginatam, delinetum in illustr. g,merum D. Lamarck. Multis saracteribus propriz sui generis, forma corolle, sitn stamimum. et pracipue indole seminis. Memoria: Norouha dicavit D. Stadman. In horto Mantitiano coliur, nomine Ponai des Indes.

\section{I T I C E S.}

25. CHR YSOMALLUM, A T. Calix 1-phyllus, urceolaris, 5-dervatus. Corolla irreguiaris, tubulosa, incurva, villososericea; limbus patens, 5-fidus. Slamius $/ 4$, corollá longiora. Stylus fongindine staninum; stigura duplex. Drupa ovatia, calix persistens. Nucleus osseus, f-locularis, loculis monospermis.

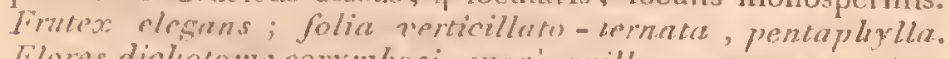
Flores dicliosomn rorymbori, sneprid axillares. Xgusos, auratus,

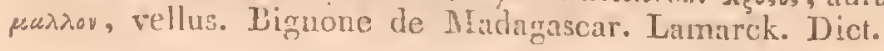

26. HAI.ODENDRUM, $\Lambda$ P. Calix imbricalus, duplex; exterior, brevior; squamuac: / roncave; inlerior pariter /4-squammosus, corollam iuclurlens. Corolla campanulata, limbus 4-fidus. Filanenta breria, cornile laciniis inserta; anthere subrotunde, interne dehisceutes. Orarinm oblongum, 4-spermum. Slyl. o. Stiqmat. 2. Fruetus.... bilocularis; loculi 2-spermi. Semina apice afhixa. A rluscula moritimn, saliciformis; folia opposita ; flores apree Elomerati. An hujus ondimis? An RLangitu album Frmph. amb. 3 vol. Tal, 76 ? Aricenia, 
Back. Bruce, Itiner. Tab. 3'. A clearactere Ariccniæ mnltim

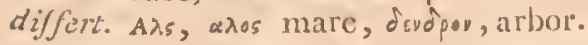

\section{PERSO N A T AE.}

27. NORTF, IA, A P. Calix monophyliu;, sublitabiatus, 5-dentatus, 5-angularis. Corolla ringeus, labio superiore 2 -fido, inferiore 3-lobo; lobi rolundati. Slaniula 4 didynana; antherre, loculi 2 distincti, superiores contigux. Ovar. contcum. Styl. basi inflexus. Sligma bilamellatnm. Capsula conica, 2-valvis, 2-locularis; dissepimentum valvis parallelum. Scmina minuta. Herba erecta, ramosa, ramuli altemi, f-goni; folia opposita, sulsessilia, dentata. Filores axillares, longre pedunculati, Scrophulariis adjiciendum sed distinctum genus; affinis Dodartice. Alewa species manritiana labiun Glechoma”. Affinis Torenize ex Juss.

\section{B O R R A I N E E.}

28. BONAMIA , A P. Nov. gen. Tah. V. Calix 5-phyllus; foliola concava. Corolla Iubulosa, limbus 5 -fidus. Stamina 5 exserta laciniis affixa. Stylıs unicus, bifurcalus, corollâ longior; stigmata capilata. Bacca; semina q́ funto affixa. Embrio absque perispermo, couvolutus. Fruex delilis : folia alterna, simuto; flores densé corrmubosi, lerminnles. Cordice uffinis. $A$ D. Bonami, Prodromi Filore Nounetensis antore. Omni perpenso, milui videtur Convolvulis affinior.

\section{O N V O J V U L I.}

29. HYDROLTA, A P. Calix monophyllus, 5-ficlus; lacinia basi dilatate. Corolla monopetala, rolata, tubus brevis; ventricosus. Stamina 5 laciniis inserta; filamentum hrere; anthera sagiltate. Ovarium simplex; styli 2 arcuati. Capsula, valvis 2 parum iutrollexis, rccptaculo connivcutihus, ef indè 2-locularis, apice dehiscens; receptaculum carnosum. Semina minuta, nidulantia, sulcala. Herloa palustris, cmulis simplex. teres, basi unda; fulia nllerna; flores axillares, pedunculi bini, vel solitrarii. Hydrolce affinis, sed insertione staminnm. precipué distinctus.

\section{G E N T I A N $\mathbb{N}$.}

3o. LISIANTHUS, T. Calix 5-filus. Corolla infundibuliformis, limbo 5 -lido. Stamina 5 ; aubcro subsessiles fauco 
corollae inserke, comniventes. Stylus simplex, elongatus. Stigma capitatum bitidum. Capsula bivalvis, marginibus iutroflexis cum receptaculo centralı conniventibus, iudè bilocularis. Semiua minuta. Ilerba vel su/frutices elegautes groudiftora: folu opposita, Irinervin. Ad Gentianam maximé accedunt, sed frucrus biloculuris. A liquot notis tum, inter se, tum ab aliis congeneribus aliscrepant; sed postea facilius elncidabuntur Iconum ape.

\section{A P O C I N E $\mathbb{E}$.}

3r. TANGHINIA, A P. Calix 5-fidus, patens. Corolla calice longior infundibuliformis, fauce dilalatâ. limbo plano, contorto, 5-lobo. Stamina 5; authere sessiles dilatatione tubi inserlie, cordiformes; tuherculi sub quitque antherit. Ovariun duplex; stylus unicus; stigna capitatun, apice bituberculatum, antheris inclusum. Drupas 2, vel unica, abortu pyrifornes, acmminatic. Nuclcus filamentosus, lignosus; perispermum nullum; embrio inversus; cotyledones maghie, erasse, concarcs. Arbor rlegans : finlin conferta rami erecsi; fores panionlati, rerminules. Arbor renenatissima, semen procipue. Voa Tanghing. Madag. malé nomen. A "Cerbera Manghas? 7rille Giermer, 708. Tall. i2'3 et 12f. Sed tnnc malè descriptum gemns et distinctissimum à Thcvetiâ.

32. VOACANGA, A P. Calix. Foliola 5 involuta. Corollit infundibuliformis. Iimbus patens, coutortus, lacinia late. Stamina 5. Anthere 5 sessiles, satriltate, fauce corollie inserta. Recepraculum carnosum; warium duplex; slylus brevis; stigma subtus peltatum, 3-lobatum, apice bituberculatmm. 1accic 2 spliericece, wagne. Stmina ummerosa, internè nidulantia, carnosa. A rhor. Folia magna, oppositu; fores puniculuri; fiuctus vermenso-vuriegati. Fx liis incola eliciunt viscum. Voa fructus, Acanga pintade, sic denominatur is maculis finctús.

33. PANDACA, Nor. Calix. ........ Corolla. Stamina...... Pistillum..... Fructus ; folliculi baccati 2, oppositi, subus tricarinati, apice truncali, supernè rotundati. Receptaculım fungosım, centrale. Seıniua nidulantia, umbilicala, carmosa. Arbor abundé lactescens. Ramicrassi; folia opposita, obovara, crassa; fructus tantum differt formh exteriore is Voacanga. Flores pratervisi. In Hiorro Manritiano colimr numine Morognsi, sed nondiun fructifor. Louvouron, Madiasuscariensibus. 
34. AlAFIA, A P. Dict. Scienc. Natur. Calix parvus, 5-lobus. Corolla tubulosa, reutricosa ; limbus 5-partitus, contortus, lacinia uno lalcre integrx, allero plicato-siuuale. Staminu; filamenla 5 brevia; anllerd 5 arulx, distinclie, sed conniventes; filanenta infra antheras, pistillo alligata. Ora rium duplex. Stylus tiliformis appendicibus 5, filamenlis adnatus. Stigma cupitatum, acumiuttum, inter antheras includens. Fruclus. Frutex debilis, scandens. fiolin opposita ; flores numerosi, purpurescentes, cerminales. Alafia Madag.

35. STEPHANOTIS, A P. Calix 5-phyllus palcns, brevis. Corolla lubulosa, basi ventricosa; lintus 5-fidus, contortus. Stamina more Asclepiadum cum pistillo conlerruminata. Curpuscula similia, hicornia; sed lobi ascendentes. Ovariun duplex; stylus brevis. Fruclus; folliculi duo horisontales, acuminati, crassi. Semiua paposa, frutices volubiles, scandentes; folia ovatu; podunculi 3-flori, mumarosi. E7epevals, coronariá. Difficile curacter pruendum, sed distinctum genus ab Asclcpiadc et Apocyno. Ceropegia acuminala. Roxburgh, Plant. Curomandel. Tub. 7, videur congener.

36, PLECTANFi $\Lambda$, A 13. Calix urceolaris. Corolla. 'Tubus brevis, ventricosus; limbus coulortus aque coarclatus. Sıanina 5; antheræ sessiles, sagillate. Orarim micum. Stylus brevis. Stigma capitalum. Capsula siliqueformis, sub-tetragona, longissima, ex duobus folliculis efformata, bilocularis, marginibus introllexis, seminileris, uaturilutc discedentibus. Semina marginibus atfixa, funiculo tenui, compressa, alata; perispermum lenue; einbryo reclus; colyledones pland. Frutex vounbilis, abunde lucrescens; folia opposina; fores parwi, corymbosi; fructus singularis Bignonice. Accedit ad, Gelsemium Juss. sed distinctum. Corté ad Apocincas pertiner.

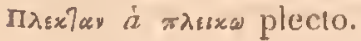

\section{E R I C E.}

37. CAVIN1UM, A P. Calix supcrus, campanulatus, 5-clentatus. Corolla campanulata, profunde 5-fida, laciuiis revolulis. Stamina ıo, basi corolle calici inserta; filameuta longitudine corolla; anthera oblonge, medio inserte, apice tantum dehiscentes. Ovarium inferum; slylus micus. Bacca coronata, 5-locularis. Scmina plurima receptaculis ccutralibus alfixis, parva; perispermum; embryo rechus. linfex erectus: folia alcema, ovata; flores racemosi, axilluies; pedunculus 
2-Zracteatis; corolla virides. Multim accedit ad Vaccinium, sed differt numcro partimu, formi corolla et liabitu. In Herb. Juss.

38. SIBURATrA, A P. Calix urceolatus, 5-dentatus. Corolla rotata, limbo 5-fido. Siamina 5 corolle inserta. Ovarimm inferuin, apice liberum; stylus brevis. Bacca rotundata, coronata, unilocularis. Semiura compressa, minula, in receptaculo centlali niclulantin. Pirutioulus. Foliu alterna, dentota; fores pari, panimulat. Caracter feré Samoli, qunmus habiun diversissimo. Sibourat, nomeiz medingess. Buobotrys, Forster, Vahl, p. 19, Tub. 6. Maesal, Forschal.

\section{O R Y M B I F E R.}

39. FTHULIA, L. Calix communis, imbricatus. Recepaculum nudum. Flosculi omues hermaphroditi. Corollula campanulata, ultra medium, 5-fida; lacinie tenues. Stylus apice 2-fidus, corollâ longior. Senten olwersè pyramidatum, nudum, 5-gonum, apice concavum. Herba. IFlores curymlosi et axillares, purpurei, folis mulifula vel serruta. Proximum Ethulice vel Struchio, sed mili ignote utraque. Ethulia conyzoides et Sparganophora.

4o. ASPILTA, A P. Calix communis, duplici serie squilmosus, cylindricus; folia 5 exteriora, apice reflexa. Corolla communis, radiata; semiflosculi ralii, ueutri, 5 vel 6 , apice bidentati, Intei. Receptaculum paleaceum; palca lanceolatæ, apice colorate. Semina oblonga, compressa, apice latiora, villosa, coronata deulibus ro minutis. IKerba prostrata ; folia oppositu, sessilin; flores solicarii, terminnles. Affinis Spiluntho, Eclipta, Bidenti, elc. sed al utrisque distincta coronuli seminum.

\section{R U B I A C E R.}

Plurima genera, sed autenti conferinda cum congoneribus Munritinus.

\section{A R A I I N .}

4T. DICORYPHE, А P. Gen. Nov. Tab. TV. Drcocc $A$. Calix superus, hirlus, 4-fidus, post deflorationen circumscissus. 
Pelala 4 ovario irserta, basi filamentorum coalia. Stamina 4 , petalis alterna ; filamenta basi lata, coalita; aulhere oblonga, filanentis continue, latere dehiscentes. Filanenta f, minora, sterilia. Styli 2. Stignı. 2. Fructus; calix circunscissus, subhexagomus, apice marginato 2-corui; cucci 2, coriacei, muluritate elasticè fissi sub apice, nouospermi. Semina apice internè aftixa, uitida, ovata, apice acuto unbilicato; perispermun corneum; embryo inversus; cotyledones plante, margine revolutæ. Fnuticulus. Ramivirgati, debiles; folia alterna; stipula 2 late, inaquales; flores capinato-umbellatr. Omni perpenso propior mihi viletur. Rhannis.

42.

Calix minimus, 5-dentalus. Corolla ...... Stamina. ...... Ovarium inferun ; stylus 1. Drupa ovata, monosperma ; semen compressun, ovatum. Arbor erecta, parim ramosa; fulia apice fuscicnlata, impari-pinnata; foliola glabra, dentata; flores paniculato-fasciculati, minimi.

43. MARALIA, A P. Calix minimus. Corolla 5-petala. Stam mina 5. Ovarium inferum, cyliudricuu. Styli 3. Bacra nigrescens, cyliudrica, 3-spermá. Fruticnlus. Folia alterna, pinnata; racemus dependens; umbellule longè pedunculatr. Affinis Aralix, sed 3-gynus.

\section{A P P A R I D E S.}

4f. OTHRYS, Nor. Calix planus, ciscoïdus; foliola 4 patentia. Petala 4 unguiculata, aequalia cun foliolis caliciuis alternantia el eoden disco inserta. Filamenta 12 ex fundo disci enata, basi connivenlia, tenuia, longa, in orhe disposita; anthere oblongac, apice insertic. Ovarium stipitalusn; stipes longitudine stanium. Bacca cyliudrica, apice recurvo. Sentua nidulantia, reniformia; embryo incurvus, absque perispermo. Arbascula. fiolia aleerna, cadnca, trifoliata; fuliola uvatooblonga, glaberrima; flores ante fiondescentiam erumpentes, rerminales, elegrantes, thyrsoidei subumbellati, pedureculi elongati. Genus proximnm Capparidi et Crateve, sed ub utroque distincum, regularitare purtium et absentia glandala.

\section{S A P I N D I.}

45. GELONIUM, Gertn. 805. Tab. I39? Calix 5-fidus. Corolla? Squamma hirsulæ 5. Discus circularis intra squanmas et 
stamina. Stamina 5 , calice longiora, basi pistilli inserta ; antherae subrotunde. Pistillum; an rudimentum tantim in quibusdam floribus inde polyganum? Ovarium minimum. Capsula bivalvis, basi coarclala, acuminala, coriacea, pyriformis; valvo medio septifere, indè bilocularis; loculi monosperni. Semina ovata, acmminata, scmi-arillata; arillus apicc lohalus; embryo crassus; lobi lrorisontules; radicula incurva. A theres; folius alterna, conjugata vel abrupte, et impari pinnata; petiolus lignescenst filores paniculati. Multis curucterilus accedit ad geuts Molincie; sed distinctum fructu 2-loculuri. Qucedam affinitas in forma fructis et arilli cum Aquilariâ. Lam.

\section{A L P I G H I A:}

46. BIPOREIA, AP.Nrota, Lam. Calix urceolaris, f-lobus; lobi rotundati, quorum 2 oppositi, cxtcrne glandulosi. Pelala 4 lanceolata, basi lata. Filancnta 8 , basi squammulit ancla ; anthere clorso insertie. Ovarium \& duplex, substipitalum; stylus unicus, longiludine staminum. Capsulæ \& compressa, leguminiformes, uniloculares, monosperuxe. A rluscula; firlius lete, alterna, punctata; umbelulla axillares, dermmómins, 5-6-flora. Genus proximum Banisteria, culice parirer 2-glanduloso et 4-partito, sed distinctum stylo nuico et synannmulis staminum. Nomen a duobus poris cralicis, sedmutandum.

47. TRISTELLATEIA, A P. ZYYUM, Nor. Calix 5-phyllus, 5-fidus. Corolla; petala 5, inllexa, ungniculata. Staminu Io, 5 alternatim minora; anthere apice adnatie. Ovarium tribus poris glandulosis impressum; stylus unicus, longitudine staminun incursus. Fructus composilus; capsule 3 peculiares; coronata appendicibus 6 planis, radialis, ex poris ovarii enatis, tres alia centrales. Semen unicum; embryo absque perispermo, convolutus, viridis. Frntex volulilis, elegans; folia inferne verticillata, quaternata, superne opposila, hasi glandulosa, integra ; flores rucemosi, lntei. Nomen 3-stella, ì figurâ finctîs. Benounouc, Madugasc.

\section{H Y P E R I C A.}

48. CHRYSOPIA, Nor. Calix 5-phyllus; foliola concava, crussa, colorata. L'etala 5 concava, crassa, convoluta; discus internus. Urceolus staninifer basi integer crassıs, profundè 5 -lobus; lobi cunniventes. Anthera 5 in utroque lobo exterue 
exaratæ. Ovarium 5-loculare; embryones aliquot centro affixi; stylus semi 5-fidus; lobi cylindrici, usque ad mediuń perforati. Fructus.... Semina crassa, oleosa; perispernum o; cotyledones coadunatx. Arbor excelsa, elegans; rami expansi, apice umbellatim couferti; foliá alterna, obata, integra; flores apice fasciculati, magni, intensé purpurei; succus lutens, abundans; mndé nomen. Kgusos auratus, oтos succus.

49. haronga, a P. Harongana, Lam. illustr. gen. It monocarpus, Nor. Calix 5-partilus. Petala 5, punctata. Stamina polyadel pha; filamenta 5, apice 3-partita, 3-antherifera; squammule 5, filanentis alterna ( Nectarimm L.) Ovarium simplex; slyli 5 ; stign. 5. Capsuli baccala; loculi 5,2 vel 3 spermi. Corculum inversum, absque perispermo. Frutices $M$ altritiani et Madagascarienses, succo lateo turgidi; folia opposita, juniora plana. Calix, pelala et juniora fulia punctis glandulosis conspersa. Haronga nomen madagascaricum.

\section{G U T T I F E R}

5o. OCHROCARPOS, Nor. Calix eliphyllıs. Corolla..... Stamina numerosa, simplici ordine basi coalita; anthere ovate. Ovarium oblongmm; stylus subnullus; stigma planum, 4.-5-(6-lobum. Bacca corticosa, multilocula ris secundùn numerum loborum stigmatis; loculi monospermi; aliquot abortientes. Scmina carnosa, arillata, psendo-monocolyledonea; radicula in apice ( sic in plerisque guttiferis) Arbor; folia verticillatocemata, integerrima, coriacea; flores axillares; pedunculi panciflori. Oxpos luteus, Kagtos fructus, a succo luteo abundans, pracipac in frucu.

5r. PSEUDALEIA, A P. Orax, Linn. Calix minimus, urceolaris, subinteger. Petala 3 in tubun comniventia. Filamenta 6, petalis arclè applicita, indè videntur epipetala; capillamenta apice 2-furca ex utroque lintere petalorum. Ovarium conicum; slylus longrtudine corollie; stigma 3-lubum. Drupa spherica, monosperma ; enbryo carnosus, absque perispermo; cotyledones carnose, indiscreto, oleose. A rbuscula ranosa; foliu alterna, levia; flores axillares; pednuculi panciflor. $A_{n}$ affinis Fissilix Coum. Juss.? \&sodaderos, falsus, à corollá mentiente corollam I-petalam.

52. PSEUDALEIOIDES, A P. Calix minimus, urceolaris, integer. Corolla; petala 4 , incequalia, basi lata, conniventia. 
Stamina 6; filamenta petalis dispuriter applicita, ut ibi appareaut inserta, lata ; authere apice inserte. Ovarium monospermun ; stylus loncritudiue corolla; stigmala 3 , globosa. Fructus.... frrmex debilis ; folia alcerna; racemi milaterules, panciflori, affinis pracedenci, a quo differt tantim munero purtinm.

\section{H L E A C E IE. A P. (Ville GeN. Nov.)}

53. SARCOLANA, A P.Gen. Nov.'Tab. IXet X.TudNGA. Urceolus carnosus, 5-deutatus, ferrugineo-tomentosus. Calix in urceolo reconditus, 3 -plyyllus; foliola concava. Pelala 5 , ba i in tubo comiventia, apice expatusa; tubus monophyllus, parvis, cingens stamina. Filamenta nunerosa, tenuia, petalis breviora, basi tubi inserta; anthere apice insertae. Ovarium 3-luculare; loculi 2-spermi; stylus unicus, cylindricus; stigma dilatatun, 3-sulcatuin. Tructus; urceolus, persistens, ampliatus, baccatus, apice depressus, pilis clausus, interne villoso-pruricns. Capsula interior 3-loctinits; loculi 2 -valtes $1-2$ sepè abortientes. Sewuiua duo centro allixa; perispernum terus, carnosum; cmbryo plicatus. Al buscula vel frucrices rumi decumbentes; stipule criduca, convolure; foliu junioru plicuta, inde adulta reluti 5-nervia, ferngineo-tomentasa; flores elegantes, paniculates. 'T'oudinga nomen Madagascuriense.

5\%. LEITOTANA, A P. Gen. Nov. Tub. XI. Urceolus subcarnosus, cylindricus. Culix; loliola 3 , urceolo longiora. Corolla Srurolena'; tubus ident. Stamina; filmenta Io. Ovar polyspermum. Fructus urceolıs, carnosus; capsula I-locularist (abortu) monosperma. Arbor frondasa habilu elegantissino; folia alterna undulutu gluberrinu; flores munerosi, corymbosi, terminales. Proximum genus precedenti à quo differt, procipué zumero staminum.

55. SCHTZOLANA, A P. Gen. Nov, Tab. XT. IxocarpFia. Nenna, Nor. Involncrum biflorum, fiubriatum, minimum. Callix; Poliola 3. Petala 5. Stamina numerosa; filarnenta tenuia; antluerw 2-loculares, utroque laterc filamenti aduala. Ovar. simplex; stylus unicus. Fructus; involucrum ampliatum, laciniatum, viscosum connivens; calix persistens. Capsula inclusa, 3-locularis, loculi polysperui. Semuna apice inserta, pudentia; corculum plicatum, in perispermo tenut. A rbores vel arBuscule elegantes; foliu alternu, avata, glabra; stipnla bina. culuce; flores numerosi, puniculati, terminales wel racem

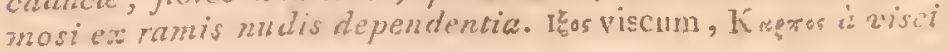


ditate involucri. Genus affine pracedentibus; sed differt precipud invulucro biforo non carnoso. Utraque accedunt multum Malvaceis; sed distincta tum ab illis, $t u m$ ub omnibus generibus adhuc cognitis, involucro et calice 3-pliyllo sub corolla 5-petalá.

56. RHODOLENA, A P. Gen. Nov. Tab. XIT. Calix. Foliola 3, concava, caruosa, glulinosa; squammulis 2. basi cinctis. Petala 6, urceolata, convoluta, utagna. Staniua numerosa, basi urceolo brevi juncta; filamenta filiformia, corolla breviora; anthera 4 angularis, dorso inserta. Ovar. 3-gonum, 3-loculare; polyspermum. Hructus. Fritex excelsas artiores scundens; folia alterna: fores terminales; pedunculi terminales, biflori; proprii sib fore incrassati; corolla maxima, incensé purpurea.

\section{A G NOLI E.}

57. LENIDIA, A P. Calix phyllus. Petala 5 margine undulata. Stamina numerosa; filamenta brevia; anthera adnate longiores. Ovaria 5, conniventia; styli, ex interiore reflexi. Capsula vel foliculi 5 , uniloculares, polysperme. Semina rotundata. Arbor elegans; folia magna, cilterna, petiolata. sinuata, juniora, convoluta, stipula caducit; flores paniculari. Bararha, nomen madaguscaricum. Dillenia, Juss.

58. PHILOMEDA, Nor. Sopnisteque, Con.? Calix monophyllus, profundè 5-fidus. Petala 5 basi altenuata. Stanina io; flanenta ferè nulla; anthercearcuata 2-loculares, non dehiscentes, sed more solunearum perforata. Pistil.; columun centralis sustinens ovaria 5 ; stylus unicus apice attenuatus; stigma simplex. Fructus; receptaculum carnosum; capsula 5 monosperma. Sencen absque perispermo; cotyledones crassx , horisontales; radicula lateralis, incurva. Frntices; folin perenantia. alterna, subdentata; stipula ucuta, caduca; fores racemosí vel paniculati. An Gomphia Srvatz?

59. OCHNA. Gen. I. Calix. Corolla Philomeda: Stamina numerosa ; filamenta longitudine anthera. Ovaria plurima, 8-Io-I2; stylus unicus, apice multifidus secundùm numerum ovariorum. Capsulæe totidein receptaculo carnoso demersa. Cotyledones craste, verticales; radicula inferior. A rbores gemmipara ; folia caduca; gemma conica; squamma concava, caduca; flores numerosi, axillares, cum foliis entmpentes, more Rosacearum. Genus distinctum a pracedenti, etcredo a) Ochnâ. Lin.

Genera Nova. 


\section{A N N O N AE.}

60. MARENTERIA, Nur. Calix monophyllus, 3-lobus; petala 6 quorum 3 exteriora, patentia majora, interiora erecta. Stamiita numerusa. Ovaria 4-5. Stigma sessile. Bacca 4-5 subpedicelate, hurisontales, scabre, ventricose, inæquales. Semina plura supernè affixa simplici ordine; structura interior Annonacearuu. Fraciculus. Ramuli scandentes; fores terminales, solitarii. Proximun genus Uvarix, sed differt figura corolla et fructis. Noronha dicavit D. Armenteries. Sed in hoc consilio Lourciro antecessit.

Plurime alia fnutices accedunt ad Uvariam. Sed alighuot notis discrepant.

6r. HeMISTEMMA, Juss. M. S. Aglaia, Nor.? Calix; foliola 5 concava. Petala 5 , requalia, apice bifida; 2 ad invicen pauld remoliom. Stamina numerosa, basi coalita, non circulariter inserta, sed exıra pistilla lineâ reclá ; capillamenta sterilia extra stanina, apice spathulata. Ovarium duplex, basi staminumi aplicitum; slylus longitudine staninum. Capsula vel folliculi 2 hirsuta, aborlu I-sperme. Semen; arillus membranaceus ; perispermum carnosum; corculum... Frntex elegans, habiur Cisti; folia lineari-lanceolatu, suliens areolaca; fiores, racemosi ; racemi nniluterales. Distincrum situ staminum. Quredam affinitas in sirucuré fructús cum Curatellâ, sed alinude diversies. Hice reponztur ratione tantiun finctus duplicis. Ciste de Madagascar. Lam. Dict. Hemistemma, Juss.

\section{E N I S P R M A.}

62. BURASAIA, A P. Dict. Sc. Nat. Flores divici. Abortu? Calix 6-phyllus. Foliola concava; pelala 6. Calix et corolla comuventes. Stamina 6 . Filamenta crassa, basi coalita; authere aduata. Flos femineus. Calix, corolla id. Filamenta 6 sterilia. Ovarium triplex; stigmata sessilia. Drupie 3 subpedunculate. Nucleus fulcatus, papilloso-viscosus; perispermum caruosum; corculum brevius, iuferum; cotyledones plana, divaricatre. Frutex debilis; folia alcerna, longè pedunculata, trifoliata; foliola ovata, integra; flores rncemosi, axillares. Proximum. Menispermo, sed videnur distinctum multis caracteribus. Nomers madrgascaricum Bourasaha. 
63. SPIROSPER MUM, A P. Calix; foliola 6, quorum 3 exteriora breviora. Corolla? Squamme 6, concavie, calice breviora Stamina 6, quorum 3 interiora basi juncta; antherw bilobæ, apice inseria. Flos femineus. Calix.... Corolla..... Nuces 8 in orben disposila, pedunculake, monospermø, incurvo; perispermum nullum; corculum cylindricum, longissimum, spiraliter couvolutum. Frutex debilis; foliu magna, alterna, multinervia; flores racemosi, dependentes. Affinior Cissampelo defectn perispermi.

\section{T I L I A C E E.}

64. ALTHERIA, A P. Calix duplex, exterior 3-phyllus; interior monophyllus, urceolaris, 5 -fidus. Corolla; petala 5 basi convoluta. 'Tubus basi corollæ adnalus, a pice 5-dentatus; a n there 5 dentibus tubi affixæ; loculi 2 distincti, exteruè deliscentes, Ovarium simplex 5-gonum; styli 5 coaliti. Capsulie 5 , coalite, monospermæ. Semina ovalo-acuminala centro affixa; perispermum carnosum; corculum viride; colyledones plana. Herta erecta, lirsuta; folia alterna, cordato-serrata; fores fusciculati, axillares, parvi. Walıerix affinis; differt pracipud capsulá in hâc simplex, forsan abom, tunc ex eodem genere.

65. ALSODEIA. A P. Nov. Gen. Tab. XVIT et XVIIT. Calix urceolaris monophyllus, 5 -dentalus. Petala 5 basi connexa. Urceolus 5 - ligulatus, busi corollis aduatus; anthera basi cujusque ligula interuè aflixa, 2-loculares. Ovarium simplex; stylus unicus. Capsula tenuis, 3 -valvis, unilocularis. Semina parietibus affixa, pauca; perispermum carnostum; corculum centrifugum; cotyledones plawa; radicula brevis. Frutices. Folic alterna, inaqualia, serrata; flores puniculati, terminales, "el fasciculati, axillares. Genus proximnm Viola situ antherarum et forma fructis, sed distiuctum regularitate corolla. Adsoósuos, hemorosus.

66. PAROPSTA. Nor. Nov, Gen. Tab. XIX. Calix. Foliola 5. Corolla? Perala 5 , foliolis calicinis alterna, figurâ et proportione conformia, basi connexa, expansa. Neclarium; corona efformala capillamentis villosis, conniventibus, simplici ordine dispositis. Filamenta 5 basi in columua brevi coalita; antheræe erectie, basi inserta. Ovarium sessile inter stamina; slyli 3 hirsuti; stigmala capitata. Capsula uuilocularis 3-valvis. Semina, pauca, valvis aftixa; urillus baccatus; perispermum carnosum. Frutex erectus. Fiolia alterna, oviso-oblonga; stipula nutle; flares 
axillares conferti. Fructificatio fere Passiflora, sed habitus diversissimus. Iructus edulis. Nomen madagascaricum, Voa Kiripil et Pavua.

\section{A R Y O P H I L L I.}

67. PHYSA. Nor. Calix 5-phyllus; foliola concava, intus colorata. Corolla o. Filamenta Io alterualiun breviora; anthere; lobi 2 discreti. Ovarium simplex; stigmala 3. Capsula 3-sulca; receptaculun centrale; valve 3 , septifera cum receptaculo conniventes, indè 3-locularis. Semina minuta, subrenifornia, numerosa. Plantula prostrata, cunliculi articulati; folia vorticillatu, quaternatu, incequaliu; flores; podunculi uniflari.

\section{POL Y PET ALE HYPOG Y N}

$$
\text { I N C I IL } T \text { AE } S \text { E N I S. }
$$

68. CALYPSO, Gen. Nov. Tab. VI. Salaciornes. Calix I-phyllus, 5-lobalus. Petala 5 , basi lata; discus centralis, rrassus, promens stamina et pistillum. Filamenta 3 breria, basi lata, contigua; anthere bilobic; lohi divaricati, externè dehiscentes. Ovarium nimimum, triquetrum, aded coulitum cmm disco, ut cjus apiccm apparcal. Bacca globulosa, premens discum. Semina patcal, supterstitia; co:culum horisontale in perispermo carnoso. Frutex. Rami erecti; folia apposita, subserruta; flores fiasciculaci, axillares, padnnculati. Multim refert ad Salaciam, Linnci; an idem.? Sed annc malé descripnum genus, nam tantimz fugicivis oculis amandatur, ad Gyuandriam. Salacioides dixi ob affinitatem indeterminatam. Affinis Hipocrateic ex. Juss.

6. BREXIA, Nor.

Calix I-phyllus, 5-fidus persistens. Corolla; petala 5 rotundala, caduca. Filamenta 5 basi in necolo coalita, intervalla finbriata; anthera apici inserla interne dehiscentes. Orarimm conicum; stylus bresis; stigna crasstm. Baccar cortice lignoso fimo, oblonga, 5-angularis; $10-$ culi 5 . Semina numerosa, trino ordine centro affixa; corculum recum. Co:yledones hemispherica in perispermo carnoso. $A \mathrm{r}$ bascula; folia alwerna, juniork longissima, spinoso-dentata. adulia ovato-oblonğa, subslentat firmia; umbella csillaras. 
7.8-flora; pedunculus communis compressus. Vanana, Lan]. Illustr. gener.

\section{POLYPETaLE'Stamina Perigyna.}

\section{O N A G R $\mathbb{A}$.}

7o. BRUGUIERA, A. P. Dict. Sc. Nat. Calix tubulosus, 5-dentatus, compressus, utroque latere dente auclus. Petala 5 calici inserta, patentia. Stamina to fundo calicis inserta; anthera ovata, apice inserta. Ovarium inferun uniloculare. Semina 4 dependentia, stylo aftixa. Stylus longitudine staminum, apice attenuatus, fistulosus. Fructus.... Arluscrula in inundatis salsis, proveniens inter Rizophoras et Sonneratias. Folia alterna, spablhlata, integra, crassiuscula, levia; Rores parvi, in spicis axillarihus sessiles, busi bracteati. Affinis generibus Myrtoïdeis inter Onagras reposicis, Conbreto ec precipue Poivrea Com. sim seminum, sed non vidi macurnum fructum. Mentorise $D$. Bruguiere dicatur, clurissint itinerutoris, qui Madagascar adiic.

\section{R O S A C E E.}

7I. MYRIANTHEIA, A P. Calix campantilutus, apice 5-fidus; foliola oblonga, conniventia. Corolla; petala 5 , basi wiguiculata, calice breviora. Stannina polyadelpha; fisciculi 5 ex $4-5$ flamentis tenuibus calici inserta. Squanma 5 fasciculis alternantes. Ovarium semi-inferum, apice conicum, includeus semina 4 ; styli 4 breves. Fructus.... Semen unicum superstes. Arbuscula vel fintices elegantes; folia alterna, brevi petiolata, crassa; flores numerosi, racemosi, axillares. Mug:os, mille, «tos, flores, Proximum Homalio, si non idem.

72. THELIRA, A P. Calix basi campanulatus; pedunculus more Pelugornii fistulosus, callici continuus. Corollai ; petcla 5. Circulus continuus, promens uno latere 6 stamina declinata . dentes 4, loco staminum deficientium; filamenta tenuia; antherze dorso affixie, latere dehiscentes. Ovarium 2 spermun. basi staminum inserlum; stylus lateralis, ex alterâ parte recurvus. Bacca? rugosa, intis villosa. Senuen muicum, crassum : perispermumo; cotyledones crasse, intequales, nnum involvens alterum, plicate; radicula inferior. Arbores alternifoline. species brackeis standulosis, spatubilis. Ex icone Gicrtaer 
junior, 1187 Tab... patet lloc genus dictinctissimum esse $a b$ Hirlellâ.

73. ASTEROPEIA, A P. Nov. gen. Tab. XV. Calix magnus, I-phyllus, 5 -fidus; laciniæe oblonga. Corolla; petala 5 , basi lata. Stamina ro basi coalita; filamenta 5 , alternè breviora; anthera apice inserta. Ovarium 3-gonum; stylus unicus, apice 3-fidus. Stigmata 3. Fructus. Calix patens, persistens. Capsula 3-locularis. Semina pauca, centro affixa. Arbor. Folia alterna in petiolo desinentes. Flores numerosi, panicnlati. Pratervisum semen maturum, ideóque penetrara structuram interiorem non licuit, et indè alubitans hinc retuli.

74. TRITFPISIUM, A P. Calix inferus, crassus, apice 5-hdus. Corolla o. Stamina numerosa, pluribus ordinibus calici inserta; filanenta lenuia.Tubusinternus, ligul is 3 terminatus, iuter stamiua et pistillum insertus. Ovarium lundum calicis occupans; moiospermum; slylus superans tubun, apice bilidus; stignata 2 tonentosa. Fruclus... Arbuscula. Rami tentes, numerosi; folia alterna, Innceolata, jnniora stipulis cadncis involntis. Genus peculiure, nulli affine distinctum tubo centrali. Undè

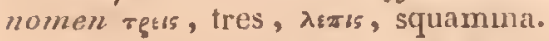

\section{E G U M I N O S A.}

75. INTSTA, N. Calix basi campanulatus, 4-partitus. Petalum unicun, unguiculatum, ovario opposito. Filamenta 9 quorum 3 tantim fertilia, longiora, declinata. Legumen oblongum, compressum, 3-4-spermum. Semina oblonga, inrervalla seminum, medullâ reforlâ, more Guilundina, et aliæe. Arbor procern; folia impari pinnatu, bijuga. Filores corymbosi. Pre se fert 2 anomalins luujus familia : corollam Amorplix et stamina T'amarindi. Nomen malagnscaricum Intsi. An Cajn Bessi Malaicensium, sive Ligum ferri. Metrosideros. Rumph. Herb. Amb. Tom. 3. Tab.

76. MLTROCYNIA, A P. Calix basi campanulatus, apice 5-lido; lacinis longe, colorate, reflexa. Petala 5 alterna, erecta. Filamenta ro hirta; anthera: subrotunda, apici inserı. Ovariun pedunculatum breve, I-spermum, hirtum; stylus longitudine stuminum. Legmen breve, subreniforme, verrucosum vel plicatum. Semen crassum, unicum. A rbnschla vel frutex; folia alterna, abrupce pinnata, multi-juga vel conjugata; foliola tenuia; flores densé spicati, axillares. 
An idem cum Scholiâ, sed fructus milii ignotus? Legument linjus refert ad Cynometram.

77. VOANDZELA, A P. Flores polygani. Hermaphroditi, externi, terminantes ramulos, papilionarei, steriles. Bracter 2 stipantes calicenn. Calix campanulatus. Corolla papilionacea; ale horisontales. Stamina diadelphi. Stylus incurvus, hirsulus. Flores feminei, subsolitarii; pedunculi reflexi, petentes terrim. Calix campanulatus. Corolla et stamina o. Ovariun 2-spermum; stylus brevis; stigma uncinatum, more $V$ iolc. Legumen subterraueum, stbrotundum, abortu I-spernum ; valve carnosie. Radicula lateralis. ILerba repens; rumi divaricati; folia trifoliata, longé pedunculata, impari remoto. Genus proximnm Arachidi, sed distinchun structurá florm femineorum. Voandzou Helic incolis Madagascariensibus, quibus coliur. ratione fructïs edulis, indè nomen. Glycine subterranea. Liun.

\section{TE R E B I N T A C E}

78. DICHAPETALUM, A P. Calix monophyllus, campanulatus, profundè 5-fidus; pelala 5, basi linearia, apice hifurca, laciniis salicinis alterna. Stamina perigyna. Filamenta 5 oblonga; anthera cordate, apice inserta, pelalis alternt. Squammule 5 ad basin ovarii. Ovarium 3-spermum. Stylus simplex, apice 3-fidus. Fructus baccalus. Integumentum carnosum, 3-locularis; loculi $x$-spermi, plernmque 2 abortientes. Semen crassum, descendens; perispernum o; colyledones crassce; radicula minima superior. Fruticulus. Rumi feré uplaylli scandentes; folia alterna, integra ; flores parvi, axillis fasciculati. $\Delta\llcorner\chi \alpha$, furcatus, твтальs, petalum.

79. TIEUCOSזA, A P. Calix campanulatus, 5-fidus. Petala 5. Stamiua 5, petalis alterna. Ovariun inferun, 3-spermun; stylus unicus, longitudine staminum. Fruckus $3 \cdot$ gonus, 3-spermus, siepè x-2 aborlivi. Nuclens rugosus, osseus; embryo absque perispermo; lobi crassi. Fruticulus debilis; folia alterna, panci-nervia, scabra, snbtius tomenloso-iandicantia, unde nomen: Aruxos, albus.

8o. SORINDEIA, A P. Polysamia dioecia? Flos masculus. Cilix urceolaris, 5-dentatus. Petala 5 lauceolata, hasi lala. Stamina plurinal, 20 circiler, fuudo calicis insertit. Flos hermaphrodilus. Calix; corolla idem. Stannina 5 fertilia? Filamenta. breviu. O ariun conicum; slylus o; stigmata 3. Drupa; nucleus 
oblongin, compressus, filamentosus. Corculum nudum, crassum. Aruscula debilis; folin alterna, impari pinnata; petiolus lignosus. Flores racemosi, axillures, parvi. Fructus edulis, ferr: Manuifere, sed multoties minor, et longé supore inferior, proriter gustn terebintianeo; indè nomen vernaculum. Manguier à grappes. Vou Sorindi. Malgache. $A n$ Mangifera pinnala. L.

\section{R. H A M N I.}

8x. IVISA, Nor. Calix turbinatus, 5 vel 6 -fidus. Petala 5 vel 6 ralici inserta, erecta. Glandula petalis alternantes. Stamilia 5 vel 6 , petalis opposila. Ovarum semi-inferum. Siyli 2-3. Fruclus.... Frutices nol arluscula; folia alterna, simuato-dentata. Flores spicati, madi, vel in alterit specie reconditi in involncris, magnis, coloratis, compressis; fructus maturus pratervisus. Utrague species alit inmumeros coccos intensé coccineos.

82. BARRALDEIA, A P. Calix urceolaris , 5-fidus. Petala 5 miuima, bifica, unguiculala, laciniis calicinis illserta. Slamina to; filamenta basi dilatata, quorum 5 petalis opposila, longiora. Circulus glandulosus extrầ pistillum. Ovarum inlerun vel in fundo calicis inmersum; stylus unicus, staminibus longior. Fructus.... Frntex erectus; rami oppositi, articulati; folin opposita, glaberrima, pellncido-punctata, subdentatr. P'ednnenli ad vestigin foliorum, breves, bifidi, deindé trifuli, demin triflori; flores parvi, glolnlosi; grimmu abunde resinosa. Nonen ducum ab amico Baranlt, qui mulens plantus collegit sim in India, trim in insuli Fruncicr; sed proxi medicince omnino deduss, omnin generosè mihi reliquit.

83. PTELIDIUM, A P. Nov. gen. Tab. IV. Calix urceolaris $\{$-lobus. Pelala 4 , ungue lato ralici inserta. Discus 4 -lobus, cingens stanina et pistilla. Stamina 4 , petalis alterna. Pistill. Ovarium compressum. Stylus o. Fructus Samara Gartn? Nux compressa; ala aucta, subcordiformis, bilocularis, putamine tenaci; loculi s-sperni. Perispermum carnosum, compressum; embryo rectus, viridis, planus; radicula minima; cotyledones Iongitudine seminis. A rbusculu erectu; folis oppositu, levia, firmia; flores parvi; racemi axillares. 


\section{N C E $R$ R T}

84. RICHEIA, A P. Calix mouophyllus, campanulatus, profundè 5 -fidus. Petala 5 basi atteuuata, apice fimbriata, calice breviora et ejus basi inserla. Stamina numerosa, fundo calicis inserta et breviora. Ovarium hemisphericum, fundum calicis occupans, 5 -sulcalus, stylus staminibus longior. Fructus; calix expansus, persistens; capsula baccata, basi attenuata, 3-sulcala, 3 valvis; 3-locularis; loculi di vcl monospermi abortu. Semina apice inserta, dependentia, basi semi-arillata; perispcrnum carnosum; embryo inscrsus; radicula oblonga; colylcdones plana. Frutex erectus; folia opposita, snbpetiolata, leviter dentata. Flores axillares; pedunculus uuiflorns, exiens ex bructeâ urceolari. 16 enditissimo amico D. Riche, vilí longiori dignissimo.

85. MACARISIA, A P. Tab. XIV. Pterospenuem. Calix monophyllus, basi turbinalus , 5 -fidus, laciniis revolutis. petala 5 , calice minora, marcescentia, laciniis calicinis altcrua. Filamenta ro basi coalita. Siylus unicus. Capsula oblouga, olivalormis; loculi 5 abortu monospermi; valra 5 medio septifere. Semina acuta, cultrifornia; entbyo invcrsus; radicula tenuis, oblonga; cotyledones plana. Frntex erecus; folia opposita, subdentata; fores parvi. Multiun refert ad Pentapctem, L. et Pterospermım, Schreb. ; snd differt defectn filamentonzm. sterilium; numero staminum, loculis r-spermis, ec pracipué insertione staminum.

\section{I C L I N E S.}

\section{EUPHORBI R.}

\section{Plurima genera conferenda enm Mauritianis.}

87. HECATEA, A P. Gen. nov. Tab. III. ADHNowiY rum. Flos masculus et femineus, in iisdem paniculis. Flos masrulus. Calix; foliola 5, concava, subinequalia, internè colorala. Corolla o. Discus centralis. Stimina; filamenfun unicum, centrale; anthera fungilormis, disco counivcns; fissura 3 ; loculi 6 cx utroque latere, indè 3 andra. Flos fomineus. Calix et discus id. Pistil. Orarium conicun; stylus o. Stiguata 3. 
Bacca conica. Semina 3 , apice affixà. Arbuscula diffisa; folia ternatin vel opposita, petiolata, levia, subcarnosa; pori glandulosi 2 ad basin, undè pristinnm nomen; fores paniculati, bracteali.

88. Macaranga, A P. Panopia; Nor. Dioícà. Flos masculus. Calix $\{$-playllus. Corolla o. Filamenta 8 , calice longiora. Flos femincus. Calix mininus, urceolaris. Ovarium desineus iu stylo liguliformi; stigma villosum, adnalum. Folliculus peculiaris, sxepè tuberculosus, I-spermus. Nucleus; testa cruslacea; perispermum carnosum ; embryo minimus, superná parte dependens. A rbores nel frutices resiniflna. Folia latn, alcerue, cordara, vel peltata; stipula cadncae; bractea, obsoleté glandulosa. Macuranga nomen mudagascaricum. Panopia, Noron. Spacies manritiana, ligno levissimo, Bois-violon dicta.

89. DIDYMELES, A P. Gen. nor. Tab. I. Caruinera. Diorca. Flos masculus. Calix. Denticuli 2 minimi. Stamina tubercula 2, basi juncla, carnosa (filamenta). Antherce sessiles; loculi 2 oblongi, discreti, exteriores. Flos femineus. Ranii axillares; pedmenli incrassati. Calix. Sqammule 2. Ovar. 2 globosa uno latere sulcata; stylus o. Stigma incrassalum, expansunı, 2-lobum. Drupa indè sulcata, I-sperma. Nucleus crassus, baccatus, superue reticulatus; tesla firma, tenuis. Embryo crassus; perispermum o; lobi crassi ; radicula minima superior. Albor. Folia alterma, sub-petiolata, integra, oblonga. Flores paniculato-racemosi, axillares. Kagua, Inux.

Plurima alia genera diclinia, sed flore masculo tantim noto.

Nomenclatura imperfecta; quantim potui nomina Madagascurica retinnt, sed lingua imperitiá in pancis nsus sum, quamvis meo judicio prestantiora, dim non sunt pronuncutu nanseosa. Alia muluatus sum ab amicis et aliis bo-

- annicis de Flora gallici bene meritis. Sancle servavi pristina Norouluix, dirm milii innotuentut. Cacerca qualiucumque succednuea effinxi. Sed crim milhi sit in animo hace omnin genera vicissim in lucem denno emittere, in opere nostro incolrato cui timlus: Mistoire des Végétaux recueilliṣ sur les Iles Anstrales de l'Afrique, quod notá Gen. Nov. in hoc opusculo indicatur. Tunc accurata recognitioni smbmillantm. cum cx lace partc, bin ex altis et iconibus illustrabmntur. 


\section{DISPOSITIO LINNEANA,}

Sistens hae genera secundim Systema sexuale.

MONANDRIA.

TRIGYNIA.
PENT A N D R I A.

MONOG Y I I A.

Tristicha, A P. 8. Nayades. Lisianthus, I. 30. Gentianne. Bonamia, A P. Convolvuli?

DIA N RIA. - Tanghinia, A P. 3i. Apoc. Voacanga, A P. 32. A pocyn. MONOGYNIA. Pandara, Nor. 33. A pocyn. Alafia, A. P. 34. A pocy".

Noronhia,Stald.24.Jasminea. Stephanotis, A P. 35. A pocyn. Plectaneia, A P. 36. A pocyn. T R I A N D R I A. MONOGYNIA. Siburatia, A P. 38. Monopel. Leucosia, A P. 79. Terebint. Dichapelalum, AP. 7o. Tereb.

Blyxa, Nor. If. Hydrochar. Xyroildes, A P. I2. Junci. Pseudaleia, A P. 5I. Sapota? Calypso, A P. 68. Rhamni?

D I G Y N I A.

Ificrothuareia, AP. 9. Gram. TETR A N D R I A.

M ON OGY IA.

Dilobeia, A P. 2 r. A petal. inc. Potameia, A P. I6. Lanti? Prelidiuın, A P. 82. Rhamni? Halodendrum, A.P.26.Vitices. Dicoryphe, A P. 4I Rhamni.
D I G Y I A. .

Hydrolia, A P. 29. Convolvuli.

T R I G Y N I A.

Maralia, A P. 43. Aralice. Sorindeia, A P.80. Terebint. H E X A N D R I A. MONOGYNIA.

Agatophyllum, Juss. 15. Lauri. Pseudaleioides, A P.52. Sap.? Thelira, A 1'. 72. Tereline. Maburnia, 13. Bromeliar? 
T R I G Y N I $\Lambda$.

Nisa, Nor. 8 r. Rhamni?

Ouvirandra, A P. 3. Nayades.

\section{OCTANDRIA.}

MONOGYNIA.

Biporcia. Malpighie.

\section{DECA N D R I .}

IONOGYNIA.

Baraldeia, A P. 82. Rlinmni? Metrocynia, A P.76. Cassive. Tristelluteia, A P. 47. Malp. Bruguiera, A P. 70. Onngra. Philomeda, Nor. 58. Magnol. Cavinium, A P. 37. Ericre. Gelouium, Giertn.45. Sapindi.

T I I G Y N I .

Physa. 67. Caryophyllece.

DODECA N D R A. MONOGY IA.

Othrys, Nor. 44. Capparides. DIGYNIA.

Physena, Nor. 2o. Apet. inc. I COSA N D R A. MONOGYNIA.

Trilepisium, A P. 74. Rosac. Mauncia, A P. I9. Apef.inc. Richaia, A P.8f. Rluammi?
POLYANDRIA.

MIONOGYNIA.

Ochna, A P. 5q.

D I G Y N I A.

Barbeuia, A P. 18. Apet.inc. PE N T A G Y I A.

Marenteria, A P.60. Anone. Tenidia, A P.57. Magnolie.

$$
\text { D I D Y N A M I A. }
$$

ANGIOSPERMIA.

Chrysomallum, A P.25. Vicic. Starbia, A P. 23. Pediculares. Campulcia, $\Lambda$ T.22. Pedicul. Nortenia, A P. 27. Scrophular.

MI O N A D E P I A. D I A N D R I A.

Dicraia, A P.4. Nayades? TRIA N D R I A.

Intsia, A P. $7^{5}$. Cassict.

PEN TA N DRIA.

Altheria, A P. 64. Tilincca. Brexia, Nor. 60. Polyp. inc. Lestibudesia, A P. I7. $1 \mathrm{mar}$. Alsodeia, A P. 65. Tiole. Paropsia, Nor. 66. Viol.

DE CANDRIA.

Leptolana, A P.5f. Chlenae. 


$$
\text { I. I N } \mathrm{N} A \mathbb{N} \text { A. }
$$

Macarisia, A P. 85. Polyp. inc. Asteropeia, AP.73.Polyp.inc. POI Y AND R I.

Schizolæna, A P. 55. Chlenac. Sarcolærna, A P. 53. Chlenac. Rhodoliena, A P. 55. Chlenac. Ochrocarpos, Nor. 5o. Guttif. Hemistemma, Juss. 6r. Ann.

SEMIPOIYADELPHA. Chrysopia, Nor. Hyperica.

\section{I A D L P H A.}

DECAN D R I A.

Voandzaia, A P. Legum.

POLY A D L P H A. DODECANDRIA.

Myriantheia, A P. Rosac.? Haronga, A P. 49. Hyperic.

S Y N G E N E I A. Ethulia, L. 39. Corymbifer. Aspilia, A P. Corymbifer.

\section{MON ECIA.}

T R I A N D R I A.

Olyra, L. Io. Gramina.
G Y N A N DR I A.

Hecatea, 88. Euphorbiae.

DIO $\mathrm{E}$ CI A.

$$
\text { MONA NDRIA. }
$$

Halophylla, A P 6. Nayades. Diplantera, A P. 7. Nayades. Hydrostachys, A. P. 5. Nayad.

DIA N D R I A.

Didymeles, A P. 88. Dicl. inc. HEXANDRIA.

Spirospermum,A P.63.Menis. Burasaia, AP. 62. Menisperm.

$$
\text { O C T } \triangle \text { N DRIA. }
$$

Macaranga, A P.87. Dicl.inc.

$$
\text { POI Y G A I I A. }
$$

Microthuareia, AP. Gramina. Bambusa, Schreb. Gramina. Gelonium, Grertn. Sapindi. Sorindeia, A P. Terebintac. Voandzeia, $\Lambda$ P. Legrzminosa. 


\section{INDEX ALPHABETICUS.}

Agatophyllum; Juss. 15. Haronga, A P. 49.

Althcria, A P. 64.

Alsodeia, A P. 65.

Aspilia, A P. 40.

Asteropeia, A P. 73.

Bambos, A P. II.

Baralbeia, A P. 8z.

Barbeuia, A P. 18.

Kiporeia, A P. ${ }_{4}^{6}$.

Blyxa, Nor. 14.

Brexia, Nor. 69 .

Bruguiera, A P.70:

Burasahia, A P. 62.

Calypso, A P. 68.

Campuleia, A P. 22.

Cavinium A P. 37.

Chrysomallum, A P. 25.

Chrysopia, A P. 48.

Dichapetalum, A P. 7 S.

Dicreia, A P. 4.

Dicoryphe, A P. 41 .

Didymeles, A P. 88 .

Dilobcia, A P. 21 .

Diplanthera, A P. 7.

Ethulia, L. 39.

Gelonium, Gartn. 45.

Halophila, A P. 6.
Hecatea, A P. 86.

Hemistemma, Juss. 6r:

Hydrolia, A P. 20.

Hydrostachys, A P. 5 .

Intsia, A P. 75.

Lenidia, A P. 57.

Leptolena, A P. 54.

Lestibudesia, A P. 17.

Leucosia, A P. 79.

Lisianthus, L. 30 .

Maburnia, A P. 13.

Macaranga, A P.87.

Macarisia, A P. 86.

Maralia, A P. 43.

Marenieria, A P. 60 .

Mauneia, A P. 19.

Metrocynia, A P. 76 .

Microthuareia, A P. 9 .

Myriantheia, A P.

Nisa, Nor. Sr.

Noronhia, Statd. 27.

Ochna, L. 59.

Ochrocarpos, Nor. 50.

Olyra, L. 10.

Othrys, Nor. 44 .

Ouvirandra, AP. 3.
Paropsia , Nor. 66.

Philomeda, Nor. 58 .

Physa, Nor. 67.

Physena, Nor, 20.

Plictaneia, A P. 36.

Potameia . A P. 16.

Pseudalsia, A P. SI.

Pseudalæoides, 52.

Ptelidium, A P. 82.

Richria , A P. 84.

Rhodoliena, $\Lambda$ P. s6.

Sarcolana, A P. 53.

Schizolena, A P. 55.

Schyphofilix, A P. 2.

Siburatia , A P. ${ }^{8}$.

Surindxia, A P. 80.

Spirospermum, A P. 63,

Starbia , A P. 23.

Stephanotis, A P. 35.

Tanghinia, A P. 31 .

Thelira, A P. 72.

Trilepisium, A P. 74.

Tristellateia, A P. 47.

Tristicha, A P. 8.

Vallifilix, A P. 1.

Voandzeia, A P. 77.

Voacanga, A P. 32.

Xyroides, A P. 12. 


\section{PRODROMUS \\ PHY TOLOGICUS}

$V$ egetabilia exhibens nuperrimè insula Madagascar detecta, secundìm inethodum naturalem Adansonianam in fumilias sive greges redacta, classibusque systematis Linnai quas attinent subdita;

Operâ et studio Domini Francisci NoroNнA, Hispani Medicinæ ac Botanicæ Professoris,

In lucem. proditurum erat anno 1787 , ope Typographice regice Insulce Francire, nisi fatum pramaturum atuthoris obviàm ipisset.

F I L I CES, les rougères. A danson, Famille 5.

NOMINA

\section{Generica. \\ Trivialia. \\ Madagascarica.}

Adianthum, Linnaus. Capillus Veneris, L. Ravi-Ravi.

Oyatifolium, Nor, Andalona.

Fruticosum, N. Famahot-Acanga.

Cicuta folium, N. Marouradin.

Cultrifolium, N. Famango.

Tríchomanes, L. Adianthosdes. Tchango.

Scalata, N. Mandadi llazou.

Acrosticum, L. Pectinatnm, L. S. Langa-Napanga.

Blechnum, L. Indicum. Thrit.

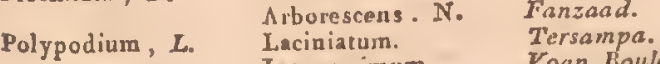

Laciniatum. Torsampa.

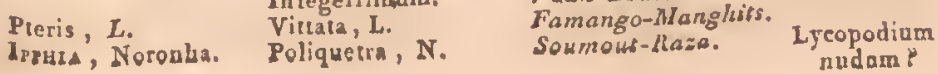




\section{OBSERVATIONS}

\section{SUR LES PLAN TES}

Q QUI CROISSENT

DANS LES ILES DE FRANCE, DE BOURBON ET DE MADAGASCAR,

Adressées à $M I . D E$ Lananck, Miembre de l'Institut, Professeur au AIusée, etc.

Au port Nord-Ouest de l'lle-de-France, ce 8 pluviôse an $\mathrm{IX}$ ( 28 janvier $180 \mathrm{r})$.

Ir y a long-temps, Monsieur, que j'aurois pu effectuer la promesse que je vous avois faite en partant de Paris, en 1791, de vous procurer un supplément pour votre excellent Diclionnaire; mais la guerre rend les communications si difficiles, qu'il n'est pas possible de rien risquer. Je vous ai écrit plusieurs fois, ainsi qu'd MM. Thouin, Richard et Jussieu. J'ai envoyé sur-tout à ce clernier, par la frégate la Cybèle, la notice des Genres nouveaux (ou que je croyois tels) que j'avois trouvés à Madagascar; inais je ne sais si cela lui est parvenu, ainsi que les autres lettres, 
je n'en reçois aucnne réponse. Cependant il cût été bicn essenticl pour moi d'avoir des correspondans qui eussent de temps cu temps réveillé ma parcsse, et qui m'eussent mis an courant du progrès des sciences. Mes vues se dirigent quelquefois vers des points qui me paroissent curicux; nais l'incertitudc oì je suis de me rencontrer avec des compétiteurs réduit unes spéculations cn funée.

C'est ainsi que la structure interme dcs Fougères me parut digne d'attention, il y a cnvirou six ans: je me mis à dessiner la coupe transversale de celles qui me tombèrent sous la main, cela me conduisit à d'autres observations qui me déternimèrent à les dessiuncr cntièrement; cul sorte que, travaillant successivement, je une trouvc avoir un recueil de plus de cent Espèces avec lcs plus grands détails sur les Racincs, les Parties intćricures, Jes Nervures et la Fructification. Cependant, pour cettc dernière, qui étoit la plus importantc, je n'ai pas ćté aussi loin que je l'eusse desirć, aticndu le manque de bonnes Lentilles; et les Plames de ce pays, quoique souvent gigantesques, n'ont pas ces parties plus grosses que cclles d'Europe; mais le peu que j'ai vu n'a porté à adopter le sentinent de Gaertner, savoir : que tout le Inystère de la Générition étoit entièrement reuferué dans les Capsules séminilères.

La difficulté que j’ai ćuc d̀ conserver les Orchidécs "en Ierbier, m'a fait entreprendre un travail semblable illeur égard; je crois aussi avoir observé du nouveau dans leur Organisation et leur Fécondation. Ces 
"olservations m'ont conduit, dans les deux Familles, à l'établissement de Genres qui m'ont paru pliss solides que les anciens. Il m'a fallu leur donner des Nons nouveaux; comme ces nouveaux Genres sont presque le double des anciens, je les ai refondus ensemble et j'ai pris une marche uniforme pour leur en forger à tous. Je sais combien cette corde est difficile à toucher, et que toutc innovation trouve toujours beaucoup de récalcitrans; mais tant que je serai dans ces îles je re trouverai pas de contradicteurs, formant à unoi tout seul la Société littéraire, l'Académic ou l'Institut: de ce côté j’en agis souverainerueut, sans que personne y trouve à redire, quitte d̀ me réformer si jamais je mo retrouve en pays de science.

Puisque nous en sommes sur le chapitre de la Nomenclature, je suis bien aise, avant d'aller plus loin, de vous faire quelques observations ì ce sujet. Vous avicz annoncé, dans votre Flore Française, des rétormes sur cet objet, mais que vous n'osiez tenter. Vous avez en un beau champ dans votre Encyclopedie pour exécuter ce projet; mais il paroît que vous avez été gêné par les idćes des Entrepreneurs. Une des choses que j'aurois le plus desirées, eût été que le Nom que vous cussicz adopté eât été le même, à la terminaison près en latir et en français. Ainsi, par excmple, vous eussiez dit avec Tournefort Abutilon en latin, an lieu de Sida; peutêtre ce dernier nom doit-il être conservé pour les Malvinda de Dillen. Vous avez souvent pris en français les noms de Runphe et de Rlıćede, cll quoi yous 
avez $\mathrm{cu}$, suivant moi, très-grande raison. Mais je me bats peut-être contre un monlin ì veut; car à l'article Nomenclature vous aurez sûrement developpé votre véritable Systême et les raisons qui vous ont obligé quelquefois de vous en écarter. J'ai apperçu dans une notice d'un journal, que M. Duchesne avoit proposé de nonvelles vues sur cette partie de la Science; mais l'article u'étoit pas assez étendı pour me faire juger de son travail. J'ai vu dans le nnêne; la mention d'un Mémoire de M. Desfontaines, sur l'Organisation intérieure des Plantes Monoeotylédones. L'exainen des Fougères m'avoit conduit à celui de l'intéricur des Palniers et des autres Arbres Monocotylédones, ce qui in'avoit fait voir beaucoup de différences sous ce rapport entr'cux et les Dycotylédones. Je ne donte pas que tout cela ne soit mieux développé dans l'ouvrage de M. Desfontaines, à moins que le plus do facilité que j'ai eu de voir ces beaux Arbres, ne m’ait procuré quelques particularités qui lui sont échappées.

Ne sachant encore le temps où je trouverai la facilité de faire mon retour en Europe, je vous envoie une notice des remarques que ruon Autopsie m'a mis à même de faire sur les trois prémiers volumes de votre 1)ictionnaire; ce sont les sculs qui me soient tombés ici entre les mains, à non grand regret; le zèle que vous aunoucez partout pour la vérité m'est un sûr garant que vous ne les regarderez pas comme dictés par la critique; elle seroit déplacée de suoi vis-à-vis de vous, puispue je vous regarderai toujours comme mon maître, ayant puisé dans votre 


\section{des Iles australes d'Afrique.}

Flore Française les principes de la Botanique; mais vous savez par expérience quelle différence il y a entre voir les Plantes dans un Ilerbier et dans des Serres, ou bien dans leur Pays natal. Je ne crois pas que rien ne soit plus capable de fiaire taire des progrès dans celte Science, que de se trouver tout d'un coup transporté dans un Pays dunt les productions snient si différentes de celles qu'on a vues jusqu'alors. Ce n'est pas tant par leur multiplicité que par leur singularilé qu'elles excitent votre attention. Depuis huit ans que je suis parti d'Europe, j'ai rassemblé à peine deux mille Plantes; anssi, comme vons le remarquez à l'article Jardin, j'en aurois vu davantage ell restant en Europe. Je viens de passer trois aus et demi à Bourbon, j’ai parconru cette île dins plusicurs sens, je n'y ai recucilli que deux cents Plantes nouvelles pour moi; et quoique cette île soit près de quatre fois plus ćlevéc que celle de France, je n'y ai pas trouvé plus de Végétanx établis naturellement. Ces deux îles ont un fonds commun de six cents Plantes environ, ct chacune d'elles en a à-pcu-près deux cents de particulières; mais il faut remarquer que presque toutes celles quisont $\mathfrak{f}$ articulières ì Bourbon paroissent nouvelles, au licu que celles d'ici sont pour la plupart des Plantes maritimes, qui se retrouvent sur presque loutes les plages situées entre les tropịues, tels que les Rizophora, le Suriana, elc. Cependint il se trouve dans ce nowbre de très-grauds Arbres qui paroissent particuliers à cette île, comme les Coloplianes et les Mapous. 
Voilà un apperçu de ce que j'ai trouvé dans ces deux îles, soit indigene, soit exotique :

$$
\begin{aligned}
& \text { Plantes cultivées............ } 250 \\
& \text { naturalisées............ } 150 \\
& \text { communes à d'autres pays.... } 350 \\
& \text { particulières........... } 500 \\
& 1,250
\end{aligned}
$$

Sur hunit cents que j'ai trouvécs à Madagnscar, cinq cents m'ont paru nouvelles. Jans quinze jours que j'ai passć an Cap, j'en ai ramassé six cents; et qucique je ne ule sois pas écarté de la ville à plus de denx licues, il y en a parmi qui ne une paroissent pas encore décrites. Enfin, la petite île de Tristan d'Acugna, où j'ai abordé en venant ici, m'a donné une celltaine ro Plantes, nais dont plus de la moitié sont des Mousses on Lichens qui pour la plupart se retrouvent en Europe. Non content de ces récoltes, j’ai voulu tenter d'en faire une autre. Il y a deux aus environ, que l'idée de l'existence de l'île de SaintJean de Lisboa s'est renouvelée; des liabitans des deux îles ont fait, ì-peu-près en même-temps, un armement pour sa recherche. J'ai offert d'être de celui qui se faisoit à Bourbon; je ıne suis trouvé pendant soixante-douzc jours balotté sur un mauvais petit bîtiuxent, mal gréé et mal approvisionné, sans voir aucune apparence de terre; c'est une triste position pour un Naturaliste, passe encore si l'Ictliyologie m'eût lédommagé, quoique faute de livres je ne une sois pas livré ì cette partie, noul plus qu'aux autres parties d'Histoire naturelle. 


\section{des Iles australes d'Afrique.}

J'ai été encore sur le point de retourner à Madagascar : c'eût été le fort Dauphin que j'aurois visité; mais le Lâliment qui devoit m'y conduire a été ailleurs; de plus, le défaut de moyens m'auroit cmpêclıc de rendre ce voyage aussi utile qu'il pouvoit l'être. Lc jeune. Chapeliery est rẹtourné depuis plus d'unc année : il y a long-temps qu'il n'a donné de ses nouvelics; je craius qu'il ue finisse par succomber à l'intempéric du climat. Il ćtoit parti avec des moyens capables de le fiaire subsister assez long-temps, mais il paroît que la rapacité des Chefśs les a épuisés plus tôt qu'il ne comptoit, en sorte qu'il est maintenant fort gêné.

Il n'y a pas d'apparence que j'entreprenne maintenant d'autre voyage que celui d'Europe; mais je voudrois n'avoir à faire qu'avec les Élémens, et ne pas risquer de voir périr en un instant, par ia suite de la guerre, un travail de huit ans.

A yant appris que la Societé d'Histoire naturelle qui m'avoit fait l'honneur de me compter parmi ses memlses, avoit repris ses travaux sons le nom de Sociétć Plilomathique, j’avois vonlu lui faire pusser un Mémoire pour lui rappeler mon existence : incertain d'abord sur l'objet, je m'étois arrêté ì lui préscntor un tableau caractéristique des scize espèces de Pandanus que j'ai olsservées dans ces îles; mais je n'ai pas truivé sous la main quclques matériaux qui me seroient nécessaires pour le terminer, en sorte que je crains qu'il ne soit pas prêt pour le départ des deux bâtimens, l'Egyptiennc ot la Confiance; vetrillcz être

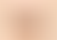


mon interprète auprès d'elle et lui témoigner l'envie que j'ai de concourir avecelle aux progrès dessciences et surtout de la Botanique; et si quelque chose dans la notice que je vous envoie peut mériter son attention, je vous prie de lui en faire part. Si vous avez lo teınps de me faire une réponse, adressez-la-moi par le Ministère de la Marine. Adicu, Monsieur, excubez mon griffonage et soyez persuadé des sentimens avec lesquels j'ai l'honneur d'être,

\section{AUBEH DU PETIT-THOUARS.}

Nota. Le mot ici, dans la Lettre, désigne l'Ile-de-Trance, parce que c'est là qu'elle a été écrite; mais dans les Observations. c'est Bourbon, par une raison semblable. 


\section{OBSERVATIONS}

Sur les trois premiers volumes du Dictionnaire de Botanique de $M$. DE Lamanck;

Failes à Bourbon, en 1799 , sur l' examen des Plantes qui croissent aux Iles-de-France, de Bourbon ẹt de Madagascar.

Arricotifr. On appelle daus ces îles Abricolier de Chine. un Prunier dout les Fruits sont remarquables par la couleur rouge de leur chair. Ils sout d'un goût très-médiocre.

* Il paroít que c'est l'espèce cultivée en Europe sous le nom d'Abricol du Pape.

Anutilon; Sida. L.

A juger par les espèces qui se trouvent dans ces îles, les Sidas me paroissent bien distincls des Abutilons.

J'ai :rouvé une dixaine des premicrs et trois des autres, dont il y en a une qui ne me paroît pas décrite; elle forme un Arbuste d'une douzaine de pieds de haut; ses Feuilles sont entières, cordiformes, très-blanches. N'est-ce pas le Sida Manriziana?

Acacie; Mimosa. L.

Dans ces deux îles il y a plus d'espèces cultivées que de naqurelles; il n'err est pas de même it Madaguscar, qui m’en a offert plusieurs très-curienses ; j'ai reconnu, entr'autres, celle arborescente figurće sous le nom de Mimosa Sassa dans le voyage de Bruce. J'ai recuélli sur son Ecorce une Gomme fort blanche, mais qui ne m'a pas paru différer de celled'A rabie. 
Acacie Fleterophyle, $11^{\circ} \cdot 28$.

Le tronc de cet Arbre curienx acquierl souvent une grosseur de trois à quatre pieds de diamètre, mais il n'est jamais d'une belle venue.

Les Feuilles des jeunes Plantes ressemblent à celles du plus grand nombre de leurs congénères, c'est-ì-dire qu’elles son l bipiunées; les folioles sont pelites, nombrenses; le pétiole coinmuu est membraneux au-dessous de la naissance despremięrs comples, comprimé, élargi vers son exlrémilé superieure, el strié. A mesure que la Plantule prend de l'accroissement les folioles diminuent en nombre. Parvenu d̀ uno certaine élération, elles disparoissent entièrenent ; il ne reste plus que le pétiole qui forme les Feuilles que vons avez décrites. Fn sorte que le nom d'Aphylla lui conviendroil mienx que celui d'Ifeterophylla.

Les Légumes sont planes, longs de trois a quatre pouces, larges de six lignes; les semences sunt oblongues, lisses et noires, altachées par un cordon replié, aussi long qu'elles. Les Créoles l'appelleul plus souvent Mapou que Tamarin des Ilamt.s. Il̉s donnent.plutôl ce dernier nom à une jolte Espèce de Sophora qui occupe des sommełs encore plus élevés.

* Plusieurs espèces apportées de la Nouvelle-FIollande pré. sentent la méme singulariqé dans leurs Feuilles.

\section{Aconas; Homalinm.}

J'en ai trouvé deux espèces à Madagascar, mais je ne les avois pas recomuues; en sorle que j’en arois formé un Geure nouvean sous le nom de Myriantheia, Gen. nov., n. 7I. Je l'avois liré de la mullitude de Fleurs dont ces Arlores se couvrent, cequi lesrend intéressans. Je n'ai jamais rencontré leurs Fruils mûrs.

Acnostique; derostichum. L.

Ce genre eutrant daus la réforme que j’ai entreprise sur l'ensemble des Foucitres, je me contenterai de laire des remarques sur quelques espèces.

Acrostique digite, $\mathrm{n}^{\circ} .8$.

Je ne crois pas que vous ayez raison d'y réunir comne 


\section{des Iles australes d'Afrique.}

variété l'A crostique anstrale. Ce dernier est assez commun daus ces deux îles sur les rochers arides; mais il y a en a deux variétés ou plutôt deux espèces roisines; l'une, avee des digitations courtes ćpanouies en érentail; dans l'autre, elles sont alongées, ranassées, imitant un Grannen; très-aiguës. Au lieu que j'ai cru reconnoitre l'Acrostichnim digiutum figuré dans les Amocritares de Linuée, dans une espece qui croit ì Midagascar dans les marais, cl qui m’it paru avoir beaucoup de rapporl arec l'Acrosticlum pectinutum, ñ.9), que j'ai recucilli au Cap, el l'Acrostichnn dichotomun, $11^{\circ} .10$, qui croit dans ees trois îlés.

* C'est maintenaul le genre Sehizera. Les deux Acrosichanm australe sont devenus l'Asplenium arstrale et l'Asplenium radiutum. Je crois plutôt quón doil les rapporter aux Pleris.

Acrostique prolifíre, $\mathrm{n}^{\circ} .32 ;$ - 1 crostichum viviparum. L. supp.

Une suile de plusieurs Individus pris dans différens endroils m’a prouvé que c'éloit une véritable Doradille, les Folioles devenant tellement étroiles qu'clles ne permellent pas ilux Fructifications de présenter leurs caractères; mais j'ai Irouvé quelquefois sur les Plantules provenans des Folioles, des Feuilles ptus larges qui ćloient dejit fructiferes; alors la Fructification formoit deur ou trois sillons menus, recouverts commedans les autres Aspleninm par une membrane mince. J'ai tronvé d'autres Indivitus à Neuilles un peu plus larges, et par gradal tous je suis venu à des Doradilles très-marquées, dont il seroil difficile de reconmoitre l'identité d'Espèces, sans les intermédiaires.

* On a rapporté cette Plante au nouveau gente Cocnopteris. Adintue; Adlimhlium, L.

L' Adiunctie rumpant, $11^{\circ} \cdot 4$, ne peut étre rapporté à ce Genre, dout il s'écurte par le Port et le Feuillage.

* Smilh a rapporté conte Plante au Davallia, mais elle n’a pas le caraclère de ce Geure.

Le caractère qui m’a semblé le phus tranchant pour les 
Adiantes, c'est que leturs Capsules séminiferes sont altachées sur une Ecaille qui est rabattue sous la Feuille.

AgYnfil ; I. Agynei. I.

J'ai rapporté à ce geure une Plante maritime commıne d̀ l'He-de-France, qui ma paru en avoir les caraclères; mais elle a bien déeidémeut Irois Slyles bifides, ils som appliqués contre le sommel de l'Ovinire qui esi concave, el finissent par s'oblitérer dans la maturalion, en sorle que vus dans cet élat ils ont pu paroitre muls et faire supposer la singularité qui a prozuré le nom de ce Genre. D'unaulre côlé, je ne serois pas surpris que ce ne fül le Puyclantuus, Bacciformis, I. 5; mais une phrase, quoique linnéenue, est mu bicn foible secours pour délerminer une Plante.

* Agrneia impubes; Ventenat, Jardin de Cels, pag. 23 et fig. 23.

Aorostrs verticillé. Le Vétivert.

Celte Graminee, cullivée aboudamment dans ces íles a cause de ses Racines odorantes et de ses Feuilles propres aे couvrir les cases des Nuirs, ne peul ètre rapportée à ee Geure. Flle me paroît devoir eu former un particulier entre los $A n$. dropogon et les Sacchanums, ayanl comme eux une Fleur pédonculée mâle on stérile à cồé d'une hermaplurodite; je ne crois pas non plus quela figure citée de Plucknet lui convienne; elle m'a paru appartenir à un Rotbollia que j'ai vu parmi les Plantes sèches rapportées de l'Tude par le docleur Barrault.

Andropogon squariosus. I. supplém.? Andr. muricanm, Relz. obs.

AIr; Allium. I.

Ily a une espece à Fenilles planes, comme celles des Narcisses, à Orubelles portaut des Capsules, doul les Fleurs blanches veinées le pourpre sont fort odorantes; je ne la crois pas décrite. Elle a été, je pense, apportée du Cap comme Plante d'agrément, mais elle s'empare du terrein où elle croît, de façon à ne pouvoir être extirpée, ce qui la fait compter sous 
le nom d'Herbe is Oignon, au rang des manvaise licrbes. La Semence m’a préscutć un phénomène qui me paroît curieux; j'ai vu pousser de la mème deux et trois Limbryons distincts. On a observé quelque chose de semblable clans lcs Orangers. J'ai vu aussi la méme chose dans le Jannrosadier, votre Jumbosier à fenilles longues, mais avec des circonstances particulières.

Voy. Nouv, Bull. Soc. Phil. $n^{\circ}, 15$.

* Allium frugruns. Vent. Hort. Cels. pag. 28.

Arrene; Vaccinium. L. Cavinium, Gen. nos. nº ; 37.

J'ai Irouvé à Madagascar un Arbuste qui a les principaux caractères de ce genre, mais dont le port cst different.

Alistfr, Cratagus. L.

Un bel Arbre fruilier rapporté de Chine sous le nom de Bibas ou Loukouct, me paroît devoir apparicuir ì ce genrc, ccpendant je ne scrois pas surpris que ce ne fût le Mespilus Japonica de Thunberg.

${ }^{*}$ C'est elfectivement lui.

\section{Aloes.}

Outre l'espc̀ce à bords ronges, $\mathrm{n}^{\circ}$. $\mathrm{I}$, il $\mathrm{y}$ en a une antre à l'rle- de-France qui n'est pas décrite.

\section{Amaranthes.}

J'ai quelques espèces encore indéterminées. On mange les Feuilles du plus grand nombre sous le nom de BredesMalabares.

A war y Llis wivipare, $n^{\circ}$. I4; Bulbine. Gertn.

Elle cst naturaliséc dans ces îles lc long des ruisseaux. Amane; Amunaria. L.

Ammane is feurs pourpres, $\mathrm{n}^{\circ} .2$.

Ammane verticillee, "n". 3.

Ces deux Plantes sont naturalisées à l'Ile-de-France. J'en ai une autre de Madagascar.

* Ellc cst figuréc par Roxburg.

Ampou fouctil.

C'est ùne espèce de Celtis qu'on nomme Andarèse dans 
ces îles; ontappelle Affonche les Figuiers. Quant à l'Hibis. rus Tiliaceus, il s'appelle Var à Madagascar, el Bar chez les Malais. Il conscive le premier nom dans ces îles.

\section{Ancistre.}

Il y en a une espèce ou variété à Tristan d'Acugra , remarquable par ses Tiges sarneuteuses el sis Feuilles qui ont presque le soyeux de l'Anserine ou du Sorbier.

*Voy. Flore de 'Tristun d'Acugna, ñ". 97 .

ANASSER.

Vous avez sûrement eu connoissance, depuis, du genre anquel M. de Jussieu a donné ce nom; jon ai trois Espèces remarquables.

ANDARESE; Premna. L.

On donnue ce nom, comme je l'ai déjà dit, ì nne Espèce de Celtis; cependant il paroíl que réellenent les Malgaclues nomment ainsi l'espèce de Premna qui croít dans ces trois iles; mais ici on l'appelle Bois de Bouc.

ANDROMEDE; Andromede. T.

Androméde in Feuilles de Sanle, $\mathrm{n}^{\circ}$. I 6 .

Celle Fispecre ne se trouve qu’à l'lle-de. France; il y en a une autre qui forme un petit Arbre d'une forme agréable; l'Ecorce de son trouc est gersee ì petites bosselures. C'est le premier Végélal liznenc qui paroisse sur la Lave refroidie. Aidromide \& Fuilles de Buis, $1^{\circ} .17$.

Il y a deux Lspèces voisines habitan les mêmes lieux; la preınière est très-petile, couchée; l'autre est droite: ses Fleurs sout plus grandes, glubulcuses, et ses Pédoncules pubescens.

ANG1R E ; Epidendrum. L.

T'aurois beaucoup de clioses à dire sur ce beau Genre ou plntôt cétle série de Plautes; mais comme clle m’a fourui un travail particulier, je me cuntentcrai de présenter ici quelques olservations.

Je juge d'après une Plante de ce pays, que la Vanille n'a pas récllemenu une Silique univalve, mais qu'il u'y a qu'un de 


\section{des Iles australes d'Afrique.}

scs côlés qui s'ouvre. Celle don je veux parler a une Capsulo longue de quitre à cinc pouces sur deux lignes au plus de diamelre. $\boldsymbol{A}$ sa maturité, elle s'ouvre par un seul côté snivant sa lunguenr; mais malgré cela on aperçoit les trois arêtes du châssis commun à toules lcs espèces, et les truis valves.

Je ne crois pas non plus qu'ellc ait de véritables Vrilles; plusieurs cspèces poussent à l'opposé ou un peuau-dessus des Feuilles des filamens horizontaux, qui sont des liacines qui s'altacheut sur les $A$ rbres qu'elles rencontrent.

Je n’ai reconnu jusquà préscnt parmi vos espicecs que les suivantes:

Le n". 26. Angrec écrit. Commun à Madagascar et ici; Graphorchis, Gen. o. Mais il y a quelques espèces voisines.

$\mathrm{N}^{\circ}$. 38. Angrec en gazon. Deux espèccs congénères; Sticliorchis, Gron.r.

$\mathrm{N}^{\circ}$. 46. Angrec distiqne. Iridorchis, Gen. t.

$\mathrm{N}^{\circ}$. 48. Angrec sterrile. J'eu ai rassemblé douzc espèces distincles, loutes fleurissanı à lcur saison, el qui constituent ụn genre très-distinct, Phyllorchis. Gen. u.

Anguine; Trichosanthes. L.

Anguines à Fruit long; Trichosanthes anguina. L.

Cetle Plante csi cultivéc pour l'usage de la cuisine, sous le nom matais de Patoles. Micheli, qui a formé le premier ce genre, a cilé ce nom comme chinois.

-Ansertae; Chenopodium.

J'ai trouvé sur l'île de Tristan d'Acugna unc espècc intéressantc qui a des rapports avec les $10^{\circ \cdot}, 0-10-I I-I 2$, ayant une odleur suatre. Je l'ai caractérisée ainsi :

Chenopodium tomentosum; Foliis deitoideis, sinnatis; Floribus in rucemis foliaceis, axillaribus, simplicitus. Fl. Ac. $1^{\circ} .86$.

Axthocène; Anthoceros. L.

Anthocere ponctue, $\mathrm{n}^{\circ}$. I.

Anthocère lisse, $\mathrm{n}^{\circ} .2$. 
Ces deux Plantes se trouvent dans ces iles, en outre uno nouvelle qui croil stir les Arbres.

Antonsmir; Antidesma. I.

Une espèce commune à ces deux íles se rapporte à votre $n^{\circ}$. 2. J'cn ai Irouvé une autre à Madagascar, dont les Feuilles sont pubescentes; l'une el l'autre n'a que quatre Elamines dans ses Fleurs mâles.

Apocins.

J'ai plusieurs Genres el Espèees eurieuses de celte Famille. Aracuine; Arachis. L. Fistache de ees îles.

Dans quel temps que j’aie observé eetle Plante, je n’ai jamais pudécouvrir aux Pédoncules fructifères de vestige de Floraison; leur extrémité est pointue et lisse: elle s'enfouee daus la terre; elle se gonlle iusensiblement el linil par devenir un Légume, sans aueune narque de Fécondalion.

AnEc; Areca. I.

Quoique jo n'aie pas vu un grand nombre de Palmiers, eeux que $j$ ai rencontrés ont sulfi ponr ne domner des connoissances plus précises sur celle holle Fanille, que celles que l'on a géuéralement: je tácherai de les développer daus un travail particulier. Je me contenterai de remarquer ici que je crois que les Palmistes doivent êlre distingnés comme Genre, des Arees. C'est ce qu'a fuil Grortner, sous le nom d' Futerpe.

Angan; Sideroxylon. L.

Plusieurs Arbres curieux se rapportent ì ee genre. On les ronnoit ici sous le $110 \mathrm{~m}$ de Bois de Fer, Bois de Pomme de Falle, Jaeot. La forme de leurs Fruits présente de grandes singulariı́s.

* Ces Arbres doivent se distribuer dans les Genres Caliaria de Gxrtner le fils, et Bumelia de Swarts. V. Gartuer, f., pag. i 16 et 126 , Tab. 200 et 202, f. 3 .

Aspatat.

Aspulat sogenx.

Je n’ui pas encore reneontré celle Plante, à moins que ee n'en soit une que $j$ 'ai trouvée une seule fois, mais sans frueti- 


\section{des Iles australes d'A frique:}

fication. Dans quinze jours de temps j'en ai ramassé seize espèces au Cap.

Astène; Aster. L.

Astère à tiges nues. $\mathrm{n}^{\circ} .4^{2}$.

Une très-petite Plante que j'ai trouvée sur les sommets de 'Tristan d'Acugna, m'a paru devoir se rapporter à cette Plante; mais je lui ai trouvé les caractères du Calendula.

* Je l'ai décrite et figurée $F l . T r . A c . n^{\circ} \cdot 9^{\text {I. }}$

Plusieurs Arbustes de ces îles ont beaucoup de rapports avec les Astéres. Ils m'ont paru en différer, parce qu'ils appartiennent à la Polygamie nécessaire, leurs Fleurons hermaphrodites élant stériles; ce qui est le cas du plus grand nombre des plantes composées qui sont dans ces ịles. Votre Baccante visqnelusc et la Conyse émoussée m'ont paru devoir se rapporter ici, car elles sont certainement toutes les deux radiées.

Armotse.

Armoise fluette, $\mathrm{n}^{\circ}$. $18 ;$ Grangeria. Juss. Gen.

Cette petite Plante se trouve dans quelques endroits aquatiques; ses Fleurons hermaphrodites sont quadri-tides. J'en ai trouvé une autre espèce à Madagascar, retharquable par ses Fleurs globuleuses, blanches et paniculées.

Armoselle ; Seriphitum. L.

Armoselle passerinö̈de. , "1․ 6. La Brande.

Celte Plante est commune sur les sommets de cette île.

Avicenne; Avicenia. L.

Un Arbre dont $j$ 'ai fait un genre particulier sous le nom d'Halodendrnm, $n^{\circ}$. 26, dans la notice que j'ai ellvoyée à M. Jussieu; m'a paru être l'A vicennia Back trguré dans le voyage de Bruce. Il m'a semblé aussi se rapporter au Mangium Alluun de Ruinpls.

Azol.Le; Azulla filiculoides.

La figure du Muscus squammosus, etc., de Feuillé, m’a fait reconuoître cette plante-là, je l'ai trouvée à Madagascar ; 
mais je n’ai pu lui découvrir de fruclification. Il paroît, suivaulle voyage du lord Macartoey, quelle croit aussi en Chine.

BACCANTE visquense.

J'ai déjà dit, article $A$ ster, que la Plante que je prends pour elle est radiée, el quilil y en a plusicurs autres qui en sont voisines.

Badanier; Terminalia cattapa. L.

Quoique je croie que vos deux espèces $\mathrm{r}-2$ soient dans ces îles, je ne les ai pas encore bien distinguécs.

Je ne sais pas si l'individu que vous décrivez sous le nom de Badamier du Benjoin, n’appartient pas au précédent, le Badamier de Rourbun.

Les individus, daus leur jeunesse, sont si différens des adulies, quil faut les suivre dans leur progression pour les reconnoîtle de la mêne espèce, ensorle que votre descriptiou se rapporte parfuilement aux jeunes de ce pays. Quanı aे Ia production du Benjoiu, voici ce que j’ai observé: Lorsqueles Arbres sont vigonreus, il découle de leur écorce un suc qui se condeuse en une vérilable Gomme; inais lor'squ'ils sont deveuus vieux, on trouve entre le Tronc el l'écorce une vérilable substance résineuse, dont l'odeur a beaucoup de rapport avec

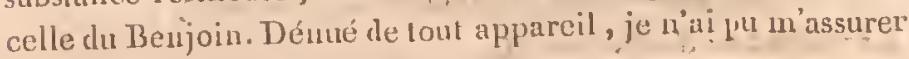
si c'étoit réellement la mème substiace.

Iu forine de cet Arbre est très-belle, quelquefois elle est singulière. J'en ai vu un qui avoit crû au milieu des roches, qui n'avoil pas vingt pieds d'élévation, et dont les Branches horizontales formoient un cercle de plus de soixante-quinze pieds de diamelre.

D'uprès les observations de M. Le Comte, ancien chirurgịen, antuateur distingué de Botanique, le Myroholan officinal quỉl culrive, est une véritable espèce de ce Genre. La disposition de ses Fenilles est un peu différente, mais elles ont uu caractère qui leur esl commun arce loutes les autres : c'est d'avoir deur Glandes à leur base. 


\section{des Iles australes d'Afrique.}

J'en ai trouvé à Madagaşar une espèce curieuse, remarquable par sa petitesse ; elle ne s'élève qu’à trois à quatre pieds ; ses Feuilles ı'ont qu'un pouce et demi dans leur plus grande longueur; mais, du reste, elle a tous les caractères du Genre. Elle croị̂ sur les bords sablonueux de la mer. Les Malgaches la uomment Voa-Fatre.

* M. de Jussicu en a fait un Geure, sous le nom de Fatroca. $B_{A \text { Dule }}$ Badula, Juss.; Ardisia, Sw.; Angiilllara, Gertn.

Vous aurez sûrement fait mention de ce Genre dans volre supplément. J'en ai recueilli dans ces f́les une dóuzaine d'espèces, plus curieuses les unes qque les autres.

Bамвоч, Arundo Bambos, L. Bambrisa, Schireb.

J'ai vil dans une de vos notes au voyage de Thunberg, que vous reconnoissiez ce Genre et son identilé avec le Nasius, Juss.

Cette dernière Plante fait la cinquième espèce que j’aie observée dans ces îles.

Baquors; Pandanus. I., suppl.

Ce Genre singulier m'a offert, dans ces îles, quinze Espèces bien distinctes. Je n'ai pas encore pu les accorder avec les vôtres.

* Voyez le Nouv. Bull. Soc. Philom. , nº. II.

BARBON; Andropogon. L.

Nous avons ici plusieurs de.ces Graminées, entroutres le Chiendent-Citronelle; c'est une espèce très - voisine de l'Andropogons Schoenanthus, et qui doit former avec elle et quelques autres un Genre particulier.

BAsIL1C; Ocymum. L.

J'en ai trouvé deux ou trois nouvelles Espèces à Madagascar :

Basilic à Fenilles charnues. Je spupçonne que vous désignez ainsi une Plante à Feuilles épaisses, cultivée ici sous le . nom de Baume; c'est une véritable.Germanec, roisine de votre Chataire de Madagascar; peut-être faut-il aussi rapporter 
à votre Basilic à Flents "blenâtres une Labiée qui croît sur les montagues de l'fle-de-Franee, elle a l'aspect de la Bugle, et appartieut aussi au geure Germanea. Brgone, horgoniz. Plum. L.

I'Espèce de ce Genre, appelće dans ces iles OseilleMarone, diflère de volre $n^{\circ} .2$, ainsi que des autres, par ses fruits cylindriques, qui n'ont aucun vestige d'ailes. BEN oleifere, Bredes morongues de cesîles.

T3essi; Crju bessi. Rumiph.

LiAlbre que les Malgaches nomment Intsi, m’a paru avoir an moius des rapports avec celui-ci. J'en ai fait un Geure sous le nom d'Inesia; Gen. $7^{5}$.

BIDFxt valu; Agrimonia molucca. Rumph.

On donne ici le nom de Piquant ou Herbe à Sornin, à celle Plante qui infeste les habitations ; on prélend quin M. Sornin l'nyaut semée pour du cerfeuil , elle s'est multipliée au point d'être très - incommude. Elle paroît différer du Biclens pilosa. $\mathrm{L}$.

Dans quelques quartiers le Bidens bipinnata s'est aussi très-nultiplić.

Bident it Flent conique ; Acmella.Les Malgachos l'appellent Angr Malao. L'Espèce commune à ces trois îles est différente d’une aulre assez répandue, quon dit venir de Ceylán. Bignone.

J'ai Irouvé une Espèce de ce Geure à l'Ile-de-France', et plusieurs à Madagascar. Elles sont remarquables par leurs Anhères qui n'ont qu'une seule loge.

Brнal des Antilles. Heliconia-Bihai. L.

Vous rapportez d'après Aublet, qu'on la cullive dans ces îles et qu'ou en couvre les cases des noirs. Je crois que cet Auteur s'est trompé, et qu'il a pris le Ravenala pour celle Plante, car je ne l'ai janais vue ici.

Blacouer. Blackwellis.

Je n'eu ai encore reconnu qu'tue Éspèce dans ces illes, et 
deux à Madagascar. Souvent les dentelures des Fenillessont très-peu marquées.

On l'appelle ici Bois de Bassin des Hauts. C'est un Arbre superbe lorsqu'il est en Fleur.

Bratti ; Sonneratia. L. ; suppl. Aubletia, Gærn.

J'ai trouvé cct $A$ rbre à Madagascar, avec quelque différence sependaul.

Brecune, Blechnum. L.

J'elı ai trouvé une à 'Tristan d'Acugua, deux au Cap, et une ici.

RLETTE; Blitum. L.

De ce non les Porlugais ont formé celui de Bredos; d'où vient celui de liredes, quo on donne dans ces îles à toutes les Feuilles qu'ou nangé comme les Epinaids, et qui sout fort nombreuses; mais il y a la Bréde par. excellence; c'est une variété du Solanum uigrum, que les Malgaches appelleut Anghivi. Ils donuent le nom d'Anga, Augan, à toutes ces Plantes. Les Malais les comprennent aussi sous une seule dénomination, celle de Sajor; cest l'Olus des Latins. (* Voyez l'ar-ticle Bredes, nouseani Dictioninaire des Sciences.naturelles. Bors.

C'est la dénomination banale de tous les Arbres. Fń cela les Créoles ont imité les Malgaches, qui donnent pour' nom général à tous les arbres ceux d'Hazon, Cazon et Cróazon, qui signifient Bois. Les Malais, dont la langue est la mêtne au fond, se servent de celui de Cajondans le mème sens.

Bramir.

Celte petite Plaute esk commune daus les lienr maritimrs de ces trois, iles. Faut-il la laisser subsister cunme Genre, ou la rapporter aux Gratinles, comme vous aveza fait depuis? Artictc Gratiole. C'est le Moniniera de Bernard Jussieu.

(*Voyez ce mot, Dictionnaire des Sciences natrurelles.). Brindones ; Brindonia. N. Oxyearpus. Lour.

Vous avez rẹconnu depuis sun vérilable caractère à l'article Mangostan ; mais je crois qu'il doit former. un Geure séparé de 
ces arbres, ayant des caractères assez tranchés poųr cela.

(*Voyez Dictionnaire des Sciences naturelles.)

Broar:; liromus.

A la plaine des Cafres, il croit deux de ces Plantes qui ont beaucoup de rapport avee celles d'Europe.' * .

BRUชั̀ E; Ericr. I.

Il y a une Espèce commutue à ces trois îles, qui s'élève à trais ou quatre pieds, souveut plus, et qui a des Fleurs peu brillantes. Dans ces deux îles, elle ne croît qu'à une certaine élévation, assez loin du bord de la ner; au lieu qu’à Madagasear elle vient presque sur le rivage. Les Malgaches l'appellent $A$ ngza $V$ idi, d'oà il paroil que les Créoles de ces illes ont fait $A m$. brville, qu'on donne à tous les Arbustes à Feuilles étroites; entrautres à plusieurs Composées. Outre eelle-lì, il y en a deux autres ici, une très-petite, et l'autre assez élevée et effilée. Elles n'ont pas non plus de Fleurs brillantes.

* Wildenow vient d'en faire un genre particulier sous lo nom de Saluxis.

BнY; Bryum. L.

Il y en a une douzaine d'Espèces dont la plupart sont communes à l'Europe.

JRYONE.

Il y en a une Espèce à l'Ile-de-France, qui ne me paroît pas décrite.

BUCHNERE; Buchnera. I.

Deux Espèces à Madagascar, dont une a le port de la Verveine officinale, et l'autre a les Feuilles pinnatifides, semblables aux supérieuress du Cresson des prés; elle est herbacée, ce qui paroît la distinguer de la Buchuera pinnatifida du suppl. Buis; Buxtus.

Il.s'en trouve une Espèce Arboréscente à Madagascar. BULEJE. Budleia. L.

J'en ai trouvé trois Espèces qui se rapprochent de votre Buleje de Madagascar, par leurs belles Feuilles tomenteuses" Je u’ai trouvé celle-ci çu'ici et cultivée. 
Buphtalme.

J'en a une Espèce de Madagascar.

BURMIANE.

Il y a à Madagascar une Plante marécageuse très-commune, qui se rapporte à celle que vous incntionnez à la suite de votre deuxième Espèce.

* J'en ai formé un Genre sous le nons de Maluurnia, elle paroît devoir se rapporter au Genre Tripterella de Michaux.

Butonic. Le bonnet carré. Baring̨onia speciosa. L. tils.

Il croît à l'lle-de-France, dans les anscs du grand port; mais c'est à Mradagascar qu'on le voil daus sa magnificence.

\section{Cabriliet. Erlletia.}

Cabrillet à longs pétioles.

Il nc croît qu'à l' lle-dc-Francc.

Il y au jardin de Pamplemouses un Arbre assez élevé quị sc rapporte à cc Genre.

- Cacalie ; Cacalia. I.

Cacalie is Fenilles de laitron. Cette plante est commune dans les cultures de ccs deux îles.

Il y en a quelques autres espèces, soit à l'Ile-de-France, soit à Madagascar, qui semblent avoir emprunté des Lactucées leurs Feuilles, des Lampsanes et des Laitrous cutr'autres.

\section{Cactrer, Cachus. L.}

La Raquette éloit commune dans ces deux îles, où elle a éió appórtée ; mais depuis qu'on a introduit par la voie de l'Indc la Cochenille Sylvestre, il y a quatre ou cinq ans, elle estbeaucoup diminuée.

Le Cactier parasite, est commun dans cos Irois îles.

Cadeláir ; Achyranthes. L.

Nous avons plusicurs Plantes de ce genre, dont quelquesunes ne sont pas encore déterminées.

Caffriyer ; Coffica. L.

Caffejerde Bourbon; Cafémaron.

Cet Arbuste s'élève à une assez grande hauteur. Ce n'cst 
point, comme vous le penscz, celui qui dome le Café du commerce; c'est l'Espèce arabique qui a été apportíe de Moka. Oulre celle-là on en cultive deux autres, plutôt par curiositó que pour en tirer profit; l'une sous le nom de Café d'Eden ou Aden, elle est plus petite dans iontes ses parties; l'aulre cst remarquable par ses Feuilles purjurescentes. Outre rela il y a des variétés plus ou moins tranchées.

Mais dans ces trois îles il y a une dixaine d'Arbustes quî se rapprochent de ce Genre, quoique s'en éloignant pour le port : l'un est lo Chazalia de Commerson.

Outre cela il y a un Genré qui en est très-voisin, et qui est certainement bien de la Famille des Rubiacées, quoiqu'il ait l'Ovaire décidément supérieur, et qui comprend dix à douze Espèces.

*C'est celui dont vous arez fait, dans volre Genera, le Genro Grertnera. M. Decandole en a fait depuis le sujet d'un mémoire lu à l'Institut.

Caеaвa; Calopliyllum. L.

Au mains deux Espèces nouvelles à Madagascar.

Calac; Carissa. L.

Un petit Arbre qui croit à Bourbon, où il est connu sous le nom de Bois Aıner, appartient à ce Genre. Soll Bois est très. estimé pour les vertus qu'on lui altribue, et la beauté de son grain qui le rend précieux pour les ouvrages du tour; unais il a été tellement recherché qu'il est devenu rare. (Voy. sa fig.)

CALITRIC; Callitriche. L.

Une petite Plantule terrestre, mais ne venant que dans des endroits humides, ma paru avoir les priucipaux carac. tères de ce Genrc; mais ses Graines sont séparées.

Camarine; Empetrum. I.

J'ai trouvé sur Tristan d'Acugua l'Empetrum Nigrnım, ou, une Plante voisinc.

* C'est l'Ein perrum rubrum de Vahl. Fl. Tr. n. 88 . 
Campanule de Bourbon. $\mathrm{N}^{\circ}$. 23.

Cette Plante est généralement plus grande que vous ne la déerivez; ses Feuilles out au moins six pouees de long, et la panicule s’élève jusqu’à deux pieds. Sa Corolle est d'un blano jaunâtre, tachée de pourpre aux déeoupures et au fond; les Etamines n'ont point d'éeailles à leur base, et sa' fruetification m'a présenté d'autres particularités qui pourroient la faire regarder comme un Genre particulier, elle fleurit en janvier et février; elle se trouve plus ou moins abondamment sur les sommets.

J'ai trouvé dans un endroit retiré de l'île, ep Fruit seulement, un Arbuste à Feuilles semblables à celles des Pruniers abondamment laileux, et qui m'a partî se rapporter aux Campanulés. J'en ai trouvé une petite Espèee à Feuilles linéaires à Madagasear.

Canamere; Saccharum.

Canamele officinale. Sachanom officinale.

Comme dăns les Barbons et autres Genres voisins, j’ai vu à eôté des Fleurs hierınaplırodites, une autre pédiculée, mais slérile.

Il paroit que dans celte Plante les Graines avortent eons. tamment, ce qui a lieu dans plusieurs autres cultivées depuis long-temps entre les Tropiques, les Bananiers entr’autres.

J'ai cru reconnôttre dans un Gramen eornmun, à Madagascar, votre Canamele en épi; mais je lui ai vu constamment deux étamines. J'ai trouvé le même earactère sur des individus sees, rapportés de Java par le Riche.

Canang. Uvaria. L.

Je crois que quelques-unes des plantes que vous rapportez au Genre Corossol, appartieunent plutôt ì celui-ci.

Cancue; Airc. L.

Quelques plantes de ees îles appartienneut à ce Genre; jo ne eonnois aucun moyen d'en distinguer plısieurs $P_{\text {atnicum }}$ paniculés et digités, qui out comme eux des Bales biflores. 
Carrier ; Capparis. L.

Caprier panduriforme.

Cet Arbuste, que je n'ai vu que cultivé an jardin des Pamplemouses, m'a offert des caractères très-différens du Capricr, ce qui m'a engagé à en faire un Geure sous le nom de Calyptranthus, dont voici les caractères:

Calice d'une seulc pièce, en cone ou toupie s'ouvrant en travers conme un opercule.

Corolle nulle;

Etamines nombreuses, disposées circulairement sans aucune glande interposée;

Pistil : Ovaire stipité, style nul;

Fruit..... inconnu.

Il me semble que la forme singulière dı Calice, le manquo de Corolle et la disposition des Etamines le distinguent fortement des Capricrs, quoiqu'ils doivent rester ì cóté de lui. Les Feuilles présentent muc singulárité que vous n'avcz pas remarquée. Il y en á de siniples mêlécs arec d'autres qui sont trifoliées, mais dont les folioles sont semblables aux siuples. Comme ses Fenilles se disloquent facilement, il se pourroit qu'eu horbicr vous ne les cussiez vues dans cet élat.

* C'est le genrc Tilacium, de la Flore de Cochinchine, de Ioureiro.

J'ai iuséré dans ma notice des Génres de Madagascar le caractère d'un autre également voisin des Capriers, qui a aussi les Feuilles trifuliées. Othris. Gon. $\mathrm{N}^{\circ}$. 44 .

Carmantine; Justicia. L.

J'ai trouvé de belles Espèces dẻ ce Gente ì Madagascar, qui mont paru nouvelles, quelques-unes aussi daus ces îles.

Les taches des Feuilles du Jnst. picta sont dans les cas de toutes les autres Panachures, n'étant qu'accidentelles. Il y a des individus qui n'en ont aucune trace. Il en est de mếme du Croton variegalun. L.

Cassr; Cassia. J.

Quoique le Canelicier se couvre ici de Flcurs d'une façon 
agréable, ce qui le fait ressembler au Cytisus Lalurnum, il produit très-rarement des fruits, eneoresont-ils très-petits. Il en est de même de la Casse de Sian. La Cassé occidentale est regardée ici comme une panacée merveilleuse, sous le nom de Souveraine. J'ai trouvé abondaument votre $11^{\circ} .48$ ì Madagascar.

Cassytur filiforme.

Je l'ai trouvéc au Cap el à Y'Ile-de-France.

Ceanothe d'Asie.

A l'Ile-de-Franee et à celte de Madagascar.

Celastre.

Celastre ondulé. $\mathrm{N}^{\circ} .8$.

Vous décrivez sous ce nom un joli Arhusle de ces îles, qu'on appelle vulgairement Bois de joli coenr; mais it m'a paru avoir des cáractc̀res particuliers qui s'écartent non seulement de ce Geure, mais même de la Famille des Nerpruns. II paroît que M. Adanson a été dans la mème erreur, car il en fait mention dans la description de la Famille des Nerpruns, sous le nom de Bois de Merle; ce nom apparticnt ì un autre Genre que M. de Jussieu a placé convenablement dans les Sapindi. Quoique les Merles soient friands des graines de l'Arbuste dont il est question, on ne lui donne jamais ce nom. Voici son vrai caractère:

Calice très-pelit, à cinq dents caduques;

Corollc : cinq Pétalestancéolés, insérés au Réceptacle;

Etamine : cinq parcillement insérés à la base de l'Ovaire ;

Pistil légèrement pédonculé, terminé en Style court;

Fruit : Capsule baccilorme pédonculée à deux valves, portant sur le milieu une arête qui forme deux demi-cloisons : elle renferme quatre Graines attachées ạu fond; dans une seeonde espèce, il s'en trouve quatre de plus, qui forment un second plan, étant attachées vers le milieu des deıni-cloisons.

Graines arrillées, contiguës; Périsperme corné; Ennbryon très-petit à la base. 
Vous voyez qu'un pareil Genre ne peut appartenir aux Nerpruns, et qu'il est de la classe des Hypogynes polypétales de M. de Jussieu; mais il u'est pas facile de lui assigner une place précise. Je ne sais pas s'il n'auroit pas quelques rapports avec les Rucacies.

* C'est le geure Senacia de Commerson.

Céraiste; Cerastium. I.

A la plaine des Cafres, autour du piton de Villers, on trouve une Plante de ce Genre; elle a tant de rapport avec les. Corastium tomentosım et arvense d'Europe, que je n'ose décider s'il y est indigène.

Charagne; Chatr. L.

La Charagne vulgaire se trouve dans quelques marais, et d'autres Especes non déterminées.

Chardon, c'est le nom sous lequel on connoît l'Argemone.

Chataire de Madagascar. L'Houmime.

C'est une véritable Espèce de Germanée.

CHÊNE des Monluques.

Une rote manuscrite de Commerson, écrite sur un exemplaire de Rumphe qui lui a appartenu, annonce qu'il regardoit avec beaucoup de fondement cet Arbre comme un Lauvier, semblable à quelques-uns de ces îles, dout le fruit, a la forme d'un Gland.

Chigomier, Combremu. L.

Chigomier de Madagascar.

Le nombre des parties de sa fiuclificalion, et plus que tout. cela la forme et la consistance de la Graine de ce bel arbuste, le rendent très-différent de l'espèce dout Gærtner a décrit et fjguré le fruit, ce qui me paroît un motif suffisant pour faire rétablir le Genre Poivrea de Commerson, à l'honneur de M. Poivre.

Cursté; Figocaque. Coin de Chine.

Vous avez bien jugé que c'étoil un vrai Plaqueminier ou. Diospyros de Linné. Son fruit est très-délicat. 
Crors, schaenzs. L.

Le Choi marisque est commun dans ces îles; je ne lui ai jamais trouvé que deux étamines: il paroît que la même chose a lieu en Europe, cas Scheuzer le déeril et lo figure ainsi. Voyez Agroscograplia, page 376 .

Il y a plusieurs autres espèces très-remarquables dans ces îles.

\section{Crrod; Brassicr.}

Il y a une Espèce cultivée dans ces îles sous le nom de Bredes-Chou de Chine, elle me paroit différente du Chou de Chine. $N^{0} .3$.

Cicca : le Cherimbelier.

Je ne sais pas trop laquelle de vos deux Espèces est le Cherimbelier cultivé ici. Je lui trouve des caractères des deux.

Crocoque, Ciococea. L.

J'ai trouvé un bel Arbuste de ce Genre à Madagascar.

Clavaire, Clavaría. T.

J’ai quelques Espèces curieuses de ce Genre.

Clifforte, Clifforicz.

J'ai quelques Espdeces de ce Genre que j’ai ramassées au Cap, elles ne me paroisient appartenir à aucune des vôtres.

Chitone; Clitoril. I. Ternater. T.

Clitore de Ternaie.

Flle se trouve dans les deux îles; mais je n'ai jamais rencontré à l'Ile-de-France que la variété à Fleurs blanches, c'est le contraire icı; M. le Comte employe avec succès la fárine de ses semences comme un purătitif minoratif, d'après l'indicution de Burman dans le Thesaurns zeylanicus.

Je n'ai vu qu'à l'Ile.de-France votre joli Clitore hetoroplyyllo

-. $n^{0}: 2$. Il y ell a une à Madagascar qui s'élèvo jusqu"au sommet des plus grainds arbres; ses feuilles sont composćes de onze folioles aigués. 'Il y en a une autre à Feuille trifoliće, rampante, dont les Légumes sont à quatre angles, comine ceux 
du Lotus tetragonolubus et à Fleur jaune. Ce qui me fait présumer qu'elle doit former un Genre particulier.

Commerine; Commelina.

Madagascar m'a offert une Espèce nouvelle, curieuse et d'un port très-différent des autres.

* Elle a été figurée par Roxburgh , plantes de Coromandel.

Goncombre ia angles tranclians; la Papangaie.

Celle Plante me paroit devoir se réunir au Momordica luffa pour former un genre particulier. C'est le Genre luffu de Tournetorl.

Ces deux I'lantes son! très-usitées dans la cuisine du pays.

Chondrile, Chondrilla. L.

Il y a une Espèce de ce Genre à l'Tle-de-France.

Conferve; Conferva. L.

Il y a quelques-unes des Espèces d'Europe el d'autres particulières.

Conise; Conysa. L.

Malgré le grand nombre do belles Espèces que vous avez rapportées à ce Geure d’après Comuerson, vous ne l'avez pas épuisé encore. Il m’en est tombé plusieurs sous la main dont vous ne paroissez pas avoir eu connuissance; d'un antre côté, quelques-unes des vótres me manquent: Je crois que quelques considérations pourront les faire partager avantageusement en plusieurs Geures.

Connare; Connaries. L.

Connare à cinq styles.

J’ai Irouvé à Madagascar plusieurs Arbustes, el un autre à l'Ile-de-France, remarquables par leurs Feuilles,trifoliées semblables à celles des Dolichos; elles m'ont paru avoir tous les caractères du Gratelier on Cnestis, Juss., excepté cependaut que leurs Fleurs n'ont que cinq Elamines, co qui ne m'a pas einpèché de les rapporter à ce Genre. Cepeudaut celui de l'Ile-de-France m'a olfert quelque chose de plus particu- 
lier. L'embryon dans les Cnestis pinné de ces îles, est enveloppé dans un P'crisperme, au lieu qu'il est nu danș relui-ri. D'après cela j’ai présumé que votre Connare étoit l'une de ces Espèces et qu’elle étoit au moins très-voisine des Gratéliers. Coquenet; Pliysalis. I.

Deux Espèces herbacées de ces îles ne me paroissent pas encore bicn déterminées. Le Coqueret Somnifére s'y trouve en outre.

Corinde, Cardiospermum: L.

Les deux Espèces sont communes dans les cultures.

Corossor, Anona. L.

Votre Corossol a crochets a des báies séparées rontenant chacune deux semences accolées, par conséquent il appartient à un autre Genre. Je pense qu'il en est de même de vos belles espèces, le Corossol amplexicanle et le Grandiflore.

* Il est probable que le Corossal á crochets est l'Uvaria zuncintatı de Lourciro; mais je ne conçois pas comment cet auteur lui attribue des Feuilles piunées.

Cotruet; Cotyledon. Kalauchë. Adanson.

Cotylet pinné.

Il parsît que Casp. Bauhin en a fait mention sous le nom de:

Sednm nicotiance flore. B. Pin.'283.

Sedum Madagascuricum. Clus.' exotic.

Le Cotylet lacinié est très-coinmun ici; quand il est en Fleur, il a l'aspect de la Chlore perfóliée, parses Fleurs jaunes et ses Feuilles glau.jucs.

Cotrbaril; Hymenner. L.

Lc Tauhourou de, Madagascar, qui donne ume trics-belle Résinc qu'on appelle impropremęut Gomme transparente, appartient à ce Geure. Je ue sais si ce n’est pas ge lui dont vous avez fatt mention à l'article Cynomètre;

CREșSon cardamine. L.

Cresson d"Afrique, $\mathrm{n}^{\circ}$. 3 .

C’est la seule Crucifère qqui parọisse naturelle à cetle île. 
Le Cresson de Fontaine a été introduit ici et s'y est trèsmultiplié. Il est quclquefois gigantesque.

Cretelle; cynosurns. L. Elensine. Gxrtn.

Cclles des Indes et d'Egypte; $\mathrm{n}^{08} .8$ et 9 , croissent ici.

Crotalarre; Crotalaria.

Je n'en ai pas trouvé d'autres que celles que vous indiquez dans ces îles.

Croton.

Le Crolon des Mouluques paroît la même chose que l'Alevrit.

J'ai plusieurs Fspèces curieuses de Madagascar. L'observa. tion que vous faites à lit fin de cet articlc est très-juste. Rien ne me paroît plus mal circonscrit que la plupart des Genres qui conposent la Famille rles Euphorbes.

Cupani, Cupania. L.

Il paroítquon a reconnu depuis quelque temps l'identité de ce Geure avec le Molinœa de ces îles.

Curcuma.

Comme vous le présumez, le caractère de ces Plantes se rapproche beaucoup de celui des Amomes: ce que l'on ne devineroit pas par le caractère de Linné.

Crcas, la Samble de Madagascar.

La gerniuation de cet Arbre m'a paru très-singulière. Elle a l'apparence Dicotyledone.

* J'en ai fait le sujet d'un mémoire lu à l'Institut, et iunprimó depuis.

Cynanque, Cynanchum.

Cynanque nue, $\mathrm{n}^{\circ}$. I.

Cctte Plaute est commune ici, où elle pend dcs Arbres, en longs filaniens, ressemblant beaucoup au Cierge parasite.

Il y en a une auire Espćce qui croît dans les Fentes de rochers, qui est droite et plus épaisse. Le lait de l'une et de l'autrc ne paroît point malfaisant, car les bœufs les mangent avidemment.

Cynangue vomitive, $\mathrm{n}^{\circ}$. 1 


\section{des Iles australes d'Afrique.}

Elle est étraugère ici, mais cullivẻe sous le nom d'Tpeca, ainsi que votre Cynanchum Maurilianum ; cului-là esl nalurel à l'Ile-di-France. J'en ai Irouvé deux Espèces à Madagascar Irès-voisines de celles-ci.

Cynonétre; Crnometra. Metmermia. Gen. nov., $n^{\circ} \cdot 77$.

J'ai Iruuve à Madagascar deux Arbustes dont les Frints ont beacoup de rapporl avec ceux de ces Arbres, mais dont les Fleurs sonı dilférentes, cé qui m'a engagé à en faire un Genre nuuveau.

Crtise ; Cytishs. L.

Cjtise des Indes: Crtisus cajan. L.

Cet Arbuate, comme l'a fort bien vuM. Adanson, forme un Gen e trés-vuisin des Dolichos el dunt il seroit très-difficile de le aéparer, si l'on s'en tenoil au caraclere essentiel de linne. Le Dolichos scarabaeoides m'a paru, malgré son port, luièlrt congeriere.

Il renferme plusieurs variélés remarquables.

* Cajan, Diclionnaire des Siences naturelles.

Dalfocianpe; Dalechampia. L.

J'en ai trouvé une Espèce à Mađagascar.

DanaIde; Paderia. L.

J'ai Irouvé à Madagascar une Espèce de Poderic, remarquable par ses Feuilles larges couvertes d'une Fleur rouge ou poussiere semblable à celles de cerlaius Chenopodiums, ce qui le rend lrès-beau; mais sull odeur félide en écarteroil ceux qui seroiout tentés de le cueillir. Votre prenière Espèce est dans le mème cas : elle couvre de feslons tris-beaux les Arbres les plus élevés, mais elle finit par les éloulfier. Votre Danaide odoranıe seroil faile pour réconcilier avec ce Genre; mais je crois qu'elle n'en duil pas fatre partie, si, comme je le présume, vous avez décrit sous ce nom we Liane commune it ces Irois îles; elle c couvre d'une grande quanlilé de Fleurs de cuuleur orangée très-odorantes, mais pertail à la tête. L'examen de ses Fruits m'a conraincu que c'éluit une véritable Espèce de Cinchona, ses Fruils étant capsulaires, à 
deux loges conteuant plusieurs semences garnies d'une aile mince et marginale; $j$ 'en ai reconnu plusieurs Espèces voisines, dont les unes ont le Fruit ombiliqué, les autres couronıé. Les Racines sont pleines d'un suc orangé qui paroît très-propre à la teinture; aussi les Malgaches en tirent-ils le rouge de leurs pagnes. Voyez un Mémoire lu à l'Institut, imprimé dans le Journal de Pliysique.

* Lu genre Danais a été reconuu depuis par Ventenat.

Datter ; Phonix. L.

Datier commun. Phanix dactylifera. L.

Vous avez mieux déterminé le caractère des Fleurs mâles qu'on n'avoit fait précédemment, en lui donnant six Etamines, et non pas trois, comme Linné; mais les Fleurs femelles ont trois Ovaires, dont un seul est fertile.

Dentelaire; ; Plumbago. L.

Nous en avous une Espèce qui me paroît celle de Ceylan. Plumbago Zeylanica. L.

D) IANELLE; Dracoina. L.

Il n'est gruères possible de séparer ce.genre de celui du Dragoniers que par la considération des Graines; mais alors il lui faudra associer votre Dragonier de Chine ainsi que celui de Bourbon, qui ont comne elle plusieurs Graines cartilagineuses, recouvertes d'une enveloppe cruslacée, au lieu que daus les autres elles sont en petit nombre et cornées.

Quant à la Dianelle demi-dorée, elle en diffère un peu; son Calice est réfléchi, ,profondément découpé en six; les Etamines sont insérées sur le milieu des découpures.

Cette helle Plante est commune dans les bois ćlevés de cette île. La première ue se trouve pas ici naturellement, ınais beaucoup aux îles de France et de Madagascar.

Diosifa.

Je in'ai pas encore reconnu toutes les Espèces que j'ai ramassées au Cap.

DodonéE; Dodonca. Plum, L.

Dodoné à feuilles étroites. 
Cet Arbuste est commun à l'île de France. Une seconde Espece se trouve ici et à Madagascar; elle ressemble beaucoup à la première, mais elle u’a pas l'odeur de pómme de Rénette comme elle.

Dolic; Dolichos. I.

J'ai ramassé dans ces trois îles plus de vingı Plantes qui semblent fairc partie de cu Genre; mais je u'en reconnois. que le plus petit nombre parmi vos Irente-cinq espèces. Leur examen scrapuleux m'a fait reconnoitre que le caraclère de Linnée ětoit très-peu trauchant. Je crois qu'il faut, à l'exemple de M. Adunson, les partager cu plusieurs, pour lesqucls ou doit prendre beacoup en consideration la furme de leurs Légumes et du Calice.

Doradille; Asplenium. L.

Comme dans les Acrostiques, je he ferai que quelques remarques.

Votre Doradille à feuilles de Plantuin mo paroit différer des autres, parce que ses parquels fructifères ne sout pas recouverts d'enveloppe. C'est maintenant le Gramitis lanceolata. Sw.

Il y a une variété de la Doradille prolifére, qui esı bipinnatifide et beaucoup plus grunde.

La Doradille prolifére est maintenant un Diplazium Dragonier; Draccena. L.

J'ai quelques espèces distinctes à y ajouter, de Madagascar.

Dryandre tinchu; Arbre a latile de bois.

ECHIT: $\dot{E}_{\text {chlites. L. }}$.

Quelques espèces de Madagascar et d'ici. Eclipte droite.

Elle croit dans les endroits aquatiques de ces îles, ainsi que l'Eclipte couchée.

LLEPHANTOPE à feurs terminales.

Cetle Plante croit abondamment ici; ses fleurons mout paru singuliers; ils sont fendus et semblables à des demi- 
flcurons; de plus, leurs Authères sont séparées; ils sont absolument dans le cas des Curolles du Scavola et du Glutago de

\section{Commerson.}

Lilemorine; Serapias. L.

Plusients Plantes Orchidćes de ces Iles pourroient se rapporter à ce Geure.

Endrach; Findrachinm. Juss.

Je n'ai Irouvé ce bel Arbre qu'en fruit.

Epuémén Ine nodifore. Tradescantia nodiflora. L.

Elle croil à l'Ile-de-France.

Rillobe.

J'en ai trouvé un au Cap, peut-êlre apporlé par les enltures. Eryturinf; Erytliriza. L. Le Nourouc.

Il y en a une Espèce qui croit naturellement sur le bord de la mer à l’Hle-de-France, du côté de la Savane et du Granả T’ort, ainsi çüà Madagascar; elle est reunrquable par ses Feuilles, qui ne sont pas caduques, et ses Folioles égales et ovales; de plus, par une tache blanche qui se trouve de cliaque côtédes ailes des fleurs.

M. Masson, à mon passage au Cap, en $179^{3}$, m'en a fait voir une espèce qu'il cultivoit et qu'il avoit rapportée de l'inlérieut des terres.

Linytroxy Lon; Eryehroxylon. L.

J'en ai deux ou trois uouvelles Espèces de Madagasear.

líthulie; Jichulia. L. Sparganophora. Vaill.

J'ai trouvé les deux premières Espèces à Madagasear. Je ne sais comment je ne les ai pas reconuues, eu sorte que jeu avois fait un Genre, qui est dans ma Notice à M. de Jussicu. Voyez $\mathrm{N}^{\circ}$. 3y.

* L'une d'clles, la seconde, est le Struchium Africanum de M. Paliso de Beauvuis. Flor. d'Oware, $\mathrm{n}^{\circ} \cdot 48$.

kUPiuries.

Dans votre exposition des Genres des Euphorbes, vous séparez le Tonghchu ou Tinchu sous le nom de Sterculiz du Dryadra. Je crois bien que ee Genre a au moins du 
rapport avec le Sterculia balanghas; mais quant au Stere. digitata, il paroît réellement appartenir aux Malvacées.

Le Securinega est très-voisin du Buis.

Enphorbe a feuilles de poirier.

C'est avec doute que j'ai rapporté ì celte Espèce un Arbuste qui devient, dans quelques cantons, un petit Arbre: il est aboudamment laiteux et ses Fleurs sont dioi ques, son lail t'st très-âcre et dangereux, ear on m'a dit que les Noirs s'en strvoient pour cuire le poisson. J'ai trouvé deux autres Esispèces arborescentes à Madagascar, et une herbacée voisine de l'Euphorbic sylvatica, ou autre liuropéenue, it la plaine dis Cafres.

Eupatorre; Eupatorium.' L.

J'ai trouvé ici el à Madagascar deux Espèces qui forment de petils Arbres; et d'autres outre celles que vous déerivez.

Fagarier heetérophylle.

Je croirois assez que lc Genre Macqnerin que Commerson avoit formé pour eet Arbre, devroit être rétabli ; car je truuve bien des différences daus son earactère.

J'ai trouvé deux Arbustes dans ces íles, l'un'à Fcuilles trifoliées, l'autre simples, opposées, qui miont l'air de se rapporter à volre Fag. $n^{\circ}$. 9. Je présume qu’ils doivent aussi former un Genre distinct; je leur eroirois quelques rapports avec les Diosmas.

* M. Bory de St. Vincent en a formé un Genre, qu'il ma dédié, sous le nom d'Aubertia.

Fernel; Fernelia. Juss.

Il y en a deux Espèces au moins.

Fétidier; Folidia. Juss.

J'ai trouré une nourelle Espèee de ce genre à Madagascar, remarquahle par son Caliee, qui n'a que trois Fulioles et qui persistent en inanière de Corne.

Ficoïne; Mesembryanthemum. L.

Dans la partie qui avoisine le Volcan, on tronve sur les roches maritimes une Espèee de ce Genre qui est de la division 
à Fleurs blanches; sa Racine est cn forme ic Navet; ses Feuilles ressemblent, pour la consistance et le goût, à celles de la Soude.

Figuier; Ficris.

J'ai trouvé plusieurs Espèces de ce genre à Madagascar ef dans ces Iles, mais je ne les ai pas aussi bien observees que je l'cusse désiré; j'aurois voulu surtout les figurer, car ce Genre sera toujours très-obscur, tant qu'on n'aura pas pris ce parti pour toutes les Espèces.

Fulao ia fipuilles de Préle; Casuarina. $\mathrm{L}$.

Cet Arbre est de la plus grande beauté sur les sables de Malagascar.

Futeav; Alisma.

J'en ai trouvé une espèce à Madagascar.

FonTINALE; Fontinalis. L.

Fontinale empennée.

J’ai trousé cette bellc Mousse au Cap de Bonne-Espérance, au pied de la montagne de la Table.

Forsckale; Forsckalea. L. S.

J'ai troncé trois Plantes dans cette Ile qui m’ont paru avoir le caractèrc de ce Geure.

Fouglires; Filices.

J’ai trouvé cent vingt Plantes de cette Famille dans ces deux Iles; Madanascar m'en a offert me vingtaine, le Cap à-peu-près autant, et la pctite île de Tristan-d'Acugna quinze, sur cent Plantes que j'y ai trouvécs. Leur examen sur le vivant m'a convaincu de l'insuftisance des Genres établis, ce qui m’a détcrminé à les changer; je crois l'avoir exécuté sur des bases plus solides et plus naturelles que celles qu'on a employées jusqu’à présent; mais le travail le plus important que jaic entrepris, a été de les dessiner le plus exactement qu'il m’a été possible, moccupant sur-tuut à bicn rondre lcs détails de leur Fructification, aulant ceppendant que m’a permis le pen de force des Loupes qui étoicnt à ma disposition.

*Depuis celte Famille aété réformée par Smith et parSwarts. 
Fraisier; Fragatia. L.

Le Frag. vesca s'est extrêmement multiplié à une certainc hauteur, sur-tout à la plaine des Cafres, au grand contentement des voyageurs; car leurs Fruits sont aussi bons qu'en Europe.

\section{Franchipanter; Plumeria. I.}

Je ne sais pas si votre $\mathrm{n}^{\circ} .5$ n'appartient pas à l'Ochrosia de M. de Jussien, qui, je crois, doit rester Genre.

CaIlLet' accrochant. Galium aparire. I.

Cctte Plante, ou une autre très-voisine, croît à la plaine des Cafres, au piton de Villers.

GALÉ; My'rica. L.

Il s'en trouve une Espèce à Madagascar, qui forme un petit Arbre; ses Graines sout couvertes d'une poussière blanche qui, vraisemblableınent, seroit de même nature que celle du Cirier de l'Amériqque Septentrionale.

\section{Galega.}

J’ai trouvé daus ces trois îles quelques Espèces de ce genre; mais elles s'écartent du caractc̀re quon lui attribue.

GanitRe; Elcocarpus. L.

Le $n^{\circ} .2$ est lc Bois canelle noir de l'Ile-de-France. J'en ai trouvé deux ou trois autres espèces à Madagascar.

Gardene; Gardenia. L.

Le $\mathrm{n}^{\circ} .1$ est le Cachepire ou Rose condé de ces îles. Nous avons dans ces îles une belle espècc de Mussanda, que plusieurs personnes ont prise pour le vrai Quinquina. Vous ne l'avez pas décrite; elle fait partie du Genre Landia de Commerson; $j$ 'en ai vu quclques autres.

Gentianes; Gentiana. I.

Plusieurs belles Plantes de Madagascar apparliennent ì cette Famille; quelques-unes paroissent être des Lisiantes; mais il y eu a parmi que je ne sais à quoi rapporter.

Geranion; Geranium. L.

J'en ai trquvé une Espèce intéressunte par son odeur 
agréable, sur l'île de Tristan-l’Acugna; c’est peutếtre la seule des Espèces africaines étraugère au Cap; je l’ai caractérisće ainsi :

Ger. foliis obscurè lobatis, innequalibus; pedunculis pancifloris; canle lerbaceo, erecto. V. Flur. Tr. Ac. $1^{\circ}$. gh. Son odeur approche de relle du Ger. odoralissim., mais elle min paru plus agréable; ses Fleurs sont purpurascentes.

Germante; Germanaca. Lam. Plectranthus. JiHer.

J'ai parlé, à l'article Chontaire el Basilic, de trois Plantes de ces îles qui se rapportent à ce Genre.

J'ai Irouvé en outre, à Madagascar, votre Germanea maculosa, on Guleope tackè.

GISEQ̨UE; Gisekin. L.

Cette petite Plaute croit sur les plages sablonneuses de Saim-Paul.

Gr AYEUL; Gladiolus.

Glayeul jaune.

Il croît sur les plages sablonneuses maritimes de Madagascar.

GLYCINE soutcrtaine.

Cetle Plante m'a paru avoir des caractères si différens des autres Genres légumineux, que jen ai fait un particulier sous le nom de Troandzain, de Voandzou, sou num Maderasse. Vutre Glyrine ì petites feurs usı très-commune dans ces îles. Voy. Geu. Nov. $\mathbf{N}^{\circ} \cdot 77$.

GNAPHALE; Gnaphralium. L.

J'ai rcconnu vos belles Espèces de ces îles.

J'en ai trouvé une Espèce herbacée sur Tristan-d'Acugna. Voy. Fl. Tr. N". go.

J'ai trouvé au Cap et daus ces trois îles une espèce herbacée qqui m’a paru la même, el que j’ai toujours prise pour le Grueplial. luteo album, commun sur les plages de la Loire. Gomart; Bursern. Jac. L.

Gomart panicule.

Cet Arbre, qui est le Bois colophane de l'Ile-de-France, 


\section{des Iles australes d'Afrique.}

et qui est le géant de ses forêts, me paroît différer, comme Genre, de votre Genuart, et avoir beaucuup de rapporis avec lc Canari. Il ne peut non plus être réuni avec volre troisième Espèce, le Colophane bàtard. C'est le Marignia de Commerson et le Dammara nigra figuré par Gærmer.

Ces denx Arbres, qui sont rommuns à l'Tle-de-France, no se trouvent point iri.

Govane; Gouania. I.

Votrc Espèce $n^{\circ}$. 4 ne vient qu'à l'Ile-de-France et ì Madagascar; le $n^{\circ} .4$ à Bourbon seulement, oì on l'appelle Liane is Mlontbrun.

Goder; Arum. L. Caladium. Vent.

Il y a deux Espèces de res Plantes cultivées dans ces íles; l'une appelée Songe, de şon nom Málgache, paroît être lc Gouet ombiliqué; l'iulre le Vira-via, du mème pays, est remarquable par son Stipe arborescent el ses grandes Feuilles; l'un el l'aulre n'ont pas dans leurs Fleurs les filamens cirrhifcres. Le hasard a fail découvrir dans les Fleurs de la dernic̀re, à M. Hubert, le mème phénomc̀ne que vous aver observé sur celles du Gouet d'Iualie, celui d'une chaleur très-considérable. Lcur grandeur lui a permis de faire une suitc d'expériences très-curieuses sur le moment où se faisoit sentir celte clialeur, sa durée, son intensité et son siège.

Je n’ai pas rencontré votre Gonet no. Is trilobé. Le Viavia est peut-ĉtre votre Gouet acuminé.

Graminétes.

Ces Plantes si essentielles me paroisscnt avoir été répandues sous toules les latiludes avec une égalc profusion.

L'observation de M. Volpré, que vous citez, sur la fabrique intérieure de l'Embryon de la semence, nc me paroit pas exacte. Il me semble que ce qu'il appelle Tuniques sont les Bales intérieures qui, dans un grand nombre de ces Plantes, cuveloppent étroitement la semence; dans toutes, les deux Styles partent du sommet de l'Ovaire, et divergent plus ou moins. 
Gratelier; Chestis. Juss.

Outre les Plantes dont j'ai parlé à l'article Connare, il y en a plusienrs autres à Madagascar, à Feuilles pinuées; la plupart sout remarquables par leurs Fruits, qui prennent une couleur écarlate très-vive. Ce ne sonl que des Arbustes grimpans qui s'accrochent aux autres par le moyen de jets uus et qui se roulent autonr des Branches des autres Arbres. Ce caractère est commun à toutes les Espèces que j'ai observées.

Gratrole; Grabiola. I.

Gratiole alsinoïde. .

Je ne sais s'il ne faut pas rapporter à cette Plante une de ces pays qui m'a paru devoir former un Genre distingué par deux Filamens stériles colorés, sortant de la Corolle. Il y en a une seconde Espèce, qui pourroit bien être aussi votre Grabiole à fenilles de Germandrée.

Grenadile; Passiflora.L.

Ayant comparé les parties de la Fructification de votre Grenadille quadrangulaire, var. 6, avec colles du Pass. quadrangularis, figurées ct détaillées avec soin par M. Sowerby dans les Mémoires de la Société Linnéene de Londres, elle m’a paru différer par plusieurs caractères. Cette belle Plante prouve que ce Genre n'est pas exclusif à l' $\Lambda$ mérique. J'en ai trouvé de plus une autre à Madagascar, qui diffère de toutes les autres par des Feuillos ailécs à cinq folioles, et ses Fruits qui sont quadrivalves; je n'ai pas rencontré sẹ Flcurs, qui peut-être donneroient des moyens de la séparer comme Genre. Deidamia alata, genres nouveaux.

J'ai donné en outre, dans ma Notice des Genres, les caractères d'un Arbuste de Madagascar qui a presque tous ceux de ce Genre, mais dont le port s'écarte beaucoup, étant droit, sans Vrilles ni Stipules. Paropsia, n. 66.

* Voyez Anuales du Musée, tome VI, page 457 .

Greuvier; Grewia. L.

J'ai rencontré un Arbre de ce Genre à Madagascar; c'est 


\section{des Iles australes d'Afrique.}

peut-être celui dont vous faites mention coume cultivé par M. Le Monnier.

GuI; Viscum. T.

Vous ne décrivez point le $\boldsymbol{V}$ isc, trenioüdes, dont M. Jussieu fait mention conıme élant dans l'Herbier de Commerson; il est commun dans ces îles. Il y en a une autre Espèce à Péduncules triflores.

Haricot; Pliascolus. L.

Il y a plusieurs espèces ou variétés de res $\mathrm{Planles,} \mathrm{cullivées}$ sous les noms de Pois du Cap, d'Achery, de Bonbeloque, etc. qui paroissent se rapprocher des Phascolus lunatus et inamceus. L. Les premiers, sur-tout, donnent un excellent légume. On a de plus les $V_{0}$ ëmes de Madagascar, dont la fructificulion est singulière, ils se rapportent au Phaseolus mungo de Linné. J'en ai trouvé deux autres espèces dans celle grande île.

HzéLIANTE; Helianthus. L.

J'ai trouvé une Espèce de ce Genre à Madagascar, rernar quable par ses feuilles hastées.

Hemonite; Femionicis. L.

II y a deux Lispèces de ce Genre dans ces îles.

Henné; Lawsonia. L.

La première Espèce est cultivée daus ces íles. J'en ai trouvé une aulre à Madagascar, dont les Fleurs n'ont que trois Pétales el trois Etamines.

Hepatiques; Marchantia. L.

Il y a quatre Espèces de ces Plantules ici.

Hernander; Hernandia. L.

Le Hernandier sonore croît aux Iles-de-Trance et de Madagascar, sur le bord de la mer. Quant à la seconde Espece, conuue ici sous le nom de Bois blanc, elle ne se rapporte point à la figure d'Aublet.

L'ouverture de la Coque de son Fruit est remarquable par un petit rebord. 


\section{4

\section{HÉvé ; IIevaer.}

Il parô̂l que la Résine élastiquc cst dans le cas de beaucoup d'autres produits dcs Végélaux, et qu'elle appartient à des Plantes très-différentes en apparencc; cclle de Madagascar provient du lail d'une Liane, qui est, je crois, du Genre Pacourier d'Aublel. J'en ai reconnu plusienrs Espèces à Madagasear. Les Pommes de Bois de natte et aulres, de la Fanille des Sapolillers, donnent un lait visqueux dout on fait unc Glu qui me paroit dic la nalure de cette Résine. Hirter.t. ; Hirtella. Jaeq., Thelira. No.72. Gen. Nov.

J'ai trouvé deux Arbres qui apparlieunent éridemment à ce Genre, mais qui offrent des diffërences qui peuvent provenir de l'inexaelilude qui paroît régner daus son cxposition. Les Caliccs des deux Arbres que j'ai vus à Madagasear sont analogues à ceux des Géranions africains; c'est-à-dire, qu'ils se prolongent en tube. Dans l'un des deux les Pédoneules et les Calices sont parscrnés de points glanduleux particuliers.

HouQuer; Holcus.

Honque perce.e.

Vous avez raison de regarder cette Plante plulôt comme un Andropogon que comme un Barbon. Wlle est commune à Bourbon.

Houx de Madngracar.

Je n'ai trouvé eet Arbuste qu'atvec ses Fruits.

HUGONE; Hugonir. I.

Jc n'ai trouvé à l'Ile-de-France que votre seconde Espèce, Inais deux autres ì Marlagascar.

Hy Drocotrife; Hydrocotyle. L.

On trouve près du port de Saint-Denis une Espèce qui se rapporle à votre Espèce de Bunaire, mais les Rayons de l'Ombelle sont simples, et dcux à trois fois verticillés par des Fleurs sessilcs.

J'en ai trouvé ume nouvclle à Trislan-d'Acugna, qui a des Fleurs en tẻle pédienlées. Voy. Flor. Ac. $N^{\circ} \cdot 9^{5}$.

J'en ai recueilli au Cap de Bonne-Espérance plusieurs 


\section{des Iles australes d'Afrique.}

Espèces, dont il y en a qui ne me paroissent pas encore décrites.

Hyoserave; Hyoseris. I.

On dcit peut-être rapporter ì ce Genre une Plante cichoracée à Tige radicante, qui croît sur les bords de la mer dans ces trois îles, et que j'ai vue sèche parmi des Plantes de l'Inde.

HYPNE; IIYpnum. L.

J'ai vu dans ces îles plusieurs des Espèces les plus communes d'Europe; j'en ai un petit nombre qui me paroissent nouvelles.

Hyroxis; IIypoxis. I.

Votre $N^{\circ} .2$ est commun à ces îles, quelquefois ses fleurs ont un tiers de leurs parties de supprimé, c'est - à-dire qu’elles n’ont que quatre Pélales ct qua tre Litamines.

HYpт is; Hyptis. Jucq.

Une Labice élancée de Madagascar me paroît devoir se rapporter ì ce Genre.

Jambosier ; Eugenia. L.

Il est très-difficile de distinguer ce Genre, par la Fleur senlement, du Myrthe, car dans toutes les Lispèces que j'ai observées l'Ovaire est à deux longes polyspermes; mais en mûrissaut il n'en subsiste qu'une, et le plus souvent monosperme; mais il y en a quelques-unes qui en contiennent plusieurs; alors il n'y a que la configuration in!ćrieure de la Graise qui puisse fournir un calaclère diflérentiel; mais en $\mathbf{y}$ ayant recours, on est obligé d'admettre les Geures Greggia et Suzyginm de Brown et de Garmer; et de telle fat. çon qu'on s'y preme, il n'y a point de caractères suffisins pour séparer des vrais Jambosiers le Ciro/lier, puisquili a, comune eux, lu Radicule et la Plımule renfermees tutre les Lobes, au lieu que dans les Suzygium elles sont placées extérietrement. Il est vrai que dans la germination les Colylédong restent en terre à la hase de la Plantule, au lieu qui ils sont soulevés dans le Giroflier. 
* Le célèbre Thumberg a pensé comme moi en réunissant le Giroflier aux Eugenia, en quoi il a été suivi par IVildenow.

La Graine du Jam rosadier, ol votre $\mathrm{N}^{\circ} .3$, présente une grande singulảrité, car elle esi partagée en trois, quatre ou cinq Lobes iréguliers, qui sont réunis deux à deux par cles Embryous, en sorte que chacune en contieut deux, trois on quatre qui germent ensemble, mais ils se tienuent lous ensembic par les Lobes ou Cotylédons. La même chose à-peuprès aryive dans le Jam longzle.

Eu géuéral, la germination dés Arbres de la Famille Myrthes présente de grandes anomalies: quelques-uns, tel que le Lecythis, ont l'apparence Monocotylédone, ainsi que volre Jambosier, $\mathrm{u}^{\circ}$. 4, ou Stravadium de M. de Jussien, en sorte qu'on est mené par des nuances jusqu’à la configuration extruordinaire du Rizophora on Mangleer, ce qui m'a conduit à penser que ce singulier Vèrétal est plus voisin de cctle Famille que de celle des Chèvre-Feuilles. Ḷe Trapa me paroît dans le méme cus.

Revenous à volre beau Genre dus Jambosiers. Il paroît que vous ne l'avez pas encore épuisé : il y en a à-peu-près quinze que vous indiquez ici, tant cultivés qu'indigènes ; i'y en ai recncilli vingt-deux, sans compter trois ou quatre do Madagascar. Malgré cela, je ne connvis pas toules celles que vous decrivez, en sorte qu'il m'en manque quelques-unes, ce qui fait quedans cesiles il n'y a guères moins d'une trentaine d'espèces de ces beaux arbres; mais c'est l'Ile-de-France qui esı la plus riche de ce côté.

JAQUIER; Artocurpus. L.

M. Huberi a élé récompensé l'année clernière du soin et du zéle qu’il met à la propagation des Arbres utiles à ces îles. Des deux Arbres à pair qui lui out été envoyés, il y a quatre ans, provenant de l'expédition d'Entrecasteaux, l'un a porté deux Früits; un seul est venu à maturité, c'est-à-clire, il est tombé deux ou trois jours avant l'époque où $M \dot{\mathrm{r}}$. Hubert vouloit le cueillir. Il avoit dix-huit pouces de tour, el pesoit uno 


\section{des Iles australes d'A frique.}

livre douze onees. Il en a fait passer sur-le-champ des tranches à tous les amateurs de la Colonie; il a été trouvé ce qu'on peut appeler solidement bon. 11 a fait beaneoup d'essais pout le multiplier par Boutures et par Marcotes, mais ils ont été infruetueux. Il désespéroit déjà de réussir, lorsque l'observation assidue l'a inis sur la véritable route de sa propagation, ce qui a été confirmé depuis par une lecture plus rétléchie du troisiène voyage de Cook. Il a reconnu que cet Arbre traçoit beaucoup et poussoit des Drageons stolonifères. Il paroît que les habitans de la mer du Sud n'ont pas d'autres moyens de le multiplier. Il est à remarquer que la variété qui porte des $G$ raines ne trace pas du tout, ce qui est à joindre à plusienrs faits, plus commuus dans ces climats que dans les autres, qui tendeut à démontrer une grande analogie entre les Graines et les Racines.

Les deux Arbres de M. Hubert sont d'une superbe venue, leur feuillage est plus découpé que celui de l'Espèce commune. Il faut espérer que sous peu de temps ces, Arbres seront unultipliés de façon à devenir très-utiles.

Je présume, avec M. Le Comte, que votre Jaquier liétérophylle n’est pas différeut du Jaquier des Indes. Celui-ci, dans sa jeunesse, a les Feuilles singulièrement déeoupées, imitant souvent une fleur de lys. Oı en distingue deux variétés, l'une à Fruit jaune, l'autre blanc : ce dernier est beaucoup plus estimé.

Il y en a une autre espèce cultivée, mais en petite quantité, qui paroît réellement intermédiaire entre le Jaquier èt l'Arbre a pain, c'est le Marau d'Yolo; on peut à juste titre le nommer Hétéroplyylle.Son Fruit ressemble à une pelote rouverte d'épingles très-rapprochées les unes des autres. MTadagascar m'en a offert une autre espèce, elle est remarquable par la petitesse de toutes ses parties.

Vous dites ne pas aroir trouvé les Chatons femelles de l'Arbre à pain dessinés par MM. Forster couformes à ceux que vous possédez desséchés; ee n’est pas étounănt, il y ù 
apparence que vous avez ceux de l'espèce ou variélé portant des Graines qui sont hćrissées, au lien que cenx de l'autre sout sinplement aréolés, sans avoir daus aucuı temps les pointes molles qui accompagnent ceux de la première jusqu’a muturilé.

Vous avez mieux décril le caractère de ce Geurc que cenx qui vous ont précédé; cependant j’urois encore quelques observalions à vous faire si le temps ne me pressuit.

Jasuin; Jasminum. L.

On cultive dans ces íles deux Jasmins qui ne me? paroissent pas decrits; cependant l'un pourroit bien être le Jasminum azoricum; le commun n'y cst pas.

Ioname; Cambares. Ouvi Malg. Dioscorea. L.

Nous arons ici plusieurs espèces de ces Plantes, mais cultivées; cependant je n'ai pu encore en découvrir aucune en Heurs; ce qui contirune ce que j'ai dit à l'arlicle Jaquier, au - sujet du rapport des Graines et des Racines; mais il y en a - "ne Espèce qui est naturalisée dans cés îles, élant origninairo te Madagascar, c’est peut-étre volre $\mathrm{N}^{\circ} .8$, dont j'ai Irouvé les Fleurs femelles seulement: clles ne répondent point au caractère de ce Geurs.

Les Malgaches en ont plusieurs Espèces, dont quelques-uncs sont excellentcs. Il est à remarquer qu'ils les appellent en grénéral Onvi, ainsi que la plupart des Racines bonnes à manger. On ue peut méconnoître dans ce nom celui d'Ubi des Malais, Ubium de Rumphe. On retronve ce mol, suivant Cook, dans toutes les îlcs de la mer du Sud jusqu'à celles de Sandwich : il y désigne par-tout les Ignames.

InMORTELIE; Xeranchemum. L.

Trislan-d'Acugna m'en a offert une Espèce formant un petil gazon à Fleurs pelites, d'abord sessiles, mais dont le Pédoncule s'alonge dans la maturité. Flor. Tr. Ac. $\mathrm{N}^{\circ} \cdot 8 \mathrm{~g}$. In DICOTIRr; Indigofera. I.

J'ai deux ou trois Espèces de ce Genre que jai recucillies ì Miadagascar, outre celles que rous décrivez. 
JoNC ; Juncus.

J'en ai trouvé une Espc̀ce à Madagascar, qui m'a paru au moins voisine du Jonc aign.

Joncinel.te; Friocanlon. L.

D'après l'examen des Fleurs de votre $\mathrm{n}^{0} .4$, le caractère de ce Genre ne mc paroît pas exact. Elle croît dans ces I rois îles.

Jongermane; Jnngermania. L.

J'en ai plusieurs Espèces qui me paroissent nouvclles. Jussie; Jussicen. L.

La Jussic rumpante est commune aux Iles-de-France et de Madagascar; elle mage sur les caux dormautes, à la façon des Potamogetons; elle pousse, dans celle position, des appendices utriculaires particuliers. Je crois que votrc Luduige jussioide appartient à ce Geure; elle a certainement huit Filamens, mais quatrc sont stérilcs. Je l'ai prise, aussi moimême, long-temps, pour un Lnduige; mais son portla réunit évidemment à ce Genre. J'en ai trouvé deux autres à Madagascar.

Il y a une saison où votre Luduigé n'a réellemcnt que quatrc filamens: dans d'autres $j$ 'en ai vu certainemeut huit. IschêME Garbue; Ischomum.

- Jc crois qu'il faut rapporter à cette Plante une Graminée de cesîles; j'cu ai dcux autres Espèces qui me paroissent nouvelles.

Ixore écarlate; Ixora coccinea. L.

Ce bel Arbuste est cultiré dans ces iles, mais il est rarcment daus fout son ćclat, parce qu'il est chargé ordinairement de Coccrs qui le cléforment. On donne le nom d'Txore, dans ces îles, à tine belle Plante de la Famille des Gatiliers, qu'on dit avoir été rapportée sous ce noin par Commerson. C'est le Volclameria Kamfiriana de Jacquin.

Vous avez raison, je crois, de réunir à ce Gcnie le paverca de Linuć. En général on it trop multiplié les Genres dans la famille dés Rubiacécs. 
La phrase dc Pluknel, que vous rapportez sous votre Ixore panicule, $\mathrm{n}^{\circ} .4$, me fcroit penser que vous décrivez sous ce nom un bel $\Lambda$ rbustc, ou plutôt un petit Arbre de ces îles, qui est remarquable, dans sa jeunesse, par de grandes Feuilles agréablement marbrées de jaunc, de pourpre et de vert, mais qui sont d'une scule conleur dans les adultes; c'est un phénomène que quelques autres Rubiacées mivnt offert.

KeTMIE; Mibiscus. L.

Je présume qu'un arbuste assez grand el élalé, de ce Genre, qui croît sur les montagnes, est celui que vous réunissez à l'Hibiscus mucabilis, comme sinmple variété; mais il u'en paroît très-distinct.

KILLINGE; Killingia. I.

Madagascar et ces îles mont offert quelques Espèces de ce Genre, qui ne me paroissent pas décriles. Ia Raciue du plus grand nombre est odoraute comme celle des Cyperns ou Souchets.

Lagerstrone; Lagerscroemeria. L.

J'avois déjà recomnu l'identité de ce Genrc avec le Munchansia. Cet Arbuste vient très-bicn dans les jardins des environs de Saint-Denis, il s'y couvre tous les aus de ses magnifiques Fleurs; mais partout ailleurs il réussit mal.

Larche; Carex. L.

J'ai trouvć sur Tristan-d'Acugna deux Plantes un peu différentes l'une de l'autre, ct qui se rapprochent du Carex uncinata; ces Plantes sont plus singulières que belles. (voy. Flor. Tr. $\Lambda$ c. $11^{08} \cdot 76 \mathrm{et} 77$.)

Ces îles $\mathrm{m}^{\circ} \mathrm{cn}$ ont offert cinq à six Espèces, le Cap de Bonne-Espérance deux à trois.

LAitue; Lactuca. I.

- On donnc ici le nom de grand Laitron à une Plante qui me paroît être volle Latiue des Indes.

L.AMPOURne; Xanchium. L.

Les Lampourdes commune, $\mathrm{n}^{\circ} .1$, et épineuse, $\mathrm{n}^{\circ} .3$, se sont naturalicées daus ces íles. 


\section{des Iles australes d'Afrique.}

Lapulier; Triumpheta.

Je erois que la Plante que cite Aublet n'est point votre nº . 1, mais le Lapulier glandulenx, $\mathrm{n}^{\circ} .8$; il est très-eommun dans ees îles. Il est nommé ITerbe á panier à l'Ile-de-France, et Itérisson blanciei. Il y a en outre, iei, une petite Espèce qui I’a que quitre pétales.

Latanir ; Lacania. Juss. Cleophora; Gærtn.

Les Fleurs femelles sont plus écartées sur leurs spadix que les mâles; de plus, leurs rameaux sont tortueux et écailleux : le Fruit eontient trois Graines anguleuses.

LAURTER; Lautrus.

Dans toutes les Espèces de Laurier que j'ai observées ici, j’ai trouvé les Anthères à quatre loges distinctes, creusées dans le filament élargi, et s'ouvrant elacune par un battant.

M. Le Comte a fait des olsservations curieuses sur les trois Espèces de Caneliers cultivées dans ees íles.

Lanrier cupulaire. $\mathrm{N}^{\circ} \cdot 7$.

Je crois qu"il y a plusieurs Espèces distinctes, quoique voisines les unes des autres dans ces trois îles; ınais les Feuilles entières de ces Arbres donnent peu de prise pour les distinguer. Suivant une note que Commerson avoit ajoutée sur un excmplaire de Rumphe qui lui a appartenu, il regardoit le Quercus moluca comme un Arbre de ce Geure; ce qui me paroît très-probable.

Le Litsai de votre Dictionuaire appartient certainement à ee Genre, ou du moins doit faire un des Genres qui, eomme vous le remarquez, doivent en être tirés. Le havensara en est très-voisin, et n'en diffère (des lauriers) que par ses Etamines à deux loges seulement, et la configuration de sa Graine.

Outre l'Espèee aromatique, j'en ai trouvé deux autres a Madagasear qui se le sont point, mais dont l'une forme un charmant Arbre.

D'un autre eôté, ni le Mruscadier, ni l'Hernandiu, ne me paroissent avoir aueuns rapports avec eette Famille. Plusieurs 
considérations que je ne peux développer ici, une font penser que le preınier sc rapproche beaucoup des Anonis.

Lenticule; Lenna. L.

Il y en a une Espèce dans ces j̉les, commune sur les eaux dormantes ; je n'ai pu encore la déteruniner, ne l'ayant jamais découscrie en Fleurs.

LICHEN; Lichen. I.

Quoique ces Plantes ne soicnt. pas si multipliées daus ces climals qu'en Europe, j’en ai cepcndant rassemblé un asscz grand nombre à Tristan-d'Acugna, au Cap, et sur ces îles; parmi plusieurs des plus communcs d'Europe, il y en a beaucoup qui me paroissent nonvelles. Mais à la plaine des Cafres, entre autres, on se croit transporté daus les landés d'Europc : la terrc y est couvertc des Lichen ericetontm, pixidatus, coccifenus, rungiferinus, caninus, .ck. ; à des Arbres pendent lcs Espèces filanenteuses. J'ui trouvé atussi à l'He-de-France le Lichen fuciformis.

Jc pense que vous vous êtes trompé au sujet d'une Plantule que je vous ai communiquée autrefois, $\mathrm{cl}$ que j’avois recueillie ì Saint-Mialo, car vous la rapportez à votre Lichen $13^{\circ} .139$. Je crois que c'est une Espèce de Fucus décrite el figurée dans Gmelin; mais vous aurez été plus à méme que moi de reconnoîlre cela.

Lreiet; Lycium. L.

Nous avons une cspèce commune à ces deux iles.

I.IMONELLIRR; Limonia. L.

Je présumequc vous avezdécrit sous le noun de Limonellier de l'lle-de-Finance, l'A rbuste ou pelit Arbre que Commerson appeloit Vepris inermis, ou Elemifera, et que M. de Jussicu rémit aux Icica; c'est ce quon appellc ici l'atte de poule sans épine. Quant à celui de Madagascar, je crois que c'est un Arbuste quc je n'ai encore vu que cultivé. On l'appelle $A$ uisaire, à causc de son excellenle odeur d'Anis. Liseroue; Evolvalus. L.

Deux Espëces se trouvent dans ces Iles: l'une d'elles cst la 
Liserole numnuluire, maintenant le Dichondra. Cette Plante paroit répandue sous toute la Zóne torride.

Liseron; Convolvulus. J.

M. Desronsseanx a raison de ne pas croire avoir épuisé ce beau Geure. Ces îles m'ont offert quelques Espèces qqui ne me paroissent pas décrites. Il demande, plus qu'aucun autre, l'attention d'un Monographe et des Figures bien complettes. Je doute que le caractère sur lequel votre Collaborateur fait reposer la distinction des Ipomées et des Liserons soit encore suffisant el ficcile à observer. Te vois, par les Espèces qui manquent, celles qui doivent composer le Genre Quamnoclit; le Convolvalus patatas, par exemple, est de ce nombre. Cependaut celui qui est cultivé dans ces îles n’a, bien,certainement, que deux Lobes à son Stigmate. L'Ipomeca coccinea, dont la Fleur a tant de ressemblance avec celle du joli Qnamoclit, a ahsolument le même cáractère que lui.

L'Ipomea tuberosa est dans le même cas. On l'a apporté depuis peu de l'Inde, sous le non de Lirne de Goindelour.

Lysynaque de Bourbau.

Celle jolie Flante croit sur les roches maritimes qui sont du cóté du Volcan, on clle forme de jolis gazons.

* Lubinia Spathulata. Vent. Hort. Cels. Tabet. pag. g6.

Litcur ; Enplioria. Juss. Sey'alia. Gicrtn. Dimocarpus. Lour.'

.Souvent les xleux lobes dé l'Ovaire réussissent et forment deux Fruits réunis. La substance charnue qui enreloppe les semences est un Arille qui n'adhère qu'd la base, en forme de bourse : ses bords sont seulement connivens, restant ouverts au sommet.

Le Rangorstan ou Ramboutan de Balavia, est une troisième espèce de ce Genre , comme je m’en suis assuré, pour les Feuilles et les Fleurs; 'sur un individu vivant, ef pour le Fruit sur un individu sec apporté de Batavia; en sorte qu'il paroît que le Genre' Nephelium doit être suppriméc.

J'ai vu, dans une note que vous avez faite à la traduction de 
Thunberg, que vous êtes dı même avis. Ce chaıgement a élé confirmé depuis par M. de la Billardière.

Le Bois de fer de l'Ile-de-France nue paroît aussi trèsvoisin de ce Genre. Vous en arez fait depuis le Genre Stad. maria.

Je désire beaucoup que ce Genre reste fixé pour perpétuer la mémoire de mon excellentami Sıatdman. C'esı un de ceux qui ont le plus contribué à la perfeclion de la Flore de l'Ile-deFrance, soit par ses propres travaux et ses excelleus dessins et peintures, soit par les secours de toute espèce quỉil a si généreusement fournis à tous les Botauistes qui ont séjourné à l'Ile. de-France. Pour moi, cu mon particulier, il a láissé à ma disposition, pendant mon séjour, tous ses livres, et ses propres remarques.

Il a suecombé depuis mon retour, dans la fleur de l'âge, aux maladies compliquées qui l'accabloient depuis quelques années.

Litsé ; Litsaea.

Comme j'ai déjà dit, arlicle Laurier, cet Arbre est du même Genre, ou au moins très-voisin. Voici son vrai caractère :

Fleurs dioiques par avorteneut, petites, rassemblées en ombelle;

Collerelte de quatre Folioles (votre Calice);

Fleurs mâles, Calice de quatre Folioles, seize Filamens; Sommet élargi en spatule, creusé de quatre loges d'authère, fermées chacune par une valye qui s'ouvre en-delıors; Ecailles mêlées parmi.

Fleurs femelles, Calice idem, Filamens stériles, Erailles mélées parmi, Ovaire simple, Style court;

Fruit pédoncule renflé.

* M. "de Jussicu a fait de re Genre l'objet de deux Mémoires: le prémier dans les Mémoires de l'Institut, vol. $I^{e r}$-; le second dans lès Annales du Musée, vol. VI.

Cet Arbre paroit se rapporter à l'un des Mackilus de Rumph. 
LOBÉLIE; Lobelia. L.

J'ai trouvé dans ces deux îles une Lobélie qqui m’a paru ne former quiune scule Espèce, quoiqu'elle varie beaucoup dans toutes ses parties. Je ne serois pas surpris que les deux Plantes de Commerson $\left(\mathrm{n}^{05} .3 \mathrm{I}-32\right.$ ) ne lui appartinssent. Elle a lcs tiges trigones, ce qui lui est commun avec quelques autres Espèces, eutre autres la Lobélie $n^{\circ} .23$, qui est naturaliséc dans le Jardin des Pampelmouscs.

LoncuItIs ; Lonchitis. L.

Il y a apparence qu'on doit rapporter à votre Lonchitis velue une belle Fougère de ces ílcs.

Lorantue; Lorcritlus.

Je ne sais si on ne devroit pas rétablir le Glntrggo de Commerson.

Luder; Ludia. Juss.

Je n'ai encore trouvé qu'une seule de vos Espèces.

LYCOPODE; Lycopodium. I.

Quoique j'en aie recucilli nne donzaine d'Espèces dans res deux iles, je n'ai pas encore tontes celles que vous décrivcz. Il y en a une Espice que j'ai trourée dans les endroits marécageux du Cap et de ces íles, gui a beaucoup de rapporls avec le Lycopode des marais. Le Lycopode a massue est trc̀s-commun à la plaine des Cafres et autrcs endroits élevés. J'en ai trouvé aussi uue Espèce voisine à Trislan d'Acugna.

Lysianthe; Lysianthus.

J'en ai de Madagascar que vous décrivez.

Mabolo; Cavanillea. Lam. Embryopteris. Gærtn.

Je n'ai trouvé ancun caractère qui m’ait paru suffisant pour séparer cet arbre des Ebéniers; peut-être pourroit-on' les distinguer ensemble des Plaqueminiers, parce qu'ils ont tous les Feuilles persistantes, au lieu qu'elles sont caduques dans les autres: $j$ 'avois cru en trouver le moyen dans la considération du Calice, qui est élargi dans lo Fruit du Clitsé; mais j"ai vu à Madagascar des Espèces qu'on ne pouvoit écarter des. 
Ebéniers qui étoient pourtant dans lo même cas. Elles n'avoient uon plus qu'un petit nombre d'Etamines. Deux sont de très-jolis Arbustes à Feuilles de Buis. Ils me paroissent trèsvoisins du Maba de Forster; en sorte que ce Genre pourroil bien être supprimé par la suite.

Malani; Malanoca. L.

Il $\mathrm{y}$ en a uue autre. Espèce à l'Ile-de-France, dont les Feuilles ne sont qu'opposées, et les Fleurs uni-sexuelles par avortement.

Mangier; Mangifera. L.

Je ne connois pas encore volre Mangier ì Fleurs lâches. Quant au Mangier pinné, vous avez raison de croire qu'il est d'un Genre particulier; je l'ai nommé Sorindeia, $n^{\circ} .80$, de son nom malgache $V$ oa sorindi.

Mangoustan; Garcinia. L.

Il y a environ quatre ans que M. Huberl a eu la satisfaclion de recueillir d'excelleus Fruits d'un Arbre qui existoit depuis long-temps dans la colonie; mais il avoit été placé sur une habitation situće dans les hauts, où il languissoit faute de chaleur. Cet habile Cutrivateur l'a lait Iransporter à grauds frais dans une situation plus fuvorable, ou il n’a pas tardé à le récompenser deses soins. Dans le méme temps un autre Individu à-pen-p̧rès du même âge, qui étoit chez M. Dessiles, a donné aussi des Fruits; il en a été de même chł\% madame Magon, àl'Ile-de-Firance. On a licu d'espérer çue les Arbres provenus de leurs Graines fructificront plutol : ce que l'on a déjà éprouvé pour plusieurs Arbres fruiliers, entrautres l'Avocat, ou Luurus persea. L., dont on désespéroit.

Je crois, comme je l'ai déjà dil, que le Brindonia dois former un Genre particulier, mais voisin de celui-ci.

Marsilea.

Marsile in quacre Feuilles.

On dit que Commerson la nommoil Ubiqua. J'ai vu la Plante que vous décrivez à l'lle-de-France et à Madagascar; elle ne m’a pas paru différente de celle que j’ai vue cn grande 
abondance sur quelques plages des bords de la Loire; mais je ne l'ai pas rencontrée ici.

-Massette; Typha. L.

J'ai trouvé la Massette à Fenilles larges au Cap; celle à Fenilles itroites est commune dans ces iles. Cependant on ne la dit pas très-ancienuement répandue dans cette île : on cite l'époque où elle a commencé à s'emparer de l'étang de Saint-Paul, où on lui donne le nom malgache de Yronre. Mauve; Malva.

On cultive ici, dans les jardins, la Mauv' glabre, $\mathrm{n}^{\circ} .40$, où on la nomme Manve de Cline.

Je n'ai pas encore rencontré volre Manse Hybiscoíde.

Voilà tout ce que je counois de volre Dictionnaire, à mon graud regret. J'ai vu, dans une notice publiée dans une Gazette, qu'il y en avoit huit volumes et huit de Planches; combien ils m’apprendroient de choses! Je présume qu'il y en a un de supplénent et un de classification.

Examen des principanx articles qui doivent se trouver dans les articles subséquens.

Melastome; Melastome.

Je me rappelle qu'un jour que $j$ 'ai eu l'honneur de vous voir, vous travailliez à ce beau Genre, et j'étois étonné de la quantité d'Espèces que vous aviez rassemblées. Vous me demandâtes même, en plaisantant, mon avis gur une de ces Plautes. Je pourrois actuellement vous en parler plus pertinemment, car j'en ai vu plusicurs Espèces curieuses à l'ile de Madagascar; parmi il s'en trouve quelques-unes de parasites; l'une se retrouve ici. J'ai long-temps cru qu'un Arbuste de l'fle-de-France lui appartenoit; mais son Fruit me l'at fait reconnoítre pour un Mentecylon. D’autres Espèces de ce. Genre curieux, que j’ai vues à Madagascar, miont fait voir beaucoup de rapports entre les deux, plusieurs ayant, comme 
les Melastomes, les Feuilles trinerves, et une configuration siugulièré d'Elamines.

Menecylon; Memeoylon.

J'ai rassemblé une douzaine d'espèces de ce Genre. Comme dans les Jambosiers, leur Ovaire est toujours à deux loges polyspermes; mais ordinairement il n'y a qu une senle Graine qui réussisse. J'en ai cependant vu quatre dans une Espèce.

L'enroulement des Cotylédons, qui sont larges et verts, distinguo principalement ce Genre. Par ce caractère et par la Germination, il me paroit avoir beaucoup de rapport, d'un côté, avec le Badamier, et de l'autre, avec le Poivrae ou Combrelum.

Meniantif ; Menyanthes.

Le Menianthes indica se trouve dans ces îles.

Menisperma; Manispermum.

J'ai décrit sous le nom de Burasaia, $\mathrm{n}^{\circ} .62$, et de Spirospermum, $n^{\circ}$. 63, dans la notice que j'ai envoyée à M. de Jussieu, deux Genres qui sont pent-être confondus dans celui du Menisperme : cependant ils sont très-différens. Le Spirosperme a beancoup de rapports avec le Cissampelos on Pareira.

Mrcocovlier; Celcis. I.

Une Espèce originaire de Madagascar s'est beaucoup multipliéc ici: c'est clle 'qu'on nomme $A$ ndarése.

Millepentuis; Hyperichin.

Il y a une charmante Espèce dans celte íle qui se rapproche de celle de Chine par ses Styles coalisés en un seul. Les Créoles lui donnent le nom de Bois à feur jaune; c'est une des Panacées les plus vantées.

Mrroboran; Terminalia.

J'ai déjà dit, à l'article Badamier, que c'en éloit une Espèce.

MNI; MInium. I.

Cornme parmi les autres Mousses, il y en a plusieurs d'Earope. 
Moliné; Molinoca. L. Cupania. Plum.

Bois de ganlettes. Chiacune de ces deux iles a une Espèce particulière. On donne aussi le nom de Bois de gunlettes ou Bois sagaie, à un Genre voisin des Savonniers et du Bois de fer de l'Ile-de-France, que j'ai appelé Doruylum.

* M. de Jussieu pense que ee Genre doit se réunir au Melicocca ou Knepier.

Monbin; Spondias. L.

Outre l'Evi des îles de la mer du Sud, il y a plusieurs autres Espèces apportées de dilférens endroits. Il y en a une autre indigène à ces deux îles, dont les Fleurs sont dioïques par avortement; on l'appelle Bois-Blanc rouge. C'est le Poupartia de Commerson.

Muscadier; Myristicr. L.

Comme je l'ai déjà dit à l'arlicle Laurier, je crois ce Genre voisin des Anones. L'enroulement des Feuilles est le mẻme; la forme du périsperne est semblable, ainsi que la position de l'embrion. Le Calice est trifide, et semble participer à la nature de la Corolle qui manqque; car il est épais et elarnu comme dans les Annones; de plus il est odorant. Ce qui confirme l'analogie, c'est que j'ai ru sur deux espèees d'Uvaria des Fleurs apétales fentles fertiles, tandis que les hermaphrodites étoient stériles.

J'en ai vu au Jardin des Pampelmouses quatre Espèces dislincles.J'ai trouvé en outre, à Madagascar, un Arbre monoïque qui avoit beaucoup de rapports avee ce Genre, mais dont les Anthères étoient différentes. Je n’’ai pas vu son Fruit múr. Natier; Imbricaria. Juss. Commers.

Ces îles contiennent plusieurs Espèces de ces beaux Arbres; ils passent pour les meilleurs bois de charpente. NenUPHAR; Nymphoca.

M. Masson mavoil fait voir au Cap une jolie Espèce de ce Geure à Fleur bleuâtre ; il l'avoit rapporlée do l'intérieur des terres. Je l'ai retrouvée à l'Ile-de-France el à Madagascar. Elle paroît être le Citambel de l'Hortus Malabaricus. J'ai 
trouvé de plus, à celle dernière île, le beau Ny'mphoca Lotus. Nuxie; Nuxia. Comu.

Fu me rappelle l'avoir vu gravé dans vos Genres.

Ochna; Ochna. L. Gen. nov., n. 5 g.

Il y a à l'Ile-de-France un joli Arbrequi a l'aspect d'un Prunier ou antre Arbre rosacé, se dépouillant de ses Feuilles, et se couvrant de Fleurs blanches avanl de les avoir reprises, et qui apparticut à ce Gcure. Il y en a deux autres à Madagascar qui lui ressembleut pour le port, mais dont les Fleurs sont jaunes. Il y a, en outre, trois autres Arbustes qui ont àpen-près les mênes caractères, mais qui n'ont que dix Etamines, et dont les Feuilles son! persistanles. C'est, je crois, ceux que Commerson appeloil Sophistèques. Philomeda. Gen. uuv., 1158. Gomplia. Swarls.

Ochrósrr; Ochrosiz. Juss. Gen.

Il paroîl que vous l’avez réunie aux Franchipaniers.

Orrvien; Oléa. I.

J'en ai trouvé trois Espèces dans ces deux íles. J'ai vu, dans vos Illuscracians des Genres, dessiné sous le nom d'Olivier de Madagrascar, le rameau d'un Arbre de Madagascar. Je le - crois d'un Genre différeut, et mon ani Statdman l'a dédié, - sous le nom de Noronic, à la mémoire de Norona, botaniste espagnol, mort dans ces îles.

Il est remarquable par sa Corolle épaisse en grelot, ses deux Elanines logées dans une cavité, et son Fruit, qui est un Driuje monosperme à Noix bivalve; sa Griline est épaisse, sans pêrisperme. J'en ai trouvé deux Espèces à Madagascar.

Orcuis ; Orchis. L.

J'ai environ quatre-viugt-cinq Espèces de ces Plantes clessinées et décrites. La stuucture de leurs Etamines et de leur Labelle $m^{\circ}$ a fourni des caracières qui $m^{\prime}$ ont paru propres ì les. diviser en Genres faciles à observer. Les Espèces parasiles se distingueut des autres par leurs Etamines, qui sont composées de deux seuls Globules distincts, et ne forment pas une masse agglutinée comsme dans la plupart des Espèces d'Europe. 
Orties; Urtica.

C'est une des fumilles les plus noinbreuses de ces îles; elle renferme des espèces curieuses.

Osmonde; Osmunda.

Nous arons une Espèce qui ressemble en petit à l'Osmunda Regulis.

OTHONe; Othona.

Il y a ici une belle Plante radiée qui paroît appartenir à ce Genre, à quelques différences près.

Oxalide.

L'Oxalis comiculatn, ou plutôt celle, je crois, qui cst désignée comme dilférente, sous le nom d'Oxalis pusilla dans un des Mémoires de la Société Linnéeune de Loudres, est commune au Capet dans ces trois îles. L'Oxalis violacea s'est multipliée au point d'être nuisible aux plantalions dans beaucoup d'habilations; je ne l'y ai jamais vue qu'à Flcurs doubles et stériles, ce qui ne l'conpĉche pas̀ de multiplier considérablement par ses cayeux. T'Oxalis sensitiva cst commune it Madagascar. La force élastique qui jelte les Semences dans l'Oxalis pusilla et autres, réside absolumeut dans l'A rille qui les enveloppe; la Catpsule n'y contribue en rien; ce qui a élé remarqué depuis long-temps par Grew et Tournefort.

Palmiers ; Palma.

Je crois avoir fait quelques observalions curieuses sur la structure intérieure de ccs Arbres intéressans.

Papangaie; Lieffu. Tourn.

Le Cucumis acntangulus et le Momordica luffu me paroissent devoir être réunis daus un genre particulier; l'un et l'autre portent des glandes remarquables sur leurs Calices at sur des bractées singulières.

Paletuvier.

Il paroît que c'est soús ce nom que vous pariez des Rizophora. Les truis Espc̀ces que jai observées mont procuré cles délails curieux que je n’ati pas le temps de détailler. 
Pareira ; Cissampelos. L.

La Fleur femel!e du Genre que j’ai nommé Spirosperme, qui paroît un ancien Menisperme, scmble eomposée de six Fleurs réunies de Parcira. Celle-ci est forméc d'un Calice d’une scule foliole unilatérale, dcux écailles intérieures ( Corolle) pareillement unilatérales, un Ovaire simple surmonté de trois Styles courts horizontaux. La Graine est reniforme; l'Eınbryon sans Périsperme roulé cu demi-spirale.

* Voyez Dict. Sc. Nal., et Journ. de Botan.

Pariétaire; Pariecaria.

Il est difficile de partager beaucoup de Plantes de ces ílcs entre les Orties et ce Genrc.

Paturin ; Poa. L.

Il y a ici plusieurs Espèces de ces Plantes très - élégantes. Il y en a une à Madagascar remarquable par ses feuilles rapprochées deux à deux de façon à paruitre opposées. Il y en a unc autre à la plaine des Cafres, qui ressemble beaucoup aux plus communes d'Europe.

Paspale; Paspalum. L.

Vous en avez fait figurer unc Espèce commune à ces íles dans vos Illustrations des Genres. J'en ai plusieurs au'tres. PHYLICA.

Le scul Arbuste de Tristau d'Acugna, est une belle Espèce de ce Genre; il s'élève à douze un quinze pieds ( $V \circ y$. Flur. Trist. Acug.; $1{ }^{\circ}$. 98). Il me paroît diflérent de ceux du Cap. Il se rapproche un peu de celıi qui croît sur les sommels de cette île, et que les Créoles appellent Genevrier.

Poivrier; Piper. L.

Vous annonecz le desscin d'en former tue Famille particulière; vous avez raison, ainsi que d'y réunir l'A nidesma. Quant au Genre même, je crois qu'il doit être lui-même parlagé en plusieurs. Du reste, je nc connois aucune Espèce qui s'accorde avec le curaclère de Linné. Plusicurs espèces à feuilles succulentes sont appclées, daus ces iles, Pourpier Marou. Quelques-unes sont dioïques. 
Polypode; Polypodium. I.

Beaucoup de nos Fougères se rapportent à ce Genre de Linné; mais des caractères qui m'ont paru tranchans miout servi à le parıger en plusieurs. Le beau Pouyrodivas arboreum, eutrautres, en forme un particulier, reconnoissable par la forme de ses Capsules séminifêres et leur euveloppe en calotte hémisphérique. Ces trois îles m'en ont offert quatre espèces distinctes. J'en ai trouvé une autre au Cap. Smith et Swartz en ont formé le Genre Cyazhea.

Pourpier; Portulaca. L.

J'ai trouvé à l'Tle-de-France deux Espèces qui se rapprochent du Portulaca. J'y ai trouvé, en outre, une autre Plante qui differe de ce Genre par le manque de Corolle. On donne le nom de Pourpier Maron aux Espèces de Poivrier à Feuilles succulentes.

PrÊLE; Equisetum.

Sur le sable des rivières ou plutôt torrens de ces îles, il croît une espèce de ce Geure.

Quamoclit; Ipomaa. L.

Il paroît que vous avez réuni à ce Genre le Convolvulus purpurens, et c'est lui qui a fourni le Caractère que vous attribuez à ce Genre. Il n'en est pas de même des autres que je vous ai cités à l'article Liseron.

QuaTelé; Lecythis. L.

On le nomme Sapocayer à l'Ile-de-Franee. Les graines avoient été rapportées, comme le dit Aublet, du Brésil, lors de l'expédition de M. d'Aché : il en éloiî provenu plusieurs pieds disséminés sur plusieurs laabitations. M. Céré en fit transporter un au Jardin de Pampelmouses, où il se couvroit de fleurs depuis quelques années; mais ce n'est que- depuis quatre ans qu'il a porté pour la première fois trois fruits, dont l'un est parvenu à maturité, et l'on espère que les Arbres qui proviendront de leurs Graines serout moins tardifs à produire des Fruits ; ce que l'on a déjà éprouvé pour plusicurs autres Arbres, l'A vocat entrautres. 
Cet Arbre m'a donné lieu à faire plusieurs remarques, en me présentant beaucoup de singrularité dans sa fructification.

*J'er ai fait le sujel d'un Mémoire lu à l'Iustitut el imprimé depuis dans mes Essais.

Quivisier; Quivisia. Juss. Com.

Ces Arbustes sont remarquables par la forme variée de leurs Fenilles. J'en ai recueilli plusieurs Éspèces.

Ramoutcur ; Flaccurtia. Juss. Sigmarota. Lour.

C'est sous ce nom que vous devez parler du Flaccirtia de Jussieu.

Ravensara; Agaloplyyllum. Juss. Erodia. Gorm.

C'est, comne je l'ai dil, un Genre voisin du Laurier. J'en ai trouvé trois Espèces, mais deux sont inodores.

Renoxcule, Ranunculus.

La plaine des Cafres et autres sonmels de cette île présente deux Kispèces ou variétés remarquables de ce Genre qui ont beaticoup de rapports avec celle d'Lurope. Vous pouvez conjecturer, par plusieurs articles insérés ici, que cet endroit in. téressant rappelle par ses productions l'Europe. Il a effectivement l'aspect de nos landes d'Anjou et de Bretagne; mais il rappelle aussi les plaiues du Cap; car au milieu de ces Plantes, qui paroissent européenues, vous voyez des Phylica et vos belles espèces de Conyses et de Graplualiums qui rappellent cenx du Cap et les Protées. Tandis que vous foulez aux pieds des tapis de Fraisier, vous voyez pointer de distance en distance des Orchides, dont une me paruit l'Orehis Bicornis du Cap. Quelques espaces sont courerts de Pulitric entremêlés des Lichens rangiferinus el coccifenus. Vuus êles embarrașsé dans les longues traînasses de Ljcopodium cluvalum. Malgré cela, vons chercheriez vainement l'émail qui règne dans les endroils les plus stériles d'Europe, ainsi que les parfums qu'on y respire, sans une seule plante qui semble faite pour suppléer à l'un et à l'autre. C'est une espèce de Myosotis assez resscmblante au AJyosotis Inpulla, mais dont les Fleurs beaucoup plus grandes prennent toutes les nuances du blanc au 


\section{des Iles australes d'Afrique.}

bleu céleste et au rose tendre; elle exhale, eu oulre, comme l'lléliotrope, l'odeur de la Vanille. Je l'ai vue, sur les sommets aliernativentent brilés el glacés du volcun, être la seule à venir égayer ses sables inoirs. Daus quelques endroits elle partageoit le terrain aver, une jolie Composée à Feuilles argentées et Fleurs durées, qui est aussi fort aboudante à la plaine. Les Graninces qui forment sou gazon paroissent aussi europeens : ce sont des $A$ grostis, des Poa, des Festuca el des Bromus. Quelques-uns, cependant, rappellent encore le Cap étaut du Geure Erlmartu. Transporté par l'idée dans volre patrie, vous cherchez en vain à décourrir à l'horizon quelques clurhers ou d'autres ouvrages de l'homme qui vous tirent du désert.

Mais des pitons rapprochés, sur lesquels s'élancent des Palmistes, vous ramènent à la \%one Torride ; el le front sourcillenx et déchiré des montagnes qui vous dominent ì droite et à gauche alleste que vous étes à Bourbon.

Je voudrois vous promener plus long-temps daus celte solitude; mais quoique le froid u'y soit pas aussi excessif qu'on le dit même ici, il n'y fait pas bou la nuit; ainsi regagnons le gîte. Reservons sa description pour un autre ouvrage, si jumais les circonstinces me peruettent de l'entreprendre.

RICIN; Ricinus. L.

J'ai trouvé dans ces illes une Espèce qui forme un assez grand Arbre, et une autre à Madayascar. Ils ıue paroissent uécessiter l'établissement d'uu nouveau Geure. $\mathrm{R}$ Iz;Oryza.

On en compte une douzaine de vatriétés ou sous-variétés qu'on cultive toutes dins les terraius secs, en atteudant cepenclant la saison des pluies. Il en est de mèue à MLudagascar, où l'ou sème les mêmes espèces dans les Horacs ou risières marécageuses, et sur les collines.J 'ai trouve daus celte dérnière \{le, ainsi qu’à celle de France, une Espèce spontance beancoup plus petite et dont les Fleurs n'avoient point de bales calicinales. Sa Panicule est droite. Seroit-ce le Type de l'espèce 
cullivée? En ce cns on pourroit dire qu'elle auroit bien changé.

* C'est un Leersia.

Rocana. Forschal.

Une Plante qui crô̂t sur les borils de la mer, dn côlé de St.-Paul, m’a paru être le Trianthemu pentandra de Liuné fils; ınais il me semble, avec Forschal, qu'elle doil être distinguée comme Genre.

Rossolis; Droserz. L.

Lo Rossolis rotundifolin croîl à Madagascar. J'en ai trouvé une autre au Cap; elle est figuree dans le Thesmus zeylanicus de Burnan, sous le nom de Rossolis foliis circa rudicum in arben dispositis. Je crois qu'on la regarle comme une simple variété, ce donl j'ai peine à me persuader. J'y ai Iruuvé aussi le Urosara capensis. Leur examen in'a confirmé ce que javois observé en Europe, que ce Genre a six Styles réunis deux at deux, au lieu de ciny que lui attribue Linné; en sorte qu'elle doit former, dans le systêne de cet auteur, la PentaulrieHexagynie.

\section{Rotbotre; Rotbollia.}

Je ne sais si le Rostollia dimidiuta doil raster daus le mêne Genre que les autres Especes qui ont les épis linéaircs et articulés , et s'il ne faudroit pas le replacer près des Panicum.

Ronce; Rubus.

Une Espèce venue des Moluques s'est beaucoup multipliée dans les défrichés. On l'appelle Framboise. Sun Fruit rappelle par sa couleur celle d'Europe (c'est le Rubus rosafolius de Smill ), mais il n'en a pas le parfuru. On trouve daus le chemin de la plaine et aures endroits élevés uue aure Ronce remarquable par ses Feuilles blanchâtres et sur-lout ses Fleurs apétales, dont le fruit ressemble à ceux du Rubus fruticusa, ou Múres de haie. Il croil aussi à Madagascar.

Rousseier ; Roussair. Smith, Icomes inedila.

Vous l'avez figurédans vos Illustrat. Gen.Je ne l'ai vu qu'd l'Ile-de-France, où il prend souvent racine sur de vieux 
Arbres, et sur-tout sur les Fougères en $\Delta$ rbres; en sorte qu'it. paroit alors parasite.

RUIzIER; Rnizicl.

Sous cet article et celui de Pentapete vous ferez men. tion de nos beaur Arbres ou Arbustes qu'on appelle içi $\mathrm{Ma}$ hant, et que, malgré leur beauté, on ne remarrque que parce que leur Ecorce est bonne pour faire des.cordes.

Ruppre; Rnppia maritima. L.

J'ai trouvé cette Plante à l'fle-de-France. SaFran.

On ne connoît ici le Curcuma que sous ce nom, et le Ba-. lisier ou Cannu indica, sous celui de Safran maron. Sagoutier; Saghs.

Je n’ai pu suisir rle différence entre le Saģus des Moluques. et le Rafia de Marlagascar.

SAINFOIN ; Hedisarum. L.

Ces iles oífrent plusicurs Espèces, sur-tout celles trifoliées. Il me paroît uécessaire de les partager en plusieurs Genres. Saracie; Sulaciur. Calypso. Gen. Nor., nº. 68.

J'a envoyć à M. de J ussieu la notice d'uṇ Genre qui pourroit bien être le Sizlacin, mais qui n'est nullement gyıandrique. C'est un Arbuste de Madagascar.

Salsepareille; Smilax. L.

Il y en a plusieurs Espèces de ce Genre dans ces îles. Sandal.

Il y a un Mimosa arborescent, très-grand, auquel on donne ce nom. Je ue l'ai pas encore vu fleuri ; $j$ 'ai cependant ramassé dessous de ses Fruit.. Il est remarquable par de larges stipules colorées. J'ai recueilli daus les bois un Drupe provenant d'un grand Arbre qu'on appelle aussi Sandal; mais je n'ai pu une procurer ni ses Fleurs, ni mème ses Feuilles.

SA poti:; Achra.s. L.

Cet Arbre, transporté d'Amérique, est peu multiplié encore.

Sapotille; Coockia. Wampi. Fruit de la Chine. 
Sarote Negro.

Espèce de Plaqueminier. Diospyros.

Savonier; Sapindils. L.

-. Nons atons ici trois Espèces, mais apportées du delıors.

SaUVAgesi E; Salungesia. L.

J'ai trouvé une Espece de ce Genre dans les marais de Madagascar. Elle me paroît, entrautres, différer de colles d'Amérique, figurées dans Aublet, par ses Fleurs penchées et les Folioles de son nectaire plus longues que les Etamines; du reste clle on a tous les autres caractères.

Sct́vore; Scrioln. L. Lohelia. Plunı.

Ces íles en présentent deux Espèces bien différentes, dont l'une paroit étre celle de Plumier, l'autre celle de Rumple. Sebesteri ; Cordia. I.

Il y en a une Espèce indigène à l'He-de-France. Scirpe; Scirjuls. L.

- Il y al plusicurs Espèces de ces Plantes daus ces íles. Quelques-nues ne me piroissent pas cucore décrites. Il y en a deux, entr'autres, remarquables par lcurs Feuilles engaînées à la manière des Iris; l'une d'elles les a fort lougues. On l'appelle Canne miran. Elle croit dans plusicurs endroits; mais principalement dans ce qu'on appelle le brîlé, c'est-àdire le bas du volcan vers lc bord de la mer. C'est la seconde Plante qui paroisse sur la lave récente. La prenicere est me belle espèce de Polypode ćlancée. A peine la chaleur a-t-ello disparu; que dans les fentes on atperçoit des points verts; ce sout les radimens de ce Polypode. Pendant plusieurs années ce sont des plantules rabongries; mais elles se reulorcent et - acquièrent un ou deux pieds de haut. Elles préparent la place pour celle Canne maron; ensuite paroissent quelques pieds de votre Androméde ì fenilles de Snule. Le Licopodium nudum s'empare de quelques fentes, ainsi qu'une grando espèce d'Angrec ì Aents odorantes. L'Andropogon schlienanthus ne tarde pas à venir s'y montrer, ainsi qu'une autre espèce, l'Andropogon aurewm de Bory, qui doit plulôt se 


\section{des Iles australes d'Afrique:}

rapporter au Saccharum : ees deux Gramens y forment souvent des gazons très-épais; uais il s'écoule, à ce qu'il paroît, beaucoup de temps avant que d'autres Végćtaux osent s'y montrer.

L’air marin semble láter la Végétalion; car les hords de la mer, même les plus escarpés, se tapissent de Scavola, de votse Conise émonssée, d'une des variétés de Lobelie, et de la jolic Lysimachie de Bourlion.

* La Canne maron est un Lepidosperma de M. Labillardière, Plant. Nov. Holl.

Sophora.

J'ai parlé, article Acacic, d’une jolie Espèce de ee Geure, nommée par les Créoles Tamarin des hauts. Elle a l'nspect de l'Anthyllis barba-joris: je ne sais si ce n'est pas le Sophora cetraptera, ses légames ayant quatre arêtes. Il y en a un à l'Ile-de-France qui me paroît l'A nticholerica de Rumphe ; mais je crois qu'il y a erreur dans la citation de Linné.

J'ai vu daus le Voyage de Thunberg que vous aviez séparé de ce Genre le beat Sophora capensis sous le nom de Virgilia.

SoveneT; Cyperus.

Ces íles un'en out offert une trentaine d'Espèces: Madagascar, sur-lout, cu a de remarquables.

* Mr. I'oiret les a décrites dans cet article de l'Encyclopédie, ainsi que les Scirpes.

Speraincoque; Spermacocce.

$J$ 'on ai trois à quatre Espèces.

Spiraigne; Sphagnum. L.

C'est une des Plantes qui s'est le mieux' accommodée de $10 u s$ les climnts; aussi l'ai-je tronvée par-tout.

Spherie; Spherio, Hall.

J'ai trouvé qquelques-uncs de ces Plantules dang ces iles.

Spherantue; Sphoranthus. I.

J'en ai trouvé une Especec ì MIadagasear, à Fleurs vertes et très-odoranles. 
Stzaculrer, Arbre de Mahé; Sterculiu. L.

Cet Arbre vient tres-vile; ses Feuilles sout digitées d'une façon renarquable; ses Folioles sout disposées en rayous au sommet des jétioles.

Ses Fleurs ont une odeur qui lui mérite bien son norn. Il fructilie rarimeut.

Stramoife; Danura. L.

Il y en a quelques Espèces apportées vraisemblablement he l'Iude; le Metel entr'autres. 11 y en a une qi:i ne me paroît pas eucure deerite.

Stryenxos; Fomiquier. Kaniram. Diet. des Seienc. Nat.

Le Vontuc de Malagascar me paroît être une Espèee de ce Genre. Il y eu a une autre qui lorme un Arbre assezélevé, dont les Fleurs ne sont que quadrifides. Le fruit est beaueoup -plus petil, et ne contient, par avortement, qu'une seule Graine. Sumac; Rhus. L.

Il $y$ a à Madagascar plusieurs Arbres on Arbustes de ce Genre, qui ont des Feuilles simples rapprochées en verticilles trois à truis.

Surrane; Suriana. Joli Arbuste.

Il est très-commuu sur toutes les côtes de l'Ile-de-France. Sicante; Salanthus. Forschal.

D’après ce que dit M. de Jussieu, de ce Genre, article Cissus, on peut y rapporter l'Arbre simgulier qu'on appelle à l'ile-de-France Mapon, remarquable par sou tionc charuu ๆưon peut, malgré son épaisseur, traverser avee un couteau. Ses Feuilles sont décomposées; colles des jeunes pieds ressemblent à celles de quelques Ombellifères; par leur téunité, elles approchent de celles des Peucedanum, tandis quo daus celles des Adultes les folioles sout ovales.

D'où vient que ces îles présenteut lant d'arbres dont les jeunes pousses sont si différentes de celles des Adultes, tels que le Ludier, le Quivisier, les Dombey ou Penupétes, volre Tagurier hitéroplyyle, ete.? Je me suis souvent fail cetto question sans pouvoir la résoudre. 


\section{des Iles australes d'Afrique.}

On donne le uom de Maporz à quelques autres Arbres remuarquables par leur tronc informe et mou ; cependant l'Acas. cie hitierophyle, qui s'appelle ainsi, a le bois assez dur.

Celui de ces Arbres qui in'a paru le plus gros est celui qu'on nomme à l'Ile-de-Frauce le Mapou des hauts. J'en ai mesuré dont le tronc très-bas uvoit douze pieds de diamètre, et d'où partoieut une foule de branches qui formoient aulant d'arbres, C'est une Espèce de $P$ isonia, qui ne diffère du $P_{\text {isonia aculeata, qui }}$ croît aussi à l'fle-de-France, que par le Calice, qui est glabre d̀ cinq pans, sans avoir les points glanduleux qui couvrent celui de l'autre. Il differe aussi des Calpidia, Genr. Nouv., pl. VIII.

Tambous; Ambura. Juss.

J'ai trouvé quatre ou cinq Espèces de ce Genre singulier. Malgré l'apparence, je ne crois pas qu'il soit roisin des Figuier's et raême de leur Famille. L'Embryon de leur semence est lugé dans un Périsperme. Pent-être ont-ils quelques rap. ports avec les Poisricrs, qui sont dans le méme cas.

* Le Genre Monimir, que j’ai décrit et figuré dans mes nouveaux Genres, est dans le même cas; c'est ce qui a engagé M. de Jussieu a former la nouvelle Famille des Monimiers. TanRouge; Wreinmania.

On prétend que c'est sur ses Fleurs que les abeilles recueillent l'excellent miel vert. ...

TE17. ; Securinega. Com. Juss.

Cet Arbre a beancoup de rapports avec le Buis, anquel il ressemble un peu par sou feuillage. On pent le compter au nombre des A rbres dont les Feuilles des jeunes pousses different de celles des adultes.

Le Fruit est petit, et composé de trois coques monospernes. Tetracire; Tetracera.

I'ai trouré à Madagascar un. Arbusle sarmentenx qui paroit se rapporter à ce Genre, ayant un Arille comrue le représente Giertner; mais il n'a que trois Capsules, en sorte qu'on devroit le nomner Tetracera tricers. Todnali. Juss.

La patte de poule Epineusc. 
Tribule; Tribulus. I.

Le Tribulus pentander de Forschal croit ici daris les sables du côté de St.-Paul et de la rivière d'Ahord, oì les pointes de ses Fruits le font redouter des Noirs et des Créoles qui marchent nu-pieds. On le fronime Págode. Jai trouvé dans quelques cours le Tribulus pilosins.

Trrouomane; Trichomanes... - \#.

J'ai trouvé plusicirrs Espècess curieuses de ces jọlis Capil- laires; ui, entraulres, velu, sur l'ile de Tristan d'Acugna. ( Foy. Flur. Tr. d'Ac., $n^{\circ} \cdot 75$ ). Ils m'out rappelé celui de 'Thunbridge que $j$ "ai trouvé en Nornandie, et dont je vous ai communiqué des exemplaires daus le temps.

.T'sunack ; Comelia. L.

Ce joli Arbuste est cultivé au jardin de Pampelmouses, où on lui a donné le nom de Cerea.

Varic; Fuchs. L.

Je u'ai pas beaucoup augmenlé mes connoissances sır ce Genre depuis mon départ d'Europe. J'en avois raviassé quelques Especes à Tristan d'Acngia ; mais je les perdis en m'embarquaut, excepté le Fucus pyriferus. Le Cap.m'en a fourni quelques-uns; mais je nen ai irouvé que très-peu dans ces íles. VAVANOU IER; Fangueira. Juss.

Cel Arbuste esı peut-être le seul des Rubiaccés qui perde ses Feuilles. Son Fruit est des plus médiocres.

VerVEINe; Ferbena. L.

J'ai trouvé à l'Tle-de-France, maturalisés, les $Y$ erhenas, - Bonariensis, Indira et Officinalis. Le Nodiflora est commun sui lous les rivages.

VERUNIQUE.

Le Veronica arvensis s'esı naturalisé dans les cultures; il est tonjours à Fleurs blauches.

-Vigne; Vitis. L.

La Vigne commune paroit indigène dans l'intérienr de Madagasco:. Il y en a plusieurs autres Espèces. Violetre; Violu.

Dans les Noles du Voyage de Thunberg, vous parlez de 
deux Violettes de l'Ile-de-Fravee. Je n'en ai point trouvé d'irdigènes; mais deux à Madagascar, qui se rapportent à ce que vous dites. J'en ai trouvé une autre dans un jardin; elle avoitle port de celles d'Europe, mais avee des pédoncules tri-

- flores; ses Fleurs présentoient le méme phénomène que celles dn Viola Mirabilis ; c'est-ḋ-dire que les petalées étoient stériles, et qu'il y en avoit d'informes fertiles; ce que j'ai observé sur quelques autres Espèces en Europe.

Urve; Ulía. L.

Ces Plantes sont dans le eas des $V$ arecs; elles ne sont pas si communes que dans les pays tempérés.

URÊAE; Urena. L.

Il y a deux Espèces de ce Genre el des Paronia; mais il y a ici une Plante qui a absolument l'aspect de l'Abutilon, par le moclleux, la forme de ses Fcuilles, et la tigure et conleur de ses Fleurs; elle me paroît néanmoins appartenir à ec Genre. Utriculatre; Utriculatia. L.

J'en ai trouvé et figuré quatre Espèces à Madagascar, dout deux ont des verticilles utrienlaires, tels que Linné en attribue à son Utricularice Stellaris.

\section{Whattheria.}

Le Waltheria Indica se nomme Guimauve dans ces illes. J'en ai trouvé un autre à Madagascar, à Fleurs blanches.

XYRTS. L.

Madagascar m’en a présenté deux Espèces, dont une est très-petite.

ZOSTÈRE; Zostert.

J'ai trouvé sur les plages de l'Ile-de-France l'Espèce d’Europe. J'ai vu une autre Plante que j'ai présumé être du même Genre; mais lé manque de Fleurs ne m'a pas pernis de m'en assurer.

On a apporté, depnis mon départ de l'Ile-de-France, une Plante du Brésil qui avoit dans son pays nne trè-grande répu- 


\section{4}

Observations sur les-Plantes

tation; elle ne l'a pas perdue ici, quoique la propriété qui l'ait mise le plus en eredit soit heureusernent iuutile ici, celle d'êlıe spécifique contre la morsure des serpeus. Cette Plante a été donnée par le eapitaine Baudin sous le uon d'A ya-pana. M. Céré a clierché à la multiplier; mais sa réputalion de panacée universelle la faisant rechercher de tout le moude, et faisant arracher les feuilles fur à mesure qu'elles poussoient, a fait craindre qu'elle ne se perdit; mais il faut espérer que, par la graude quantité de plants disséminés dans les deux iles, clle se maintiendıa ; peut́-ćtre même survivra-t-elle à l'eathousiasne qu'elle inspire.

\section{POST-SCRIPTUM.}

Peu de jours avant mon départ de la Réuniou, je vis un pied de cette Plante quon y apporlait, naais saus Fleurs; en sorle quo je ne pus faire que quelques conjectures sur sa classification. Ses Tiges herbacées et ses Feuilles opposées sansstipules les bornoient à quelques Composées, quelquies Persounées et liophiorhiza. Sa réputation me faisoit pencher pour cetle Plante, n'en ayant d’idée que par la phrase de Linné; mais à mon arrivée ici, denx Fleurs qui resloient sur un pied l'ont classé dans Corymbifères. Je lıi ai trouvé uu Calice simple, cylindrique, caliculé ¿ la base par quelques écailles, contenaut uue vingtaine de Fleurons rougeátres sans hermaphrodites; le Placenta esı légèrement alvéolé, ce qui est le caractère des Cacalies. Mais ses Feuilles opposées inférieurement et son odeur lui donnent plus d'analogie avee les Eupatoires qui, comme vous le remarquez, en sont très-voisines. En parcourant l'un et l'autre Genre, soit dans Linué, soit dans votre Ouvrage, je n'ai rien Irouvé qui se rapportát à cette Plante. Cependant, dans la section des Eupatoires, qui comprend les Espèces dont les Calices contiennent de quinze à viugt Fleurons, il y a l'Eupatoire Aromaticum et Odoratum. 


\section{des Iles australes d' Afrique.}

Il seroit trop long d'entrer dans les détails des différentes cures qu'un lui attribue; d'ailleurs M. Céré en donne un détail circonstancié.

J'espère qu'avant peu elle donnera de nouvelles Fleurs, sur lesquelles je l'examinerai plus particulièrement. Je n'ai rien vu dans Pison el Marcurave, qute nous avons ici, qui ait trait à cette Plante.

Eflectivement je l'ai vue fleurir abondamment, en sorte que j'en ai fait une description plus complète; je la joins ici avec une figure.

Tiges couchćes, remontantes, radicantes, rougeâtres, un peu velues.

Feuillcs opposćes dans le bas, devenant alterues vers le haut, scssiles, sulspatulées, longues de trois ì quatre pouces, larges du quart vers le sommel, glabres, d'un vert foncé, dentćes, sinućes vers le sommet, deux nervures peu considérables it la base, deux autres sillonnées vers le milieu, un peu épaisses.

Flenrs en panicule pauciflore, composées.

Calice comnun, cylinctrique, simple, caliculé à la hase par de petites écailles contenant une vingtaine de Fleurons hermaphrodites rongeâtres.

Semences cylindriques; aigrelle simple.

Odeur pénétrante sans étre très-forte, approchant de celle du Ligusticum levisticum ou Ache de Moutagne.

Goût un pell astringent.

M. Ventenat a fait connoitre le premier cetre Plante en Europe, dans le maguifique ouvrage du jardiı de Malmaison. Il la caractérise ainsi :

Eupatorium aya-pana. Foliis lanceolatis, integerrimis . inferioribus oppositis, superioribus alternis, calicibus sub. simplicibus multifloris.

On voit que cet autenr diffère avec moi, en ce qu'il attribue à cette Plante des Feuilles trc̀s-entières; cela vient de ce qu'il 
ne l'a vue que dessécliée, et que, dans cet état, les bords se contractent tellement, que les dentelures disparoissent.

On a apporté aussi depuis peu une Plante sous le nom de Bamhou de Chine. J'ai bien reconnu tout de snite qu'elle n'avoit rien à déméler avec les Bambous, et les Fleurs mout appris que c'étoit l'Eaphorlia tithymaloides, I., avec cependant les particularités qui la font différer des figures de Pluckenet et de Jacquin.

M. de Cossigny a rapporté de Ténérife, sous le nom de Glaciale, la Graine d'une Plante propre à faire de la Soude. D après ce que jen ai vu, c'est !'A izoon Canariense.

Parmi il s'est trouvé aussi le Mesembryanthemum glacinle; mais il étoit cultivé depuis long-temps dans ces Iles, sur-tont à Bourbon, où ses feuilles font partie de celles qu'ou mange habituellement sous le nom de Biedes, et c'est une des meilleures le ce genre de légumes. Il y a une espèce de ce genre qui croît naturellemeul sur les roches marilimes des deux colonies; elle ressemble à la Soude par son port, ses fenilles et le goút salé; ses fleurs sout blanclics : sa sarcur salée annonce qu'elle pourroil, par l'incinératiou, fournir de la Soude.

11 a apporté en méme temps des Graimes d'un Arbuste sous le 10 cle Balo, qui, quvique puant, forme un bon fourrage. D'après l'inspection des Graines, je le rapporterois au Coprosma; mais ce Genre est originaire de la Nouveile Zélande. :

* Cctte Plante est l'Asperula calabrica de Liuné fils, le Pnioria de M. Persoon. 
Te vais terminer cette Nolice par rapporter l'arlicle Calac que j'ai eomposé pour le Non'eun Dictionnaire des Sciences nazurelles, en ajoutant la figurc du Calac, bois amer.

Calac (13ot.) Carissa, Linu. Ja première espc̀ce conuue de cc Genre étoit nomunée Kalaka daus la languc tanoule. C'cst le Carendang on Rendang de Java, suivant Rumphius; le Carandas de l'Inde menlionné par Garcias, Caspar Bauhin et Rumphins; le Calac de l'Isle-de-France, où il a été naturalisé. Iamarck a adopté ee dernier nom pour désigner eu français lo Gcnre entier, qui, dans l'enscmble des Fanilles, apputicnt à la série des Monopélales hypogynes, et fait partic des A pocynées dans la scetion des ovaires simples. Il a, eomme les Genres qui l'avoisinent, dans l'ordre naturcl, un Caliee t cinq divisions, une Corolle tubulée, divisée en einy lobes et chargće d'autant d'Etanines, un Ovaire surmonté d'un style et d'un stigmate simple bilobé. Son Fruit est unc Baie parlagéc cn deux Loges par un Réceptacle tenant lien de cloison, qui supporte de chaque côté plusieurs Graiues comprimécs, altaehées par lcur centre, bordécs d'un fenillet membraneux, et rcuplies par un l'érisperme corné, dins lequel est lozé l'Embryou, dont les Colylédons sont aplatis. Cc Genre comprend des Arbres et des Arbusles d'un port remarquable. De chaque bifureation des rameaux sortcnt deux jé́doncules, qui avortent dans la parlic inférienro et sc eliangent en Epines raneuses très-forlos. Sur les cing Espc̀ces rapportées à ce Genre par Wildenow, deux n'ont pas ces Epines. L'Arduina, semblable par son port, a été réuni avec raison à cc Genre par Jussicu, depuis, qu'on a reconnu que le Calac avoit un scul Ovaire an lieu de deux assignés par Linnxus, cl il forme une sixic̀me Espèce. Nous en avons trouvé deux autres fort intéressatutes, l'une à l'Ile-de-Bourbon (la Réunion) et l'autre ì Madagascar, en sorte qu'il comprend maintenant au moins huit Fspèces qui n’appartiennent qu'aux pays chauds de l'ancien Continent. Ce Genre, ẹomme nuus lavons dit, est rangé par .Tussicu dans la troisièıne section des Apocinées. Il y suit le genre Thevetia, séparé récemment 


\section{8}

\section{Observations sur les Plantes}

par Jussieu du Cerbera, que' ses deux Ovaires accolés reportent à une autre section. Il sert encore à ćlablir un passage des Genres Ruuwolfia, Oplioxylum, Thesecia, au Caniram ou Siryclinos, dont il se rapproche beaucoup par la siluation'des Graines allachécs sur leur centre à un Réceptacle central, par la strnciure de leur Embryon et de leur Périsperme, par la pulpe du Fruil qui est mangeable dans sa parfaile malurité, et par la qualilé annère de sou bois. Il diflère cependant du Caniram en ce qu'il est laileux.

Liespèce la mieux connue et la plus intéressante est le Carandas de Rumph., Herls. Amboin., vol. 7, pag. 57 , 1. 25 , Carissa Carandas, L. , que Roxburgh a figuré de nouveau dans les Plantes de Coromandel, vol. 1, pag. 55, tab. 77. C'esl un Arbuste loible, diffus, à rameaux presque horizontalemen bifurqués, garnis dans les points noneux de division de deux Epines opposées, également horizontales et sonvent olles-nếnes fourchues. Les Feuilles sont opposées, ovales, obtuses, lisses, luisantes, remarquables par la régularıć de lcurs inserlious. Une paire est placée aux nouds et se croise avec les Epines; une autre s'insère sur lo milieu des Rameaux à une distance égale de deux nouds et de leursćpines. Les Pédoncules paroissent lerminaux el géminés; mais il esı aisé de s'appercevoir qu'ils sont de même nature que les Epines, et que par conséquent ils doivent êlro naturellement ačcompagnés de deux rameaux, ce qui arrive dans d'antres Espèces. Ils portent ordinairement trois belles Fleurs blane de lail, semblables à celles de Jasmin; la Corolle est infundibuliforme, à ciny déconpures aiguës. T.e Fruit, qui est toujonrs simple, est une Baie du volume d'une petile Prune, mais plus alongée, noire, luisante, quand elle est mûre. Flle conlient ordinairement huil graines comprinees; elles sont eınbriquées sur un Placenta cenıral, el renversées. Cet Arbrisseau croît naturellement dans l'Inde, où il s'accommodo de tous les terraius : on l'a apporlé à l'Ile-de-France, ou il so multiplie facilement. Il est très-propre à faire des haies, que ses fortes Epines rendent difficiles ì traverser. Ses Fruits, avant 
leur maturité, servent, comme beaucoup d'autres, à faire des Alchars très-estimés; ce qui consiste à les conlire dans le vinaigre itvec du pinent. Iorsqu'ils sont múrs, ils sont trèsrecherchès par les naturels du pays et méme par les Européens.

La seconde espèce est ligurée encore par Rumpliius, sous le nom de Spina spinarıın, fig. 3, ou Epiue sur Epine, d'où Linnæuıs a tiré le noun trivial de Carissu spinarum. Elle se distingue par son port arborescent : ses Fenilles sont ovales, aiguës, veinées; les découpures de sa Corolle sont lancéolées, oblongues.

Elle diffère d'une troisième Espèce dout Forschal avoit cru devoir former un Genre particulier sous le noin d'Antura, par ses Rameaux it peine pubescens, ses Pédoncules solitaires, bifides, et sa Corolle plus grande.

Cette troisième Espèce est nommée par Vahl, Fidulis, Calac comestible, parce que ses Fruits sont recherchés dans l'A rabie heurense, sa patrie. Ses Ranneaux sout velus au sommel; ses Fenilles ovales, aiguës, saus nervures apparentes, et les découpures de sa Corolle sont laucéolées-linéaires.

L'A rduina, uu Calac double-épine du Cap de Bonne-Fspérance, est un Arbuste ì Rameaux diclıotomes, acconpagués de deux Epines droites, deux fois bifides; les Feuilles sont opposées, cordifurmes, très-entières. Les Fleurs sont terminales, fasciculées et blanches, les baies rougeâtrés. Elle a été figurée par Miller, tab. 30o, sous le nom de Lycinn. On la cultive main. tenaut au Jarlin des Plantes. Flle denande la serre chaude pendant l'hiver.

Denx deruières Espèces qui sont sans Epines, ont été déterminées par Vahl daus ses Symbolce botanicre. Il nomme Ja preuiere inermis, et la distingue par ses Feuilles ovales, cordiformes, saus nervures; l'autre, qu'il nomme mitis, el qu'il figure, t. 59, est caractérisée par ses Feuilles luncéolées et amincies. Liune et l'autre sont originaires des Indes Orientales.

A ces Especes connues précédemment doivelut se réunir plusieurs autres très-remarquables. Nous nous bornerons à en faire connoître une de Eourbon, parce qu'elle peut devenir très- 
utile, et à en indiquer une autre de Madagascar, qui a beaucoup de rapport avec elle.

Calac de l'Ile-de-Bourbon on Bois amer. Celle Lispècc, qui n'a pascucore été décrite, est remarquable par son port et par les proprićlés quon lui attribue. Elle formc un petit Arbre dout le tronc, à peine de six pouces de diamètre, cst recouvelt d'uue écorce mince el gercée; ses Ramcaux sont réunis en une cime très-garuie et pyramidale. Les Branches se bifurquent : cntre deux bifurcations il se trouve trois à quatre couples de Fenilles ovales, acumiuécs, fermes, lisses, marquécs de trois à ciuc nervures latćrales. Les Pédonculcs sout extra-axillaircs, longs de deux pouccs, et sont armés d'une ou de deux Epines; ils poltent une ou denx Flcursà cinq découpures aignës. Le Fruit cstune Baie peu succulentc, longuc d'un pouce, rétrécie au sommet en une pointe mousse; son ccntre est cccupć par un Réceptacle qui se partage en deux; il est couvert de douze à quinze Graines aplaties et borlées d'un ccrcle membrancux. Le Bois de cet Arbre est très-compacte, d'un jaune plus foucé que celui du Buis, anquel il ressemble; il peut le remplacer avautageusement pour les ouvrages du tour: il a, de plus, une saveur anère, qu'il communique à l'cau par infusion, et que l'on regarde commc très-stomachiquc. Quelques personuez en out fait faire des gobelets dans lcsqucls on laisse séjouruer du viu; il acquiert par ce moyen une amertume très-estimée. Cet Arbre croit dans lcs Labitations élevées, autour de St.-Denis à Bourbon; mais il est tellement recherché par les Cı'ćoles, qui le regardent comme une Panacée, qu'il est difficile d'en rcncontrer des pieds d'ume grosseur assez considérable pour être cmployés aux ouvrages du tour.

Calac de Managascar. C'est un Arbuste qui a bcaucoup de rapport avec le Bois aner; mais ses Feuilles sont plus arrondies, ses Fleurs plus petites, ainsi que ses Fruits, qui sont presque ronds. Il y a apparencc qu'il jouit des mêmes propriétés (A. P.)

De l'Imprimeric de P. Gugrfier, rue du Foin-Saint-Jacques, $n^{\circ}, 18$. 


\section{COURS \\ DE BOTANIQUE,}

'Appliqué aux productions végétales qui croissent is l'Isle-de-France.

\section{PREMIÉRE PROMENADE.}

Sur les différentes Parties qui composent ordinairement une Fleur.

M. D'A R TENÁ venoit de se fixer, depuis près d'un mois, sur une habitation de l'Isle-de-France, dont il avoit fait réccınment l'acquisition : amateur passionné de la Nature, il avoit eu plus d'égardà la beauté des situation qu'au revenu qu'il pouvoit en tirer. Il y avoit conduit Paul son fils, âgé d'environ lıuit ans. Chaque trait de cet aimable enfant lui rappelant ceux d'une épouse qn'il avoit perdue, redonbloit son amour paternel; mais il ne croyoit y satisfaire qu'en cultivant avec soin les facultés physiques et mornles de cet être chéri. Partisan éclairé de l'éloquent auteur d'Emile, il avoit cherché à faire un choix dans ses priucipes, en mettant de côté tout ce qui lů parois-

Cours de Botanique. 
soit exagéré. C'est ainsi que, destinant son fils à vivre dans la société, il savoit que, quelqu'état qu'il embrassât et quelque fortune qu'il eût à cspérer, il auroit des devoirs à y remplir. D'apres cela, il croyoit que, le pliant de bonne heure à ce joug nécessaire, l'habitude le lui rendroit plus facile ì supporter; mais on même temps il vouloit ne le lui faire sentir que le moins possible : par exemple, il ne crut pas qu'il dût attendre que son fils cût seize ans pour lui montrer à lire et à écrire; il jugea, au contraire, qu'en commençant le plus tôt possible il lui épargneroit beaucoup de dégoûts et de difficultés; mais il ne lui mit point entre les mains l'alphabet commun, il en connoissoit trop bien les défauts, qu'une longue routine a consacrés. Il cut à choisir entre plusieurs autres méthodes, également ingénicuses, qui avoient pour but d'instruire en amusant : il crut reconnoître dans lcs unes et les autres plusieurs avantages et plusieurs inconvéniens; en sorte que de leur cnsemble il s'cn fit une particuliere, par laquelle il apprit en même temps à lire ct à écrire à son élève. Quoiqu'il cât adopté principalement les moyens qui lui parurent les plus propres à piquer sa curiosité, il ne tarda pas à s'apercevoir que, par la mobilité d'esprit, qui est le partage de l'enfance, les caractères, qui ćtoient d'abord des jouets, devinrent inditférens, et qu'il fallut finir par employer un peu de contrainte pour les fairc prendre. Cependant, en variant ses moyens, il ćtoit parvenu en assez peu de temps à le faire lire et écrire couramment. 
Chemin faisant, il lui avoit donné des notions sur les objets qui s'étoient présentés. Il voulut, à cette époque, prendre une marche plus directe, et commenecr à développer en lui les gerınes des connoissances utiles, ct sur-tout lui on faire naître le gout. Aucune étude ne lui parut plus propre à remplir ce but que celle de la Botanique ; car, excrçant la mésans la fatiguer, elle accoutume l'csprit a mettre de l'ordre dans les idées, ca attirant l'attention sur une des belles parties de la Nature. Il ne vouloit pas non plus lui mettre dans les inains d'autres livres que celui de la Nature. Il cherchi à le lui faire lire directement; cn sorte que c'étoit l'ayant sous les ycux qu'il résolut de lui cn dévclopper l'alphabet. Rien de plus propre à ce dessein que des Promenades qui, en lini faisant faire un exercice salutaire, devoient lui procurer de l'instruction. Desirant en bannir toute contrainte, il ne vouloit pas même proposer à son fils de l'accompagner; il desiroit que l'idéc scmblât lui en 'venir de lui-même. Peu de jours après sa prise de possession, ils en avoient déjà fait une ensemble, mais les tracas d'un nouvel établisscment, et plus que tout cela le mauvais temps, avoient fait différer à M.D'Artenai l'exécution de son projet. Débarrassé de ces soins, il sort un matin dans cettc intention. C'étoit unc de ces belles unatinées, que la privation que l'on a ćprouvée rend encore plus délicieuses; cc n'étoit cependant pas le printemps si célébré, ce inoment où la Nature sort d'une profonde léthargie, qui sembloit wenacer d'un engourdissement éterne!. 
Dans cette île, où, grâces au climat, on n'éprouve point ces fortes vicissitudes, la Nature n'offre pas aux poètes, dans le cours des saisons, de grands contrastes; ce ne sont que des nuances plus difficiles à saisir.

Le printemps ici est la convalescence d'une beauté : une légère maladic a pâli ses charmes, mais chaque jour les ramène à leur premier éclat; les progrès rapides qu'ils font attestent qu'avant peu ils seront encore plus brillans qu'auparavant.

Ainsi, tandis que son fils s'amusoit à quelque bagatclle, à qui il donnoit beaucoup d'importance, il passe sans aff'ectation à côté de lui. = Où allez-vous, japa? - Promener. = Je voudrois bien aller avec vous. - Oh ! non, tu es trop occupé. = J'aime ellcore micux aller avec vous. - Fripon, tu crois que j'ai encore une orange dans ma poclic, comme la dernière fois. = Je vous assure, papa, que ce n'est pas pour cela._Eh bien, allons, viens. = A proposd'Orange ( 1 ), allons-nous voir cet arbre autour duquel vous avez fait abattre les lianes qui l'accabloient, et arraclier les Framboisiers (2)qui l'entouroient, parce que vous disiez qu'il nous en donneroit des Oranges? Il y a longtemps de cela. Je ne sais pas; malgré tout ce que vous avez $p u$ me dire, j'ainois micux encore ces Framboisiers, j'y trouvois quelque chose de bon; au liea qque votre arbre, qui ressemble ì tous ceux qui l'entourent..... tenez, je crains bien qu'il ne vous paye pas de tout ce que vous avez fait pour lui. - C'est ce gue nous allons roir. Ces Framboises te tiennent bien 
au cour : tu ne te sou yiens donc plins de la façon dont elles avoient arrangé tes mains par leurs ópines?

Ils se dirigdrent effectivement vers un endroit où IM. D'Artenai, ayant trouvé un Oranger fort négligé, l'avoit fait dégager. Comme c'étoit un des endroits les plus pittoresques de l'habitation, il comptoit y faire des embellissemens.

Là se trouvoit un commencement de jardin qu'il vouloit étendre, et y rassembler les productions des quatre parties du Monde, que cet heureux climat permet de réunir, tandis qu'une lisière de bois, qui avoit été laissée, réunissoit la plupart des arbres indigènes quela Nature a destinés à décorer cette île. Près de là, un escarpement dominoit un ruisseau qui bondissoit de cascade en cascade. En approchant, une brise légère leur apportoit l'odeur la plus suave.. = Alı! que cela sent bon par-ici! s'écrie l'enfant. En mêmo temps il découvre l'arbre; mais il ne le reconnoîtroit plus, si un banc placé an pied ne lui assuroit quo c'est le même: car lorsqu'il l'avoit vu la dernière fois, il ne portoit que quelques feuilles, dont le vert sombre étoit encore reubruni par une Croûte noirâtre (3); mais depuis, de nouvelles pousses s'étant développées, l'ont entièrement reconvert d'une verdure tendre; des milliers de fleurs d'un blanc éclatant, lavées de pourpre, percent ì travers, et offrent aux yeux dus petit boulhom ne un spectacle inattendu. - Eh bien, tu vois, mon fils, je n'ai pas eu affuire à un ingrat. $=$ Pour cela non, car voilà de jolis bouquets. Vous allez me permettre d'en cucillir? 
Après en avoir cueilli une branche, l'avoir sentie et retouruée de tous les côtés, cffeuillé le plus grand nombre des fleurs, il dit avec un léger sompir: Papa, c'est bien joli ! mais il n'y a point là d'Oranges, et les Framboises..... - Je vois que tu es pour le solide; mais regarde de tous côtés: n'as-tu pas lù de quoi te procurer le plaisir de te faire des égratignures tant que tu voudras? Il n'y en a que trop; je voudrois avoir fait disparoître jusqu'à la dernière. Mais revenons à notre arbre ; voyons si j'ai lieu d'être conteut des présens qu'il m’a déjà faits, et s'il ne m'en fera pas quelque autre. De la maison, tu l'avois jugé sans le voir. Il t'a déjà agréablement surpris. Avec quel plaisir tu respires les parfums qu'il répand! Cherchons bien si nous n'avons rien à espércr de ces fleurs. Tu en as déjà gâté plusieurs. Prends-en une toute seulc... Bon.... Exannine-la avec attention.

$=\mathrm{Je}$ vois cinq feuilles, qui font comme une étoile, c'est ce qu'il y a de plus beau dans la fleur; et puis voilà tout plein de machines jaunes qui sont au bout d'un petit bâton ; et puis en voilà un autre qui est au milieu : c'est encore un petit bâton, qui est gros aux deux bouts; c'est comme un pilon; et puis..... et puis.....-Et puis..... est-ce là tout? = Oni, papa. - Voyons un pcu : pour bien nous en assurer, mettons toutes ces petites machines, ces petits bâtons chacun ì part. Mets-les là sur le banc. = Tenez, voila les cinq feuilles; elles sont venues toutes senles. Ah ! voilì un petit plat qui est cn-dessous, que je ne voyois pas; mais aussi, c'est qu'il est bien plus petit 


\section{Première Promenade.}

et n'est pas si beau que les feuilles. Voila tons les petits bâtons : olı! oh! ils sont attachés les uns aux autres par le côté. En voilì quelques-uns qui sont tont seuls. Il ne reste plus que le bâton qui resscmble ì un pilon; il est lit tout seul à se carrer. Il tient plus que les autres; et je n'ai plus dans les doigts que la petite écuelle, qui est an bout de la queue. Je ne me serois pas douté qu'il y eût tant de choses dans cette fleur. - Ni moinon plus : des Choses, des Machines, des Bâtons, des Ĺtoiles! = Je crois, papa, que vous vous moquez de moi. Vous faites comme Azor notre menuisier, qui youloit que je susse le nom do ses outils, et qui rioit parce que je les appelois des machines. Il a vu aussi que ce n'étoit pas bicn sorcier de connoître une verlope, un valet, et puis.....- Et puis tu vas me faire passer toute la boutique d'Azor en revue. Tu te crois déjà aussi habile que lui, parce que tu as attrapé le nom de ses outils : mais comment as-tu fait pour les savoir? = Pardi, je les lui ai demandés; et s'il $y$ avoit des noms pour nos petites machines, je les demanderois aussi. - Pourquoi pas? $=$ Bah! qui se sera amusé à aller dénicher cela au milieu de ces fleurs? Est-ce qu'il y en a? - Oui, mon fils. = Vous les savez donc? En ce cas, vous allez me les dire? - Oui, mon fils, cliacun de ces morccanx a son nom : voyons si tu les retiendras aussi bien que ceux des outils d'Azor. D'abord, la petite écuelle s'appelle un Calice (Voyez, planche $\mathbf{r}^{\mathrm{rc}}$, fig. a et b); l'étoile est la Corolle (c); chacune des fenilles qui la composent est un Pétale; les bâtous sont les Éta- 
mines (d); le pilon du centre est le Pistil (e). = Mais en voili beancomp : je ne sais pas si je pourrai les retenir. - Comment as-tu fait pour retenir les outils? =En redemandant ceuxqunej'avois oubliés. - Elı bien! tu seras tonjours ì mêue d'en faire antant. = Mais à quoi tont cela sertoil? - Sais-tu à quoi servent les outils d'Azor? = Oui. - Comment l'as-tu appris? = En le voyant travailler; mais je n'aurai pas besoin de cela : vous m'avez dit les noms de si bonne grâce, que vous medirez de même à quoi cela sert; au lieu qu'Azor est si grossier! d'eilleurs il ne parle que créole $\left({ }^{*}\right)$, et

(*) On sait en général que dans nos colonies les Nògres qui y ont été transportés de différens points de l' $\Lambda$ frique, se sont formé uu jargon qu'nn numme patais créole. Il est composé, à peu de chose prẹ̀s, de nots français, mais qui sont pour ainsi dire déshabillés de toutes les formes grammaticales, 'untr'autres les verbes n'ont que la terminaison de l'infinitif; c'est la syntaxe réduite à la plus grande simplicité. Aussi les noirs nouvellement introduits, ceux méme des castes les moins civilisées, sont-ils bientót en état de comprendre et de se faire entendre; les enfans des Colons sont dans ce cas, ils apprennent bien plus vîte à parler de cette manière. Pour peu qu'ils soient à mème de recevoir quelqqu'éducation, ils ont bientôt épuré leur langage; peut-être même, si on s'y prenoit bien, sont-ils mieux préparés pour recevoir les principes de la grammaire.

En exaninant la formation de co jargon, j'ai cru pouvoir me rendre raison de l'altération de nos langues du midi de l'Europe, elles descendent évidemment du latin; la plıs grande partie'des mots qui les composent sont au fond les mêmes; les finales et la construction sont ce qui les distingue le plus. Eh bien, que l'on se reporte maintenant au temps le plus brillant de l'empire romain, que l'on fasse attention à cette foule d'ęclares qui étoient 


\section{Premiere Promonade.}

vous ne voulez pius me le laisser parler, - Moi? Je t'ai laissé baragouiner tant que tu as voulu. = C'est vrai; mais c'est ce monsieur qui est venu se moquer de moi.-Eh bien, il t'a rendu service, puisque cela t'a fait prendre sur toi de te déshabituer de cette manière de parler : elle convenoit à un enfant; mais si tu l'avois conservée étant plus grand, on auroit pux croire que tu n'avois pas reçu d'éducation. Tu es donc venu à bout toutseul de connoître l'usage des outils. 'Tu peux faire la même chose ici. = Ici, c'est bien différent; d'ailleurs, vous m'avez dit les noms, vous pourrez bien aussi me dire cela. - Je t'ai dit les noms, parce que tu ne pouvois pas les deviner; mais pour le reste, tûchons ensemble de le découvrir. Voyons ce que devient tout cet assemblage.

Ces fleurs ne sont pas dans le même état. = C'est vrai : en voilà qui sont recoquillées en petite boule; en voilà de plus longues, tonjours fermées; puis les

transportés de tous les points du globe, il n'est pas douteux qu'ils ne se fussent fait un langage créolc, comme nous dirions actuellement, mais quils nommoient vernacula, de verna qui signifioit esclave né dans la maison, exactement ce qu'oul nomme Créole maintenant. Les articles auront alors reparu pour les déclinaisons, et les personnes pour les conjugaisons, et c'est ce qui distingue plus fortement nos langues modernos: que l'on se transporte maintenant vers la décadence de ce vaste empire, on verra que l'éducation, négligée alors, ne s'occupa pas de ramener les enfans libres, élevés par les esclaves, à la pureté du langage, et par-là il se sera sensiblement altérć. On sent qu’un pareil sujet ne peut se développer dans une simple note. 
fleurs épanouies; enfin en voilà de tout-à-fait passées. - Prends unc épingle, et ouvre une de celles qui sont encore en Bouton, les plus avancées. = La voilà; c'est la mênc chose que dans les autres. - Est-ce bien la inême chose? =Oh! non; cette machine jaune, qui est au bout du bâton, est plus grosse ; au lieu que celle de la fleur ouverte est toute chiffonnéc et couverte de poussière. Est-ce que cette poussière étoit dedans? - Oui, cette machine jaune étoit un sac destiné à la contenir, ou plutôt deux sacs; car tu peux voir qu'ils s'ouvrent de deux côtés. On appellc ce sac Anthère, et le bâton lui-même Filament. = Et notre Étamine, que devient-elle? - Les derx ensemble font l'Étamine : c'est comme un couteau, qui a un manche et une lame. = C'est vrai, je n'y pensois pas. Le Filament est donc le manche? - Vois inaintenant la fleur passée. $=$ Il n'y reste plus que le pilon, le Pistil, je veux dire. - Cherchons sur d'autres branches. = Al! ! voila une des boules qui est pius grosse que mon pouce. Mais..... c'est une petite orange! Ah! il y en aura peut-être de plus grosses. J'ai beau chercher, je n'en trouve pas.

Elı bien, es-tu réconcilié avec mon Oranger? = Pouah! comme c'est mauvais! - Je le crois bien; tu dois voir qu'elle n'est pas encore à son point : cette petite boule, qui n'étoit pas plus grosse que la têtc d'une épingle, est déjà devcnuc de la grosseur de ton pouce; elle a cucore ì croître avant de venir à celle d'une orange bonne ì manger. $=$ C'est bien la le bout de mon pilon; oh ! oui, voilà encore la petite 


\section{Premicre Promenate.}

écuelle qui est dessous. Le reste est donc tombé, le bâton et l'autre gros bout? - C'est vrai ; ce sont trois parties qui forment ensemble le Pistil : la boule qui devient l'orange, est l'Ovaire. Ce nom lui vient du latin ovum, ouf, parce qu'il contient les semcuces ou -graines, qui sont comme les œufs des plantes. Le bâton est le Style, et l'autre bout est le Stigmate. = Mais ça commence à devenir plus long que la boutique d'Azor. Cette Corolle qui est si belle! ct ces Étamines, tout cela est donc inutile? il n'y a que cet Ovaire que je n'apercevois pas, qui est bon à quelque chose? - Comme tu y vas! tu as bien vîte déciclé. Il est bien vrai que ces Pétales, qui font tout le charme de la fleur, ainsi que les Ltamines, n'ont duré qu'un instant, et que roilat la terre qui en est jonchée; mais en les examinant plus attentivement, peut-être pourrons-nous leur trouver quelque moyen d'être utiles. Mais voilà un Grain de pluie, tâchons de gagner la inaison avant qu'il ne soit arrivé; d'ailleurs nous avons autre chose à faire. = C'cst vrai, j'ai à écrire. A propos, si , au lieu des mots que vous me dictez, vous me donniez tous les noms de nos petites machines?- Tu as raison, c'est le moyen de te les rappeler quaud tu voudras.

\section{NOTES.}

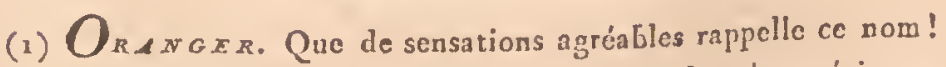
La Nature semble avoir voulu réunir ses faveurs les plus précieuses sur les arbres qu'il désigne. Utile dulci, telle est la devise q̣u'il a 
fou:nie. Puissc-t-il donc devenir l'emblême de mon ourrage! puisse l'Enfance y puiser le gon̂t pour le spectacle de la Nature, qui pourra, par la suite, lui procurer des plaisirs purs sans satićté. Que, par son moyen, le jeune homme, en exerçnt son activité, puisse arquérir des connoissances qui lui seront utilos dans quelque position qu'il se trourc; que la jeune beauté, en voyant faner le bouque dont elle aime à se parer, en tire des leçons moins sérieuse que celles des inoralistes; que la mère de famille y trouve à augmenter les ressources de son industrie; que le colon intelligent y soit secondé dans ses projels d'améliorations! Enfin, puisse-t-il devenir un dépòt où clı̃ụe âge, chaque profession y puisse rencontrer l'utilc et l'agréable! MIais que cliacun en particulier, content de ce qu'il pourra y trouver de son gontt ou à son usage, ne repousse nas ce qui rue lui eonviendroit pas si bien; qu'il songe que si l'oranger exhale par ses flcurs un parfum si exquis, que si la pulpe de son fruit offre la saveur la plus ngréable, il est armé d'épines qui ont leur manière d'ètre utiles, et que l'anertume qui réside dans ses feuilles et dans l'écorce de son fruit, peut etre d'un grand secours contre les maladies qui nous afligent.

Peut-ètre ici quelques personnes voudroient me roir percer la nuit des temps, et déterminer l'époque où ces arbres ont été connus; si ce sont eux que l'antiquité savante et allégorique a désignés sous le nom de Pommes d'or', gardèes dans le jardin des Hespérides. D'autres pourroient demander qu'avec le pinceau brillant d'un Saint-Pierre, je les promène sous des berceaux parfumés; ınais je vais m'arrêter sur des détails plus arides, ce sont ceux de la classification.

Cet arbre fait partie du Genre Citrus, Citronnier, de Linné. Ce Naturaliste le place, daus son Systéme, dans la Polyadelphie Icosandrie. Le promicr de ces deux noms veut dire Plusieurs fraternités ou confréries; le second indique qu'il y a unc vingtaine d'Etamines. Il désigne, par le premier, que ces Etamines sont réunies en plusieurs faiscenux. Dans l'Ordre naturel de M. de Jussieu, il donne son nom à une famille qui ne conticut que des 


\section{Notes de la prenière Promenade.}

arbres arbustes, la plupart intéressans. La Nature n'en avoit point placé dans cette ile, mais la culture en a introunit plusieurs, qui. paroissent s'y plaire, tels que douze espèces environ du genre Citronuier, comme Limons, Bigarades, Vangusaies et Pamplemouses; plusieurs autres de différens geures, tels que le .Vurraia, Buis de Cline; des Limonia, tels que l'Orangine, ou Meia Conchi de Chine; le Cookia, ou Mampide Chine, improprement appelis Sapotille.

On sait par quel art une partie de l'Europe a joui de ces beaux arbres. Les Orangeries sont devenues les plus beanx ornemens des palais. Le philosople pourroit les voir avec dédain, comne des monumens de luxe; mais le savant les verra avec plus de complai.. sance, en considérant que le cultivateur, s'étant exercé à procurer à ces hótes délicats toutes les comnodités que le climat leur refusoit, s'est rendu de la plus grande utilité pour l'listoire naturelle. Appliquant successivement les connoissances qu'il avoit acquises ̀̀ des végétaux moins précienx en apparence, le Botaniste a vu, sans s'écarter de sa patrie, s'épanouir des riclıesses qui auroicnt demandé plusieurs années passées dans l'agitation des voyages, pour les voir crô̂tre sur leur sol natal : ceci toucheroit peu une quantitú de personnés accoutumécs à regarder les spéculations des sciences comme peu intéressantes pour la société; mais elles verront avec plus d'intérẻt les Serres devenir un entrepôt, par le moyen duquel les deux Mondes se sont comuuniqué leurs richesses. Nous en verrons plus bas un exemple remarquable dans l'histoire du Cafeyer.

Tandis que l'Europe a épuisé les ressources de l'art pour vaiucru la Nature, ici on l'a abandounée à elle-mème sans lui prêter aucun secours : aussi ces arbres sont-ils loin de répondre a ce que l'on devroit attendre du climat. Fauti-il en accuser le sol? et si l'Ile-deBourbon l'emporte émineument de ce cúté sur celle de France, le doit-elle à son industrie (ce qui lui feroit honneur), ou lien estelle plus favorisće par la Nature? Ce qui sembleroit appuyer cette dernière assertion, c'est que, dans certains quartiers, l'on voit, a milicu des liabitations aluadonnées depuis long-temps, des 
Orangers magnifiques qui offrent plus de fruits que de feuilles, tandis que dans d'autres ou leur prodigue en vain des soins.

Un flénu diminue considérábleınent la récolte le leurs fruits. Lorsqu'ils commencent à mûrir, on voit le dessous del'arbre jonché de ces fruits, qui, par leur belle couleur, semblent annoncer que la maturité a évité le soin de cueillir, et qu'on n'a qu'à ramasser; mais l'on découvre bient6t que l'apparence est trompeuse, et qu'ils son t tons gâtés. Une piqqure à peine visible est la cause ou le résultat du mal. Il paroît provenir d'un œuf qu'une mouche y dépose arant sa matırité : l'insecte qui on naît, après avoir subi les métamorphoses communes à tous ces animaux, se fait jour pour sortir; et le fruit, gàté avant d'être mûr, tombe.

Nous revieudrons, daus le cours de cet ouvrage, sur ces arbres intéressans; nous nous bornons ici, ainsi que dans les antres articles, à une simple notice qui puisse donner une idée des principales Familles naturelles établies dans ces íles.

(2) Le Framboisier. Quelque commun que soit cet arbuste, il est étrnnger à ces îles; mais il s'y est naturalisé de façon à incomnoder. On sait avec quelle promptitude il s'empare des friches. Il est bien différent du Framboisier d'Eırope, ainsi que de dix.neuf' autres espèces rapportées an genre Rubus, Ronce.

Le docteur Sinith a décrit et figuré cet arbuste sous le nom de Rubus rosaefolius. Icones inedita, tabula 60.

Linnó a rangé ce genre dans la $12^{\circ}$ classe de l'Icosandrie, de la section de la Polygynie. Ce mot d'Icosandrie veut dire vingt maris ou Etamines; et le second, plusieurs fenumes ou Pistils. Le premier nom, suivant sa signification, ne devroit exprimer que le nombre des Etauines; mais il désigne de plus leur position, celle d'être plantées sur le Calice même. Cette considération fait le fond de la Métlicule de M. de Jussien : ce genre y est placé dans la famille des Rosacées. Il y a trìs-peu d'espèces de cette famille indigènes à ces flles; elle est au contraire très-nombrense en Europe : c'est une des plus intéressantes par les présens qu'elle nous fait; aussi a-t-oz cherché à eu multiplier un grand nombre, qui sont remarquables 
par leurs fruits, tels que les Fraisiers, les Poiriers; Pommiers, Pêchers, Pruniers, enfin lếs Rosiers qui donnent leur nom 2 toute Ia famille. Suivant M. de Saint-Pierre, ce Framboisier est originaire de Chine : si son fruit avoit un peu du parfum de celui d'Europe, il seroit plus recherché ; malgré cela, depuis quelque temps il a acquis dan' l'opinion, car maintenant il paroît sur les tables, soit dans son état naturel, soit en gelée. La saison où il est le plus abondant, juillet et août, ne lui donne pas, au dessert, beaucoup de concurrens.

(3) Croûte noirütre. Elle est le résultat d'un fléan inconnu a l'Europe. Par elle, l'arbre placé dans une situation qui sembloit promettre le plus heureux développement, devient semblable a ces miséral,les avortons que l'on tîche d'élever au centre des grandes villes. Au premier coup-d'œil, on croiroit que cela provient d'un air chargé de fumée qui y auroit déposé une couche de suie. Quelques cul tivateurs éclairés attribuent cet effet à l'extravasion des sucs de la feuille, occasiounée par la piquúre de différens insectes du genre Coccus: ces animaux, plus connus sous le nom de Poux, dévastent la plupart des arbres. D'après l'examen que j'en ai fait et la manidre dont elle se propage, je crois plutôt que c'est une plante parasite, qui pent-ctre fait partie du genre nombreux des Lichens. Quand on l'examine à sa naissance, on observe des fils noirs très-déliés, qui divergent en tous sens; l'extrénité de quelques-uns devient de nouveaux centres, d'où il en part d'autres. Se multipliant \& l'infini, ils finissent par former une croûte continue. Cependant je n'ai pu encore découvrir rien qui ent l'apparence de fructification; mais j'en ai aperçu de très-marquée sur d'autres taches également parasites, et qui paroissent avoir infiniment d'analogie avec celle-ci : il y a plusieurs espèces distinctes, qui forment une nouvelle section, dans ce genre des Lichens.

C'est ainsi qu'on nomıne ces croùtes, ou expansions foliacées de différentes couleurs, qui so trouvent sur les troncs des arbres, sur les rochers, sur la terre même, et qui ning prour toute fructification que des tubercules ou des bassins de différentes formes. Ce sont les pre- 
ıniers agens de la végétation et qui préparent par leur décomposition 1a place pour d'autres végétaux. On les confond souvent avec les Mousses; mais ces dernidres s'en distinguent facilement par leur couleur, qui est toujours verte, et par leurs tiges produisant de véritables feuilles. Comme les Lichens, malgré leur petitesse et le peu de complication de leur contexture, paroissent vivre trèslong-temps, il n'est pas étonnant qu'on en trouve rarement en Europe, sur les feuilles. Conme elles ne durent que quelques mois, clles ne pourroient donucr à ces plantules le temps de se développer : il u'en est pas de méme ici, oủ cette parure des arbres voit souvent les saisons se succéder saus tomber ni se flétrir.

Linné, dans son livre intitulé Species Plantarum, avoit porté le nombre de ces plantes à quatre-vingts espèces. Par le supplément donné par son fils, ils sont montés á cent trente; M. Lamarck en a décrit cent cinquante; enfin, depuis peu, on en a reconnu plus de truis cents. Ils forneut à eux seuls une fa mille qui doit être partagće en plusieurs genres. On les croyoit, comue le plus graud unmbre des plantes regardées comme imparfaites, qui forment la Cryptogamı de Linné, plus communs dans les pays froids que dans ceux situés entre les tropiques, excepté cependant les Fougères; mais il paroît qu'ils sont plus également répandus. Ces îles eu contiennent un assez grand nombre d'espèces, Bourbon sur-tout; et ce qu'il y a de singulier c'est que ses sommets, tels que la plaine des Calfres, sont décorés de heaucoup d'espèces communes à l'Europe, entre autres celle que le Renne sait tronver en Lnponie, sons la neige la plus épaisse. Depuis peu de temps M. Achar, célébre botaniste suédois, a publió un ouvrage sous lo titre de Mcthodus Zichenum, dans lequel il fait me lamille particulière de ces plantes; il la partage en vingt-trois geures, auxquels il rapporte plus de six cents espèces. 


\section{DESCRIPTION ABRÉGÉE D E S ISLES}

\section{DE TRISTAN D'AGUGNA;}

Lue dans la Séance particulière de la première Classe de l'Institut, en jauvier 1803.

La Botanique n'est point une science qui puisse s'acquérir dans l'ombre du cabinet (I). comme l'a. remarqué Fcntenelle dans l'Éloge de Tournefort; aussi, dès qu'un jeune homme a goûté les charmes que présente cette belle partie de l'Histoire naturelle, il cherche l'occasion de se satistaire et de se procurer des jouissances; d'abord, comme Jean.Jacques, il en trouve sur la cage de son oiseau, dans le monron; son jardin lui en présente de nouvelles; insensiblenent ses courses et ses desirs s'étendent, les plantes les plus. communes ont de l'attrait pour lui; inais dès que par le moyen du systêmé qu'il a adopté, il est parvenu à découvrir leur nom, elles reprennent leur première trivialité : il lui faut de nouveaux alimens.

(1) J'ai transporté, depuis la composition de ce morceau, ce préambule à la tête de la préface de mes nouveaux genres; majs comme il se trouve quelques changemens, et que d'un autre cots je me fais une loi d'imprimer ce Mémoire textuellement, tel quo je l'ai lu à l'.'nstitut, je n'äi pas cru devoir éviter cette répétition. 
La variété des sites entraînantcelle des productions, il parcourt avidement ceúx quil'ẻnironent': depuis le gras pâturage, les bords ombragés des ruisseaux, jusqu'aux arides bruyères, tout attire successivement ses pas et augmente ses rếcoltés; comue dans toutes les autres sciences, modeste dans le commencement, il suit pas à pas céux' qui l'ont précédé, et regarde comme une véritable découverte de reconnoître leurs traces; mais bientot il desiré voir son nom parini tes inventeurs, il voudroit dérolieir quelque chose à ses rivaux; et parcourant des contrées qui ont été si souvent fouillées, il he peút espérer d'y en réncontrer. Lit-il la relation d'un voyageur, il se croit' al'ses côtés; comptarit pour ricu lés dángers qui sont le partage des courses lointaines, il vódroit' aù mểine prix aroir été à mểme de rainasser à pleines unains les végćtaux cxtraordinaires auxquels le narratcur n'a dounć le plus souvent qu'une atterition médiocré.

Tel estl'enchaînement.des sensatious que j'ạ épronvées depuis i 780 , époque à láquelle je nio siis livré tout enticr âl'cétude des Plantes. Après avoir conquis systématiquement celles qui avoient entouré nnon luerceau, c'est-ì-dire esquissé la Flore de l’A ñjou, si j'cusse suivi mon gont, les Alpes, les Pyrencés, ne m'anroient point effrayc par leur's précipices; mais attaclıc parl'état ınilitaire quej'avois cmbrassé,je nepouvois parcourir que les pays les plús monotones anssi le goût des voyages lointains quí avoit été l'illusion ulez mon enfauce, sc réveilla-t-il en moi. Une occasion se; présentu poun la satisfaire : je l'émbrassai avidenient. 
Tout sembloit me promettre les plus gränds succès; l'amour fraternel devoit être le lien de cleux parties qui, malheurensement pour le progrès des sciences, n'ont pas marché jusqu'à présent avec tonte l'harmonie qu'on enit pu desirer, ponr que les grandes expéditions de découvertes eussent tout le degré d'utilité qu'on devoit en attendre. Mais au moment où j'allois' jonir des sacrifices de toute espèce que nous avions faits inon frère et moi, après avoir surmonté toutes les difficultés que f'aisoient naître les circonstances du monent, je me trouvai séparé de lui par un événement qu'elles produisirent; il fut obligé "de partir tandis que l'accusation la plus absurde me retenoit en prison. Ce ne fut qu'un mois après que je pus m'embarquer, dans l'espoir de me réunir à lui à l'Isle-deFrance; mais c'en étoit fait, un armement qui devoit faire honneur au génie entreprenant de mon frère, traversé an-dedans par les malheurs du tenips, fut détruit à l'extérieur par la puisillanimité des agens subalternes d'une nation avec qui nous étions en pleine paix. Cet événement in'a séparé à jamais dı compagnòn de mon enfance, et m'a préparé des regrets pour le reste de ma vie. (Vóyez la note à la fin.)

Dans toute autre circonstunce j'aurois été effrayé de l'entreprise que je faisois. C'étoit sur un frêle bâtiment de cent tonneanx que je me risquiois a faire une si longue traversée. Il est vrai que lé.bî́tintent de mon frère, sur lequel j'entreprenois'un voyage bien plus,considérable, étoit encore plus petit; nais il y avoit.un équipage plus nombrenx; car moi, passager, 
je faisois le dixieme homme du bord. Aussi cette traverséc eût paru fort désagréable à tout autre; mais les contrariétés que nous ne tardâmes pas à éprouver tournèrent à l'a vantage de ines goûts dominans; la principale fut qu’après être resté en calme pendant près de six semaines sous la ligne, le manque d'eau détermina le capitaine à relâcher ì Tristan d'Acugna; et à ma grande satisfaction nous ne tardâmes pas à gagner son parallèle. Toutes les observations prouvoient que nous avions été jetés considérablement dans l'Ouest par les courans; cependant nous craignîmes de l'avoir laissé dèrière nous, car nous suivîmes cinqjours ce parallèle sans pouvoir la découvrir. Nous nous consolions dans l'espoir d'arriver sous peu au Cap de Borine-Espérance, lorsqu'un matelot montant à six heures du soir sur le pont pour prendre le quart, s'écria qu'il voyoit la terre. On peut juger de la sensation que nous éprouvâmes tous en reconnoissant la vérité de cette exclamation : il y avoit apparence qu'elle étuit en vuc au moins depuis midi; mais les espérances déchues les jours précédens avoient endormi la vigilance. On recomnut facilement que nous étions en vue de la moyennede ce petit groupe d'îles; on unanœuvra toute la ruit pour se conserver à-peu-près à la même distance. C'étoit le 2 janvịer $179^{3}$, quatre mois juste après notre dejart de Brest. .

Au point du jour nous nous trouvâmes. assez près de cetteîle; clle étoit dansl'Est quart Nórd-Est, ct nous cachoit unc partic de la plus grande, dont le sommet 
se perdoit dans les nuages; au loin, dansle Sud, nous en voyions une autre plus petite; ure foule d'oiseanx, mais pas très-varićs en espèces, nous cnvironnoient. Cette île a reçu, à juste titre, le nom d'Inaccessible: elle nous parut effectivement inabordable de tous les côtés ; nous la côtoyâmes d'assez près, ce qui nous la fit voir sous différens aspects, sous lesquels j'essayai de l'esquisser. Elle est escarpéc de tous les côtés en falaise, et terminée par un plateau un peu bosselé. M. D'A près, sur les renseignemens de M. d'Etchevery, ne marque que cinq licues de celle-ci it la principale; ınais cette distance nous parut plus considérable, et ce ne fut que vers mili que nous vînmes y mouiller. Nons laissâmes au loin dans le Sud-Onest la plus pe. tite, remarquable par deux mornes.

L'aspect du mouillage où nous étions, situé dans la partie Nord, étoit des plus sauvages; c'étoit une montagne escarpée en falaise, couverte cependant de verdure jusqu'au sommet; un terrain beancoup plus bas s'avançoit vis-à-vis de nous et se prolongeoit sur notre droite; il formoit un renflement escarpé de vingt pieds à-peu-près d'élévation au-dessus du rivage. Du milieu, vis-à-vis précisément le vaisseau, descendoit une belle cascade; sur la gauche, une petite baic alloit jusqu'au picd de la montagne, qui étoit nue dans cet endroit; un peu plus loin, une ravine la sillonnoit presque perpendiculairement; it peine fûmes-nous nouillés qu'on jeta des lignes : clles n'étoient pas descendues au fond, qu'on retiroit du. poisson. C'étoit sur-tout une espèce de Vieillc. 
Il est aisé de juger de l'impatience que j'avois de descendre à terie, et de prendre possession de cette Ile au nom de Flore; cn approchant nous apercevions le rivage couvert de Phoques : il y cn, avoit denx espèces; nous craignions de les effaroucher par notke présence; mais ils étoient si peu faits aux approches de l'lioume, qu'ils bougeoient à peine.pour, nous laisser passer. Le bord du rocher, et ses anfractuosités étoient garnis d'unc unultitude de Pingouins qui se laissoient preudre facilcment. Je laissai lientôt le règne animal pour une livrer àmon occupation favorite; nais j'éprouvai beaucoup de clifficultés à prénétrer daus ce terrain neuf, car il étoit entièrenent occupé dans certains endroits par une espèce de Gramen, en forme de rosean. Je trouvai les bords du ruisscau qui fournissoit la cascade, tapissés de Fouइère et de Capillaires; d'autres endroits étoicnt couverts par un arbuste du genre Phylica. Ses troncs, entassés ct entrelacés, ne périssoicntque de vétusté, il en résultoit une barrière preşu’impénétrable, et ce ne fut pas sans bcaucoup de peine que je revirs avec une cinquantaine de Plantes dont la plupart me parurent nouvelles.

Je profitai les jours suivans de toutes les occasions d'aller à terre; unais la foiblesse de l'équipage fit que ce ne fit pas aussi souvent que j'aurois voulu; et que je ne pus disposer de personne pour m'aider dans ines recherches. J'eus dans ces courses beaucoup de difficultés à vaincre, la dernic̀re sur-tout : j'entrcpris de gravir jusqu'au sommet; après avoir échappé aux dan- 
gers les plus imminens, près d'arriver àmon but; je une trouvai arrêté par un escarpement liorrible. Je n'éprouvai pas moins de difficultés ł̀ redescendre, en sorte que la nuit et la pluic m'nyant surpris, je fits obligé de rester au pied d'un. Phylica et d'y attendre le jour. Lafaim etilesroid'm'empechant de fermer l'œil, je me: trouvois livré à mes réflexions : on pent juger que dans cette position elles n'étoient pas gaies. Le: mauvais temps pouvoit avioir forcé le bâtiment d'appareiller, ce qui étoitivraisemblable: Eh bien, cette idée ne me tourmentoit point. Je me traçois le genre de vie que, nouveau Robinson, je pouvois mener, et - je passois en vue les ressources que m'auroit fournies cette Islè. On avoitété affectivement trèsalarné à hord de ne pas me revoir; on craignoit que; je ne me fusse ségaré'tout de bon, ot le capitaine se disposoit \&̀ rassembler mes effets pour me les déposer qquelque part; arrivé à bord, on me fit des reproches obligeans sur les inquiétudes que j'avois cansées, et on sédisposa à apparieiller. On s'aperçnt alors que fes craintes d'être robligé de quitter le motillage il l'improviste, n'étoicnt pas saus fondement, car au premier effort pour lever l'ancre, le cable, usé par le mauvais fond, se rompit : c'étoitle 7 janvier, en sorte que nous étions restés quatre jours à ce rionillage. Quand nous fùmes dans l'Est de l'isle, le capitaine enroya encore son canot à terre dans l'espérance de trouver des tortues; mais nous n'en aperçûmes pas de traces; nous nous contentâues de remplir le canot de Pingonins. Je ne trouvai rien de nouveau dans cette partic pour aug- 
menter mon. Herbier. Ces Pingouins nous furent d'une grande ressource, et furcnt les'seuls vivres frais que nons eûnes jusqu'au Cap de Bunne-Espérance, pour lequel nons fîmes route; mais pendant tout ce temps, qui fint de vingt-six jours, ils ne voulurent rien manger, seulement ils barbotoient dans des gamelles d'eau de mer qu'on leur donnoit de temps en temps; ils couroient librement dans l'entrepont, et se détendoient vivement par leur beo tranchant quand on les aga çoit. Les natériaux que j'avois rassemblés.pendant ce séjour medonnèrent une occupation agrénble pour les réunir; mais privé de livres, tous ceux que j'avois rassemblés et préparés pour mon voyage étant restés à bord de mon malhenreux frère, je'ne pus mettre à la description que j'ébauchai de ces isles toute l'cxactitude que j’aurois desirćc. Ce n'est pas.la seule fois que j'ai ressenti cette privation : elte:a influé fortement sur le reste de mon voyage, et:in'a arrêté souvent dans ines recherches.

Quoique ce petit groupe d'isles soit peti fréquenté des Navigateurs, il paroît qu'il a été découvert dès les premicrs voyages des Portugais, puisque Tristan d'Acugna qui leur a donnćson nom, a été un des compagnons d'arnes d'Albuquerque. Mais je n'ai pas encore étó đ̀̀ même de faire des recherches historiques à ce sujet : tout ce que j'ai pu recueillir làdessus se bornc à la notice que $M$ : D'A près a publiée dans son Neptune oriental. C'est la relation faite par M. d'Etchevery qui y a relâché; il y joint la traduction de celle qui est insérée dans le Pilote anglais. 
La description qu'ils donnent de l'aspèct de ces isles est assez fidèle, mais trop peu étendue pour qu'on. puisse s'en faire une idée exacte : c'est à quoi je vais tâcher de suppléer. J'ajoute une esquisse de cartc qui pourra, tout imparfaite qu'elle est, aider à ma description. Il en est de même des vues que j'y joins; ce sont des esquisses bien rudes, ce sont mes preniers essais dans ce genre; je n'ai pas perfectionné depuis ma manidre de dessiner, mais j'ai du moins appris le moyen de le faire plus exactementet plus utilement, j'aurai occasion d'en clire un mot plus bas.

Un des points les plus importans à constater, ¿c'est la position de ces îles, comme intéressant la navigation. Il paroît que jusqu'ì présent elle n'avoit point été bien déterminée, car plusieurs navigateurs l'ont cherchée en vain, et nous l'avons rencontrée beaucoup plus tard que uous ne comptions, toutes errenrs compensées; anssi M. le Gars, notre capitaine, qui malgré sa grande. jeunesse avoit acquis beaicoup d'expérience, d'après le résultat de plusienrs' distances du Soleil et de la Lune, détermina la position de notre mouillage par $13^{\circ} 45^{\prime}$ de Longitude occidentale, ce qui est un peu plus de deux degrés Est que celle de M. D'Après, qui est de $16^{\circ}$. On pourroit infirmer l'autorité de notre capitaine; mais la relation d'un voyage qui a été fait depuis, la confirme a peu près, c'est celle' d'Érasme Gower; il place son mouillage par ${ }^{*} 1^{\circ} 4^{3 \prime}$ du méridien de Greenwich, ce qui,donneroit à-peu-prds $\mathbf{1} 4^{\circ}$. L'on doit certainement avoir plus de confiance dans les obser- 
vations de cet habile marin, parce qu'il étoit pourvu de tout ce qui pouvoit assurer sạ position. Cependant je n'ai pu faire açcorder la détermination qu'il a donnée des autres Isles, avec mes propres observations. Sa Latitude est de $37^{\circ} 12^{\prime}$ Sud.

Suivant M. D'A près, cette Isle a cinq lierés de tour, peut-être en a-t-ellc un peı plus. Elle m'a paru de forme arrondic. Cet auteur, parle peu d'une de'ses dimensions très - remarquable, c'est, sa prodigieuse élévation; je ne crois pas qu'elle soit beaucoup audessous de mille toises, ce qui s'accorde assez avec le rapport du.conmodore Er, Gower, qui dit qu'on peut l'apercevoir de 25 lieues.

Tout annonce que c'est un ancien Volcan éteint; Jes rivages, en quelques endroits, sont formés d'un sable noir ou de galets absolument semblables à ceux. de l'isle Bourbon; toutes les roches ne m'ont parı jêtre que des laves plus ou moins détériorées; sa forme aussi confirune cette origine, c'est un plateau escarpé de tous les côtés, d'où il se détache quelgues pitons; quelquos-uns sont liés à la unasse générale par des revers étroits, sur lesquels on ne peut pasøer qu'à califourchon. Ils sont composés de laves tellementicn décomposition, qu'on ne peut faire un mouvement sans en faire ćbouler une grande quantité à droite et à gauche. J'eri ai revu de pareils à Bourbon, où les Créoles les connoissent sọú le nom de Côteaux maigres: Dans l'Est il y. a quelques roches détachées dans la mer, mais le plateau est surmonté par un piton qui ın'a paru an mojins.le ticrs de, la 
hauteur'totale; et il est tellement élevé, qu'il est -presque tonjours enveloppé de muages, en sorte que nous ue l'avons àperçu que le jour de notre départ.

Les éboulemens, ont formé des attérissemens plus ou moins eonsidérables sur les bords de la mer; - le -jlus remarquable ćtoit eelni qui étoit vis-à-vis notre mơuillage, il paroissoit avoir 'été-formé d'une pre- midre digue de Jave qui faisoit 1 un rempart; ensuite l'espace qu'elle laissoit entr'elle et le pied de la mon- Lagne avoit été successivement rempli par les éboulemens et recouvert par les déeopnpositions de végétaux; anssi ce terrain me parnt-il d'une grande fertilité, il étoit couvert par-lout de végétaux : il est vrai que quelque grande que parût l'aridité de eertains endroits, ils n'en étoieut pas inoins eouverts de verdure; les pentes, quelque rapides.qu'clles fussent, étoient garuies de végétaux, oxeepté les esearpemens toutà-fait à pic.

La partic qui fórmoit la gamehe de la baie n'ćtoit -pas d'une si bonne qualité, son'sol n'étoit composé que de roeailles dont la plupart paroissoient frâicheunent descendues du sommet; il renfermoit une petite lagune d'eau sammâtre.

Située sous une latitude qui promet une température heureuse, il est eeperidant craindre que cette Isle n'éprouve des vieissituides clésagrëables : an mitieu el à l'embouchure du vaste canal que forme l'Oeéan allantique, son pie doit attirer de tous côtés les nuages; aussi la verduré quini couvre toutes scs parties semble anuoncer beaueoup d'humidité, 
ce que dénote mieux encore la nature de ses végétaux, puisque lc plus grand nombre d'espèces appartiennent aux Mousses et aux Fougères. Le froid ne doit pas y être très-vif quoique son pic se couvre de neige suivant M. d'Etchevery.

Séparée des deux continens par un espace considérable de mer, elle est dans un grand isolement qui ı'a pas permis à une grande varićté de productions de venir s'y établir; aussi, vu la fécondité de quelquesunes de ses parties, n'y sont-clles pas très-varićes. Le Règne aninal est composé, comme on peut le supposer facilement, des espèces amphibies tant en Quadrupèdes qu'en Oiseaux.

Le rivage étoit bordé, comme je l'ai dit, de deux espèces de Phoques; le plus considérable occupoit les plages les plus unies, sur lesquelles il se trainoit avec peine; je le pris d'abord it lataille pour le, Lion raarin, mais il n'avoit ni la crête ni la .crinière des deux espèces décrites partr le lord Anson. Il paroissoit avoir les inêmes mœurs qu'cux, étant également polygame et très-attaché à scs fumelles et à ses petits, il se mettoit au-devant d'eux quard on vonloit les attaquer. J'en ai vu qui avoient près de quinze pieds de long. La forme des poils de cet animal etoit très-singulière : ils étoient assez écartés; c'étoit ure espèce d'écaille pointue recourbéc au sommet, ce qui les rendoit très-rudes, de-là j’ai présưuć que ce pouvoit être le Phoque que l'on a nommé Hispida.

La seconde espèce étoit le Phoca-Uisina ou Ours de mer. Il étoit beaucoup plus agile que l'autre, 
aussi grimpoit-il sur des pointes de rocher; il paroissoit également attaché à ses femelles et à ses petits. Quand on approchoit, il avoit un cri de furcur; mais quand il nageoit, ce qu'il faisoit arec beaucoup de vitesse et en jouant, il avoit une espèce de grognement assez doux. Son poil étoit épais et très-doux. Il avoit une odenr très-forte, qui nous empêclia d'en gon̂ter. Il n'en fut pas de même de l'autre espèce, nous la trouvâmes fort bonne; les jeunes sur-tout avoient une chair très-délicate, comparable à celle de l'ngneau, comme le dit M. de Saint-Pierre dans ses Etudes de la Nature. Sans le passage de cet auteur, je n'eusse pu vaincre la répugnance de nos matelo!s à goûter de cet animal. Nous avions embarqué vivans des jeunes des deux espèces, mais la première étoit si vigoureuse qu'on ne put la retenir ; nous en conservâmes un de la seconde jusqu'au Cap; mais jusque-là il n'avoit jamais voulu rien manger, c'est-à-dire pendant vingt-six jours; et en approchant, nous trouvant entourés du Fucus turbinatus ou Trompe de mer, l'idée me vint de lui en présenter; il en mnangea très-avidement, ce qui me confirma dans l'idée que les Varecs étoient leur principale nourriture.

J'ai déjà remarqué que les Oiscaux, quoique nombreux, n'étoient pas trc̀s-variés, car je n'en distinguai que quatre espèces aquatiques: l'une surtout fourmilloit; c'étoit la grande espèce de Pingouin, remarquable par les plumes jaunes qui couronnentsa tête; l'Aptenodytes chrysocome: leur poute paroissoit faite depuis long-temps. Sur les croupes un peu 
élcvées se trouvoit l'Albatros, Diomeda exiulans: posé à terre, il se laissoit prendre sans bongor : je trouvai encore un jeune, couvert de duvet. Il me donna l'explication d'un fait qui nie tourmcntoit. J'avois rencontré des mottes de terre eylindriques, d'un pied à-peu-près de diametre et d'élćvation, asscz régulièrement construites; je reconnus que c'étoit le nid des Albatros. Une petite espèce de Sterna, ou Mirondelle de mer, voloit familic̀rennent. autour clu vaisseau; un Larus, ou Goéland, brun's'approchoit beaucoup de nous sur Ic rivage. Telles sont les especes qui se font rentarquer par leur multitude. Il y a apparence que dans les autres partics ou daus différentes saisons il s'en trouveroit d'antres; il y en avoit sur-lout une qui paroissoit n'occuper que lc sommet. de la montagne, mais en telle quantité, qu'elle formoit un ruage que nous' distinguions à peinc à la vue; je présnme que c'est cette espèce de Pettrel connuc à Bourbon sous lc nom de Folıquet oil Taille-vent, qui habite les sommets les plus élevés et s'y loge dans des trous comme des Lapins.

Il n'est pas étonnant de rencontrer ces hôtes sur ce point de terre, il semble destiné à être leur rendcz-vous; il n'en' est pas de même des espècés purement terrestres : il paroissoit difficite qu'il vînt s'y en établir; cependant j'ai vu denx Oiseaux terrestres, l'un, ressemble pour la taille et le plumage à la Grive, quoiqu'il parût du genre des Fauvettes; d'aurre ressembloit au Verdier.

Je n'ai pas trouvé d'insectes remarquables, excepité 
des Islés de Tristan d'Acugna.

un Ver. luisant plus petit que le nôtre; une Larve: rongcoit les Épis du Gramen Arundinacé ; il y avoit beaucoup de Monches'semblables à la commune, le. long du rivage, Passarit la nuit sur cette isle, je ne fus incommodé par aucune espèce nuisible. Il me. reste à parler du. Règñe végétal.

La mer y présonte plusieurs espéces de Varec:. le Fucus pyrifer ou giganteus s'y fait remárquer principalement; il est si abondant le long du rivage, que notre canot avoit peine à aborder. Il y en a plusieúrs antres espèces; parmi les plus communes de l'Europe', j'en ai trouvếale particulières, mais je perdis toute la collcction que j'en avois f'ite, en montantì' bord par un-gros ternjs. J'ai récolté dass les parties de l'Iste que j'ai parćourues, une centaine de plantes, dans ce nombre il n'y en a que quatorze de dicotylédones ou parfaites. La plus reụ̣arquable est une espèce de Philica qui forme un Arbuste de quinze pieds de haut, c'est le seul qui puisse donner du bois de chanffage ou propre à de menus ouvrages; il y a un autre sous-arbrissean, c'est un Empetrum; que je prenois pour le Nigrium; il porte un petit fruit rógeâtre qui a un goût aigrelet assez agréable:

J'ai trouvé deux plantes aromatiques : un Chenci podium ì feuilles tomenteuses, différent des Ambrosiödes et Botrys; un Geranium, ou plutôt Pelargonizu, qui a quelques rapports avec le Pelarg. odoJatissimuın, mais qui est différent; c'est, je crois, le scul de cette nombreuse tribù qui ait étć trouvé, 
jusqu’à présent hors du Cap de Bonne-Espérance: C'est Ja plante la plus agréable de cette Flore. La scule plante qui puisse être potagère est une espèce d'Ache, Apium; elle a un gout fort, un peu aromatique, mais qui n'annonce rien de vénéncux: mon exemple n'a pu engager nos Matclots à en manger. Il est vraiscmblable que c'est la même espèce dont les navigateurs ont fait un grand usage au détroit de Magellan, et dont ils se sont bien trouvés.

Il y a un petit détachement de la famille des Composées, formé d'un Gnaphalium herbacé d larges feuilles cotoneuses, voisin des Filago; d'un petit $X$ 'ranthemum en gazon, et d'une espèce de Souci, Calendula, qui est une des plus petites plantes do cette Famille; je n'ai trouvé cette dernière que sur le revers d'un des sommets les plus élevés où je sois parvenu.

Uu sous-arbuste sarmenteux rampe abondamment, c'est un Ancistrum à feuilles de Sorbier ou d'Argentine. J'y ai observé un genre nouveau (du moins je le croyois tel, c'est le Nertera ou Gomozia) de la famille des Rubiacées qui renferme deux esp łces, cc sout des plantes rampantes herbacées; l'une ressemble parfaitement a la Morgeline, l'autre a le port aussi d'une plante de cette Famille; leurs fleurs sont peu apparentes et solitaires au sommet des rameaux; il leur succède une petice baie ronde d'un rouge brillant, mais d'un goût désagréable.

Une espèce particulièred'Hydrocotyle, un Rumex sous-ligneux, qui a un gout désagréable, etle Che- 


\section{'des Isles de Tristan d" Acugna:}

zropodium Album, plante curopéenne, doht je n'ai rrouvé qu'un pied, achèvent toutes les plantes de cette classe.

Dans les plantes Monocotylédones, il ne se trouve que quelques Graminées et Cypéroïdes. Il y a quatre espèces de Carèche ou Laiche, dont deux se réunissent avec le singulier Carex uncinatus. Parmi deuxespèces de Scirpe, il y en a une petite qui croît partout en formant des gazons très-épais; il y a des côtes arides qui n'ont pour secouvrir que des nattes serrées et écartées de cetle plante.

Dans les mêmes endroits il $y$ a un autre gazon formé par un très-petit Phalaris. Une plante du même genre, mais plus rare, s'éleve jusqu'a deux pieds : li panicule de ses fleurs est ramassée en épi ; ellc est d'une consistance très-molle qui promettroit un bon. fourrage.

L.e plus remarquable de tous les Gramens, par sa taille et par l'abondance avec laquelle il croît, forme zın Genre particulier, distingué par son stile simple. Il a le port du roseau des sables, et s'ćlève de quatre à six pieds; il est tellement abondant dans les terreins. fertiles, qu'il barre presque le passage. Il croît aussi sur les sommets les plus élevés, où il m’a rendu les plus grands services, parce qu'attaché fortement par ses racines, il m'aidoit à grimper.

Voilà tout ce que j'ai rencontré de plantes dites par faites. La Cryptogamie de Linné y est beancomp plus nombreuse. J'y ai distingué entr'autres quinze espèces de Fougères très-belles. Celle qui me frappa le plus étoit un.Pleris arborescent, que j'ai revu depuis 
dans plusieurs endroits; il a le port d'un petit Palmier. Toutes les ravines étoient tapissées d'un bel Adianthum. J'ai trouvé aussi un Trichomanes remarquable par l'abondance de poils roux qui le couvrent.

Les Mousses sont encore plus nombreuses : outre plusicurs espèces communes à l'Europe, il y en a de particulieres; quelques-unes étoient en fructification, mais les autres non, ainsi que plusieurs Jongermans et Marchantes. Les rochers étoient garnis aussi de Lichens, qui, comme les Mousses, étoient mêlés d'cspèces communes et particulières. Les troncs des Phylicas, entrautres, m’en ont présenté de très-élégans. Jc n'ai trouvé que quatrc espèces de la famille des Champignons. Telles sont les produc. sions végétales que j'ai trouvées établies par la nature sur ce sol. Tout annonce qu'un bien plus grand nombre pourroicnt s'y naturaliser; placée cntre l'Afrique et l'Amérique, ses productions tiennent de ces deux climats : elle a de commun avec le Cap le Phylica ct lc Geranium; elle tient d l'Amérique par ses Fougd̀res et l'Ancistrum, et aux contrées froides par ses Mousses.

D'après lc peu que j'ai vu, cette Isle paroît trèshabitable : d'abord, la petite plaine qui étoit vis-à-vis notre mouillage fourniroit des productions végétales pour quelquesfamilles; les montagnes nourriroient du bétail ct du gibier; la mer offre une pêche abondante. Elle pourroit être un objet de spéculation pour une puissance maritime, en fournissant une rclâche do safraîchissement ou un établissement de pêclie.

Il seroit cependant à craindre que cette Isle no 


\section{'des Isles de Tristan d'Acugna:}

füt sujette à des secousses violentes de l'air : il n'est pas probable qu'elle en ait encore de souterraines à craindre, le volcan paroissant éteint depuis longtemps; cependant sur des croupes que j'ai parcourues, tous les arbustes étoient brûlés, à moitié déracinés, et entassés les uns sur les autres. Je ne sais si c'est un événement naturel qui a causé ce bouleversement, ou bien s'il a été produit par l'imprudence de quelques navigateurs. Ils auront mis le f'eu aux broussailles; les troncs dessécliés et los racines pourries n'auront plus lié la terre, alorsles pluies les auront renversés. Il paroît que cet événement étoit récent, car une foule de jeunes Arbustes poussoient pour les remplacer; ils avoient une pousse d'un an tout au plus. En peu d'années la perte sera réparée.

Ce n'cst pas la seule trace que j'aie rencontrée du séjour précédent de quelque vaisseau : ainsi dans d'autres endroits il $y$ avoit des vestiges de feu; mais je trouvai avec plus de plaisir un petit coin de terre qui avoit été défriché. On avoit sûrement semé plusieurs sortes de Graines ; mais deux seulement avoient prospéré, des Raves et des Laitues; l'une et l'autre étoien en Fleur et en Graine.

J'appris, à mon passage au cap de Bonne-Espérance, que cela provenoit vraisemblablement d'un vaisseau Américain qui avoit séjourné sur cette isle pour la pêche, celle de la Baleine sur-tout. Ces géans de la mer nous parurent effectivement trèscommuns dans ces parnğes; ils nous présentèrent un spectacle continuel les jours qui précédèrent notre 
arrivée, et de notre mouillage nous en voyions fréquemment; il en passoit mềne entre la terre et nous. Je trouvai sur le rivage la tête entière d'un de ces animaux, qui devoit avoir été monstrucux. C'est un monument de destruction qui subsistera sûrement long-tcmps. Il semble que l'homme n"imprime ses traccs que par la dévastation; ce n'cst que par-là que nous avons marqué notre séjour dans cette île. Nos matelots assommèrent un grand nombre de Phoques, pour le plaisir seulement de tucr : nous essayâmes d'en saler un ; mais au bout de quelques jours'il prit un si mauvais goût, que nous fùmes obligés de le jeter à la mer. Il n'en fut pas de même des poissons qui furent préparés : nos matelots, qni avoient été d̀ la pêche de la Morue, y réussircnt très-bien; aussi nous furent-ils d'une grande ressource; et si nous ellssions eu plus de sel et plus de monde, ils eussent on peu de temps completté une cargaison, tant la pêche étoit abondante; mais elle n'étoit pas très-variée, c'étoit une espèce de Vieille; on ne prit qu'une Morue, quoique M. d'Etchevery assure qu'elles y soient trèscommunes. Il dit la même chose des Tortues; mais nous ne pûmes en apercevoir de traces: je n'ai vu que quelques débris de Crabes, et je n'ai pas remarqué de coquillages.'

L'eau que nous embarquâmes étoit excellente et bien supérieure à celle que nous prîmes par précaution à notre passage au cap de'Bonne-Espérance. - Il me reste maintenant ì dire un not sur l'esquisse de la Flore que-je présentę.., On peut demander d'abord jusclu'à quel point elle peut domner une 
idée de la totalité des Plantes qui croissent sur ce petit point du globe : pour cela il faut passer en revue los différentes herborisations que j'ai été a portée de faire. Le 3 janvier, ou le premier jour de notre arrivée, je descendis à deux lieures ct je me rembarquai à sept, ainsi je passai cinq heures pendant lesquelles je recueillis une cinquantaine de Plantes.

Le 4 , le canot ne put aller à terre parce qu'il falloit le radouber, je mis ce temps a profit pour examiner ma récolte, et pour la première fois j'essayai de dessiner les Plantes qui me parurent les plus remarquables. Jusques-là $j$ 'avois fait quelques essais qui ne m'avoient pas satisfait, le besoin me rendit plus habile, et depuis ce moment je n'ai pas cessé d'esquisser les objets qui m’ont paru les plus inportans.

Le 5 , je descendis à terre à midi, et je me rembarguai à huit heures, avec une trentaine de Plantes nouvelles.

Le 6, le canot devoit aller de grand matin à terre, mais ce ne fut qu'à neuf' heures qu'il y aborda; je restai toute la journée jusqu'au lendemain à dix Iheures, qu'on vint me chercher. Je ne recueillis que vingt Plantes de cette longue course, quoique je fusse parvenu à une grande ćlévation.

Le 7 , eufin, jour de notre départ, je passai une heure dans un autre point de l'isle, où je ne découvris rien que je n'eusse vu précédemment.

On voit par cette diminution graduée de mes récoltes qu'il est vraisemblable que j’ai rassemblé la. wajeure partio des richesses végétales de cette isle. 
Son examen in'occupa agréablement jusqu'à mon arrivéc au cap de Bonne-Espérance; mais il ne me restoit d'ouvrage de botanique que le Genera de IM. de Jussieu; ce n'est qu'à l'Isle-de-France que je me trouvai à même d'en consulter un petit nombre d'autres; par leur moyen j'établis une nomenclature telle quelle.

Tel est le résumé des observations que j’ai faites dans le court espace que j’ai passé sur cette Isle ; sa position intéressante in'a toujours fail regretter de n'avoir pu y prolonger mon séjour : en outre, pour en tirer plus de parti, il m'eût fallu des connoissances préliminaires qui me manquoient; mais je suis bien persuadé qu'un Minéralogiste, un Zoologiste y eussent eu de l'occupation pendant plus de quinze jours; mes plus grands regrets ont été de ne pouvoir faire des opérations géométriques pour donner une idée précise de la position et de la forme de ces Isles; mais dénué d'instrumens, ce ne fut que par les reldvemens de la boussole que je pris quelques matériaux. Ce ne fut qu'en partant précisément, que je m'aperçus de quelle utilité pouvoit être pour cet objet un octant ou tout autre instrument de réflexion; il étoit trop tard, la seule opération que je fis fut de prendre la hauteur du point le plus haut qui füt devant nous, il étoit de 20 degrés sans compter le piton que je ue voyois pas, tandis que le plus près que j'aie approché de la montagne de la Table, je ne lui ai trouvé que 12 degrés; car ce fut en approchant de ce fameux promontoire, que je me convainquis combien l'usage des instrumens à réflexion 


\section{'des Isles de Tristan d'Acugna:}

étoit propre à relever les terres pour connoître leur gisement et leurélévation. Ce dernier point manque , it mon grand étonnement, dans les plans exacts que nous ont donnés les savans navigateurs qui ont illustré la fin du dernier siècle.

L'intéressant Leguat, qui, comme Énée, cherchoit avec quelques compagnons d'infortune une nouvelle patrie d̀ travers les mers, passa à la vue de cette île à la fin du dix-septième siècle. C'étoit une de celles où il comptoit trouver la tranquillité ; mais le capitaine qui le conduisoit, auquel il soupçonnoit avec raison. des intentions contraires aux siennes, ne voulut pas y mouiller sous quelques prétextes. D'après son aspect il se la figuroit charmante: il voyoit des collines ombragées de grands arbres; il eût certainement trouvé bcaucoup à rabattre s'il y fût descendu', et sur-tout s'il y eût séjourné. Cependant je crois qu'il y eût trouvé autant de ressourcesqu'à Rodrigue, où il passa deux ans et demi. La comparaison de cotte isle avec une infinité d'autres,sur'-tout de celles situées entre les Tropiqnes, ne lui seroit pas favorable; mais il en est beaucoup à qui elle paroît bien supérieure : l'isle de l’Ascension entr'autres, sur laquelle Osbeck ne trow va que quatre espèces de plantes établies par la nature; il est vrai qu'elle paroît destinée à ne pouvoir janais être hâlutée par.l'homme. Cependant quand on lit la description de l'isle de Pâques, on reconnoît qu'on ne peut, de ce côté, assigner aucune borne ; Cook et ses compagnons n'y trouvèrent que vingt plantes, en comptant celles qui y étoicnt cultivées; il est vrai que ses. labitans paroissent être la race la plus misérable qui 


\section{Descr. abrég. des Isles de Tristan d" Acugna:}

existe. D'un antre côté, l'île Sainte-Héld̀ne est une preuve de ce que peut l'industrie d'un penple civilisé, car je doute que pour ce qu'elle tient de la nature elle soit supérieure à Tristan d'Acngna. Les isles Falkland, quoique beaucoup plus considérables, ne sont guère plus riches en végétation : par ce que l'on peut saisir dans le vague des descriptions de Dom Pernetti, elles auroient beancoup de rapport de ce côté. Il paroît que le seul arbustequ'on y trouve aussi seroit un Phylick.

Je joins à cette description quatorze figures de plantes, j'espère publier par la suite une vingtaine d'autres, dont j'ai les dessins, avec des observations sur les plus inportantes. Les numéros les rattacheront à cette Esquisse : je me suis servi, pour désigner les différentes parties de la fructification, des mêmes lettres dont j'ai fait usage dans mes genres nouveaux: elles sont minuscules ou majescules, suivant que les objets sont de grandeur naturelle, ou grossis à la loupe : a $A$, la fleur détachée; b $B$, le calice ; c $C$, la corolle; $\mathrm{d} D$, les étamines; e $E$, le pistil ; $f F$, le fruit....; $k K$, la graine.

\section{NO T E.}

Depuis que ce morceau est écrit, la Cour de Portugal a reconnus la légitimité de nos réclamations, et a accordé 334,000 liv. pour indemnitér. Ma famille et moi, nous nous sommes empressés de faire bavoir cet événement par la voie des journaux, aux intéressés de cet armement, soit comme souscripteurs, soit comme ayant fait partio de son équipage. 


\section{ES Q U ISSE}

\section{DE LA FLORE}

DE L'IS L E

\section{DE TRISTAN D'ACUGNA.}

ACOTYLEDONES, LES ACOTYLÍDONES.

FUNGI, IES CHaMpignons.

I. MERUIIUs:

Petit Champignon hémisphérique, attaché par le côté aux vieux troncs d'arbres.

2. Agaricus. Tourn. Boletus. $L$.

Petite espèce, at tachée par le côté aux troncs pourris.

3. Sphreria. Hall.

4. Peziza. $L$.

Orbiculaire, purpurine en-dessus, velue en-dessous.

ALGE, IES ALGUES.

5. Conferva Scoparia. $L$.

6. Ulva umbilicalis. $L$.

7. Fucus pyrifer. L. Pernetti, Voyage aux Malouizes, tom. I, p. 553. Herb. ${ }^{\text {re }}$.

Racine par grospaquets; tige simple, filiforme, de 
méme substance, ainsi que les feuilles, que nos Varecs arborescens; feuilles d'un seul côté, pétiole renflé, turbiné, épais, en vésicule; feuilles lancéolées, dents aiguës sur les côtés; surface plissée; feuille extrêne servant de bourgeon, commençant à se fendro, un petit nœud annonce la vésicule.

8. Fucus plocamium. Gmel. Fucus. Herb. $1^{\text {re }}$. Commun au Cap.

9. Fucus palmatus. $L$.

Il y avoit plusieurs espèces particulières de Varecs sur le rivage, qui m'ont paru nonveaux; je ne sais par quel malleur je perdis toute la collection que j'en avois faite, en me rendant a bord par un gros temps. Il y en avoit un, entr'autres, semblable au Fucus digilatus; mais l'appendice étoit arrondi et divisé en un bien plus grand nombre de lanières.

10. Lichen viridiflavus. N. Membranaceus, laciniis superne late virens, subtius flavescens, scutellis turbinatis, oris laciniatis. Herb. $\mathbf{1}^{\text {re }}$.

Sticta crocata Ach. Methodus Liche. $n u m$.

Lanières larges, laciniées, d'un beau vert, bords et dessous jaune-dorés; écussons en trompette sur le milieu des feuilles, hords déchiquetés, intérieur fauve. Sur les vieux troncs des Pliylica. Une espèce d̀-peu près pareille au Cap de Bonne-Espérance et à l'Isle-deFrance; on la trouve aussi en l'ortugal.

11. Lichen Tenellus. N. Umbilicatus, Laciniis rotnndolatis, pubescens, peltis marginatis peduncularis. Herb. ${ }^{\text {re }}$. Sticta?

Espèce _élégaute à lanières larges, arrondies, bleuâtres, pubsescentes; Écussons pédonculés, formant un. 
rang sur le bord, convexes en-dessus, fauves. Sur les vieux troncs.

12. Lichen pubescens. $N$. Umbilicatus, cinereus, lobis conniventibus, tuberculis centralibus, convexis. $N$. Herb. $1^{\text {re }}$.

Rosette cendrée, attachée au milieu, velue en-dessous; bords découpés en lobes arrondis, comnivens; tubercules centraux, sessiles, convęxes et fauves. Sur les vieux troncs.

13. Lichen xerampelinus. N. Umbilicatus, laciniis latis tenuibus. Sticta xerampelina. Horb. $2^{\mathrm{e}}$. 14. Lichen gelatinosus. $N$. Collema. Ach . 15. Lichen. Laciniis latis verracosis.

16. Lichen caninus. L. Peltidea canina. Ach. Herb. $2^{\mathrm{e}}$ : Plante européenne, ainsi que les suivantes.

17. Lichen centrifugus. L. Parmelia centrifuga. Acht 8. Lichen farinaceus. L: Parmelia farinacea. $A c h$.

19. Lichen caperatus. $L$. Parmelia caperata. Ach. 20. Lichen scyphifer. $L$. Bxomyces pyxidatus. $A c h$. 21. Lichen gracilis. L. Bæomyces gracilis. Ach. 22. Lichen paschalis? $L$. Stereocaulon paschale. $A c h$ : 23. Lichen vulpinus. L. Parmelia vulpina. Ach.

Id. Au Cap et à l'Isle-de-France.

24. Iichen plicatus. L. Usnea plicata. Ach. 25. Lichen ..... Crustaceus. Herb. 3e.

Croutte blanche, parsemée de points noirs; qui conrroit entièrement le sol dans les endroits les plus élevés où je sois parvenu.

\section{MABCHANTIE; IIS U'LATIQUES.}

26. Marchantia hemispherica. L. Herb. $2^{e}$.

Chapeau hémisphérique entier; deux espèces de $\mathrm{Ca}$. 
lices formés de lanières membraneuses, logeant chacure un Globule.

27. Marchantia glauca. $N$. Herb. $1^{\text {re }}$.

Feuillage membraneux, "glauque, marqué de points blanchiatres; écussons campanulés; bords d'un rang de dents aiguës membraneuses; un petit nombre de corpuscules logés dedans.

28. Marchantia polymorpha. L. ? Herb. $1^{\text {re }}$

29. Anthoceros lavis. L. Herb. $1^{\text {re }}$.

Au Cap, aux Isles die France et de Bourbon.

3o. Jungermania palmata. $N$. Merb. $3^{\mathrm{e}}$.

Jungermania flabellata, La Bill. Nov. Holland. Plant. II, p. 109 , tab. 254 , f. 1.

'Tige simple, s'ćpanouissant'en une feuille palmée repliée sur les côtés; lobes dentés; nervure jusqu'as sominet.

Quelques individus ont. des paquèts pulvéruIens sur la nervure; d'autres, une espèce de calice pareillement partant de la nervure, à cing découpures aiguës den.tées. Je l'ai retrouvée au Cap de Bonne-Éspérance.

3r. Jungernania sinuata. Herb. $2^{\mathrm{e}}$.

Tige simple; feuilles alongées, quelquefois rameuses, sinuées sur les bords.

32. Jungermania pinguis? L. Herb. $1^{\text {re }}$.

Foliole épaissc, repliée; grains pulvérulens le long de

la nervure. Id. A u Cap et à l'Isle-de-France.

33. Jungermania complanata. L. IIcrh. ${ }^{\text {re }}$.

3i. Jungermania reptans. L. Herb. ${ }^{\text {re }}$

35. Jungermania tamariscolia. L. Herb. $\mathbf{r}^{\mathrm{re}}$

36. Jungermania crassa. N. Herb. $1^{\text {re }}$.

Singulière espèce, mais trouvcóo sans fructification. 


\section{MUSCI , LES MoUSSE.}

37. Bryum pyriforme. L. Herb. I $^{\mathrm{r}}$. 38. Bryum hypnoïdes. L. Herb. $2^{\circ}$.

Trichostomum canescens. Hedw:

39. Bryum scoparium. L. Dicranum scoparium. Hedw. Cecalyphum scoparium. Beauv. Herb. $2^{e}$. 40. Bryum heteromallum. L. Dicranum heteromall um:" 41. Bryum incurvatum. N. Foliis setaceis, filamento tenui; pixide turbinato-incurvata. Herb. $1^{\text {re. }}$

Trematodon, longicollis; ATichaux, Amer. Bor.; Villars, Jardin de Strasbourg, pl. I, f. 1. Dicranum longicollum; Bridel, muscolog. supplem. 223.

Je l'ai retrouvé aux Isles de Bourbon et de Ma. dagascar.

A près être restée long-temps inconnue, cette singulière Mousse s'est présentée, vers le même temps, aux yeux de Michaux en Caroline, à ceux de M. Villars, dans les bois de la Grande - Clartreuse, ct aux miens au milieu de la mer Atlantique.

42. Bryum serpillifolium. N. Foliis obovatis, la'ts virentibus, filamento brevi, pixide turbinata. Herb. $\mathrm{I}^{\mathrm{re}}$.

13. Bryum.

44. Bryum. Espèces sans fructification. 45. Bryum.

46. Polytrichum vulgare. L. Herb. ${ }^{\text {re }}$.

47. Mnium hornum: L. Herb. $1^{\text {re }}$. 48. Mnium cylindricum. N. Herb. I. ${ }^{\text {re }}$ 
49. Hypnum taxifolium. L. Fissidens taxifolius. Hedw: Bourbon, Isle-de-France.

5o. Hypnum bryoïdes. L. Fissidens bryoïdes. Hedw: 51. Hypnum elongatum. N. Frondibus simplicibus, pennatis. Herb. $\mathbf{I}^{\mathrm{re}}$.

An fissidens? An trichostomum ?

52. Hypnum naviculare. N. Herb. $2^{\mathrm{C}}$.

Frondibus simplicibus, aculis; frondibus crmbiformibus mucronatis. N. Pterygynandrum viscosum. Beauv.

Je l'ai retrouvée à Bourbon, sur les sommets de la rivière du Màt , mais toujours saus fructification.

53. Hypnum. ... .

Espèce qui ressemble à celles d'Europe, mais que je n'ai pu déterminer.

54. Hypnum minimum. $N$.

Espèce européenne, que je n'ai pas non plus encore déterminée.

55. Hypnum reflexum. $L$.

56. Hypnum sciuroïdes. $L$. Sans fructification.

57 . Hypnum purum. L. $\}$

58. Hypnum striatum. $N$. Herb. $1^{\text {re }}$.

Orthothricum fimbriatum. Beauv. IIypnum. , foliis confertis; clyptra conica; striato lucente.

Isle-de-France, Madag. Bourbon.

59. Lycopodium clavatum ? Herb. $2^{\mathrm{e}}$.

Lepidotis diaphana. Beauv.

FILICES, LES FOU G ĖRES.

6o. Pteris palmæformis. $N$. Isle Bourbon, Isle-de- 


\section{de Tristan d'Acugna.}

France. Vid. Pterigraph.82-83. Caudice arboreo foliis pinnatis, auriculatis centralibus fructiferis, consolutis. Herb. $3^{\mathrm{e}}$.

Souche de deux pieds de haut, de quatre pouces de diamètre, couronnée à la manière des palmiers par des feuilles ailées : pinnules rapprochées, étroites, auriculaires à la base, d'un vert jaunâtre, fructifères au centre, roulées sur les bords.

* Elle a beancoup de rapports avec l'espece qui croît a Bourbon sur la lave refroidie, et à la montée de la plaine des Cafres, que M. Bory de Saint.Vincent a fait figurer dans son Voyage, tab. 32, sous le nom de Pteris osmundoides, et que M. Swarts nomme Onoclea boryana; mais elle en differe par plusieurs caractères, ainsi que d'une troisième, qui croît dans l'intérieur de l'Isle-de-Prance. Je les ferai connoître dans mon travail général sur cette famille.

61. Pteris? vittarioides. $N$. Fronde simplici, lineari; marginibus revolutis. Herb. $1^{\text {re }}$. An Ptcris? an Acrostichum?

Feuilles très-simples, linéaires, repliées sur les cotés, couvrant la fructification. $A$ u Cap et à l'Isle-de. France.

Elle est très-distincte du Pteris lineata ou Vitfaria, de Smith.

62. Acrostichum succisæolium. $N$. Herb. $2^{\text {e }}$. Fronde simplici, lanceolata, villosa. Vid. Pter. tab. 42. B.

Feuilles simples, lancéolées, pétiolées, couvertes endessus et en-dessous de poils roussâtres; feuilles fructifères plus élevées, couvertes en-dessous de poussière noire. A l'lsle-de-France.

63. Acrostichum laurifolium. Fronde simplici, lan- 
ceolata, lucida.Vid. Ptcr. 43, C. Herb.3e.

Cette plante ressemble beancoup à la précédente; mais elle est toujours plus grande, et ses feuilles sont glabres, luisantes, ressembluntes à celles du Laurier : la poussière qui couvre le dessous des feuilles fructifères est d'un beau jaune : elle est rare en fructification. Au Cap, à l'Isle-de-France, Bourbon.

64. Acrostichum ciliare. Fronde simplici, margine ciliatd. N. Sans fructification. Vid. Pterigraph., tab. 85. Herl, $5^{\mathrm{e}}$.

Isle-de-France et Bourbon.

65. Acrostichum polytrichoides. N. Fronde pinnata; pinnulis integris, concavis. Herb. $3^{\mathrm{e}}$.

Feuilles ailées; pinnules arrondies, concaves endessous; fcuilles fructifères plus élerées, un peu plićes; enveloppe recourrant entièrement les graines.

* On doit rapporter cette plante aux espèces de Pteris dont M. Swarts a formé son genre Onoclea.

65. Polypodium aquilinum. N. Fronde tripinnatifida. caulibus villosis, punctis fructiferis parvis, et raris nudis. Herb. ire.

Feuillage plusieurs fois ailé, tiges velues, rameaux inclinés et rapprochés en-dessus ; feuilles crénelées, un seul rang de points au pourtour.

Cette fougère est la plus grande de l'isle d'Acugna, et s'élève jusqu'à quatre pieds; sa racine ressemble à celle du Pteris aquilina.

67. Polypodium tomentosum. Fronde bipinnatifida, caulibus tomentosis losis foliolis, crenatis, punctis fructiferis, parvis et nudis. Herb. $\mathrm{I}^{\mathrm{re}}$.

Cette espèce est élégante, à feuilles. bipinnées, fo- 


$$
\text { de Tristan d'Acugna: }
$$

liolos crénelées, un seul rangr de points rangés le long du hord, sans enveloppe.

J'ai représenté un raneau bipinné au sommet; jo ne sais si c'est un simple accident, n'en ayant vu qu'un seul dans ce cas.

68. Polypodium villoso-viscidum. N. Fronde decomposith, foliolis crenntis, villoso-viscidis, punctis fructiferis nudis. $N$. Herl. $1^{\mathrm{re}}$.

Feuillage plusieurs fois ailé, tiges et feuilles cou* vertes de poils glanduleux capités; fructification sous lo repli des bords des feuilles en petits payuets ronds, sans enveloppe.

69. Polypodium calyptratum. N. Fronde bipinnatifula, pinnulis pinnatifidis, fructificatio calvptra peltata inclusa. $\lambda$.

Tiges et feuilles fermes, points fructiferes abondans, couverts d'une enveloppe brune attachée par le ceutre. J'ai retrouvé le même caractère de fructification à plusieurs autres Fougères du Cap et de l'Isle-de-France, mais elles sont beaucoup plus grandes: j'en ai fait un genre que j'ai nommé Struchiofilix.

* Cette plante se rapporte aux Aspidium de Swartz. 7o. Blechnum australe. L? Fronde pinnatifdd, pinnulis aurculatis. $N$. Herb. $2^{\text {re }}$.

Au Cap Bonne-Espérance.

71. Asplenium crassum. N. Fronde pinnatifida, pinnulis incisis, aculd dentatis; lineis parallelis. Herb. $1^{\text {re }}$.

........Adianthum Jamaicense lonclitidis anplioribus foliis, non ramosum; pediculo 
atro nitente. Pluckn. Almag. 11; Phyt.' T. 252 , f. 5 .

Feuilles épaisses, luisantes, ailées; folioles à dents aiguës, pointues à l'extrémitiè, embriquées; fructification en ligues paralleles, semblable à celle de la Scolopendre; écaill es lancéolées, grises, larges, transparentes. Sur tou te la côte, le long des rochers.

72. Asplenium filipendulxfolinm. N. Fronde pinnatâ; pinnulis multifidis, laciniis linearibus, obuzsis villosis. $N$. Herb. ’e.

Espèce très-élégante, à feuilles alongées, ailées; pin* nules multifides, découpures linéaires aiguës ; fructifications peu nombreuses, alongées, sans enveloppe. * Grammitis, Swartz.

73. Asplenium marinum. $L$ ? Fronde pinnata, pinnulis inciso-dentatis. Herb. $\mathbf{r}^{\mathrm{r}}$.

Fenilles ailées; folioles découpées, aiguës. Au Cap et à l'Isle-de-France.

74. Adianthum xthiopicum. L. Fronde decomposith, foliolis rotundis, crenatis. Herb. $\mathrm{I}^{\mathrm{re}}$.

Espèce élégante, très-abondante le long des ravines. Au Cap.

75.Trichomanes aruginosum. N. Fronde pinnata, pinnulis multifidis, laciniis linearibus, villis ramosis. $N$. Herb. $3^{\mathrm{e}}$.

Trichom. hirsutum. L? Frondibus pinnatis, pinni alternis pinnatifidis, pilosis. $L$.

Cette petite plante a lo port du Trich. tunebrigense; mais elle est couverte de poils ferrugineux bi et trifurqués; la fructification occupe le sommetdes rameans logés dans de petits godets peu apparens. 
Il y a à l'Isle-de.France un Trichomane velu, mais qui paroît en différer.

\section{MONOCOTYLÉDONES.}

\section{CYPEROIDEA, LES SOUCHETS.}

76. Carex hamosa. Uncinia gracilis. N. Spicd unicd, superne mascult; arista uncinatd; culmo gracili foliis longiori. Herb. $1^{\text {re }}$.

Carex uncinata. L. F. Hamata ex basi utriculi (Nectaris, I.) Spica simplici, androgynA, lineari, supernd mascula, aristis fixminarum uncinatis, masculis muticis. L. S. p. $\{13$.

Chaume nu, triangulaire, lisse, mince, haut de deux à trois pieds; feuilles longues, étroites à sa base; un seul épi mâle au somimet linéaire; fleur femelle, base calicinale élargie au sommet, scarieuse sur leg bords.

Utricule alongé, velu; arrête particulière parlant de sa base interne, crochue au sommet, unie fois plus longue que l'utricule; semence ovale; un style, arec trois stigmates; anthères linéaires.

77. Carex brevicaulis. Uncinia brevicaulis. $N$. Spica unica, superne mascula, crassiore, arisis uncinatis, culmo foliis breviore. Herb. $2^{c}$.

Cette plante diffère de la précédente par son épi plus épais et plus court, et par son chaume beaucoup plus court que les feuilles.

* M. Persoon a formé un genre de ces espèces de Carex, remarquables par leur arrète crochue. Il leur

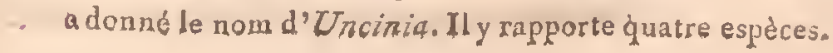


78. Carex: : . Spicis confertis, sessilibus, herma: phroditis. Herb. $\mathbf{1}^{\mathbf{r}^{\mathrm{e}}}$.

79. Carex.... Spicis pluribus masculis, fomineis pedunculatis. Herb. $\mathbf{I}^{\text {re }}$.

* Plus de deux cents espèces sont rapportées maintenant à ce genre: comme leurs caractères spécifiques sont tirés de parties peu saillantes, il est difficile de les déterminer, sur-tout sur le sec.

8o. Scirpus sulcatus. Culmo nudo, compresso, sulcato; capiulo globato. Herb. $1^{\text {re }}$.

Chaume nu, de huit pouces jnsqu'd dix - huit de hauteur, un peu comprimé, sillonné tout du long; gaîne membraneuse à la base, mucronée d'un côté; plusieurs épillets sessiles au sommet, ramassés en têtes globuleuses, une bractée en-dessous; épillets coniques, écailles, monsses; style divisé en trois, presque jusqu’à son origine. An Cap?

8. Scirpus prolifer. Culmo repentè stolonifero; spiculis paucis proliferis. Herb. $1^{\mathrm{re}}$.

Cette espèce est petite; elle pousse des chaumes tralnans, ramassés en gazons denses : les épillets sont aut sommet; ils sont souvent prolifères.

Cette plante croit par-tout, dans les endroits les plus arides des montagnes, elle forme de petits gazons d'un beau vert.

\section{GRAMINEAE, IES GRAMINÉES.}

82. Ponceletia arundinacea. N. Herb. $\mathrm{I}^{\mathrm{re}}$. Gluma zuniflora, bivalvis; calix bivalvis : stylus zunicus; stigmata duo.

Bale extérieure, bivalve, uniflore; valves inćgales, carinées; bale intérieure, à deux valves inégales, l'une 


\section{de Tristan d'Acugna.}

aiguë, l'autre mousse; trois étanines; style simple, alongé, divisé au sommet en deux stigmates ninces; graine comprimée, ovale, marquée à la base d'une tache(Chalaza de Gaertner), acuminée par le vestige dı style; fleurs rassemblées en un épi composé, resserré; épillets unilatéraux.

J'ai consacré ce genre à la mémoire de l'abbé Pon celet, qui en 1779 a publié une histoire naturello du Fromcnt, ouvrage plus curieux que solide.

Ce Gramen diffère du plus grand nombre des autres par son style simple : ce qui le fait rapporter à la $\mathrm{XI}^{\circ}$ section de M. de Jussien, dans cette famille. Il se rapproche, pour le port, du Roseau des sables : c'est la plante la plus multipliée de l'Isle; elle en couvre toutes les parties, depuis les bas les plus humides, jusqu'aux sommets les plus élevés où je sois parvenu. Sa racine cst fibreuse, très-tenace.

Quoique Linné ait rapporté indistinctement le plus grand nombre des Graminées à la Triandrie Digynie, il y a plusieurs espèces des plus communes, qui n'ont qu'un seul style bifide, connue l'Alopecurns pratensis: ce qui n'a pas échappé à Leers, qui l'a figuré ainsi.

83. Phalaris mollis. N. Panicula molli in spicâ coarctata; foliis pubescentibus. Herb. $\mathrm{I}^{\mathrm{re}}$.

Chaume ćlevé de deux à trois pieds; feuilles pubescentes, molles, longues de six à sept pouces, larges de six lignes à la base; panicule resserré en épi.

34. Phalaris cespitosa. Panicula pauciflora subspicata, culmo repentè stolonifero. Herb. $\mathrm{I}^{\mathrm{re}}$. Petite espèce à chaume rampant, stolonifere; pania culo pauciflore, resserré cn un épi long d'un pouce.

Cette plante courre quelquefois, à elle seule, us grand espace de terrain. 


\section{I CO T Y L E O N E S.}

\section{POLYGONEF , IES POLYGONES:}

85. Rumex frutescens. Valvis seminum integris, granuzlatis. $N$. Herb. $1^{\text {re }}$.

Tige droite de un à deux pieds, suffrutescente; feuilles ovales, arrondies aux deux extrémités; épis. denses; valves des semences, avec un grain épais.

Elle se trouve tout le long de la Falaise; mais elle croit plus abondamment dans une petite crique saunâatre. Elle a un gon̂t âpre, désagréable.

86. Chenopodium tomentosum. N. Foliis deltoideis, tomentosis, sinuatis; floribus in spicis foliaccis, axillaribus simplicibus. Herb. $1^{\text {re }}$.

Tige de deux ì trois pieds, sous-ligneuse à la base, velue, cotonneuse, rameuse; feuilles cunéiformes à la base, lancéolées, sinuées, dentẻes; fleurs en petits. épis, foliacées, axillaires.

Toute celte plante a une odeur forte assez agréable, dans le genre du Chenop. Botrys, et autres espèces odar rantes. Elle est commune par-tout.

Cette plante"a de commun avec les Chenop. Botrysambrosioides multifidum et anthelminticum, l'odeur fort et agréable de ses feuilles. Elle diffère des trois dernières parson duvet cotonneux, qu'elle a de commun avec le Botrys; mais elle en differe par la fornı de ses feuilles et par ses épis simples et foliacés.

37. Chenopodium album. L. Herb. $2^{\circ}$.

J'ai trouvé quelques piods de cette plante européenn. 


\section{ERICF, LES BRUY'ARLS.}

88. Empetrum nigrum? Herb. ${ }^{\mathrm{r}}{ }^{\mathrm{B}}$.

* Empetrum rubrum. Vahl. Procumbens, ramulis pubescentibus, foliis oblongis, margine re. volutis, suprascabriusculis. Wild.'Tom.IV, pag. 7 ז3.

Sous-arbuste à fenilles nombreuses, linéaires, repliées en-dessous, los bords se rejoignant, ce qui les fait paroître fistuleuses. Il vient dans les endroits les plus arides, alors il est entièrement couché; lorsqu'il croit dans un terrain fertile, il est plus droit.

Au mois de janvier, il nétoit plus qu'en fruit, sess fleurs étant desséchées. Il se tronve rarement fructifere; sa baie est rouge et a un petit goût aigrelet quu n'est point désagréable. Voici les caractères que in'ont préscutéa les flcurs desséchées.

Fleur hermaphrodite; calice de trois folioles, ovale persistant, trois pétales lancéolés se flétrissant; un filament alongé, filiforme, portant une anthère à deux loges distinctes, ovales; pistil; style s'épanonissanten entonnoir, divisé par plusieurs stigmates; fruit; bai uniloculaire; 7.8-9 semences disposées en rond sur un seul rang.

\section{CORYMBIFER E , LES CORYMAIFERTS:}

§g. Xeranthemum cespitosum. Snrculis nuifloris; pedunculo unifloro, elongato. Herb. $2^{\mathrm{e}}$.

Rejets formant un petitgazon; feuilles petites, ovales, formant une rosette; le bouton est au centre, d'abord sessile, ensuite s'élerant sur un pédoncule de substanco terdie, d'un pouce de long ; calice cmbriqué ; ćcailles. 
luisantes, intérienres, plus longues. Aigrette des semenees pédonculée. Dans les endroits arides des montagnes. Quoiqu'il soit assez commun, je n'ai pu rencon. trer sa fleur au moment de sun épanouissement.

* Cette planto paroít avoir des rapports avee le Chapa talia de M..Ventcnat; mais elle en diffère par beaucoup de points remarquables : elle doit former un genre particulier.

90. Graphalium pyramidale. $N$. Herbaceum, cantlibus simplicibus; floribus in spica folios congestis. Herb. $\mathrm{x}^{\mathrm{re}}$.

Tiges sinples, redressées; feuilles longues de denx pouces, spatulées, mucronées à la pointe; fleurs à éeailles. rouillées, ramassces en un épi épais, fenillé au sommet. Dans les bas et sur les hanteurs.

9г. Calendula pusilla. N. Caule simplici, stolonifera Calendula pumila. Forst. Prodrom. Herb. 3 e.

Calendula Magellanica. Wild. 2344.

Aster nudicaulis. Lam. Dict. Comm. Herb. Foliis subspathulatis, apice tridentatis, caule subaphyllo, flore mutabili. Comm. Herb.

Petite plante très délicate, qui a l'aspect d'un Draba; sa tige cst simple, garnie de quelques rejets a la base; feuilles ovales, dentées; pédoncule alongé, uniflore; éeniltes colorćes; demi-fleurons étroits, blancs lavés de pourpre; quelques fleurons fertiles, ceux du centre mâles. Sur le revers stérile du plus haut sommet que j'aie gravi.

Il paroit que c'est la'même plinte que Commerson a trouvée au détroil de Magellan; mais ce n'est certaisement pas un Aster. 


\section{de Tristan d'Acugna.}

RUBIACÉS.

Erythrodanum. N. Character essentialis; calix minimus, superus; corolla monopctala, quadrifida; stamina fundo corolla inserta; stylus. bifidus; stigmata hirsuta; bacca umbilicata, disperma.

Calice. Rebord à quatre dents peu marquées:

Corolle. Supérieure, campanulée, à quatre divisions, ver. dâtre.

Étamines. Quatre, insérées sur la base de la corolle; anthères arrondies.

Pistil. Ovaire inférieur, arrondi ; un style partagé en deux; stigmate velus, débordans de la corolle.

Fruit. Baie arrondie, ombiliquée, rougeâtre, aqueuse; deux semences,

Semences. Deux semences accolées, ovales, arrondies endessus, plates sur l'autre côté, sillonnées.

Embryon. Droit, logé dans un périsperme corné.

Disposition. Fleurs solitaires, logées à l'extrémité des rameaux, dans un entonuoir formé par les pétioles'élargirs des dernières feuilles et les stipules.

Herbes rampantes, radicantes; feuilles opposíes, succulentes; stipules intermédiaires, ayant le port des Alsines.

Ce genre se range dans la Tétrandrie Monogynie du systême de Linné, près du Pavetta, dont il ne paroît différer essentiellement que par l'insertion de ses étamines et son style bifide. Il a aussi le plus grand rapport arec le Coffica, dont il ne diffère que par le nombre des étarnines: 
92. Erythrodanum alsineforme. N. Cespitosa, caulibus radicantilus; foliis ovatis, pedunculatis, integris. $N$. Herb. $1^{\text {re }}$.

Nertera depressa, Sm. Icones ineditos fasc. 2, tab. 28. Gaertn., Trailé des Fruits, 1, p. 124, tab. 26, f. 1. Gomozia granadensis $L$. suppl.

Petite plante rampante, formant des gazons tapis contre terre, d'un vert gai, tiges radicantes; fenilles opposées, pétiolées, ovales, acuminées, ressemblantes à celles de la Morgeline; petit fruit rouge, logé au sommet des rameaux. La baie a un goùt désagréable.

Elle croit par-tout à Tristan d'A cugna, dans les endroits les plus bas comme dans les plus escarpés.

* La figure de Sinith représente fort bien cette plante quant au port : elle a d'abord été trouvée par Mutis à lit Nouvelle-Grenade, et enroyće à Linné; ensuite par Bancks et Solander aux Terres Antarctiques.

93. Erythrodanum majus. $F$. Cululibus repentilus, foliis subsessilibus, marginibus calloso-undulatis. Herb. $\mathrm{I}^{\mathrm{r}}$.

Nertera assurgens. $N$.

Cette plante est plus grande dans toutes ses parties que la précédente; ses tiges sont simplement ramp̧antes à la base et redressées vers le sommet; les feuilles sont subsessiles, nvales, onduiées en leurs bords, avec us bord calleux.

Elle a le port du Cerastinm aquaticums.

Epuof od ayou, noun grec de la Garance, d'Epulpos rouge, et qui lui convient, à cause de la couleur de son fruit.

* Ce genre est certainement le Gomozia de Mutis et de Linné fils, le Nẹtcra de Gaertner et de Smith; 


\section{de Tristan d'Acugna.}

zmais le caractère qqu'en ont douné ces auteurs, pris rraisemblablement sur des individus secs, étoit trèsincorrect : ainsi elle a éridemment un calice, quoique très-petit; un style simple, mais bifrde; l'embryon do ses graines m'a paru droit, non renversé, comme lo décrit et le figure Gaertner.

\section{OMBELLIFERÆ， LES OMBELLIFÈRES.}

94. Apium australe. N. Foliis bipinnatis, cuneiformibus; ranulis verticillatis, umbellis sessilibus confertis. Herb. $1^{\text {re }}$.

Est-ce l'espèce trouvée au détroit de Magellan ct dans les isles adjacentes?

Feuilles bipinnées, pinnules cunéiformes, dents aiguës ; rameaux verticillés; oubelles sessiles au sommct, partant plusieurs du mểne point; fleurs blanches; semences courtes marquées de trois sillons.

Son odeur et son golt sont assez agréables; cependant je n'ai pu déterminer, par mon exemple, les matelots à en manger.

95. Hyclrocotyle capitata. N. Foliis rotundatis, obscurè lobatis; floribus capitatis. Herb. $1^{\mathrm{re}}$.

Monoïque par avortement?

Fleurs en tête, rondes; fleurs pédonculées, une écaille caduque à la base.

Fleur mâle; ovaire stérile; deux styles; corolle de cinq pétales entiers lancẹolés.

Fruit ; deux semences lisses, unies, accolées.

Tiges rampantes, hérissées, ainsi que les feuilles, de poils rares et longs; feuilles arrondies, crénelées et irrégulièrenent lobiées; Aleurs ramassées en têtes, axillaires, pédonculées. 
* Wildenow rapporte dix-huit espèces à ce genre, qui sont répandues sous toutes les latitudes. On doit s'attendre que ce nombre sera au moins doublé daus une Monographic que prépare M. de Jussieu, dans laquelle se trouveront insćrées toutes les Espèces que j'ai recueillies au Cap de Bonne-Espérance et aux Islec de France et de Bourbon.

\section{GERANIA, IES GÉRAINES:}

96. Felargoninm Acugnaticum. Folits rotundis, obsm curè lolialis. Herb. Ire.

Geranium. L.

Tige lierbacée, haute d'un pied, élaguée; feuilles. opposées, inégales, à longs pétioles, arrondies, à lobes peu marqués et inégaux; d'u vert foncé, stipules caduques. Uive dixaine de fleurs ramassées en ombelles sur un long pédoncule, avec une collerette, petites, rougeâtres.

Toute la plante a une odeur assez agréable, quoiquo un peu forte; elle a quelques rapports avec le Gcran. odoratissimum, mais elle en diffère beaucoup.

Elle est commune dans toutes les parties de l'isle que j'ai parcourues. Elle étoit en pleiue floraison, mais les fruits n'étoient pas mûrs.

Je crois que c'est, jusqu'à présent, la seule espècc de Pelargonium, qui ait été trouvée hors des environs du Cap. On en connoît maintenant cent cinquante espèces.

\section{ROSACEAE, IES ROSACÉES.}

97. Ancistrum sarmentosum, N. Pernetii, Voyage. aux Isles Malouines, p. 549 ? Foliolis ob. 


\section{dè Tristan d'Acugna.}

Zongis, dentatis, subtus villosis; caule sarmentaceo, elongato. Herb. $x^{\text {re }}$.

Tiges sarmenteuses, rampantes, sous - ligneuses; feuilles ailèes arec impaires, stipulacées à la base; qua tre à cinq paires de folioles, les dernières écartées, plus petites, velıes en-dessous, dentées; elles ressemblent en petit $a$ colles du Sorbier domestique, ou du $P$ otentilla anserina.

Elle est commune par-tout. Le plus grand nombre avoit passé la floraison.

* Vahl a réuni ce genre à l'Acacna; il en décrit treize espèces, dont aucune ne peut se rapporter à celle-ci.

\section{RHAMNI, , LES NERTRUNS.}

98. Phylica arborea. N. Foliis ovato-acutis, verticillato-ternatis; floribus capitatis. Herb. $1^{\text {re }}$ Arbuste, le seul de l'isle; il s'élève jusqu'à la hauteur de quinze pieds; trone de sis pouces de diamètre.

Feuilles ovales, laneéoĺes, cotonneuses en-dessous, verticillées trois à trois, et ramassées au sommet.

Fleurs ramassées en tète terminale, cotonneuses, odorantes, cinq pétales opprosés aux divisions du calice; ovaire inférieur; fruit, espèce de baie sèche onbiliquée, à trois loges monospernes.

Cest la seule plante ligneuse propre à faire du bois de chauffage et de menus ourrages, que j'aie reneontrée sur cette Isle; elle y est très-abondante.

Cet arbuste fleurit rarement, à ce qu'il paroit, n'en nyant trouvé que quelques individus en fleur, beancoup moins en fruit.

* Wildenow rapporte dix-neuf espèces à ce genre, toutes originaires du Cap de Bonne Espérance. 
46 Esquisse de la Flore de Tristan d'Acugna:

Est-ce le même arbuste dont parle Pernetti, Voyage aux Isles Malouines, p. $5 .\{8$ ?

Il a beaucoup de rapports avec celui qui croít sur les sommets élevés de Bourbon.

Dans un petit espace précédemment cultivé, se trouroient les plantes suivantes :

99. Lactuca sativa. L. La Laitue cultivée. roo. Raphanus sativus. L. La Rave.

Gen. Spec, Famil. Gea. Spee.

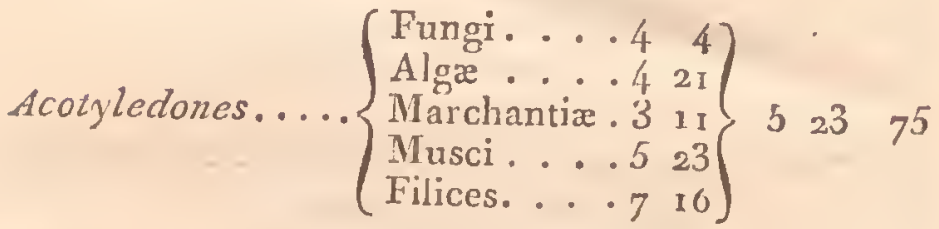

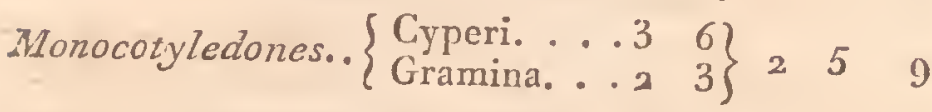

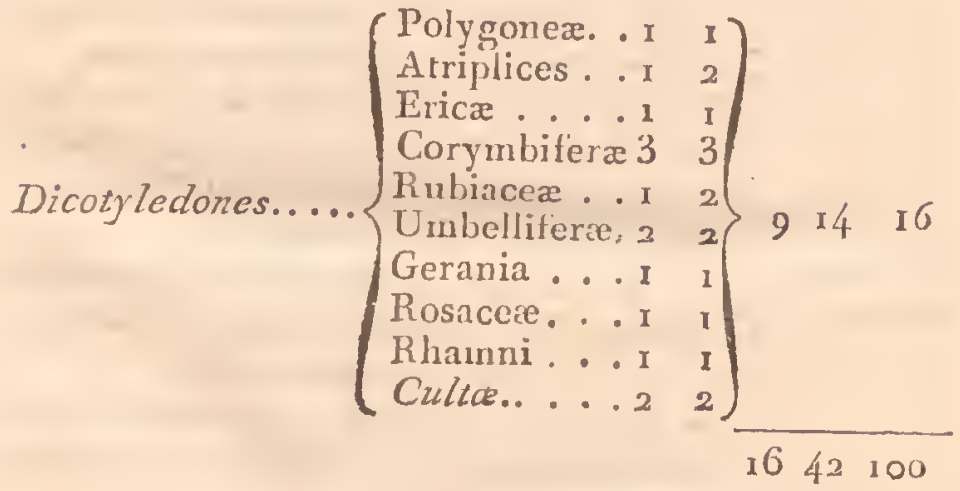

F I N. 


\section{TABLE ALPHABETIQUE}

DES

\section{NOMS GÉNERIQUES.}

Ácena. Vahl. No. 9 S. Acrostichum. L. 62 à 65 . Adianthum. L. 74. Alianchum. Plukn. 7 . Agaricus. 'T. 2. Ancistrum. L. 98. Apium. L. 94. Authoceros. L. 29. Aspidium. Sw. 69. Asplenium. L. 7 x a 73 . Aster. Lam. 9т. Plechnum. L. 70 . Beoniyces. Ach, 20 \& $2 t$. Bolctus. L. 2.

Bryum. 37 \& 45 .

Carcx. L. 76 à 79 .

Calendula. L. $9^{\text {r. }}$

Cecalyphum. Beauv. $3 g$.

Chaptalia. Vent. 8g.

Chenopodium. L. 86 et 8 . Collema. Ach. 14.

Conferva. 1. 5.

Dicranum. 1Ied. 39 \& $4 \mathrm{r}$.

Empetrum. L. 85 .

Erychrodanum. N. 92 et $9^{3}$.

Filaga. L. go.

Fissidens. Hed, 49 \& $5 \mathrm{r}$.

Fucus. L. 7, 8, 9.

Geranium. L. $9^{6}$.

Gnaphalium. L. 90. Grammicis. Hted. Sw. 72, Hydrocotyle. L. $9^{5}$.
Hypnum. L. No. 49 à 58 .

Jungermania. L. 30 a 36.

Lactuca. L. 99.

Lepidotis. Bcanv. 5g.

Lichen. L. 10 à 25.

Lycopodium. L. $5 g$.

Marchantia. L. 26 à 28.

Merulius. Jnss. I.

Mrum. L. 47 aे $4 \mathrm{~S}$.

Onarlea. Sw. 60 et 65.

Parmelia. Ach. 17 aे 19, 23.

Pelargonium. L'Her. 96 .

peltidea. Ach. 16.

Phalaris. L. 83,84 .

Peziza. L. 4 .

Polypodium. L. 6.6 a 69,

Polythricum. L. 46.

Ponceletia. N. 82 .

Pteris. L. 60, 6t, 65.

Perygynandrum. Hed. 520

Rhaphanus. L. 100.

Rumex. L. 85.

Scirpus. 80.

Sphoria. Hall: 3.

Stercocaulon. Arlı. 22.

Sticra. Ach. ro dे 3 .

Trematodon. Mich. 4 r.

Trichostomum. Hed. 38 .

Ulva. L. 5.

Uncinia. Pers. 76,77 .

Usnea. Ach. 2 \%.

Xerauthemum. L. 8 g. 


\section{TABLE DES ABRÉVIATIONS}

$\mathbf{E} \mathbf{T}$

\section{DES AUTEURS CITÉS.}

A ch.- Acharias. Merhodus Lichenum, 1 So3.

Benuv, - Palisut de Beaurois. Prodrome des 5 e et $6^{\circ}$ Familles de $l^{\prime}$ Etheo; gamie, 1805.

Bill. - La Billardière. Nova Hollandia Plantarum specimen, i 804.

Bory.- - Bory de St.-Vincent. Voyage dans les principales isles de l'A frique.

Brid. - Samuel Bridel. Muscologia recentiorum, 1797.

Comm. - Crmmerson. Herbiers et manuscrit.

Forst. - Forster. Prodromus, 1786.

Gaert. - Gaertner. De Fructibus ct Seminibus Planzarum, 1788....1797.

Gmel. - Jeau-Frédéric Gmelin. Historia fucorum , 1; 68 .

Hall. - Albert Haller. Historia Planiarum Helvetie, 1;68,

Hed. - Jollannes IIedwig. Descriptio Muscorum, 178 iे $179^{5}$.

Iler. L L'Héritier. Geranologia, i $78 \%$.

Juss. - Antainc-Lauren de Jussien. Genera Plantarum, I 768.

Lam. - Lamarck. Dictionnaire de Bozanique, Encyclopédie, 1,83 et suiv.

L. - Limnxus. Species Plantarum, $1753,{ }_{7} 762$.

Systema Vegetabilium, curanze Mutray, i 784 .

L. F. - Linnorus filius. Supplemenzum, $178 \mathrm{r}$.

Mich. - Michaux. Flora Boreali-Americana, 1803.

Mutis. Letzres munuscrizes:

N. - Nov. ou Nouveau. Planee non encore décrize.

Pernetti. - Dom Pernetti. Voyage aux isles Malouines, $176 \mathrm{gy}$.

Pers.-Persoon. Synopsis Plantarum, 1805.

Plukn. - Pluknet. Alnzagestum et Phytographia, rGgi.

Pter. - Pterigraphia nostra ou Description MS. des Fougères des isles Aus* zrales d'Afrique.

Sm. - James Smith. Icones Plantarum inedite, 1789,1791 .

Siv. - Olaïs Swartz. Synopsis Filicum, 1806.

T. - Tournefort. Institutiones rei Herbarice, 1 goo.

Vahl. - Martinus Vahl. Enumeratio Planzarum, 1805.

Vent. - Ventenat. Description du Jardin de Cels, an VIII.

Vill. - Villars. Jardin de Strasbourg, 1808.

Wil. - Wildenow. Species Planearum, 797 et suiv. 


\section{TREIZIĖME ESSAI.}

\section{Notice historique sur la nature et les fonctions de la Moelle et du Liber;}

Lue dans la Séance particulière de la Première Classe de l'Institut, du 5 mars 18 ro.

Toutes les Sciences ne sont composécs que de deux partics, les Noms et les Cnosre.

Leur but est de satisfaire la curiosite sous ces deux points de vue; par lí clles se réduisent à ces deux questions: Comment nommez-rous telle cuose que je vous présente on que je désigne? on que signifie tel Noм que j'entends prononcer pour la premiere fois?

Les élémens les plus abstraits ne sont qu'une disposition telle, qu'on puisse parvenir, de proposition en proposition, ou de question en question, jusqu'aux dernières bornes de l'espace que comprend la portion de doctrine faisant le sujel de l'ouvrage.

La définition des Muts ou des Noms est donc la première base de toute comnoissance.

Quand elle est bien faite, elle devient le vrai critérion des opinions nouvelles; car on aperçoit souvent que, par ce moyen, celles à qui on donne ce titre ne le méritent pas, étant d'anciens faits sculement revêtus de nouvcaux Noms. 
Sous le point de vue d'ou j'ai envisagé la Végétation, j'ai posé pour base que le Bonrgeon éloit son premier mobile; mais j'ai établi, de la manière qui m’a paru la plus précisc, ce que j'entendois par ce mol; el quoique je lni aie donné une signification un peu différente de celle que plusicurs agronomes lui donnent, il n'en est pas moins vrai qu'on ne peut faire difficulte de l'admettre, pour me comprendre, dans le sens que j'ai adopté; cependant on ne ponrroit, d'autorité, faire prendre à un mot une signifieation opposće à celle qui est reçue, saus nuire à la clarté, parce qu'il faudroit, toutes les fois que ce mot se présenteroit, faire un effort pour se ressouvenir de la signification qu'on lui a donnée; ainsi il est avanlageux de se servir, le plus possible, des termes dans l'acception qui est la plus généralement adoptéc. Pour le mot Buurgeon, trouvant les avis partagés, j’ai pris le sens qui me convenoil le nueux; mais je l'ai fixé de manière que dans mes ouvrages il ne reparoisse jamais que dans celui-là.

Parni plusicurs propositions que j'ai émises et qui paroissent les plus contraires à l'opinion généralement reçuc, des Paradoxes, en un mot, il en est deux surtout de très-l'emarquables.

La première, c'est que la Mozice reste dans le corps de l'arbre, de mêne diamètre et de même nature que dans la jeune branche ou Scion de l'année qu'elle s'est formćc.

La secoude, c'est que le Liren est toujour's indépendant du Bois on de l'Aubier, et, par conséquent, ne lui donne pas naissance. 


\section{Sur la Moelle et le Liber.}

Pour juger ces deux Paradoxes, il s'agit donc de savoir si je doune aux mols Moelle et Liber la même signification que le plus grand nombre des auleurs qui m’ont précédé.

Quant an premier, la Moelle, il ne peut y avoir. de doute lin-dessus: quand on fend un morceau de hois, i] n'est persoune, même des enfans, qui ne reconnoisse pour Moelle la substance qui est au centre.

Ainsi, celle proposition est une question de fait: on n'a qu'a me montrer des troncs d'arbres où la Moelle aura disparu, on anéantira tout ce que j'ai dit là-dessus; d'un autre côté, si j'en montre dans des troncs d'arbres très-vieux, je l'aurai établie.

M. Bose dit posilivement (Nouveau Cours d'Agriculcure) que la Moelle va luujours en diminnant dans un tronc de Surcau, et qu'clle disparoît totalement à la quinzième année.

Voilà un Surean qui a au moins vingt ans, dont cependant la Moelle est aussi large que dans ancune branclie de l'annćc.

Le niême anteur dit que daus la Vignne la Moelle est très-large dans les branches de l'année; qu'elle diminue, la seconde et la troisième; et qu'cnfin. elle disparoît la quatrième. Voilà des tronçons de Cep qui ont plus de six aus, 'el daus lesquels je maintiens que la Moelle est aussi large que la première année de sa formation.

Qu'on examine les búches de Cliĉne les plus grosses, on y tronvera, dans toute la longucur, la Moclle telle qu'elle éloit la première anuéc de sa formation.

Je présente deux morceaux de Cep de vigne. Dans 
le premier il n'y a pas de trace de Moelle: ce n'est pas parce qu'elle a disparn, mais parce qu'il n'y en a jamais eu, altenduque c'est un tronçon de racine. C'est ainsi que l'a fort bien figuré Grew, Analom of Plants, Lab. 17.

Dans le second, la Moelle est heaucoup plus large à une extrémitć qu'à l'autre : on pourroil encore croire que ce servit une preuve qu'elle disparoîtroit à raison de vétusté; mais il est facile de voir que l'extrémité ò̀ se présente la Moelle la plus large est l'inférieure, et par conséquent la plus ancienne : cela vient de ce que les scions qui ont continué la tige, n'étoient pas de même diamètre.

Il y a un mois passé que j’avois demandé la parole à M. le Président pour lire ce Mémoire; mais des matériaux nombreux qui se sont succédés lui ont empèché de me l'accorder. Depuis ce moment, M. Bosc, excité par les objections que je lui ai faites, a cherché à y répondre. C'est dans celte inteution qu'a la Séance particulière d'Agriculture, de mereredi dernier, il a apporté des tronçons de vicux pieds de Vigne; il en a montré deux qui étoient àpeu-près de même diamètre, de denx à trois pouces, mais cependant d'àge différent. J.e premier avoit douze ans déterminés; l'antre étoit de benucoup plus vieux, suivant toutes les apparences, mais saus aucunc date précise. Le premier avoit une Moelle de deux à trois lignes; dans l'autre, elle étoit à peine d'une ligne; il a montré en même-temps des portions supérieures du premier Cep, dans lequel la Moelle étoit beaucoup plus large. M. Bosc s'est cru en droit de conclure de-là que la Aloclle alloit toujours en 
diminuant. Quand on lui accorderoit cela, il y auroit encore bien loin jusqu'à sa première proposition, qu'au hout de quatre aris la Moelle disparoîl dans les branches de Vigne. Mais ici jc ne vois que dcux faits : le premicr, qu'il y a des tronçons de Vigne dans lesquels la Moelle a deux ou trois lignes de diametre; l'autre, qu'il y ell a oil elle a à peine une ligne. Je vais $y$ en ajouter un troisième, en présentant un troisième tronçon qui a certainement plus de douze ans, et dans lequel la Moelle a jusqu’à trois lignes de diamètre.

Voilá donc trois exemples pris au hasard : que prouvent-ils? Que le diamètre de la Moelle varie dans les Ceps de V igne, el qu'il y a apparence que, d'un côlé, on pourroit en trouver de beaucoup plus mince, et, de l'antre, de beaucoup plus grosse.

Je joins de plus unc csquisse qui, quoique faite à la hâte, et comme les figures de géométrie, pourra donner l'idée de la manière doni chaque Sarment, pouvant devenir le moule d'un Cep plus ou moins gros, doit douner un corps médullaire de diamètre trìs-inégal.

Actuellement reportons-nous à l'année oì chacmu de ces tronges étoit lc développement d'un Bourgcon; celuici a produit une jeune branche ou Sarment, tels qu'ils existent maintenant sur toutes les Vigues. Hé bicn, sur le même pied nous en trouverons dont le calibre correspondra parfaitement à celui des trois Ceps présentés.

Voici un Sarment qui pcut représenter celui qui a donné naissance au tronc quc j’ai soumis à l'examen. On en trouveroit facilement dc plus gros; mais certainement il peut passer pour un Sarment vigoureux 
eton peut dire en assurance qu'il y en a beaucoup plus au-dessous qu'au-dessus.

Quant ì la seconde proposition, concernant le Liber, elle n'est pas si facile à constater, parce que ce mot de Liber n'est pas aussi précis que celui de Moelle; il faut donc s'aider des opinions des auteurs précédens pour le déterminer. Voici le tableau que j'en ai extrait d'un ouvrage particulier que je me propose de publicr :

Lıви, Anatomie Végétale, partic intéricure de l'Ecorce d'un arbre.

Ce mot est latin; il avoit dans cette langue plusicurs significations : d'abord, comme adjectif, il tenoil à libertas, et signifioit libre; comme substantif, il désigrnoit l'scorce intéricure; et comme cette substance paroît être la première sur laquelle on ait tracé les caraclères de l'écriture, clle a donné son nom aux recueils d'écriture qui, sous le nom de Livres, sont devenus les dépóts des connoissances humaines.

Quelques auteurs ont prétendu, au contrairc, qu'on avoit donné ce nom de Liber à celte partic, parce qu'elle étoit disposée en feuillels comme un livrc. Virgile s'est servi de ce mot dans le sens d'Ecorce intérieure : Uiloque docent inolescere libro.

Columelle cst celui qui en a le plus souvent fait usage, cntre autres, liv. 5, chap. Io : ita librum arloris inolescere sinilo.

Pline s'en est servi aussi dans le même sens; mais Isidore de Séville est le premier qui cn ait donné l'explication.

Liber est corticis pars interior dictus a liberato cor- 


\section{Sur la Moelle et le Liber.}

sice, id est ablato. Est antent medium quoddam inter lignum et corticem.

Ce mol est passé dans notre langue sans éprouver ' d'altération : par là nous sommes plus riches que les Latins. Quelqques auteurs ont bien tenté dé le changer en Liviret, mais il est maintenant reçu du plus grand nombre avec sa terminaison latine; cependant il ne se troure pas encore dans les dernières éditions du Dictiomaire de l'Académie.

Ruell, qui, lors du renouvellement des seiences, eut le mérite de réunir dans un corps d'ouvrage, sous le titre de De Naturh Stirpium, tout ce que les anciens nous avoient laissé sur les Plantes, définissoit ainsi celle partic: Pars tamen corticis interior, quac ligno pressius adhoret, Liber erit, is quibus scribimns libris nomen dedit. Pag. 3.

Clıarles Etienne, dans son ouvrage très-intéressant sous beaucoup de rapports, le Proedinum rusticum, donne dı Liber une définition parcille; de plus, il cite les auteurs anciens qui ont parlé de cette partie.

Césalpin, qu'on peut à juste titre regarder parmi les modernes comme le vrai foudaleur de la $\mathrm{Ph}_{\text {ysiologie et }}$ de l'Anatomie végétales, s'est plus étendu sur ce sujet. Ainsi, suivant lui, l'licorce est composéc de deux parties : la première est la plus interne, elle est plus dure el plus robuste; on la nomme Liber dans les Arhres: la seconde est plus tendre et plus inince dans les Germes ou jeunes pousses, mais clle devient rude a mesure qu'elles vieillissent, et finit par se crevasser dans les Arbres: 
A partir de ce moment, je r'ai pu découvrir aucune opinion imporlantc sur lc Liber, jusqu'à l'époque où parurent presqu'cnscmble Grew et Malpighi.

-av: Grew ne, se sert pas du mol Linen; mais il paroît cependiant séconformer à l'opinion de Césalpin, car il dit positivement que l'Ecorce est composéc de deux -partics : l'une extérieure, qui cst parenchymatcuse; l'antre, intérienre, qui est ligneuse.

Quant à l'usage de ceḷte partic intéricure, voici ce qu'il dit: "Ensorle qu'une partie de l'Ecorce sc déta" chant du cólç de l'intérieur, va augmenter le Bois, n cin acqućrant de la solidité ct de la vigueur, Iandis " que l'autre se réunit à l'ancicnne Ecorce, ct, la " chassant successivement, elle devient elle-même une "nouvclle peall.

Malpighi en parle au contrairc d'unc manière trèspositive. Ainsi, il dit, pag. 2 : "I.c Lilser consiste ^ en fibres ligneuses, qui s'cnveloppent réciproque* ment en forme de Réscau.

"La Cuticule (épiderme) étant enlcvéc, on trouve " an - lessous un nombre plus ou moins grand de " couches de fibres ligneuses, qui, ponr l'ordinairc, ". sont (implicila) croisćcs ensemble en forme de "Réscaı : clles se recouvrent réciproquement comme - Ics tuniques d'un Oignon, et parcourent toute la "longucir du Tronc. Cependant elles sont disposćes „ de manièrc que les aires du Réscau ou les mailles "deriennent sensiblement plus ćtroiles à mesure "qu'clles approchent du corps du Bois, en sorte - qu'elles sont preśque oblitérées dans le Licer. 
" zusqu'a ce que le Liber soit déterminé près du * Bois, le Liber ou l'enveloppe intéricure de l'Ecorce * est contiguë au bois. "

11 est donc clair par tons ees passages, que Malpighi reconnoît le Liber comme une partie intégrante de l'Ecorce; mais il diffère de Césalpin, cn ce qu'il la distingue du corps intermédiaire de l'Ecorce.

Cet autcur ayant une fois déterminé la nature de celte sulsstance, il cherche à connoitre sa destination. Voici celle qu'il lui allribue, pag. 23 :

e Outre la coction des alimens dont nous venons " de parler, il paroîl que l'Ecorce est destinée à une " autre fonction, savoir l'accroissement des végétaux;

" car l'augmentation des végélaux arrive (comme nous * le ferons voir dans une autre occasion ) par l'addi" lion qui se fail chaque année d'une nouvelle cnve"loppe de fibres, qui formées d'abord de séries hori* zontales d'utricules, acquièrent de la solidité, et " enfiu deviennent une subsiance réellement ligneuse.

* La nature, dans chaque saison, détermine de nou"veanx rangs de fibres qu'clle force d'abord a porter „ les alimens nécessaires au développement, ce que

" pernet leur mollesse; et enfin, lorsqu'ils ont acquis n de la rigidité, elle les applíque sur les partics * contiguës du Bois; en sorte qu'il en résulte une " nouvelle augmentation du Tronc el des Rameaux - par une nouvelle zone ligneuse. On peut conclure - de là que la principale partie des Arbres est la - portion d'Ecorce qui touclie le Bois, puisque c'est

- par son moyen que la vie de la Plante est perpétućc 
" (comme uous le trouvons dans le Saule, le Pelplier " et l'Olivier), et que les 'Trones se grossissent. La por-

- tion extéricure de l'Ecorce, pour l'ordinaire, est

* désorganisée par l'injure de l'air et de la Iranspi-

- ration. C'est pourquoi il est probable que les Plantes

"dont les tiges sont annuelles, ou du moins qui ne

* durent qu'un court espace de temps, et qui ne sont

".pas pourvues d'une portion ligneuse réunic en

* cylindre, sont privćes par la nature d'licorce, et * n'ont quine cuticule, ou du moins n'ont que des "faisceaux ninces de fibres; mais que dans les autres, " qui éprouvent pendant un long espaee de temps unc " augmentalion, il existe unc écorce."

Ainsi, l'opinion de Malpighi est clairenent exprimée; c'est que le Liber, qui est unc portion d'Ecorce, s'en détache pour forner les nouvelles couches ligncuses.

Mais il ne dit ni en quelle saison précise celle opération s'exéeute, ni par quels moyens.

Voilà donc le Liber qui prend une grande importance, puisque c'est de lui que dépend d'abord la nutrition des $A$ rbres et ensuile leur augnentation.

Malpigbi est devenu, peudant un asscz long espace de temps, le seul guide de l'Analomic végétale : il eut cel avaulage sur Grew, parce que son ouvrage étoit écrit en latiu, tandis que l'autre élaut en anglais, ne fut pas si généralement répandu; aussi 'lournefort adopla entièrement l'opinion de Malpighi; mais il nc s'expliqua nulle part précisément sur le Liber.

Linué, comme Tournefort, ne colnut long-temps que Malpighi; il adopla entièrement son opinion sur 
la nature du Liber, le reconnoissant comme la couche inlérieure de l'Eeoree, et sur son usage; mais il aida benueoup à propager eelle doetrine, ell la contractant à sa manière dans un des axiômes qui composent sa Philosophie botanique. Constaı Vegretabile ex medulla $\mathrm{x}$, vestita ligno 2 , facto ex libro 3 , secedente à cortice 4, inducto Epidermide 5.

Le Végétal consiste dans la Moelle revêtue du Bois provenant du Liber, qui se détache de l'Éeoree enveloppée elle-même de l'Ĺpiderne.

Rien de plus coneis que eette phrase. Si elle est vraic dans tous ses points, voilà les bases de l'Anatomie végétale posées; mais s'il en est un seul de douteux, . elle devient plus nuisible qu'utile; el c'est précisément ce qui est arrivé.

Linné adopta ces principes de confiance, et ne fit aueunc tentative pour les lémontrer. Il fut eneore plus loin : puisant dans Césalpin l'idéc ingéniense que la fleur n'étoit que la manifestation des parties intérieures, il assigna à ehacune d'elles la fonetion qu'clle devoit remplir dans ce mode imp̧orlant de la Végéctation.

Ainsi l'tepiderme donne naissanee au Calice, le Liber à la Corolle, le Buis aux Etamines, et la Moclle au .Pistil.

Le développement de cette idće fit, sous les titres de Metamorphosis Vegetabilium et de Prolepsis Plantarum, le sujet de trois de ses dissertations qui composent les Amonitates. Plıs brillante que solide, elle a été généralement adoptée; mais ce n'est pas 
ici le lieu d'examiner jusqu'à quel point elle est vraie.

Duhamel, circonspect à l'excès, fut par là l'opposé de Linné : observateur exact et clairvoyant, il s'occupa, pendant toule sa vie, avec une patience sans égale, à faire des expériences nombreuses. Voici comment il caractérise le Liber dans le Vocabulaire qui termine sa Pliysique des Arbres.

"Quclques personnes ont nommé Liber toutes les " couches de l'lícorce; mais d'autres ont nommé ainsi "senlement la partic de l'Ecorce qui confine au bois." Il paroît dans tout le cours dé son ouvrage qu'il est de ce dernicr avis. Quant à son usage, on voit qu'i] penche bcaucoup pour l'opinion de Malpigli; mais ses nombreuses expériences lui avoient fait voir tant de difficultés, que, comme je l'ai dit dans un de mes Essais, il n'a pas osé prononcer une décision.

C'est dans ce seul et unique but qu'il s'avisa de faire passer des fils de métal à différentes profondeurs dans l'Ecorce, et même entre le Bois et le Liber: continuées pendant plusicurs années, elles le laissèrent dans le doute, comme je l'ai annoncé.

Les termes daus lesquels il s'éloil exprimé devoient engager ses successeurs is continuer ses recherches; mais on aima micux adopter d'antorité une opinion, et l'axiome de Linné préralut.

Je n'ai pu découvrir jusqu'a présent qu'un seul homme qui ail ose s'écarter de celte route battue; c'est M. Mustel : ancien militaire retiré, il se livra à la culture, el étudia plus la Nature que les Livies. Aussi, jusqu’à 
présent, il paroit qu'on n'a pas fait beaucoup d'allention à son Traité de la Végétation, quoiqu'il y ait un grraud nombre de vérités clairement énoncées : on peut dire aussi que plus d'une fois il s'est égaré; mais le nombre de ses véritables découvertes l'emporte, je crois, de beaucoup sur celui de ses erreurs.

M. Mustel avoit fort bien reconnu qu'il se formoit en mêne-temps une nouvelle Couche de Liber et une nouvelle Couche de Bois, toujours indépendantes l'uue de l'autre : ne pouvant accorder cela avec la prétendue conversion du Liber en Bois, voici ce qu'il imagina pour meltre d'accord la Nature et les Livres:

" Je crois être fondé à juger que les dépôts de la " sève montante, joints aux émanations du corps ligneux, " forment un Liber qui ensuite se convertit en Aubier; " et que le même effet de la sève descendante, joint "aux émanations intérieures de l'Ecorce, forme aussi ^ un autre Liber qui se convertit en une nouvelle "Couche corticale; ainsi se forment, perdant l'été, * deux Feuillets de différens Libers, dont l'un appar* tient a Bois et l'autre à l'Ecorce.

"La sève nouvelle les sépare au printcunss pour " en former de nouveaux entr'eux.

"Je n'ai adopté d'autres opinions que celles qui * mont paru démontrées par l'observation et par l'expé" rience."

C'est en vain que M. Mustel a cru trouver un biais pour mettre tout le monde d'accord; personne n'a fait altertion à son opinion, et l'on a toujours répété, avec. Linné, que le Liber se changeoit en Bois. 


\section{XIIr ${ }^{\mathrm{e}}$. Essai. Notice historique}

Ainsi son opinion est, qu'il se forme une nouvelle Couche de Bois et une d'Ecorce, indépendantes l'une de l'autre. Le non commun de Liber, qu'il donne dans le seul but de s'accommoder aux opinions reçues, ne détruit pas la vérité de son observation.

Hill, volumineux auteur Anghis, a heaucoup écrit sur l'Anatomic végétale : il a fait un grand nombre d'observations curieuses; mais il s'est trop livré aux hypothèses. Il reconnoît trois parties dans l'Ecorce, qu'il distingue par trois mots anglais : Rind, Barke, Blea. Ce dernier correspond au Liber.

Plusieurs alnées se passent sans voir paroître d'ouvrage important sur cette malière, jusqu'au moment où M. Scunebier, compatriote de Bonnet, traducteur et ami de Spallanzani, entreprit de riunir en un seul corps d'ouvrage la Ply-siologie végétale.

L'auteur s'y montre plus Métaphysicien que Naturaliste. L'emboîtement des germes et la préexistence des Organcs sont les principaux points qu'il cherche à' établir; ensorte quon duit toujours distinguer les faits qu'il établit, des conséquences qu'il en tire. Les premiers sont souvent nombreux et tirés pour l'ordinaire des meilleures sources; très-peu sont le fruit de sa propre observation.

Voici comment il s'exprime (tom, I ${ }^{\mathrm{er}}$, pag. 127):

"La couche qui furme l'Ecorce ne paroit pas homo^ gène. On découvre d’abord qu'elle est composée de "Couches d'une espece et d'une épaisseur variables "n darıs les différentes Plautes. L'Epiderme cst la Couche 2 la plus extérieure; on trouve cusuite le Tissu cellu- 
\ laire ou le Parenchyme, ensuite les Couches corti" cales et le Liber. Ces Organes particuliers feront " les sujels des articles suivans. "

Effectivement, après avoir passé en revue ces différentes parties auxquelles il donne lien improprement, suivant moi, le nom d'Organes, il ell vient au Liber. (Pag. 186.)

"Le Liber est la dernière Couche corticale du côté » du centre de la Plante.

On peut voir par ces différens passages, que Sellnebier regarde, comme tous ses devanciers, le Liber comme unc partie constiluante de l'Ecorce, et qu'il ne laisse aucun doute la-dessus.

Mais dès qu'il s'agiı d'en indiquer l'usage, alors les raisonuemens et les conjectures premnent la place des faits.

" On est porté à croire que le développement de * cette partic de l'Ecorce forme le Bois. " ( $\mathrm{Pag} .1 \$_{7 .}$ ) Ici il parô̂t être de l'avis de Malpighi et de Liuné; mais subtilisant de plus en plus, il parvient à former un être purement de raisous.

"Il se sépare (le Liber) plus aisément de l'Ecorce - au printemps. Il est alors plus tendre, sa coulcur est - différente du Bois, el il forme le Bois quand il a - acquis toute sa dureté. "

Il est bien clair, par ces passages, que le Bois lire son origine du Liber; et d'après ce que j'ai fail voir, qu'il regarde celui-ci comme faisant partie de l'Ecorce. Cependant il dit ensuite :

« Le Bois et l'Ecorce n'ont pas une origine commune. 
"(Pag. 197.) Dans la formation de l'Aubier, ce " n'est pas loute l'Ecorce qui donne naissance à l'Au"bier; les Couches corticales ne se eliangent jamais ¿ en bois, comme Duhamel l'a fort bien prouvé. "Ainsi, comme on le démontrera sans doute une " fois, le Liber doit être composé des réscaux de " l'Ecoree et du Bois, dont les plus extéricures forment ^ toujours l'Ecorce, et les intérieures produisent cons„tamment le Bois. „

Ainsi, en dernier résultat, il espère qu'on trouvera une substance entre le Bois et l'Ecorce, qui se séparera en deux pour former l'un el l'autre.

Mais il est bien loin de reconnoître positivement son existence. Comme elle a échappé jusqu'à présent à tontes les recherches, je crois donc être fondé a la regarder comme un être de raison.

Un Anglais, justcment célebre pour avoir, comme poc̀te, prêté des charmes à la Botanique, Darwin, apres avoir publić une Physiologic Animale, sous le litre de Zoonomie, en a donné une Végélale, sous celui de Phytologie. C'est un des ouvrages les plus remarquables qui ayent été publiés depuis long-temps sur celle partic de la science, et je suis bien étonné qu'on n'en ait pas donuć cncore une traduction.

Il contient un grand nombre de fails très-curicux, les uns recueillis daus des auteur's anglais que nous ne connoissons pas; les autres appartiennent a Darwin lui-même, élant le fruit de ses propres observations.

Suivant lui, la végétation consiste dans le développenient des Bourgeons; cliacun d'eux est une nuuvelle 
plante supportée par les anciennes (c'est l'idéc de Linné). La nouvelle couche intérieure de l'Ecorce, par conséquent le Liber, quoiqu'il ne lui donne pas ce nom, est analogue au Caudex ou 'Tigelle qui rćunit la Plunule à la Radicule. De celte idée, si simple dans le fond, il tire des aperçus trís-lumineux; mais licutòt il abandonne une route aussi neuve pour reutrer daus le senticr batlu, en disaul que la couche de l’aunée précédentese détrche pon former me nouvelle couche d'A uhier ou de sap wood, Bois à sève, comme le nomment les Anglais.

Ensorte qu'il adopte, dans toute son élendue, l'opinion de Malpighi et de Linné, la conversion du Liber en Bois, sans en fouruir de preuves nouvelles.

"L'Ecorce forme une enveloppe plus ou moins n épaisse à la superficie. Celte enveloppe est composéc „ elle-même du 'Tissu herbacé, qui est la couche la ^ plus extéricure des couches corticales qui viẹmuent " ensuite, et du Liber qqui est appliqué immédiatement n sur le corps ligncux. Il est facile de séparer l'Ecorce du - reste du végétal. ”

Depuis long-temps l'étude de la Physiologie végétale paroissoit négligée en Frauce, lorsque Jes travaux de M. Desfontaines sur la distinction des parties inté-rieures des Monocolyledones el des Dicotyledones excitèrent l'attention. M. de Mirbel se trouva entrainć dans celte carricire; et bientôt, dans un âge où l'on ćludie encore ordinairement, il fut regardé comme un guide.

Publiant de nombreuses observations d'ahord daus le Journal de Plyssique, et enfin dass un ouvrage

Estais sur l'Organisation. 


\section{XIIIe. Essai. Nolice historique}

particulice sur ce sujet important, il eut occasion de passer en revue toute la science; par-tout il anmonça de nouvelles découvertes; cependant il se contenta de répéter, avec tous ceux qui l'avoient précédé, que le Liber se changeoit en $\Lambda$ ubier. Il ne doma ancume nouvelle preuve de celle assertion; il ne paroit pas même avoir examine les sonrces de cette opinion; ensorte qu'il l'a propagée, seulement de tradition.

Voici comment il s'exprime daus l'article ArrRe, qu'il a fourni depuis ponr le nouveau Diclionnaire des Sciences Naturelles:

“ L'licorce forme une enveloppe plus ou moius ^ épaisse à la superficic. Celte enveloppe est composéc "elle-même du 'Tissu herbacé, qui est la couche la "plus extérieure des conches corticales qui viement » ensuite, et du Liber qui est appliqué inmédiate" ment sur le corps lignaux. Il est facile de séparer " l'Ecorce du reste du végéial. ”

On peut reconnoître, dans ce paragraphe, l'opinion générale sur le Liber; mais ou ne la retrouve plus dans ceux-ci, extraits de l'article Boos.

" La nouvelle couche, en s'organisant, acquiert elle" même une teinte verdâtre : on lui donne, dans cet n état, le nom de Liber, nom qu'elle quitte bientôt "pour prendre celui d'Aubicr."

Enfin, à l'article Brancne, 10m. IV, pag. 312 :

"On appelle Liber une couche verte placce sous „ l'Epiderme. Celte couche se change en Bois, et se " renouvelle sans cesse ; elle seule végète......"

Il est manifeste, par ces passages, que l'uuleur 


\section{Sur la Moelle et le Liber.}

confond avec le Liber et les Couches corlicales, ce que Duhamel a désigné sous le nom d'Enveloppe cellulaire.

Ensuite M. de Mirbel accorde une grande puissance à celte partie; car c'est d'elle, à ce qu'il assure, que partent les Bourgeons.

Cependant il est facile dé voir que ceux-ci communiquent directement avec le parenchyme intérieur ou Moelle de la branche, et que les Fibres des Feuilles qui en font les parties intégrantes prement naissance dans le corps ligneux lui-mềne.

L'auteur n'avoit jusques-là appuyé son sentiment d'aucune preuve qui lui tût particulière; mais dans un mémoire subséquent, lu d'abord à l'Inslitut, et ensuite imprimé dans les Annales du Musée, il annonce une expérience décisive; elle consiste à faire passer des fils à différentes profondeurs dans l'Lcorce.

Ce qu'il y a de singulier, c'est que, dans son Traité de Plysiologie, M. de Mirbel rapporte cette expérience comme étant toute entière de Duhamel, et que, dans ce mémoire, il dise que cet auteur avoit seulement voulu s'assurer si l'A ulier se changeoit en Bois.

Il est cependant certain que toute la différence qu'il y a, c'est que Duhamel, prolongeant son expérience plusieurs années, est resté dans le doule; et que M. de Mirbel a décidé, au bout de quatre mois, que le Liber se changeoit en Bois.

Tel étuit l'élat de la science, lorsque M. De Jussien me donna l'honorable tâche de faire à sa place' l'article Вotanique pour le Diclionnaire des Sciences Atalurelles. Je ne l'cus pas plutôt acceptée, que je fus 
effrayé de l'engagenent que je venois de prendre; il falloit paroître à la place de celui que l'Europe entière considere comme le premicr Botaniste.

Il me falloit remuer a-la-fois toute la science. Je fus donc obligé d'esquisser en même temps un plan, et de l'exécuter de suilc. Je suis encore à savoir jusqu'à quel point j’ai rempli l'intention du savant que j'ai remplacé.

Parvenu à la Physiologic végétale, il sc présenta de grandes difficultés. Livré depuis long-temps à l'étụde de la Botanique, j'avois recueilli des faits sur toutes ses parties; mais je n'avois pu les faire cadrer avec le pelit nombre d'auteurs que j’avois été à même de consulter. J'en ćtois venu au point de projeter une étude approfondie de l'Auatomic végétale faite sur la nature clle-méme; mais l'agitation de ma rie ne m'avoit pas permis d'exécuter ce projet.

Les circonstances pressant, il fallut prendre un parti. Je fus obligé de suivre en plusieurs points le sentier baltu. C'est ainsi que j'attribuai, comme tont le monde, l'augmentation du Bois au Liber. Cependant je jetai les premières bases de mon systême, en assignant, pour cause de l'augmentation des Arbres, le dévcloppement des Bourgeous.

J'avois saisi un fil qui me faisoit souvent reconnoître les erreurs où je me trouvois entrainé avec la multitude; mais il ne m’étoit plus permis de reculer; du moins, il en résulta pour moi cet avantage, que lorsque j'eus achevé cette tâche, j'avois pris une idée plus juste de l'ensemble de la Végétation. 
Croyant alors avoir découvert des vérités importantes, il me sembla que, dans le siècle des lumières, je ne pouvois trop me hâter de les publier. Cependant j'ai pris lous les ménagemens possibles pour ne pas heurter de front l'opinion depuis long-temps accréditée; ensorte que le premier Mémoire que je lus dans le sein de celle Assembléc ne sembla avoir pour objel que de décrire l'angmentation en diamètre du Dracæua. Cependant iy foudois tout l'essenticl dé ma doctrine; savoir, que toules les Fibres ligneuses étoient continucs depuis l'extrémité des Feuilles jusqu'à celle des Racines.

Dans le second, j’ai pronvé, d'une manière qui me paroît jusqu’à présent inébranlable, et cependant la plus simple possible, que la couche annuelle du Liber se formoit simultanément avec celle d'Aubier. Il s'en suivoil la conséquence direcle que le Liher ne pouvoit se changer en Bois; mais je ne la tirai point par amour pour la paix. On ne m’a su aucun gré de ce ménagement.

- Depuis ce moment, j'ai cherché en vain à ćtablir une discussion réglée.

Un froid slacial a été répandu autour de moi. Si on m’a altaqué, ce lı'a jamais élé ell face. On a scmblé même se faire un mérile de cetle manière de comhattre, cll mettant en avant mon caractire, qu'on a toujour's ćtć forcé de respecter, et mes autres travaux bolaniques, de l'élendue desquels on est forcé de convenir pareillement.

Jusqu'i présent personue ne m'a fait encore une objection qui fût de quelque poids. Toutes celles qui 
me sont parvenues n'ont prouvé qqu'on n'avoit pas lu les premiers Mémoires, qui sont cependant depuis trois ans entre les mains de tous les Botanistes.

Un autenr anglais, M. Knight, publie, dans les 'Transaclions Philosophiques, depuis plusieurs anncies, des Lettres sur la végétation; elles sont adressécs à sir Joseplı Bank. Comme IM. Mustel, il paroît avoir plus . étudié la nature que les livres; en sorte quil rend conıpte des phénomèues qu'il ohserve. Jusqu'à préseut on ne connoît en France ses travanx que par les extraits de qnelques-uns de ses Mémoires, publiés dans la Bibliothèque Britantnique. D'après ce que j’ai été à même de lire, il unc paroitroit désirable que l'on traduisit complétement tout l'ensemble de son travail.

D’après ce que j'ai pu saisir en le parcourant, je crois être d'accord avec lui sur les faits, peut-être beaucoup moins sur la théorie. Comme M. Mustel, il paroit altribuer la formation du Bois à la sève montante, et celle de l'Ecorce intérieure ou Liber à la sìve deseendante; mais il regarde aussi, conme lui, que ces deux parties se forment indépendamneut l'nne de l'autre. Celte doetrins se trouve répandue daus ses différens mémoires; mais il l'énonce plus positivement dans uu de ses derniers, qui se tronve daus le volume des Transactions de 1808 . Il a pour titre, de l'Incon. versibilité de l'Ecorce en Bois. Voici comment il le termine :

"Je ne tenterai point de déeider snr Je mérite des * théories de Malpighi et de Hales sous le rapport * de la reproduction de l'Ecorce intérieure; mais je ne 
" peux, en aucune manière, admettre l'hypothèse de "Malpighi et des autres auteurs relativement a la traus"mutation de l'Ecorce en Aubier."

Plusieurs auteurs allemands se distingnent maintenant par leurs recherches pliysiologiques, tels que MM. Link, Sprengel, Rudolpli, Tujranus et Bernhardi; mais je u'ai pu prendre jusqu'a présent une counoissance positive de leurs opinions. Cependant M. Mirbel, secondé par M. le Docteur Bilderlink, a entrepris de répondre aux objections que ces dernicrs lui ont faites.

Il est très-rare qu'on puisse prendre une idce juste des opinions d'un auteur par les réponses d'un adversaire : il me paroit cependant que je me suis rencontré avec plusieurs d'entre cux, sur-tout pour la formation du Parenchyme.

Le nouvel ouvrage de $M$. de Mirbel a pour titre, Exposition de la 'Théerie de l'organisation r'égétale; mais c'est en vain que j'y ai cherché une Théoric, je n'ai vu que des morccaux délachés, qui sont loin de former un ensemble tel que ce titre sembleroit l'annoncer. Par la manière dont j’ai envisagé la Végétation, la plupart des points que M. de Mirbel défend cuntre ses adversaires ne paroissent d'un très-petit intérêt.

Je cruis avoir porté des coups plus directs à la doctrine de M. de Mirbel; et, comme je l'ai annoncé plusicurs fois, ici il ne s'agit rien moins, cntre lui et moi, que de notre existence en Physiologie végétale. Si j'ai raison, son édifice s'écroule par la base et est renversé. Si j’ai tort, mes idées doivent être regardées eomme un songéc.

Il étoit donc plus important pour M. de Mlirbel de 


\subsection{Xille. Essai. Nolice historique}

détruire les inculpations que j'ai dirigées contre lui. Cependant, daus tout son volune, il n'est pas fiit mention de mes attaques; mon nom u'y est pas prononeé : mais comne M. de Mirbel üindique pas toujours le but oì se dirigent ses coups, je puis présumer que plusieurs passages de son ouvrage me sont adressés. C'est sur-toul dans le morceau intitulć Observations sur l'origine el le dércloppement des vaisseaux propres et du liber, (qu il paroît avoir en vue de prouver", plus directement ru'il n'a fail jusqu'a présent, que le Liber se cliangeoil en Aubier.

Mais là j’ai vu des figures moins idéales que celles yqu'a publićes l'auteur jusq̨u’à présent sur l'anatomie végćtale; elles peuvent être comparées avec celles de Grew, et il a, à l'imitation de cet auteur, en l'altention de meltre à côté le morceau fignré de grandeur naturelle; eusorte qu'on peut facilement répéter el constalcr ses observations.

Mais daus aucun de ces faits ainsi présentés, je ne trouve ni celle multilude d'expériences, ni ces observalions très-concluantes que M. de Mirbel annonce depuis long-lemps, pour prouver la transmulation du Liber en Bois.

De plus, il riy a aucunc des plantes ou arbres cilés, qui ne puisse me servir, comme le Marronier d'Inde et le 'Tillenl, à prouver que, dans l'espaee de six semaines, à partir da développement des Bourgeons, il ne se forme d'un côté une couche de Liber, de l'autre une d'Aubier, toujours indépcndantes.

Ce volume est terminé par la réimpression du Mé- 
moire sur la marche des fluides dans le végétal. Lù, nonseulement M. de Mlirbel ne parle pas de l'altaque directe, mais honnête, que j'ai faite à cel onvrage ; mais de plus, il a laissé intact le passige dans lequel il s'attribue l'invention d'avoir fait passer des fils d'argent pour constater celte transmutation du Liber.

M. de Mirbel a continué son plan de défense négatif; ainsi, lisant, dans nne occasion solenuelle, un morceau sous le titre de Coup-d'neil sur l'état présent de l'Anatomie ct de la Physiologie végétale, après avoir parlé fort brièvement de ses prédécesseurs, il s'est fort étendu. sur ses propres travaux, de manière que tous les spectateur's étrangers à la Science, qui ont assisté à celte Séance, ont dû remporter lidéc que M. de Mirbel s'occupoit, sans rivaux, de cette partie importante de la Bolanique.

Lil, il a professé les mêmes opinions sur le Liber, le regardant loujours comme la source des Bourgeons et des Fleurs, et sur-tout sur sa transmutalion en Aubier, mais loujours sans aucune preuve directe.

Jc n'ai remarqué dans ce discours, qui, lu reste, étoit agréablement écrit, qu'une idéc qui m'ait paru nouvelle; c'est d'attribuer la différence qui existe cntre les Feuilles alternes et les opposées, à une espèce de Bride qui retient celles-ci altachées l'une à l'autre. J'avoue que la Nature ne m'a encore rien présenté de semblable.

M. Poiret a adopté de confiance les principes de M. de Mirbel; ensorte que, dans l'article Tigs, d'un des Cours d'Agriculture qui viennent d'ètre publiés, il lui 
attribue pleinement l'idéc d'avoir fait passer des fils de métal à différentes profondeur's dans l'Ecorce.

Un autre Cours d'Agriculture a été cxéculé concurrcmment. Les Savans les plus distingués dans celle partic ont travaillé de concert, pour réformer l'Abbé Rosier; M. Bosc se distingue parmi cux, par le nombre et la variété des articles qu'il a fournis. La Pliysiologie végétale, entr'autres, est son onvrage; mais là il paroît qu'il a ćté fort gêné, parce que, d'un côté, il ne vouloit pas se donner la peine d'cxaminer mes idées, et que, de l'autre, il vouloit tâcher d'admettre un biais pour réformer quelques-unes des anciennes opinions qui tomboicut en ruine.

L'A rticle Lilor est un de ceux qui a dû le plus lui coûter pour remplir ce double but. Voici les principales propositions qui y sont renfermées :

“ LiBer. Je donne ce nom, avec Malpighi et Sen"nebier, à un Réseau rempli d'abord d'un mucilage "parenchymatcux, et ensuite de parencliyme, qui » existe, entre l'icorce et l'Aubier, dans toutes les * Plantes de la classe des Dicotylédones, et qui, dans - l'opinion la plus probable, sert à créer, chaque anuée, » et une Couche nouvelle d'Aubier, et une Couche "Corticale."

M. Bosc dit qu'il suit l'opinion de Malpighi et de Scnncbier; mais il y a un point important qu'il a passé sous silence, quoique ces denx auteurs y fussent d'accord, c'est que le Liber est unc portion intégrante de l'Ecorce, conme je l'ai fait voir par leur's passages cités. Il est vrai qu'en subtilisant, M. Sennebier fuit par 
faire un être de raison de cette parlic : c'est douc celui-là qu'a adopté M. Bosc.

"On voit facilement le Liber daus la plupart des "Arbres." Oui, quand, avec: lous les anleurs dont nons avons passé en revue les opinions, ou prend pour lui la Couclie intérieure du Liher; mais jamais, dans aucuu temps, on ne voit de substance distincte intcrmédiaire, exceplé la Couclie glutincuse inorganique, nomméc Cambium, et qui n'existe que pendant le temps que l'Écorce est séparée du Bois, c'est-à-dire, à commencer lors du développement des Bourgeons.

Cependant, à la fin de son A ricle, l'aųteur dit que c'est pendant l'hiver fu'ou l'aperçoit le mieux.

"Il y a tout licu de croire que la sève, en s'or" ganisant, devient d'abord Cambiun, etc.

"C'est dans ce Pareucliyme naissant que se passe "l'acte le plus inportant de l'accroissement végétal. "Le Liber d'un côlé et l'Aubicr de l'autre en sont le " résultat; inais le premier n'étant plus qu'un organe " inutile aprés que l'assimilation est opéréc, il est $\Rightarrow$ rejeté de l'Ecorce, dont il devient partie coustituante.» On voit donc que l'opinion de M. Bosc se réduit à imaginer une substance, d'abord isolée et unique, mais qui se sépare en deux portions, dont l'une forme de l'Ecorce et l'autre du Bois; nais il ne s'accorde point du tout avec Malpighi, qui, comme je l'ai fait voir dit positivenent que le Liber est une partie intégrante de l'Ecorce. Il n'est pas plus d'accord a vec la définition de Senncbier : par suite de cclte définition, il résulte, suivant M. Bosc, qu'on ne devroit plus dirc que les 
cordes d'Fcorce de Tilleul sont faites de Liber; cependaut, par condescendance, il veut bien laisser continuer cet usage, cu sorte qu'il y aura un Liber matériel, et un Liber rationel.

Mais il reste toujours cmbarrassé dans plusicurs occasions pour accorder sa définition avec les faits. A insi, à l'article VIG e, il dit positivement, en deux endroits, que cet Arhuste important n'a pas de Liber. Il s'ensuivroit, d'après sa définition de celtc partie, que cette Plante riappartiendroit pas aux Dicotylédones, et qu'en second lieu elle ne croîtroit pas en diangètre. Cependant M. Bose recounoit, avec tous lcs aulcurs, qu'clle parvient souvent à une grosseur prodigieuse.

Telles sont donc les opinions émises sur le Liber par les aulcurs qui sont parvenus à ma connoissance. Il s'ensuit, I․ que tous, jusqu'à ces derniers temps, l'ont regardć comnıc une partic intégrante de l'Ecorce;

$2^{\circ}$. Que tous l'ont regardé comme la source de l'accroissement du Bois, excepté M. Mustel, cn France, et M. Kuight, en Anglelcre.

Il ne me resteroit donc plus qu’à exposer mon propre sentiment sur cet objet. On peut le voir dans le $X T^{c}$. Essai (art 24, pag. 313.) On y trouvera done l'opinion sur le Liber que je professe depuis quatre ans. Depuis près de six mois clle est exposée dans un ouvrage publié, mais qui éloit cutre les mains des plus habiles Botanisies depuis plus long-temps.

Jc crois que, dorénavant, tout autcur qui écrira sur cet objet, et qui voudra faire preuve de bonne foi, doit en tenir compte, soit pour l'adopter, soit pour la 
rejeter ; mais alors il doit exposer les raisons pour lesquelles il s'écarte de mon avis: c'est par ce moyen seulement que les sciences peuvent faire des progrès. Quand on met des faits à la place d'autres faits, ce n'cst. pas une critique que l'on fait : il n'y en a point en histoire naturelle.

Le seul jugement que j'aic pu recueillir jusqu'a présent sur cette opinion, ou plutôt sur ma théorie en général, c'est qu'elle étoit fausse et qu'elle n'étoit pas nenve.

On sent que dans les règles de la civilité une telle sentence cût dût être prouvée, et non pas énoncée; mais depuis quatre ans qu'elle m'a été notifice, on ne s'est pas mis en devoir de le faire.

La première partie, qu'elle est fausse, est la seulc qui intéresse la science : car si ccla est démontré, per importe que je l'aie imagince ou que je l'aie empruntce d'un autre, elle doit rentrer dans l'oubli d'où je serois supposé l'avoir tirée.

C'est donc là le point important à constater. J'ai fait parler la nature, il faut donc juger si je l'ai bien interprétée.

Après cela, ce n'est pas à ccux dont je détruis l'opinion à discuter sur l'originalité de ma découverte; car s'ils prouvent après coup qu'elle étoit clairement exprimée dans quelques auteurs précédens, pourquoi ne l'y ont-ils pas aperçue, et se sont-ils mainteuus dans l'erreur?

C'est la marclie ordinaire de l'esprit humain dans les scieuces: dis l'instant qu'il se présente des idées 
nouvelles, elles sout combattucs sans examen; faut-il les adnettre par la force de la vérite, on feuillite les bibliothéques, el l'on ne manque pas de tronver dans quelques passages isolés, les germes de la découverte.

- J'ai aunoncé des le commencement de mes Essais sur la Végétation, que j’avois fait des ćtudes d'après nature; mais que, quoique l'ensemble de mon systène en fût le résultat, je m'occuperois par la suite de découvrir les auteurs dont les opinions ponvant s'accorder avec les miennes, sembleroient m'avoir devancé, pour leur en rendre tout l'honncur qu'ils méritent.

Ici je viens de le faire pour le Liber.

Il en résulte que le Germe de l'idée par laquelle je fais descendre le Liber du Bourgeon, existe dans Darwin, et que la formation indépendante de l'Aubier est formellement prononcéc dans Mustel.

J'aurois bean protester queje ne conmoissois pas ces deux auteurs avant de l'avoir publiće, toute la gloire de l'invention ne leur en reviendroit pas moins.

Mais anssi ces deux helles conceptions se trouvant mêlées, dans cliacun de ces deux auteurs, avec des idées fausses, elles pouvoient y rester long-tenıps enfouies.

C'est à la route nouvelle que j'ai suivie que je dois de les avoir reconnues directement, comme dérivant l'une de l'autre, et de les a voir démontrées également l'une par l'autre, de manière à ce qu'on ne puissc plus maintenant en douter.

Malheurensement, je me vois senl jusquàa présent à porter un tel jugrment, et personne ne peut être juge dans sa propre causc. 
C'est en vain que, dans dcux occasions imporlantes, j'en ai invoqué une capable de me désiller les yeux, si par hasard je m'étois fait illusion; le plus grand silence a toujours tenu lieu de décision.

Cependant j'ose me flatter que si j'avois pu discuter mes principes daus des conférences particulières, j’aurois pu facilement convaincre de lcurs vérités; peut-être alors auroit-on reconnu avec moi que la Physiologie végétale, fondće sur des bases solides, reprenoit une face entic̀rement nouvelle; j'aurois alors osé présenter 'l'ouvrage dans lequel je les ai consignécs, à ce brillant concours qui va illustrer cette annéc mémorable de l'Histoirc de Napolćon.

$\mathrm{Jc}$ vais toujours le déposer sous vos auspices : peut-être que lorsqu'une nouvellc époque Décenuale ramenera cette lutte honorable, l'effet qu'il aura produit lui aura mérité plus d'attention. 


\section{R APPOR T}

Sur un Mémoire ayau pour titre : Essai historique sur la nature et les fonctions de la Moelle et du Liber.

(LE. Secrétaire perpétuel pour les Sciences certilie tue ce qui suit est extrait du Procès - Verbal de la sénuce du lundi 3o juillet 18 ro.)

Nous avons été chargés par la Classe, MM. Desfontaines, de Jussieu et moi, de lui rendre compte d'un Mémoire qui a pour titre: Essailistorique sur la nature el lesfonctions de la Moelle et du Liber, par M. Aubert du Petit-I'louars.

L'auteur, après s'être étendu sur la nécessité de bien définir les ter'nes dont on se sert dans les seiences, lors sur-tout que leur vérilable acception n'est pas encore bien fixée, rappelle qu'il a avancé sur la Physique végétale plusieurs propositions contraires à l'opinion la plus généralement reçue, et il en cite deux pour exemple; la première, que la Moelle reste dans le corps de l'Arbre de même dianıètre et de même nature que dans le jeune Scion oì elle a été fornée ; la seconde, que le Liber est toujours indépendant, du Bois ou de l'Aubier, el ne lui donne pas naissance.

M. Aubert du Petit-Thouars cite à l'appui de la première proposition le Tronc d'un Sureau qui avoit au moins vingt ans, et dans lequel la Moelle est aussi large que dans aucune Branclie de l'année. Il a observé la 
mème chose dans une Vigne qui avoit plus de six ans, et dans des Troncs de vieux Chênes.

Dans une autre Vigne la Moelle avoit, vers sa partie inférieure, un plus grand diamètre que supérieurement, les Scions qui avoient continué la Tige étant d'un moindre diamètre, comme le remarque l'Auteur.

Nous avons répété ces observations sur de très-gros pieds de Sureau, d'Epine blanche, de Chêne, de Hêtre, de Charmille, d'Orme, etc.; et dans aucuns la Moelle n'avoit disparu pour être remplacée par du Bois; elle y conservoit souvent autant de diamètre que dans les jeunes Branches. Ainsi il est évident que la Moelle ne s'oblitère pas, conformément à l'opinion de M. A ubert du Petit-Thouars, et comme l'avoit déjà avancé en 180r, M. Knight, dans les Transactions Philosophiques, où après avoir rappelé que la Moelle, dans les jeunes Pousses, est remplie d'une humidité qui contribue singulièrement à la Végétation, il dit qu'à la seconde année cette Moelle devenue sèche, l'espace qu'elle occupe ne se remplit jamais par le corps ligneux, comme quelqques Naturalistes l'ont pensé.

Quant à la seconde proposition du Mémoire dont nous rendons compte, savoir que le Liber est toujours indépendant du Bois ou de l'Aubier, et ne luj donne pas naissance, $M$. Aubert du Petit.'Thouars est encore dn même avis que M. Knight, dont nous avons, dans les Transaclions Philosophiques pour 1808 , un Mémoire at ce sujet; mais nous ne devons rien dire de cette partie du Mémoire de l'Auteur, puisqu'elle est déjà imprimée dans le travail qu'il a publié sur la Phy.. sique végétale. 
Nons pensons que M. Aubert du Petit-Thouars ayant confirmé les observations de $\mathbf{M}$. Knight, ct contribué ainsi a fixer un point assez important de la Physique végétale, celte partie de son Mémoire mérite d'être impriméc par extrait dans le Recueil des Savans Etrangers.

$$
\begin{aligned}
& \text { Signé : } \\
& \text { De Jussiev, Desfontaines, Labillahmiere. }
\end{aligned}
$$

La Classe approuve le rapport et en adopte les conclusions. 


\section{OBSERVATION.}

On voit, par le Rapport de MM. Ies Commissaires de l'Institut, qu'ils ont recomnu la vérité du prenier des Faits soumis à leur cxamen, savoir, que la IHoelle restoif dans le corps des Arbres telle qu'elle étoit formée, sans éprouver de diminution: quant au sccond, la formation indépendante du Bois et du Liber, ils ont annoncé qu'ils ne pouvoient s'en occuper, attendu que cettc partie de mou Mémoire étoit précédemment imprinée. Mais il en étoit de même de la première; car je l'ai énoncée dans le même ouvrage.

Ils ont dit de plus que ces deux fails avoient été aperçus et décrils par sir Knighlıt, dans les Transactions philosophiques. Je l'avois dit, pour ce qui con-cerne le Liber; mais il faut considérer que le Mémoire de ce savant est dans les Transactions de 1808 , et que jai émis celte vérité daus le sein de l'Institut, au commencement de 1805 . Je ne veux point par là m'attribuer l'honneur de cette découverte, puisque je l'ai revendiquéc pour M. Mustel, page 56.

Quant à la Moelle, je n'ai point cité M. Knight, quoique je connusse parfaitement son opinion à ce sujet, puisqu'on ne l'a trouvée dans ses Mémoires que par ce que j'en ai dit verbalement. Ce silence là vient seulement de la marche que j'ai suivie daus l'exposition de ce fait; clle consistoit à présenter la uature elle-même. Jc réservois pour une autre occasion à remplir l'engagement que j'ai pris, pag. 36 de mes Essais, de faire connoitre les opinions des autenrs qui mont 
précédé dans la carrière que je poursuis maintenant; et je l'ai déjà exécutë toutes les fois que les circonstances me l'ont permis. (Relisez les pages 29 e८ 3o.)

Jé pourrois dire que celte opinion étoit une conséquence naturelle de la manière dont j’ai expliqué la formation de la Moelle, dans mon second Essai, pag. 21 ; mais la vérité est que je ne l'avois pas reconnue. J'étois tellement imbu de l'opinion contraire, soutenue par tous les auteurs qui ont écrit sur la Botanique, que je cherchois à découvrir comment pouvoit se faire le changement ou la réduction de la Moelle, lorsqu'apprenant l'existence des travaux de M. Knight, je me mis à parcourir les Mćmoires où il les a consignés. Je fus frappé de la quantité d'observations qu'ils contenoient. Je regrettois de ne pas les avoir à ma disposition pour les traduire entièrement. J'arrivai enfin a un passage ou il disoit qu'il étoit étonné qu'on eût répété jusqu'alors que la Moelle disparoissoit dans les vieux troncs d'Arbre. Celte phrase fut un trait de lumière pour moi; je fus obligé de fermer le livre, à cause de l'abondance des conséquences que j'en tirai sur-le-champ. La dent d'or n'existoit pas. Tout de suite le témoignage de mes yeux me confirma celle grande vérité. C'est donc bien réellement à ce savant que j'en dois la connoissance. Je regrette de n'avoir pas eu le temps depuis de contiuucr une lecture plus réfléchie de ses Mémoires.

Il est du petit nombre des observateurs qui ont plus étudié la Nature que les Livres; aussi a-t-il fait beaucoup de véritables découvertes. M. Mustel, comme je l'ai déjà dit, appartient aussi à cette classe estimable de savans. Varennes De Fenille est dans le même cas; il 
n'a raconté, dans ses Mémoires sur l'Administration Forestière, que ce qu'il avoit vu dans la nature; de là il est arrivé que souvent il est débarrassé des Préjugés généralement établis. C'est ainsi qu'il avoit recunnu que la Moelle ne diminuoit pas dans les Troncs de Sureau. Voici ce qu'il dit à ce sujet, tom. II, pag. 286: « II n'est * pastoujours vrai que le creux médullaire se remplisse * dans les gros Troncs, ainsi que l'annouce Dulamel "(Traité des Arbres et Arbustes). J'ai deux échan* tillons qui témoignent le contraire.

On voit par ce passage que, de ces deux exemples, il n'avoit pas osé tirer une conséquence générale; vraisemblablement qu'il possédoit d'autres morceaux où la Moelle étant beaucoup plus mince, il pouvoit penser qu'elle avoit diminué.

Voici maintenant le passage de Duhamel (1. II, p. 255): "On sait que les jeunes Branches de Surcau n sont remplies d'une Moelle abondante, et que les "enfans se servent de ces jeunes Branches pour faire - des canonnières et des sarbacanes. On ne trouve " point de Moelle dans les gros Troncs; alors le Bois - de Sureau, qui est très-dur et liant, sert à faire " différens ouvrages. "

M. Bosc s'est plaint de ce que j'avois aftéré les passages que j'avois cités de lui, et que je n'avois pas exposé fidèlement son opinion, puisqu'il pensoit que le Liber ne se changeoit point en Bois. 11 cst vrai que pour la brièveté je n'avois fait qu'un extrait de ce qui me paroissoit établir l'opinion de l'auteur. Je rétablis ici les passages dans toute leur intégrité. 
"Liber. Je donne ce nom, avec Malpighi et Sen" nebier, à un Réseau rempli d'abord de Mucilage "parenchymateux (voy. Cambium), et ensuite de " parenchyme qui existe entre l'Ecorce et l' $\Lambda$ ubier dans "toutes les plantes de la classe des Dicolylédones, et - qui, dans l'opinion la plus probable, sert à crécr " chaque année une, couche d'Aubier et une couche 2 corticale.

„On voit fagilement le Lirer dans la plupart. des "Arbres, en enlevant l'écorce avec quelques précau». tions, relatives à l'espèce, à la saison ou à la manière " dont on a opéré. Son élude est d'une grande impor"tance.

"Il y a tout lieu de croire que la sève, cu s'organi" sant, devient d'abord Cambium; que ce Cambium " sc solidifie, et devient un parenchyme rempli d'une m- matière amilacéc, et que c'est daus le parencliyme " naissant que se passe l'acte le plus important de l'ac" croissenent végétal ; le Liber d'un côté, et l'Aubier "de l'autre, en sont le résultat:mais le premiern'étant " plus qu'un organe inntile aprés que l'assimilation est do,opérée, il est rejeté vers l'Ecorce dont il devient "partie constituante, lorsqu'urt-notzeau Cambium „vient le forcer d'élargir ses mailles ponr lui faire place. . C'est pirce que je erois quiei les fonctions pre" mières du Liber sont fort différentes de çe qu'elles " scront dans la suile, que jeme suis appuyé de l'au- torité de Malpighi et de Scnnebier au commence- ment de cet article, Dubamel ct beaucoup d'autres

- physiologistes ne distinguant pas le Liber de la der* wicre couche corticale. 
„D'après cela, la partie du Tilleul dont on fait des n cordes, n'est pas véritablement le Liber, mais les - dernières couches corticales.

n Écurce, partie extérieure du Tronc et des Branches " de la plupart des végétaux; je dis de la plupart, parce - que Desfoutaines a prouvé, dans un excellent Mé- moire sur l'organisation des plantes de la classe des - Monocotylédones, que celles dé cette classe n'en " avoient réellement pas. Ainsi nos Fougères, les Pal" mier's, les Gramincees, les Liliacées, les Orchi" dées, etc., en sont privés. » (J'avouerai que cette dernière proposition nc me paroît pas confurme is cc que m'a préscnté la nature.) « La partic vraiment active 》 de l'Ecorce, celle dont l'influence produit presque ex" clusivement lesphénomènes précédens, c'est le Liber, " c'est-à-dire la plus nouvelle des couches corticales, " celle qui crée en même temps et l'Aubier el l'E„ corce.

"Il sembleroit, d'après une multitude de raisons, - que l'Ecorce ne devroil jamais se changer en Bois. "Cependant il est un cas où elle le fait, c'est lorsqu'on * fait une greffe par approche, ou lorsque deux'Bran" ches ou Rameaux se soudent naturellement. Dans tous * ces cas, l'Ecorce disparoit sans qu'on sache encore "comment. "

On a cité ce fait comme contraire aux principes que j'ai posés. On peut voir ce que j'en ai dit, p. 276 de mes Essais.

"On peut encore réunir deux Branches, sans en" lever l'Ecorce au point de contact. L'augmentation " qui se fait de part et d'autre, pressant fortement 


\section{$40 \quad$ XIII . Essai. Notice historique}

2 ces deux Ecorces, elles sont forcées de céder en se

" déchirant; mais ordinairement il en reste un lam-

" beau enchâssé dans le nouvean bois. Si par hasard il

- n'en restoit point, cet effet viendroit du déchire-

"ment complet de l'Ecorce; il ne pourroit être altribué

" à la transmutation du Liber en Bois : autrement,

- il faudroit dire que l'Epiderme se seroit changé aussi

* en Bois, puisqu'il disparoît également.

J'ajoute encore deux passages de M. Bosc.

"....Dans le Sarment de l'année, la Moelle occupe

". presqque tont le diamètre du Bois; l'année suivante,

" elle diminue; la troisième anuée, il y $\mathrm{cn}$ a encore

- un peu; enfin, la quatrième, clle a tolalement dis-

"paru." (Art. Vigne, 467.)

" N'ayant ni Liber, ni couches corticales, la végé" tation de la Vigne differe de celle des autres Arbres, » et elle peut être greffée sans avoir besoin dn contact " des deux Ecorces. "(Art. Vigne.)

Ce dernice paragraphe mérite une allention parliculière, parce qu'il présente un fait très-important pour l'Históire de la Greffe. Il y en a quelques autres analogues dont je n'ai point parlé dans l'article que je lui ai consacré au XIIe. Essai, art. 22. Je vais profiter de celle occasion pour en faire le sujet d'une addition particulière. 
Addition sur des cas particuliers que présentent les Greffes.

La Quintinie avoit eu connoissance de ce fait, car il dit positivement que le contact des deux Ecorces est nécessaire pour la réussite de la Greffe, excepté dans la Vignc. Je dois la connoissance d'un fait analogue à un Amateur de culture distingué par l'universalité de ses connoissances et la place qu'it occupe. Il m’a donc appris, il y a déjà quelque temps, que les Jasmins, délicats comme ceux de Catalogne et ceux d'Arabie ou Mougris, apportés pendant l'hiver par les jardiniers Génois, étoient greffés d'une manière particulière, car la Greffe étoit implantée comme une cheville an centre, du sujct et daus sa Moelle, sans qu'il y cût coïncidence entre les Ecorces, et que cependant le bon marché de ces Arlustes étoil garant quails devoient reprendre facilement. Il me dit en même temps qu'il paroissoit qque ce genre de Greffe avoit été pratiqueé par les Ancieıs, el qu’elle avoit même précédé la Greffe en Fente; ce qui étoit démontré par un passage de Pline, livre XVII, chap. 14 .

Ratio postea duplex (inserendi): et prima inter corticem Ligrumque inserendi. Timebant prisci Truncum findere: mox inforare ansi medio. Ipsigue Medulla Calamum imprimebant, unum inserentes: neque enim plures capiebat Medulla.

Voici comment Du Pinet traduit ou plutôt paraphrasc ce passage :

"Cela fait, on peut enter les Greffes en deux sortes, dont " la première est de mettre les Greffes entre l'Ecorce et le "Bois, et de fait les Anciens craignoient denter en fente du " commencement, et néanmoins ils se sout bien liasardés du " depuis, voire jusques à percer le cœur des Sauvageaux, toutefois " ils n'y pouvoient mettre qu'une Greffe (lequel encore ils " entoient en la moelle du sauvageau)." "

On voit aussi, par la manière dont parle Pline au sujet de la Vigne, qu'une des trois manières de la greffer, suivant Caton, étoit de faire coïncider les moelles de la Greffe et du sujet. 
Liarlicle Ecusson, de M. Bosc, présente encore quelques faits qui ont du rapport avcc ceux-ci. Ils sont d'autant plus remarquablcs, qu'ils lui paroissent contrarier la théorie qu'il a adoptée pour expliquer lcs Grcffes; il est donc cssentiel de voir s'ils s'accorderont micux avec mes principes.

"On doit à M. Juge quelqucs observations sur l'Ecussonnage, " qui mćritent place ici.

" I․ Il a placé un Ecusson au milicu d'une large ampu"tation d'écorce, ct de manière qu'il ne touchoit à aucune " partie de cette écorce; puis il l'a recouvert pour qu'il ne fût " pas exposé à l'action desséchante de l'air; cet Ficusson a poussé. "La fonclion des deux écorces n'est donc pas néccssairc?

" $2^{\circ}$. Il a placé un Ecusson de travers ou horizontalement, et " cependant cet Ecussou a fourui son bourgeon, qui s'est rclevé " pour prendre la direction perpendiculaire. La rencontre des „ vaisseaux n'est donc pas nécessaire?

" $3^{\circ}$. Il a fcudu longitudinalcment une Greffe de six mois, " et il a remarqué que le bourgcon avoit poussé cles fibres à ira"vérs la partic ligneuse jusqu’à la moelle.

" Ces couséquences, tirécs par M. Juge, sont rigoureuses; " cependant il faudroit avoir observé arec plus de soin qu'il „ ne paroil l'avoir fait, ce qui sc passe dans les circonstances " où il a nuis les Fcunssons pour regarder commc détruite l'ex"plication simple et généralement avouée qui précède."

Il y a donc dans ces faits une circonstance générale, c'est que, contre l'opinion commune, lcs Greffes, soit en Fente, soit en Ecusson, peuvent pousser, quoique leurs Ecorces ne coïncident pas avee celle des sujets. Cela contrarie la théorie génćralemont adopléc; mais cela ne dérange en rien celle que j’a exposéc. Dans tous ces cas, la Greffe sc trouve dans les mémes circonstanccs qu'une branche ou qu'une tige sur laquelle on a pratiqué la Circoncision. J'ai fait voir dans mon $X I I^{\circ}$. Essai, que par la communication latérale des Fibres ligneuses chaque Bourgeon pouvoit tirer son aliment par les Fibres intérieures: celui de l'Ecusson fait la même chose. 
Il faut encore se rappeler ici ce que j'ai dit, que les Greffes n'éloient autre chose que des Marcoltes ou des Boutures, et végétoient de la mème manière.

Dès que leur extrénité inférieure est en communication avec l'humidité, le Bourgeon péut se dérelopper. On sait aussi que les Boutures réussissent même quand on les plante renversées. Il n'est donc pas étonnant que les Greffes se comportent de même er qu'elles surmontent les difficultés qu'on leur oppose.

On doit présumer que cés Greffes réussissent plus difficilement que les autres. II paroît que la Vigne a, de ce côté, plus d’avantages que les autres, ce qui paroîtroit provenir de la singularité de sa siructure inlérieure. J'ai déjà fait remarquer que ses Rayons médullaires formoient des lames continues d'une Feuillo a l'autre; de plas, ils sont verts dans les jeunes pousses, ce qui annonce un état particulier de végétation.

Quanl ì la dernière observation de $M$. Juge, que le Bourgeon greffé finit par conmuniquer par des fibres directes avec l'intérieur ou la Moelle, rien de plus simple que cet eflet, il est une suite nécessaire de la tendance qu'il a pour se metre en communicalion avec. le sol ou l'humidité. Daus la méthode ordinaire, il trouve un chemin facile entre le Bois et l'Ecorce: dans celle-ci, ce chemin lui manquant, il est obligé de s'en pratiquer un nouveau; alors ce sont les interstices du Bois qui lui fournissent le moyen de gagner ainsi le réservoir d'humidié le plus proche.

Ici je regrette de n'avoir pas plus de détails sur ces expériences, non que je les révoque en doute, elles me paroissent trop conformes à la marclie de la nature, mais elles pourroient procurer de nouvelles lumières sur la $\mathrm{Physiologie} \mathrm{végétale:}$

Il paroît gu'il faut encore ranger M. Juge dans le petit nomhre d'observatenrs qui out plus étudié la Nature que les livres. C'est le même vraisemblablement qui a publié, il y a vingt ans, un Traité sur le Chéne; s'il a continué ses observations depuis ce temps-là, il doit en avoir fait une abondante récolte. 


\section{Opinion de Roger Schabor sur les Boutons et les Bourgeons.}

L'abbé Roger Schabol occupe une place distinguée parmi ces Observateurs dont on a parlé précédemment, qui doivent plus à la Nature qu'aux Livres. Il passa loute sa vie à cultiver les Arbres fruitiers et à étudier les principaux phénomènes qu'ils présentent dans leur développement, et il uc se détermina qu’à la fin de sa carrière, âgé de soixantc-dix-sept ans, à publier le fruit de tant de recherches. Ce fut dans un Dictionnaire dik Jardinage, en un volume. Cet ouvrage n’étól que le résumé d'un travail plus considérable qui devoitparoître successivement; mais l'Auteur mourut un an après, sans avoir pu mettre son dessein à exécution. Ses manuscrits furent confiés à son ami La Ville-Ilervé, qui les rédigea; ils gagnèrent du côté du style, car celui de Schabol est très-incorrect; mais ils perdirent de leur originalité, car co Rédacteur chercha à rapprocher les opinions de l'Auteur le plus qu'il pût de celles qui étoient le plus généralement reçues. Ce n'est donc que dans le Dictiounaire publié par Schabol lui-méme que l'on peut réellement prendre une idée de sa véritable doctrine; on y trouvera des laits très-curieux et d'excellentes observations. Mais il n'est pas aussi heureux dans les conséquences qu'il en tire pour en former une Théorie : il auroit dủ, auparavant de l'entreprendre, revenir à l'étude des auteurs qui l'avoient précédé, pour mieux se mettre au courant de ce qui avoit été écrit sur cet objet.

Ses articles Bourgan et Bouton suftisent pour donner une idée de ses principes. J'y joindrai quelques remarques qui feront voir jusqu’à quel point je m’eu suis rapproché avant de les connoître.

Bourgen. Bourgconner (1); mot propre au jardinage et qui n'est employé ailleurs que par comparaison. On appelle Bour- 


\section{sur la Moelle et le Liber.}

geon la Pousse de l'année, qui provient d'un điil on Bouton. Quand le Bourgeon devient Bois, on le nomme Branche; mais tant qu'il est vert il se nomme Bourgeon.

Quelques-uns, peu instruits, confondent le mot de Bourgeon et de Bouton, mais mal-ì-propos; sans être versé dans le Jardinage, on sait que tonjours un Bourgeon vient d'un Bouton on Eil qui lui a donné l'étre. Il faut pourtant excepter de cette règle générale ceux des Bourgeons appelés Faux-bourgeons, dont il sera parlé ci-après, qui naissent immédiatement de la peau; mais que l'on en fasse la remarque, et l'on reconnoítra que toujours, soit à la Tige, soit aux Branches, où croissent ces Faux-bourgeons, un petit Bouton vert renfermant le Germe du Bourgeon, a précédé. La différence de ce dernier arec les Boutons, produits suivant le cours de la nalure, c'est que jamais le Bourgeon, qui nait de cet Wil ou Bouton adventice, n'est franc comme l'autre; toujours il est fláche (flasque) et poreux; au lieu que le Bourgeon, contenu en petit dans l'đEil, a été bien autrement travaillé pendant tout le temps que le germe a séjourné dans le Bouton, il y a été cuit et digéré.

Bourgeonner se dit quand au Printemps les Yeux ou Boutons des Arbres font paroître au-deliors un commencement de Verdure qui s'alonge par la suite.

On appelle Faux-Bourgeons (2) toutes les Pousses des Arbres qui ne sont pas sorlies d'un Gil ou Bonton, mais qui percent directement de l'Ecorce.

Parmi ces Faux-bourgeons il en est qui sont quelquefois trèsprécieux, dans le cas sur-tout où il faut garnir un vide dans un Arbre, ou même le renouveler.

D'ordinaire on détruit les Faux-bourgeons à cause que presque toujours ils sont mal placés et parce qu'ils font confusion; mais il est des moyens sûrs, pour, de ces Faux-bourgeons, faire des Boutons à fruit.

Bouton ou CEil(3). On ne voit pas trop pourquoi on a donné l'un et l'autre nom à cetle partie des Plantes d'où naissent les Peuilles, les Fleurs et les Fruits de toute Plante. 
Un Bouton est une petite partie saillante, forméc de la plus pure substance de la Sève, qui renferme l'Embryon de tout Rameau dans tonte Plante, et qui ı'est jamais produit, ni foumi que par l'cutremise d'une Feuille.

Voici une observation qui n’a point encore été faite (4) nulle part, et qui est autant curieuse qu’importante; savoir, que, comme il n'estpoint de Bauton saus Feuille, il n'est pas non plus de Feuille sans Bouton. La Feuille est faite pour le Boutou, afin quelle le nourrisse et le substutute, de mème que le Bouton est fait pour la Fenille, afin de recevoir d'elle la subsistance. Sans Feuille point de Bouton, il faut qu'il avorte; et saus Bouton la Feuille seroit inutile et deviendıoit oisive ; voilà ce que le Jardinier ignore. Que l'ou cu fasse la remarque, et l’on verra que la première chose qui paroît quaud un $\Lambda$ rhre pousse, et lorsque l'Gil s'ouvre at Printemps, ce sont des Feuilles ou des Follicules ( Bractées des Botanistes) pour administrer la nourriture au Bourgeon naissant, à l'exception de la Figue (5), qui pousse sans Fcuilles; il en sera dit la raisou ailleurs. L'hiver, le Bouton n’agit pas au-dehors, paree qu'il est privé de sa Feuille, qui est sa nourrice, et en tout autre temps la Feuille est attaclice au Bouton tant qu'il n'est pas tout-ì-fait formé, et sitôt qu'il a son complément sa fcuille tombe.

Telle est la seule cause de la chûte des Feuilles (6) quand elles rombent naturellement et sans cause forcéc. Tout ce que les uns ct les autres, parmi les Savans, ont imaginé à ce sujet de la chûte des Feuilles, est purement gratuit de lenr part. Il laut être sur le tas même pour suivre la nature et la voir opérer.

On compare les Boutons ou les Yeux des Plantes, à des Ciufs ou à des Graines. En effet, tout ce qui se passe dans la formation d'un Cuf et d'une Graine, se renouvelle dans la formation d'un Bouton; et de mème tout ce qui se passe claus un Gur, qui devient animal vivant, et dans une Graine, qui devient Plante, se peint également dans le Bouton derenant Bourgeou, Fleur et Fruit. 


\section{$\operatorname{notat+\infty +\infty }$ \\ Remarques sur ces Articles.}

(1) Bourgeon; Bourgeonner. On voit ici que Schahol prend ce mot dans l'aeception la plus counuune, qui est de désigner la Branche sortant du Butlton ou du Gemma; pour moi, c'est la jeunc Pousse ou le Scion. Il n'y a pas dans cet article un motif de plus que ceux que j'ai exaunine.s quand j'ai exposé Jes raisons qui m'ont détermine à donner le nom de Bourgeon à ce que Kozer noume Bouton, ce qu'on regardc comme lc Gemna des anciens, tandis que ce mot de Bouton ne duit, suivant moi, s'appliquer qu'à là Eleur non développece.

(a) Faux-bourgeons. Par ce uot l'auteur désigne tous les Bonrgens qui sortent coutre l'ordre ordinaire de la nature, c'est-à-dire hors de l'aisselle des Feuilles; plus bas il les nomme adventice. Deptris j’ai désigué par l'épilhette d'adventif une des trois sortes de Bourgeon que j'ai distivguec.s. Il est certain yu'd cette époque je ne connoissois pas ce passage, cn sorle que je me suis rencontre, en partie, avec sicluabol; je dis en paric, parce que je doune un sens beancoup plus restreint is ce ierue gu'il ue le fait; cur, suivant tui, ce sont les Bourgeous qui sortent du 'rone et des grossos Branches, et non pas aux vestiges des Feuilleg de l'aunée précédente; tandis que, suivant moi, la plupart de ces Bourgeons étoient dans te principe à l'aisselle des Fenilles: mais leur Végétation a été suspendue pendant un temps plus ou moins long, les autres appartenoicnt à ces Sipules; e sout ceux que j’ai uonnés Supplementaires. Eufin, je ne regarde coume Alvensifs que ceux qui sortent de parties ou il n'y avoit manifestemint aucune Feuille, tels sont ceux qui sortent des Racines ou des Bourrelets. Ces bourgenns sont écailleux; an monirnt de leur apparition dans les $\Lambda$ rlores de nos elimats, pue $i a i$ ćté à porlée d'observer, ils sont semblables a ceux qui sorteut de l'nissellr de lenrs Fuil!es, et je n’ai print été à uéune de les cxaniner daus le petit uoubre de ceux de notre pays yui n'ont pas d'écailles. Mais à l'Ile-de-l'rance j’ai ea occasion d'eu voir deux qui m’ont presenté un phénounène qui in'a paru très-singulier : l'un est un Prockia de Linué; l'autre, le Grangeria de Cominerson; inus les dewx ayant une Eeorce charnie, qui se renouvelle tous les aus, ont l'air de ne pas ca avoir du tont. Aussi le premier cst connu des Creoles sous le nou de Bois suns licorce. J'ai rencontré a plusieurs époques des Trones de ces Arbres qui itroient élć coupés à quelque distance de la terre, sur la ligne trui separe l'Ecorce dı Bois : ì la place du Bourrelet qui se forme ordinairesuent à cet eudroit, il se trouvoit une suite de Mamclons irréguliers dans leur forme et leur volume; ils etoient d'un beau rert et très-cassans; en sorte qu'ils paroissoient couposćs, ca grande partic, de Parenchyus en ċat de Végétation. Quant à leur forme, ils ressembloient, par leur surfiec lisse ct luisante, et par l'arrondissement de leurs extréuités, à des coulures de eire vertéfigées sur le clamp. On distinguoil sur quelques-uns de petiles écailles écarties les unes des autres; on voyoir, par une succession graduée, qu'elles tendoient à se changer or Fcuilles, et qu'elles finissnient par prendre Je caractère de celles des grands Arbres de lenr espece; ensorte que ccs Mamelons se changeoient en Scions ou jeunes Branches parfaites.

(3) Bouton on OEil; rould done ec que je nomme Bourgeon : en clangeant senlement re mot, je me troure parfautement d'accord asec Schabol, ill Je défuit très-bien; Rosier a èté plus loin que lui en distinguant ces deux mots : suivant lui le point gerıant est un OEil, il devient ensuite Bouton, et cnfn, au l'rintempi suivant, c'est qu Bourgron. It est facile de voir care ce 
Ternier auteur a pris l'essenee de son article Bouton dans Schabol; mais il le dénature cntièrement, en sorte qu'on n'y peut reconnoitre le fond de son opinion.

11 parojt qu'on roudroit maintenant distinguer eette partie, en adoptant dans notre langue le mot latiu Gemma, eroyant que les aucicns le désignoieut ainsi; inais suivant Adanson, c'est une crreur qui dure depuis longtemps; voici comıne il s'exprime a ce sujet, pag. 134 de sa préface : \& Pline " connoissoit les Bourgcons des Plantes, quil appcloit Germen. Il paroit " qu'il pensoit que les Banrge sns se léveloppent comme les Graines, au unoins " eomme les Monocotylédones; ct il avertit qu'il ne faut pas confondre avec 3) eux les Boutons a Fletrs, quil appelle Gemma. Germen aulcm, dit-i], " est id quod el ipsis arborum Surculis primo vere exil, cl quo deindé "folium pioducilur: nam Gemma proprio floris quanquim u.trumqua 3) confundatur. Mlalgré cetle remargue de Pline, Rai, en 1682 , est tombé 3) dans cette confusion, qui a été suivie jusqu'á ce jour, ct il a eru pou") voir distiuguer les Arbres d'avec les Herbes, par lc moyen des Bourgcons;

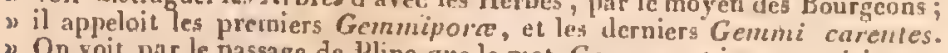

"On voit par le passage de 1)inc que le not Gcmma est iupropre ici."

(4) Folci une observalion qui n'a point èlé faile.

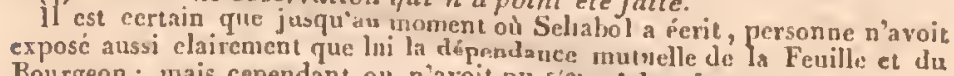
Bourgeon; mais cependant ou n'avoit pu s'elsposher de remarquer que les Bourgeons poussoicnt plus souvent aux aissclles qu'ailleurs. Pline l'avoit fait entendre, mais Césalpun l'a dit positivencnt. Germinis autron eruptio nou cx omni parte caulis fil: sed majori et parte cx alis foliorum, qud scilicel parle folii pcdiculus ncctilur cauli, inibi enim oculus csi fuluri germinis, quasifolium cjus custodiendi gralia sit apposilum, sinu guodam in corlice reliclu, qua ab codem cxoriens abscedit. Linné, dans sa premiere dissertation intiulée Prolepsis Plantarum, a été plus loin en assignant pour lo moment de l'apparition du Bourgeon celui oủ la Feuille se développe au Printenpips. Qunm primum Arborcs verno tempore folia sua explicant, Gemman in singulis folitifalis observamus. (Amen., vol. VI, pag. 320.) Dans le cours de eette dissertation et de la seconde, sous le meme titre, l'anteur eite plusicurs faits importans sur ce sıjes; snais ce n'est pas ici le lieu de les examiuer.

Ces passages étoicnt faits pour jeter une vive lunière sur le principe de la Végctation, mais elle est restco long-lemps obseurcie. Malgré l'assertion de Linné, on a continue a dire, dans les prétendues théories de la Végétation, que les Bourgcons ne ponssoient que vers lo milieu de l'été, longtemps après l'apparition des Fenilles; si on a reconnu quils poassoient ph frçuenunent aux aisselles des Feuilles qu'ailletus, on a pretend" que e'toit aे raison d'un Bourrelet naturel qui se trouvoit à ectte place, ce qui étoit
justement prendre l'Effet pour la Cittse.

(5) La Figue.

Si Schabol eût poussẻ plus loin son observation, il auroit reconnu que le Bouton qui dnit devcnir Figue roussoit an-ilessus d'un vestige de Fenille de l'année précédente; en sorte qu'il étoit rédlement axillaire comme les
autres.

(6) Chúte des Feuillcs. lci l'auteur a été entrainciau.deli de la vérité, en donnant pour eause de la chúle des leuilles la cessation de leir utilité lorsque le Bourgeon est entierenent forné, ee 'fu'il n'auroit pas fit s'il eût songé : $1^{\circ}$. aux Arbres qui garclent lcurs feuilles pendant hiver; et $2^{\circ}$. sil cut remarqué que daus jresque tous les Arbres de nos climats les Bourgeons sont entiércuient formés, au julus tard rau commoncenent d'Aont, et ne preanent plus d'accroissetrent visible jusqu'à la chúte des Feuilles, gue n'a souvent licu que plus de trois mois aprés. 
Hore tratirnate are
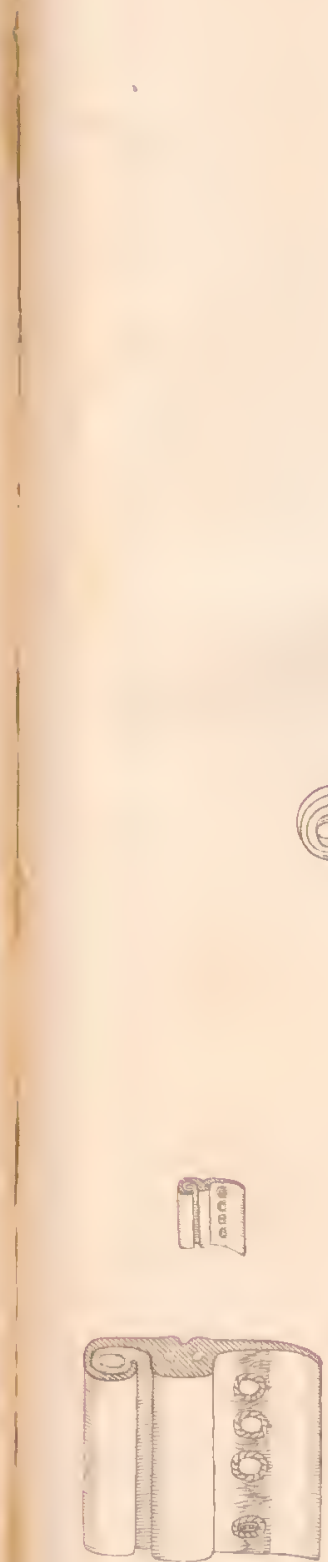

$14 \cdot d e 1504$
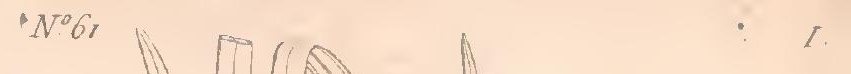

Flor: Ir.ace N:65.

II .

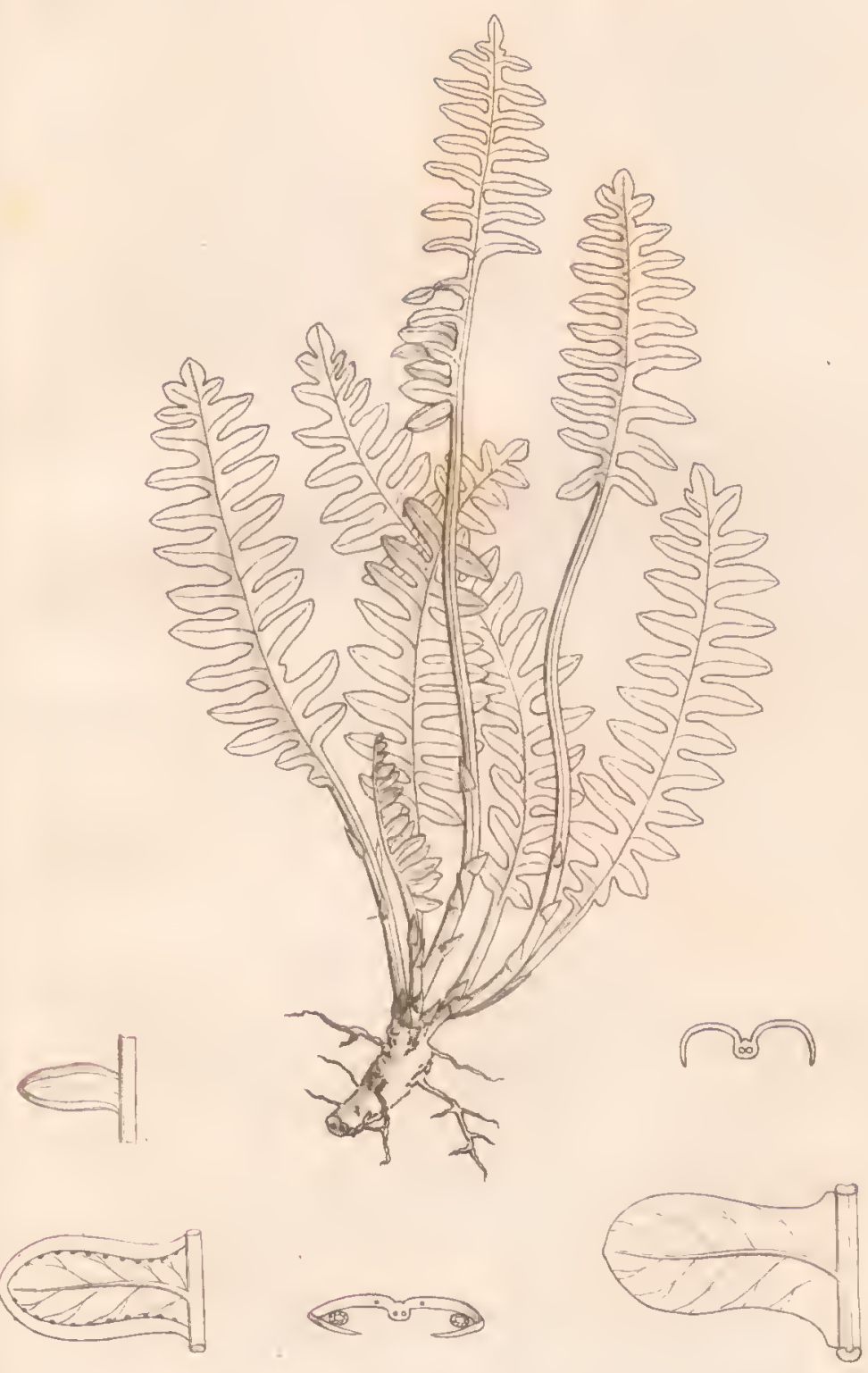





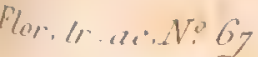

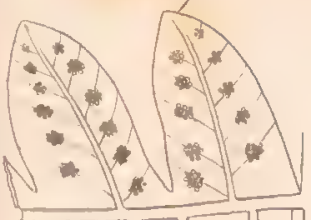

III

0

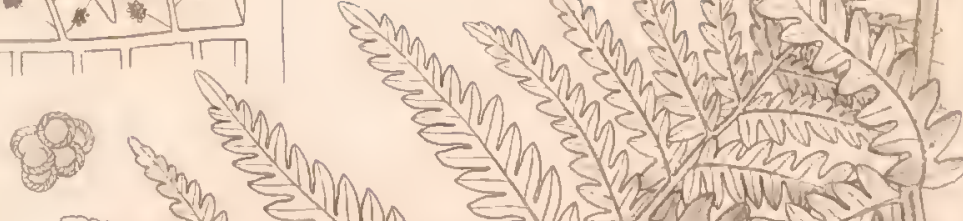

कह

हैe

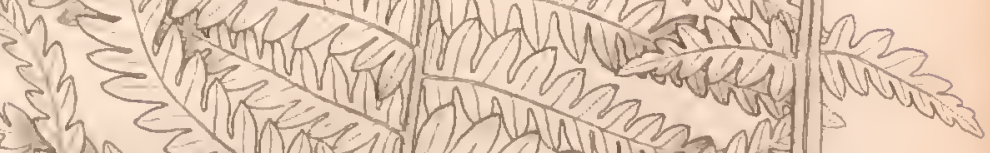

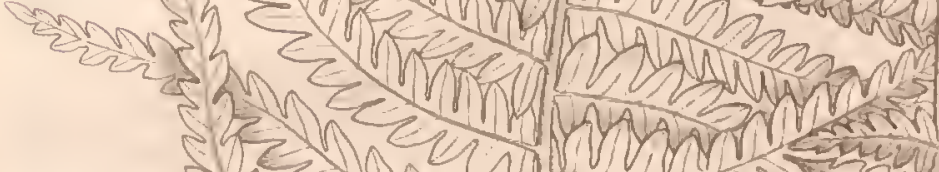

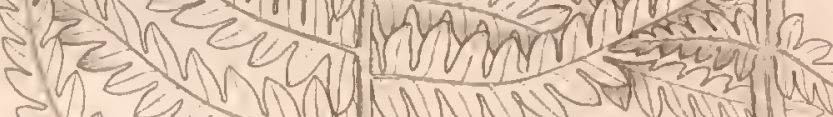

s.

5

L a m MN

zhevermm nom

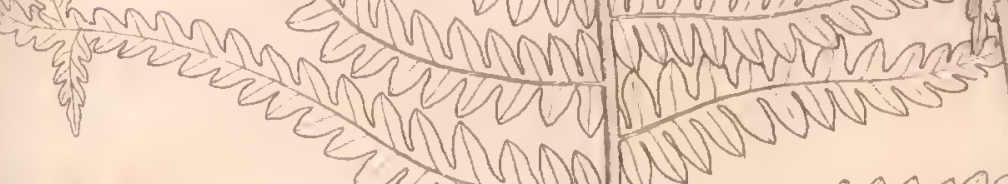

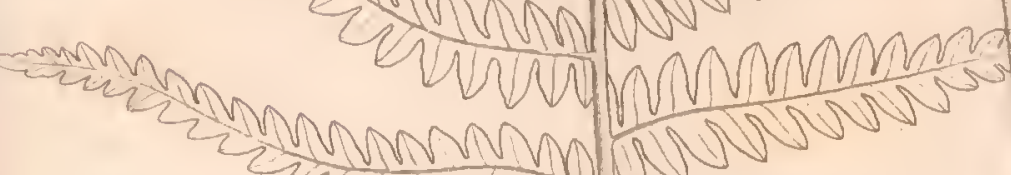
rammon ou

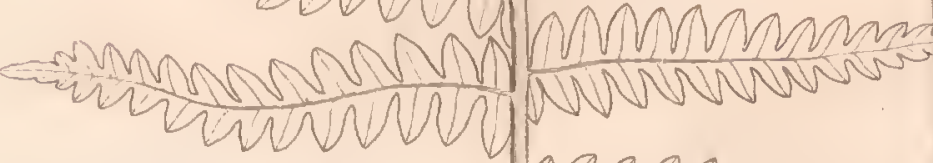

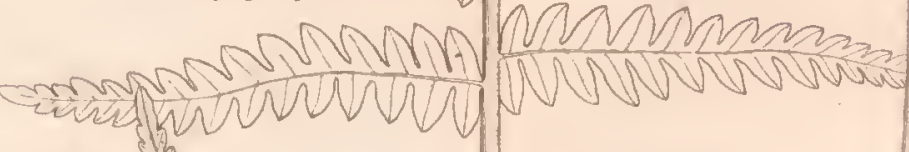

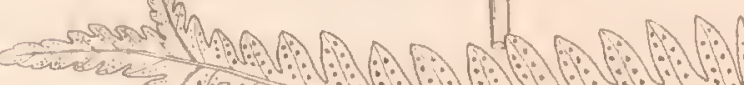

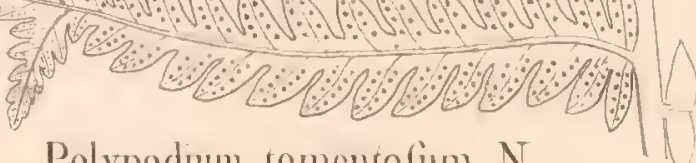





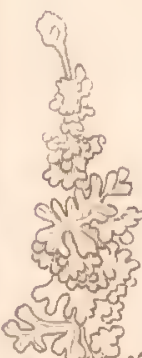

siva,

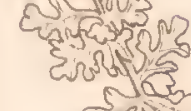

हsatis

and $x_{3}$

हो

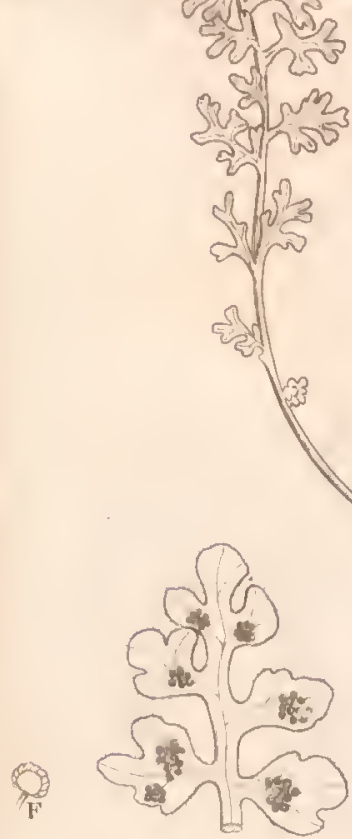

\section{(ब)}

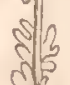

sid?

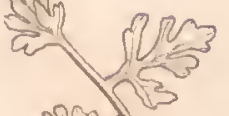

हा?

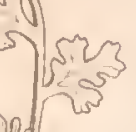

5) 153

(1)

wis

cons

chow?

तn

ल3) 25

डा होगी 2

in wivis

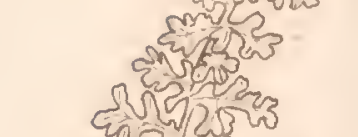

प्र०ण 253
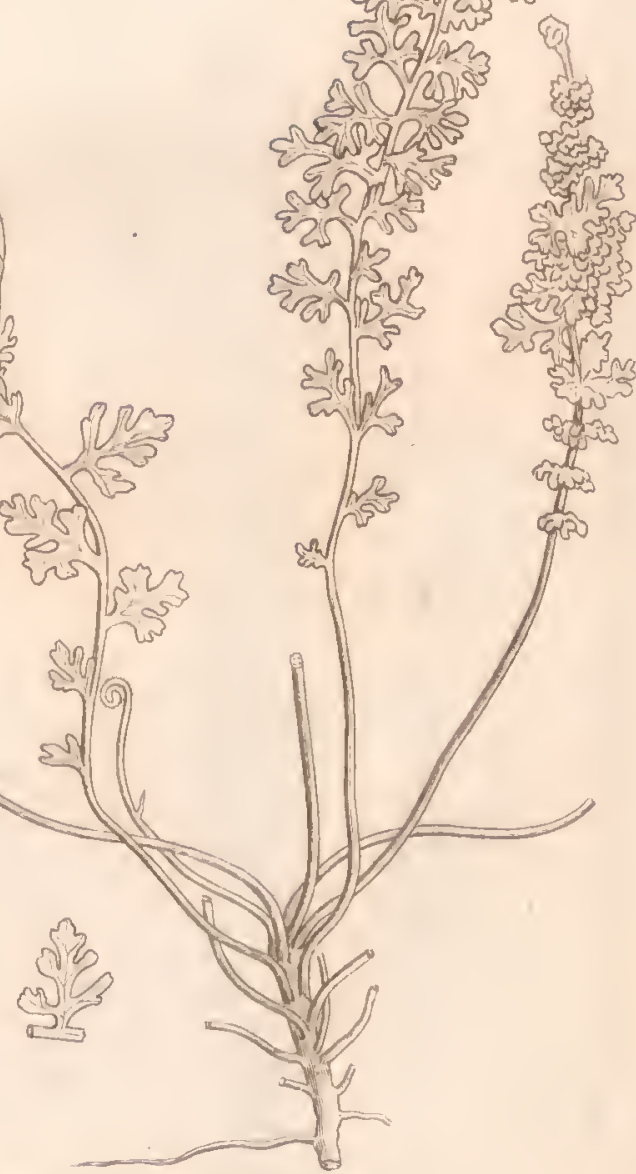

d.p. 

Flor. $11 \cdot a c \cdot 7^{6}$.

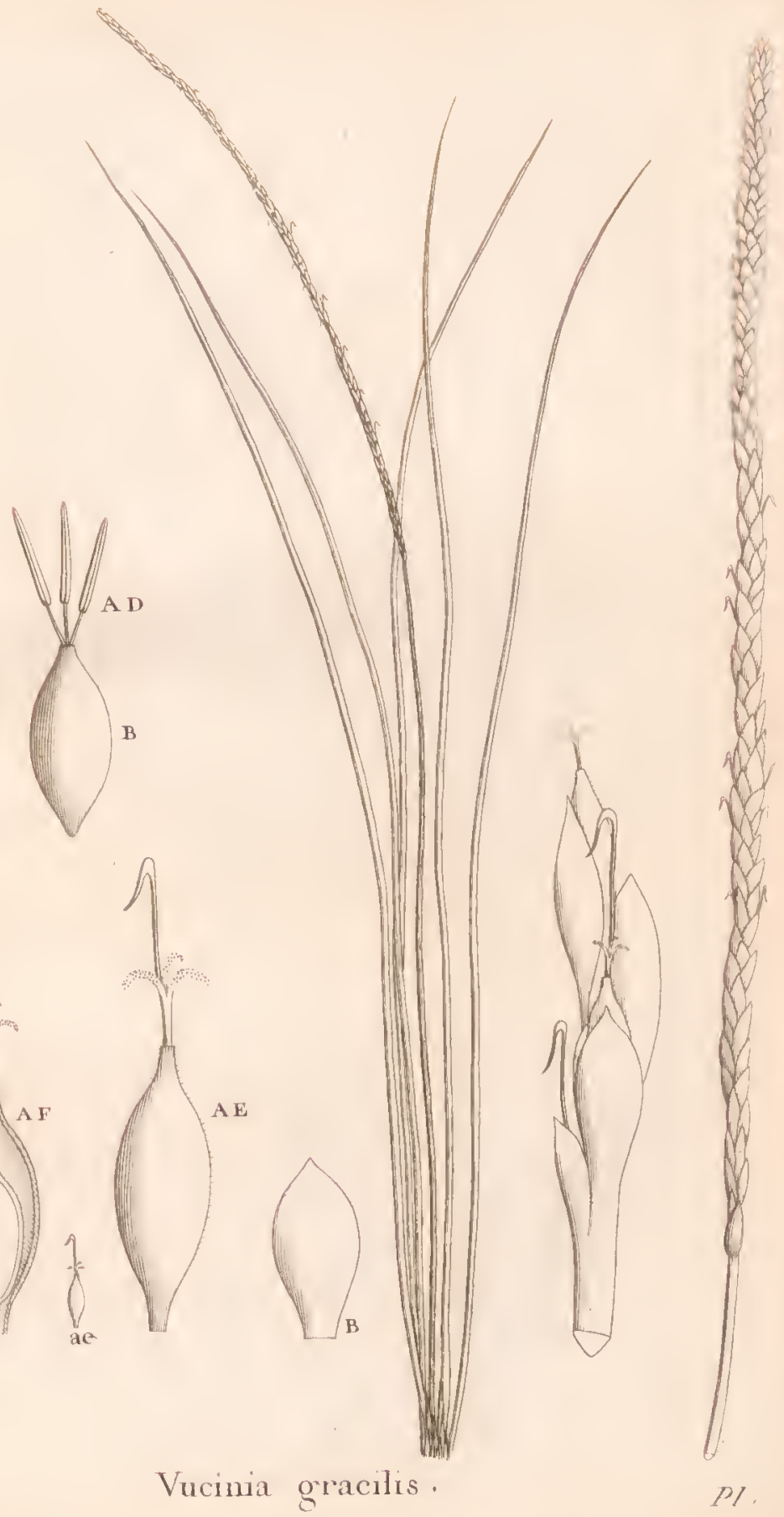





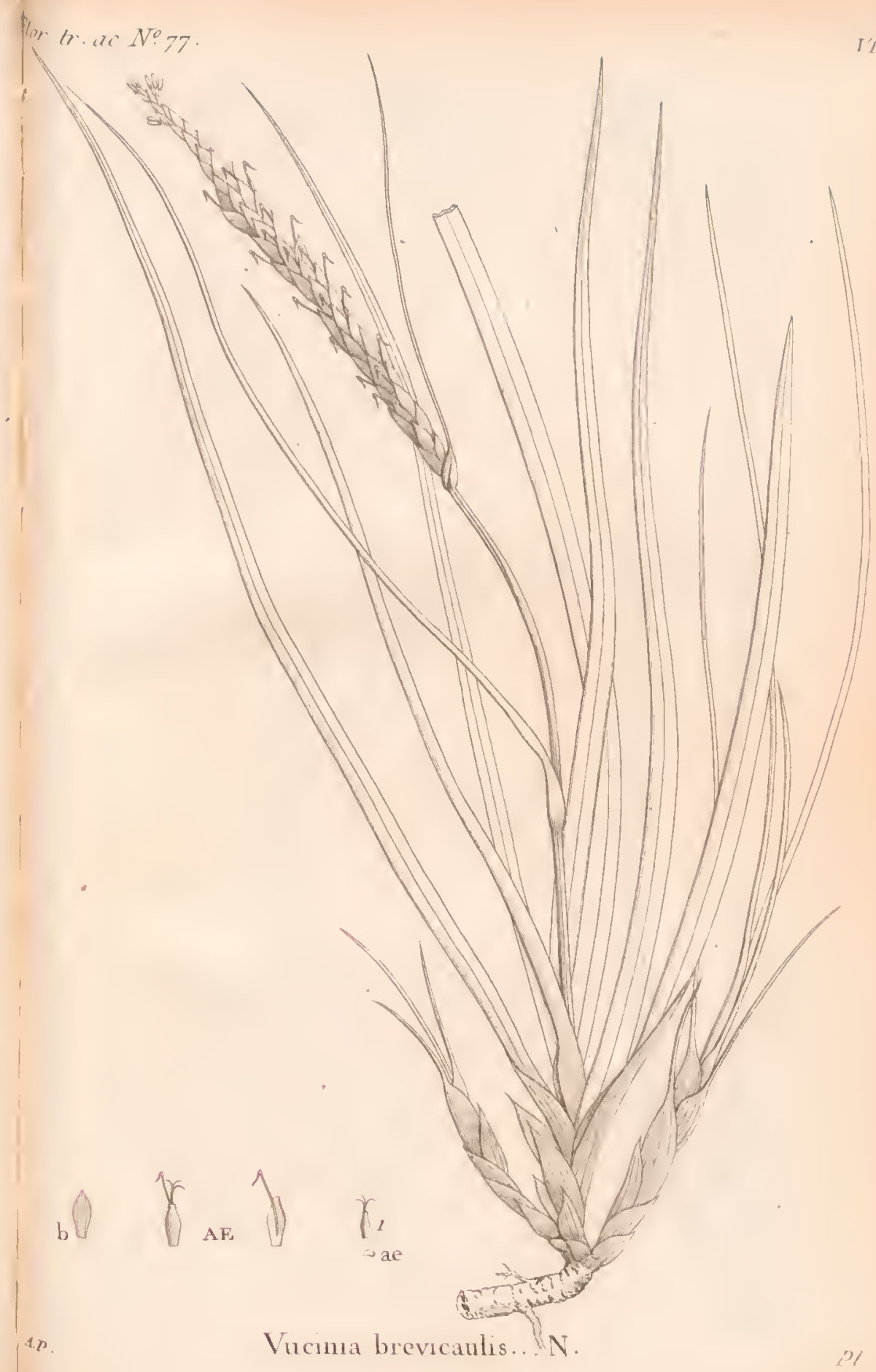





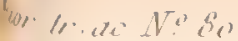
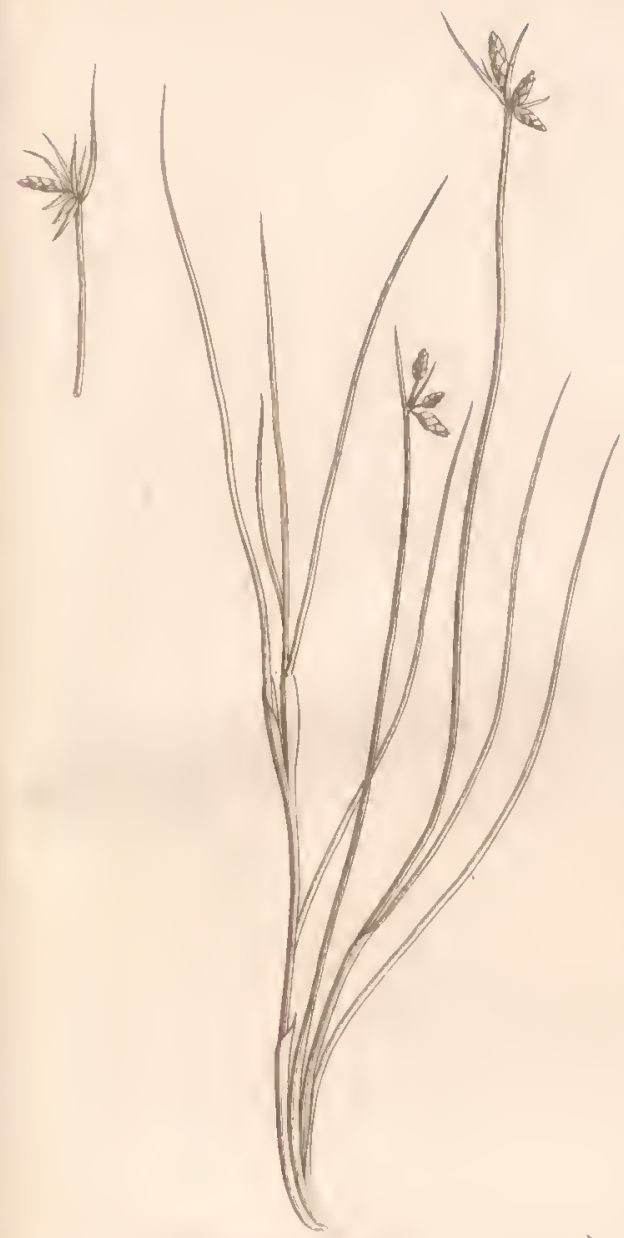

Scirpus prolifer

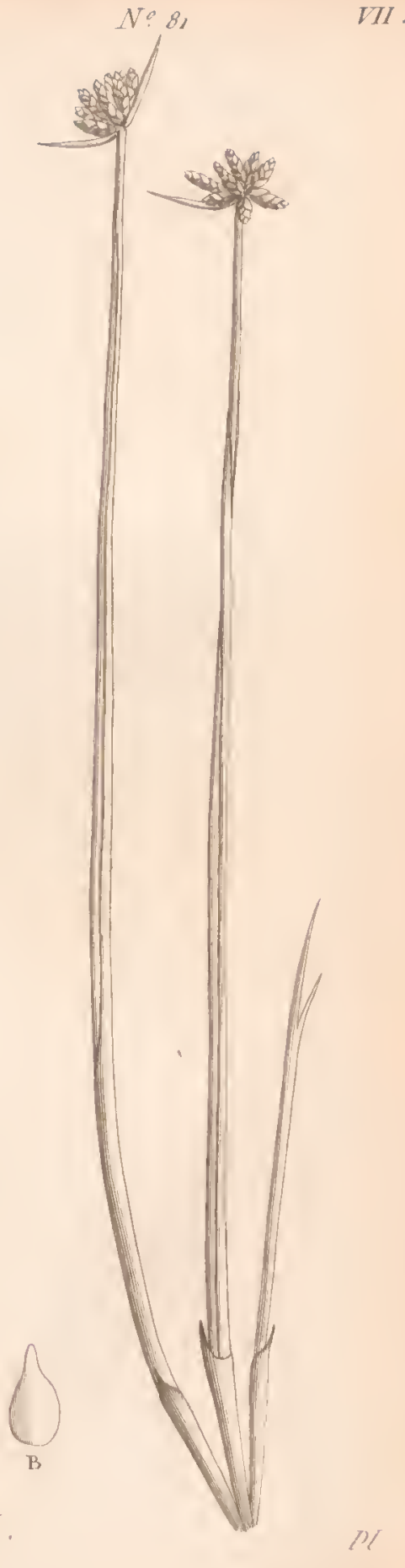





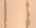
(n) 

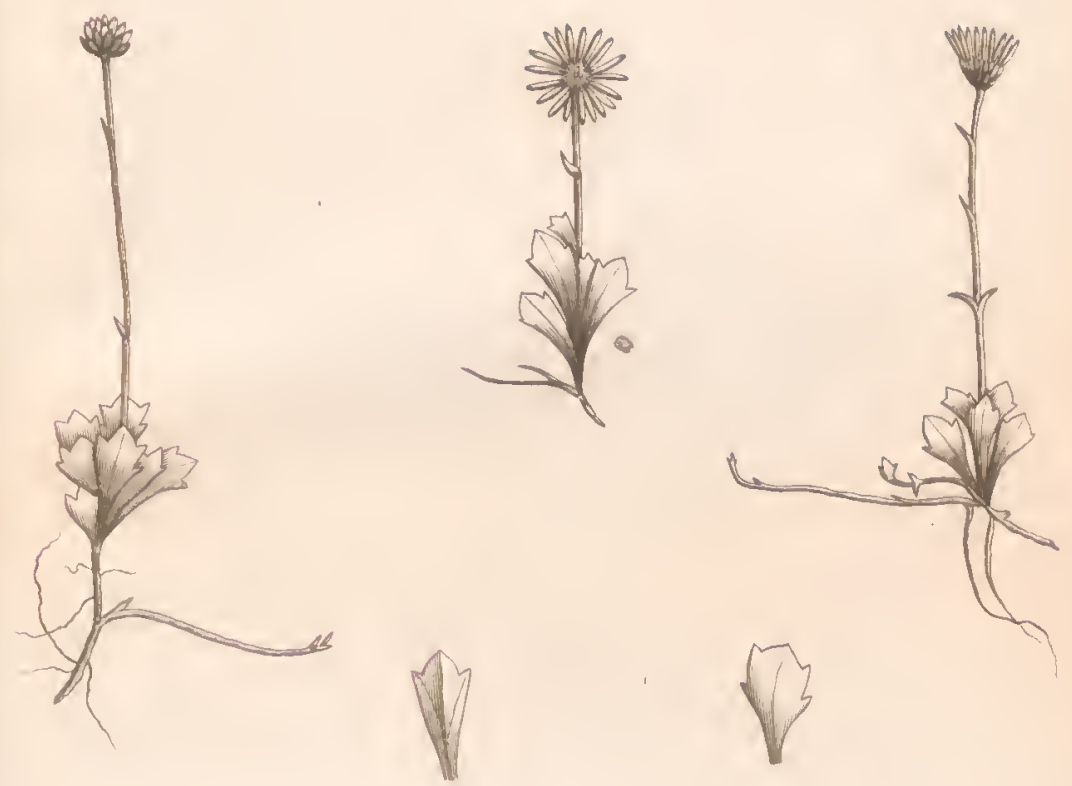

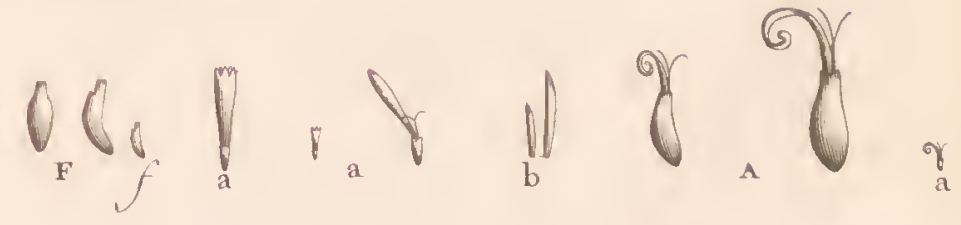





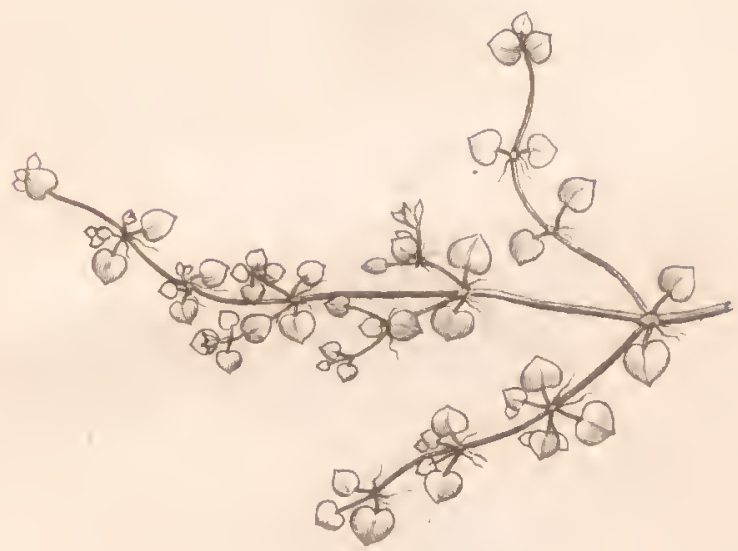

Ge

Nertera depreba 

lon. Ir. ac. Nog 3

$(a)^{3}$

i. $f Q^{\prime} a_{f}$
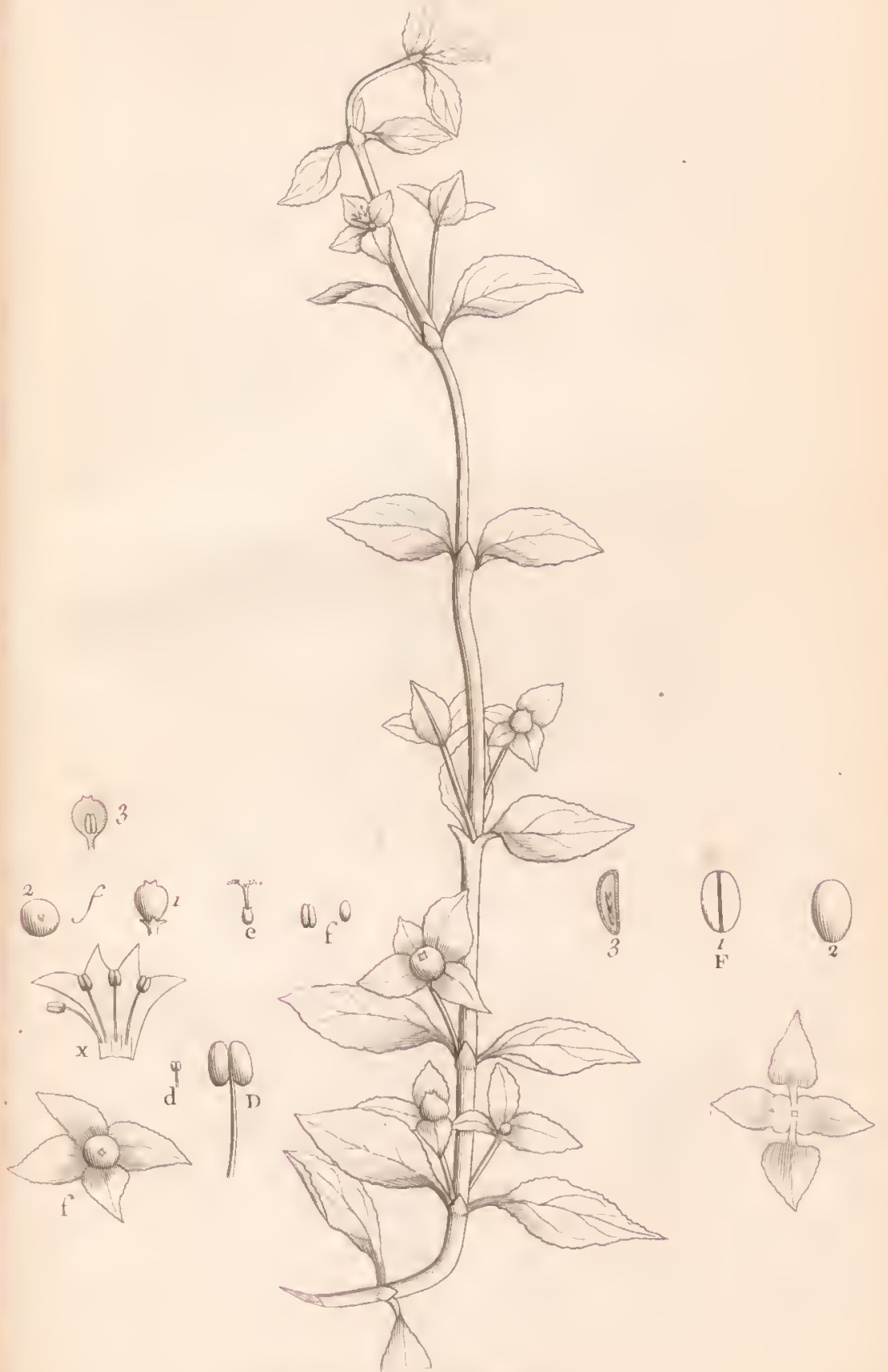

$4 p$

Nertera aflurgens..N. 

$h \cdot 1 r \cdot d x \cdot N: 0.5$

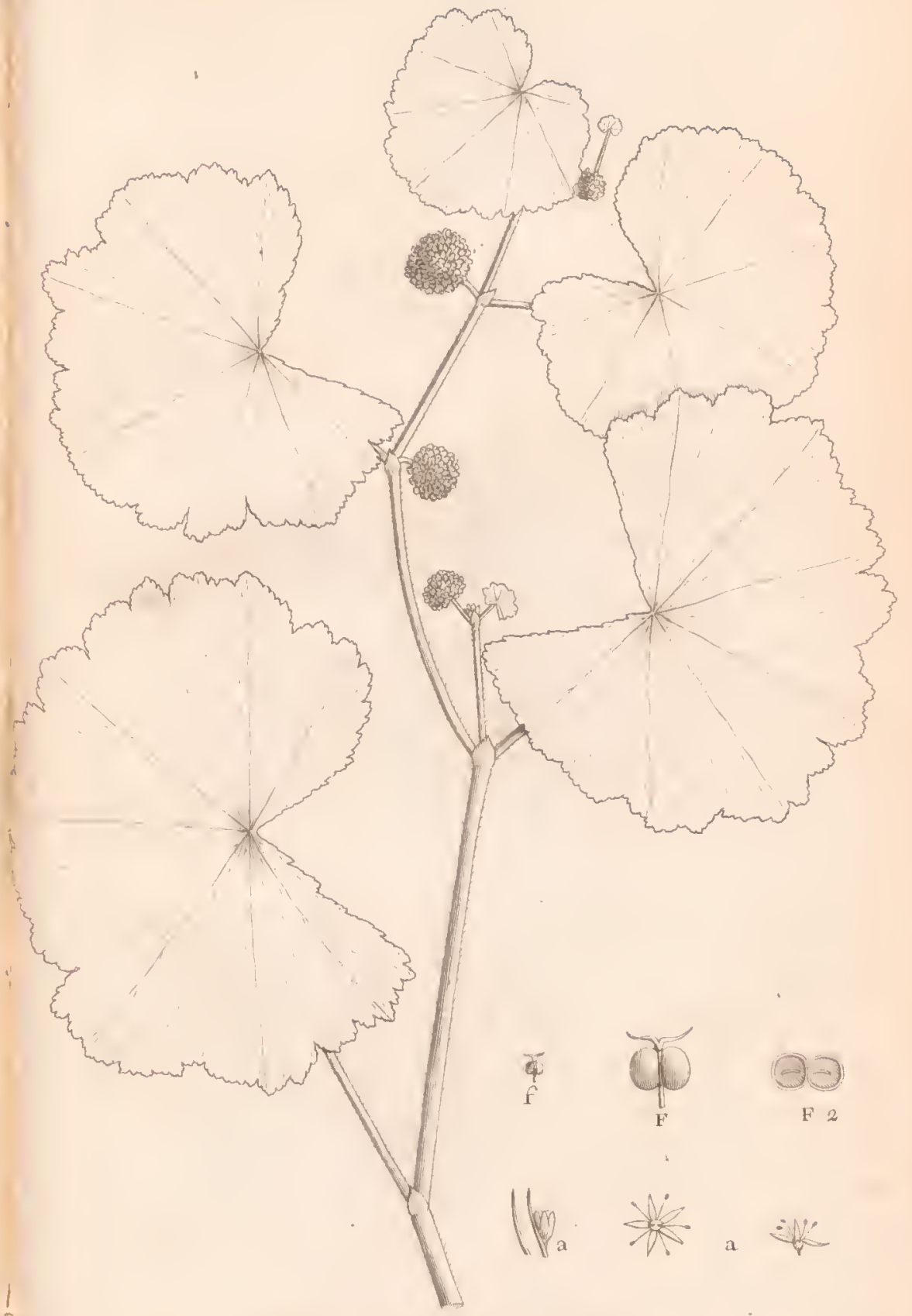





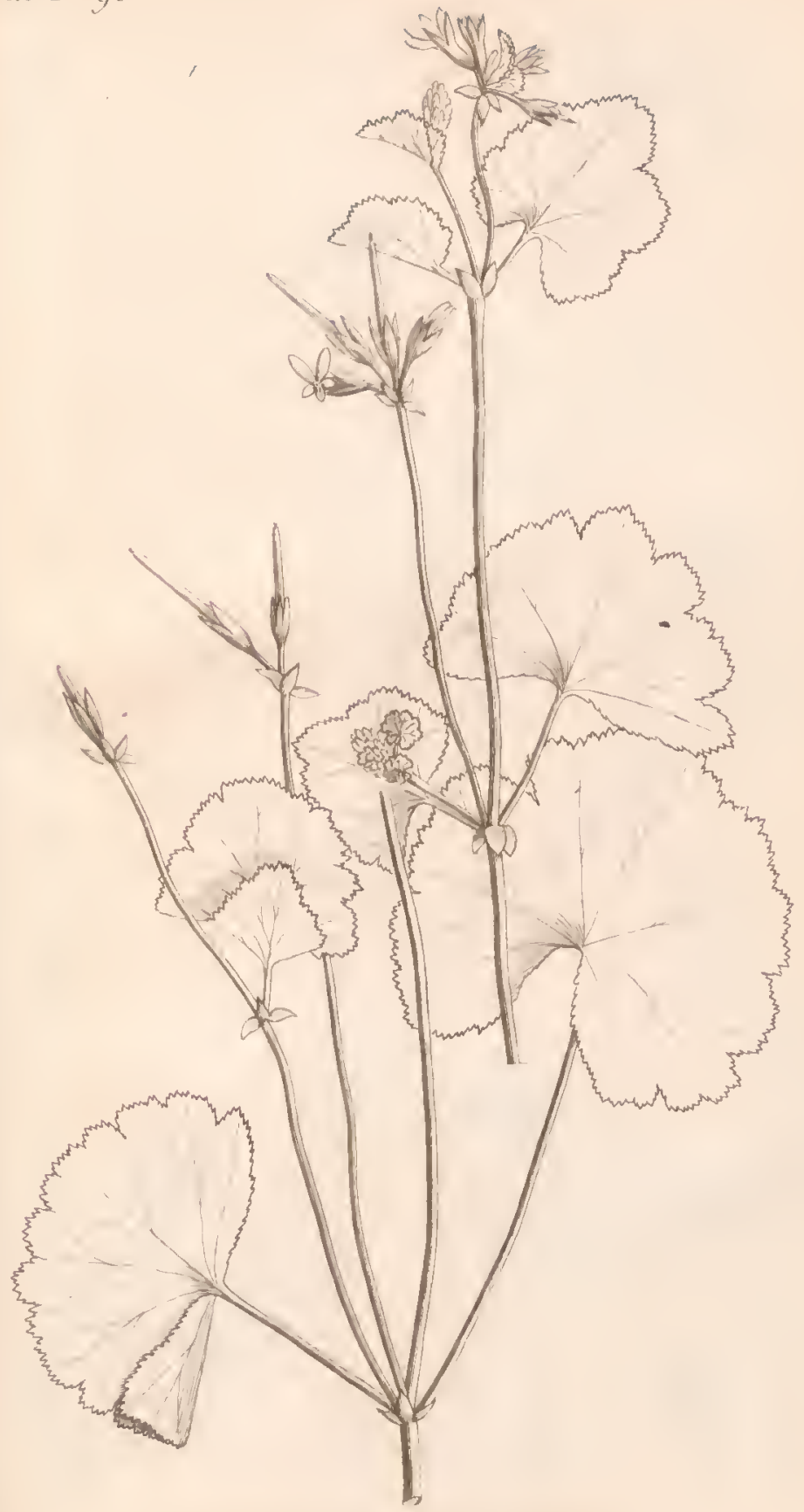

Petargonium acugnaticum 

entes dear llew durstrater didirupues

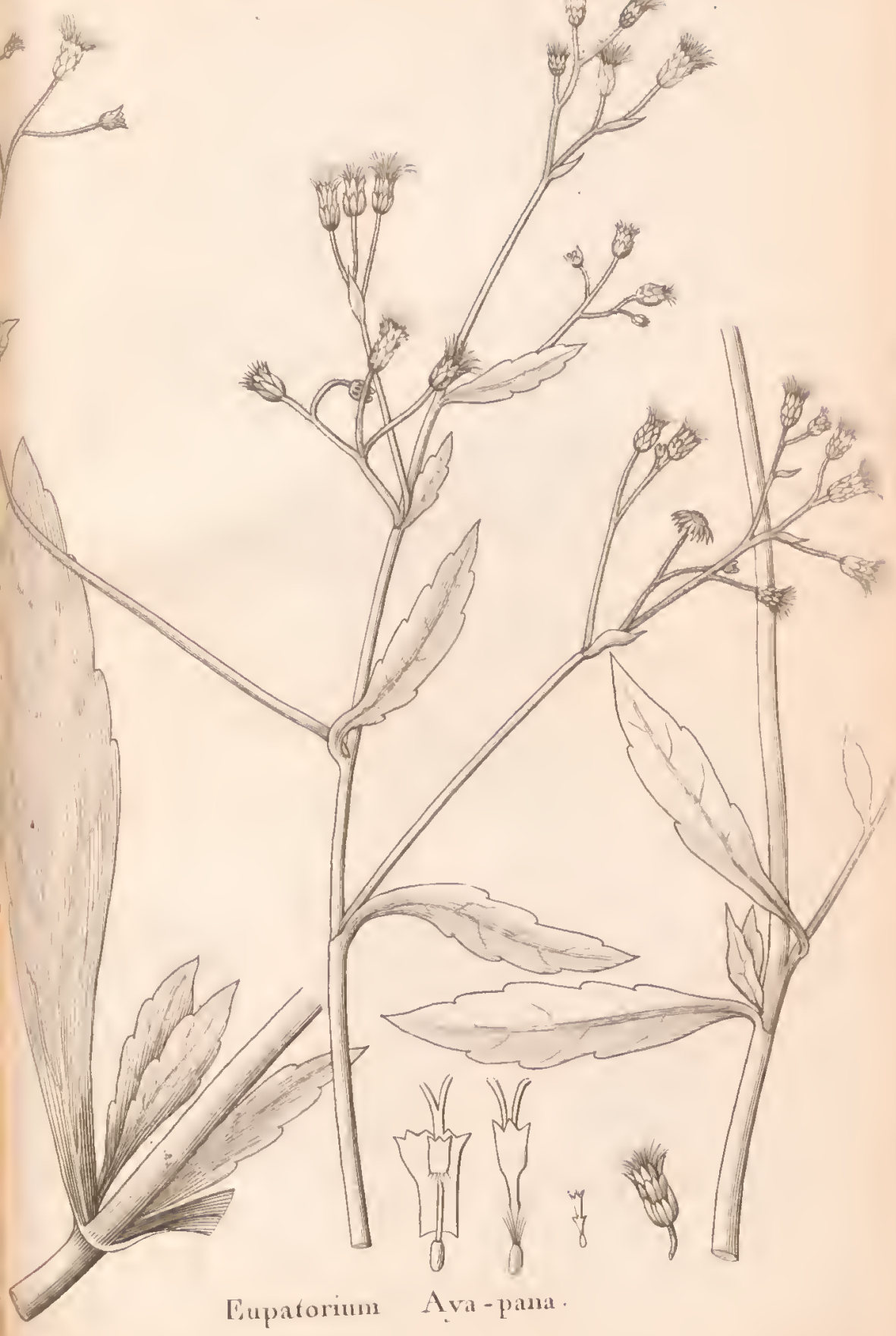



Phnter der Iles antrinles dApr 



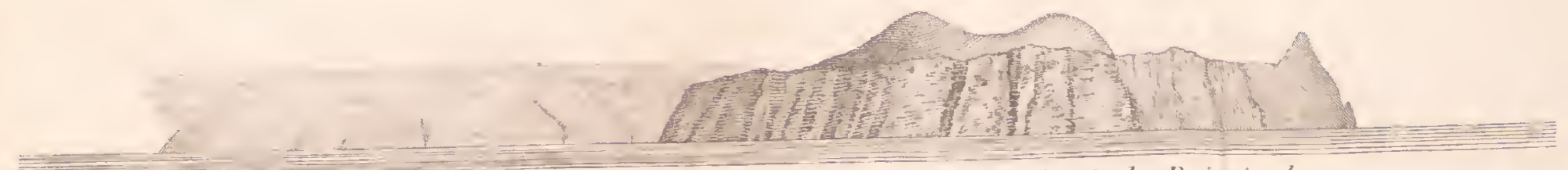

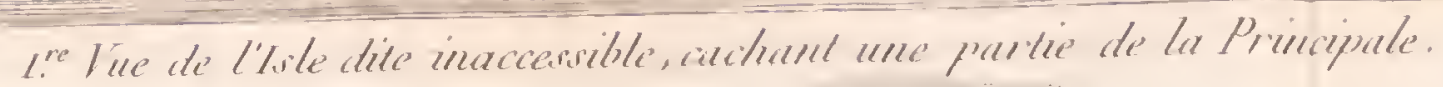

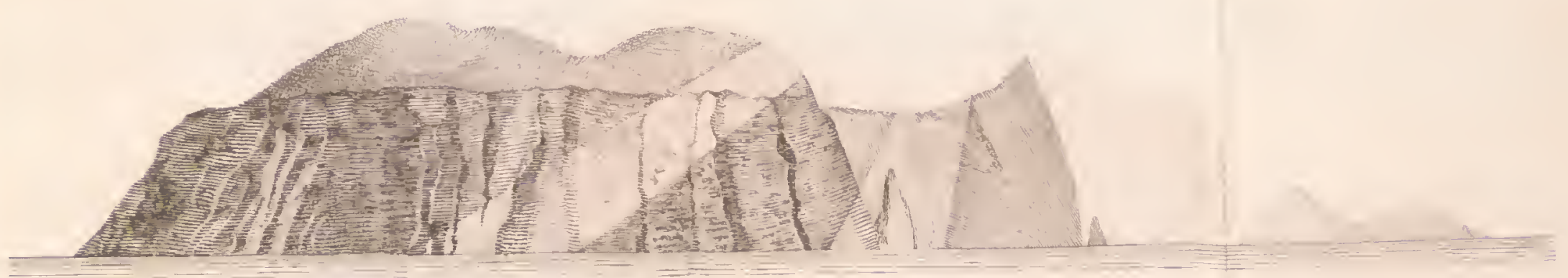
2e. Tue ter la même Tsle et de celle de du. Roßignol.

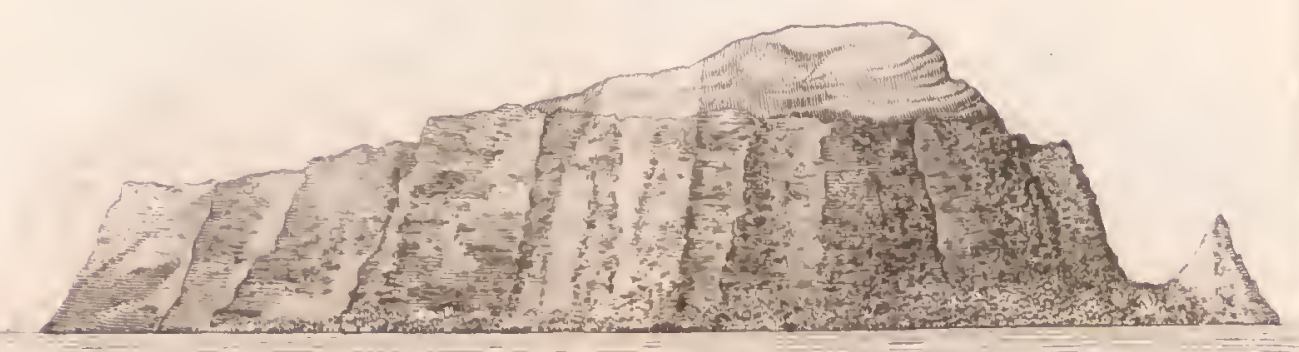

3. Tue de l'Isle Inaccefsible. 



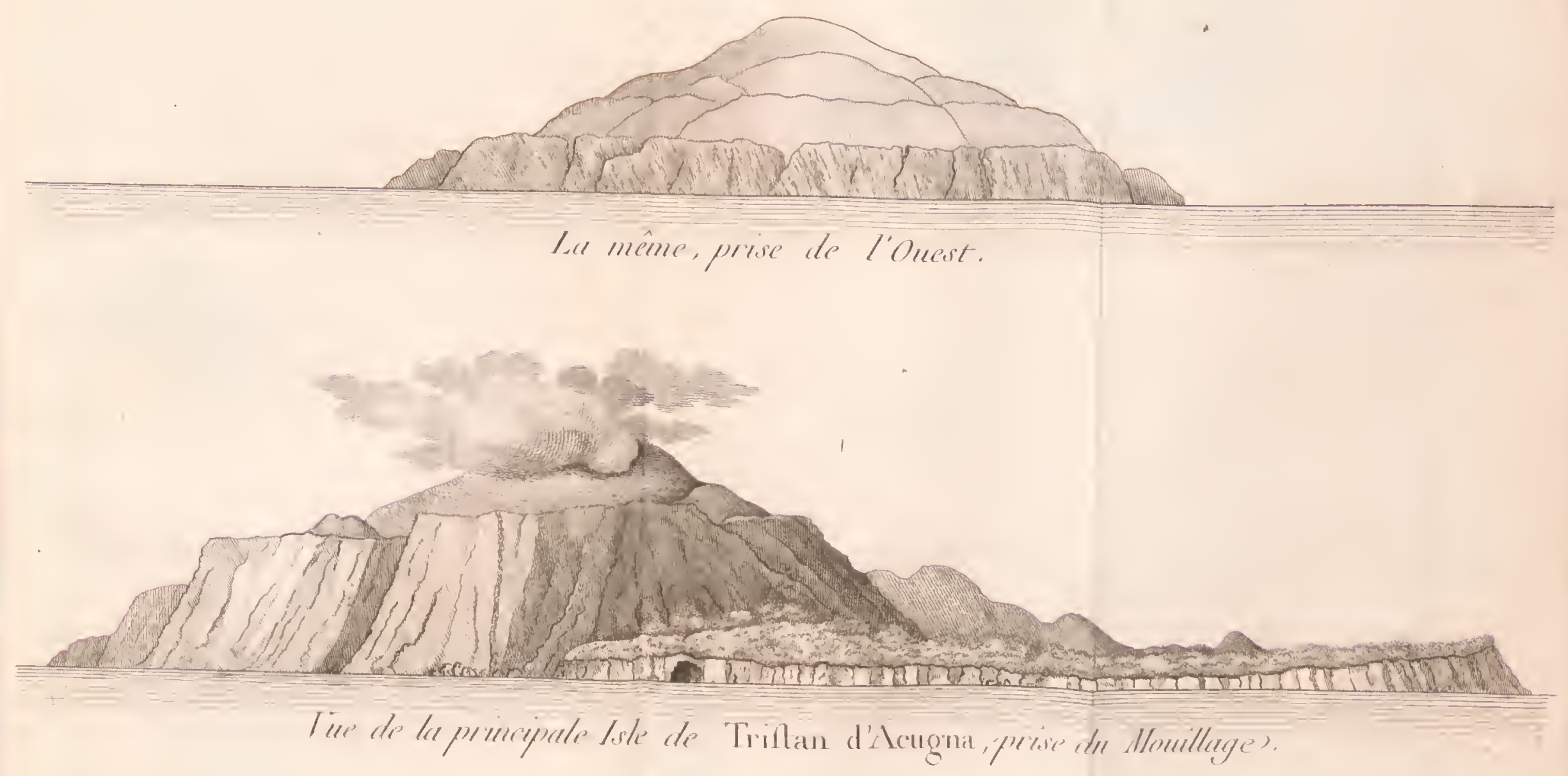





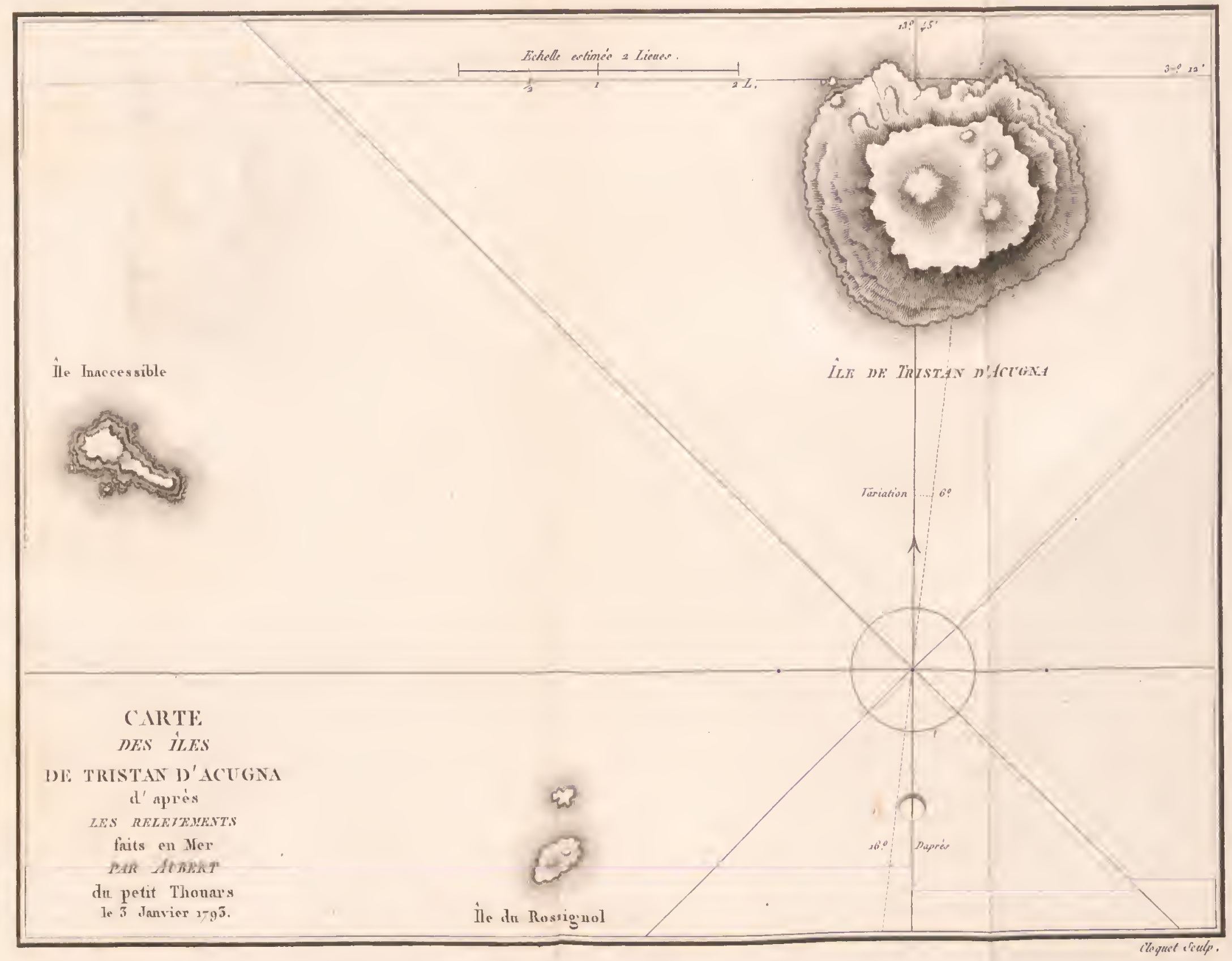




